\title{
Konstellationen von Schreiben und Philosophie
}

Im letzten Kapitel wurden die Schreibsituation Nietzsches sowie die Entstehung des Wanderers im St. Moritzer Sommer 1879 beschrieben. Es liegt nun an den nächsten Kapiteln aufzuzeigen, inwiefern die Schreibsituation und der Produktionsprozess in die Philosophie einwirken und selber Teil der Philosophie sind. Um die Konstellationen von Schreiben und Philosophie aufzuzeigen, untersuche ich vier Themenkomplexe, die für den Wanderer spezifisch sind. Diese Themen werden anhand von ausgewählten Manuskripten analysiert und mit der St. Moritzer Schreibsituation verbunden. Dadurch gerät die Dynamik der philosophischen Arbeit innerhalb der Schreibsituation in den Blick.

\section{Schreiben und Autorschaft}

Während den Arbeiten an den ersten drei Aphorismenbüchern beschäftigt sich Nietzsche intensiv mit dem Thema der Autorschaft in künstlerischen Arbeitsprozessen. Zunächst kritisiert er im Zeichen seiner historischen Philosophie die metaphysische Sicht auf Schaffensprozesse. Er verwirft die Genieästhetik, indem er Schreiben und Lesen als Handwerk, d.h. als künstlerische Produktionstechniken im Sinne einer téchne beschreibt (3.1.1). Durch die Unterscheidung von Schrift und Rede identifiziert Nietzsche das Schreiben als eigenständige und dialogische Praktik (3.1.2). Während die Genieästhetik die Umstände des Schreibens ausblendet, hebt Nietzsche die materialen, körperlichen und alltäglichen Bedingungen des Denkens eigens hervor (3.1.3). Im Wanderer wird mehrfach auf die St. Moritzer Schreibsituation, insbesondere auf das Spazieren im Freien, verwiesen. Philosophische Autorschaft besteht für Nietzsche zunehmend darin, spezifische Schreibverfahren in ausgewählten Schreibsituationen auszuüben.

\subsubsection{Geniekritik und Handwerk}

Menschliches ist ein Angriff auf alle «metaphysische Philosophie», worunter Nietzsche den Grossteil der deutschen Philosophie, aber auch seine eigenen Frühwerke zählt. Dem setzt er eine «historische Philosophie» gegenüber. ${ }^{1}$ Der

1 MA 1, KSA 2, S. 23.
(c) WILHELM FINK VERLAG, 2019 | DOI:10.30965/9783846764053_004

This is an open access chapter distributed under the terms of the prevailing CC-BY-NC-ND License at the time of publication. 
wichtigste Grundsatz dieses aufklärerischen Unternehmens lautet «Alles aber ist geworden». ${ }^{2}$ Im vierten Hauptstück von Menschliches mit dem Titel «Aus der Seele der Künstler und Schriftsteller» überträgt Nietzsche diese radikale Metaphysikkritik auf Kunst und Literatur. Die Aufklärung sei noch nicht gründlich auf die Entstehung von Kunstwerken angewendet worden, weshalb sich dort metaphysische und romantische Vorstellungen hartnäckig halten konnten. ${ }^{3}$ In der 1886 geschriebenen Vorrede zum zweiten Band von Menschliches spricht er von einer «a n ti ro m an ti sch en Selbstbehandlung», mit der er sich von Wagner und Schopenhauer loslöste. ${ }^{4}$ Nietzsche wendet sich gegen die romantische Selbstinszenierung der Kunst als Genieästhetik, Vollkommenheit, Originalität, Perfektion, Spontaneität, Regellosigkeit, Beseeltheit, Unmittelbarkeit und Inspiration. Er misstraut den Selbstinszenierungen der Künstler und Autoren. Zu diesem Zweck thematisiert Nietzsche in den entsprechenden Aphorismen die Arbeitsweise, Produktionsbedingungen und Werkzeuge der Künstler. Diese erzählen jeweils eine andere Geschichte der Werkentstehung als jene, mit der die Autoren sich selbst und die Leser wiederum die Autoren schmücken.

\section{Kritik der Genieästhetik}

Die Genieästhetik wird gemäss Nietzsche nicht durch die Kunst, sondern durch die Selbstinszenierung der Künstler und die Eitelkeit der Rezipienten hervorgebracht. Da der Künstler wisse, dass sein Werk durch den Anschein einer «wundergleiche[n] Plötzlichkeit der Entstehung» intensiver wirke, richtet er sich nach der Forderung, «Das Vollkommene soll nicht geworden sein ${ }^{5}$ Im künstlerischen Schaffensprozess gebe es jedoch keine plötzlichen Wunder und göttlichen Eingebungen. Nietzsche vermutet im Wunsch nach dem plötzlichen Gewordensein von Dingen die «Nachwirkung einer uralten mythologischen Empfindung». ${ }^{6}$ Zugleich schmeichelt der Genieglaube der menschlichen Eitelkeit. Denn im «Cultus des Genius» gestehe sich der Rezipient bei der Verehrung eines Kunstwerks ein, zu Gleichem nicht fähig zu sein. Folglich will es seine Eitelkeit, dass dieses Kunstwerk «mirakulös», «göttlich» und «wunderbar» entstanden sei: «Jemanden〈göttlich〉 nennen

2 MA 2, KSA 2, S. 25.

3 Vgl. MA 147, KSA 2, S. 142f.; MA 110, KSA 2, S. 109-111.

4 MA II, Vorrede 2, KSA 2, S. 371.

5 MA 145, KSA 2, S. 141.

6 Ebd. Vgl. auch MA 147, KSA 2, S. 142f.; MA 159, KSA 2, S. 149. Im Sinne der Geburt der Tragödie mache die Kunst das Leben erträglich, «dadurch dass sie den Flor des unreinen Denkens über dasselbe legt.» (MA 151, KSA 2, S. 144). 
heisst, 〈hier brauchen wir nicht zu wetteifern `.» ${ }^{7}$ Die Genieästhetik kaschiert demnach das eigene Unvermögen. Die Bewunderer lieben das Genie letztlich «a u s Eitelkeit». ${ }^{8}$ Deshalb spreche man von Genies bloss auf Gebieten, die dem menschlichen Intellekt angenehm sind und in denen man keinen Neid empfinden will. So werde die Verehrung auf eine Genialität projiziert, welche kennzeichnend für den Rezipienten sei und nicht für die Kunst.

In Menschliches, den Vermischten Meinungen und im Wanderer gibt es zahlreiche Aphorismen zu Schriftstellern, Künstlern, Komponisten und Philosophen, in denen Nietzsche die Arbeitswerkzeuge, Produktionsbedingungen und Wirkungsästhetik thematisiert. Als gelehrter Philologe kennt Nietzsche die für die Textkritik verwendete Analyse von Schreibtechniken, -stilen und -konventionen. So hätten Homer und die griechischen Dichter absichtlich «inn er hal b» guter Stile, Konventionen und Regelwerken geschrieben:

In Ketten tanzen. - Bei jedem griechischen Künstler, Dichter und Schriftsteller ist zu fragen: welches ist der n e u e Zwang, den er sich auferlegt und den er seinen Zeitgenossen reizvoll macht (sodass er Nachahmer findet)? Denn was man «Erfindung» (im Metrischen zum Beispiel) nennt, ist immer eine solche selbstgelegte Fessel. «In Ketten tanzen», es sich schwer machen und dann die Täuschung der Leichtigkeit darüber breiten, - das ist das Kunststück, welches sie uns zeigen wollen. ${ }^{9}$

Regeln und Auflagen schwächen die Schreibkunst eines Autors nicht, sondern stärken und verfeinern diese. Die Individualität des Künstlers liegt nicht im Weglassen oder Umgehen der Konventionen, sondern in der Anpassung an alte Zwänge und in der Erschaffung von neuen, die wiederum konventionell werden könnten. Als Philologe sieht Nietzsche die Eigenschaft antiker Schreibkunst darin, sich virtuos innerhalb der Techniken, Regeln und Konventionen zu bewegen. Es gebe eine «Freiheit in Fesseln»: Denn wer seine Fesseln kenne und beherrsche, könne trotz bzw. in ihnen tanzen. ${ }^{10}$ Diese handwerkliche Sicht kehrt die Qualitätskriterien der Genieästhetik um: Nietzsche lobt an

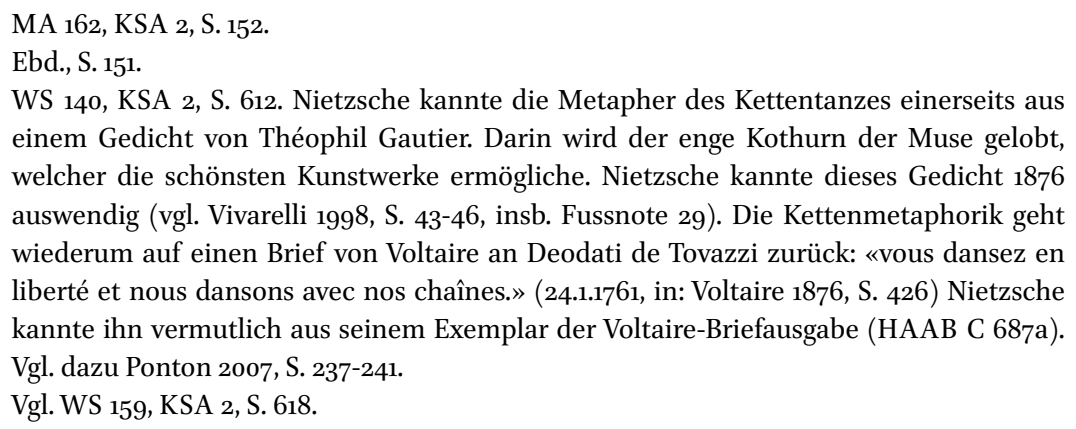
einem Gedicht von Théophil Gautier. Darin wird der enge Kothurn der Muse gelobt, welcher die schönsten Kunstwerke ermögliche. Nietzsche kannte dieses Gedicht 1876 auswendig (vgl. Vivarelli 1998, S. 43-46, insb. Fussnote 29). Die Kettenmetaphorik geht wiederum auf einen Brief von Voltaire an Deodati de Tovazzi zurück: «vous dansez en liberté et nous dansons avec nos chaînes.» (24.1.1761, in: Voltaire 1876, S. 426) Nietzsche kannte ihn vermutlich aus seinem Exemplar der Voltaire-Briefausgabe (HAAB C 687a). Vgl. dazu Ponton 2007, S. 237-241.

Vgl. WS 159, KSA 2, S. 618. 
den grossen Klassikern deren Konventionalität und will Originalität nach dem griechischen Prinzip: 〈dreiviertel Konvention〉 und ein Viertel Eigenes. Originalität ist ein Supplement und Zeichen der virtuosen Beherrschung der auferlegten Ketten. Stil und Denken seien im praktischen Vollzug des Schreibens ineinander verwoben: «Den Stil verbessern - das heisst den Gedanken verbessern, und gar Nichts weiter!» ${ }^{11}$ Nietzsches Provokation läuft darauf hinaus, dass gerade dort, wo vermeintlich Originales geschaffen wird, meistens Schlechtes herauskommt. Denn frei fühle man sich dort, wo man die Regeln und Abhängigkeiten nicht spüre. Das zeigt sich in der doppelten Verwendung der Kettenmetapher im textkritischen und metaphysikkritischen Sinne. Nietzsche setzt der Idee eines freien Willens die Abhängigkeit von Ketten gegenüber. Seine Lösung lautet nicht, sich frei zu fühlen, sondern sich seiner Abhängigkeiten bewusst zu werden:

Wie aber, wenn das Umgekehrte wahr wäre: dass er [der Mensch] immer in vielfacher Abhängigkeit lebt, sich aber für fre i hält, wo er den Druck der Kette aus langer Gewohnheit nicht mehr spürt? Nur an den neuen Ketten leidet er noch: - «Freiheit des Willens» heisst eigentlich Nichts weiter, als keine neuen Ketten fühlen. ${ }^{12}$

Das ist ein Angriff auf die Anhänger künstlerischer Originalität und der Genieästhetik. Die Suche nach Originalität ist demnach keine Suche nach qualitativ neuen Wegen von Individualität, sondern die Jagd nach einem guten Gefühl der scheinbaren Abwesenheit des Gewöhnlichen.

Die metaphysikkritischen Ansichten zur Freiheit werden von Nietzsche auf zeitgenössische Texte und Kunstwerke angewendet. So lobt er die «Freiheit in Fesseln» anhand der Musik Chopins, welcher in seinen melodischrhythmischen Fesseln «wie der freieste und anmuthigste Geist» tanze. ${ }^{13}$ Händel wird vorgeworfen, dass er während der Produktion zu schnell geschrieben habe, um möglichst rasch mit der Arbeit fertig zu werden. ${ }^{14}$ Demgegenüber liege das Grossartige von Bach in den Techniken der Kontrapunktik sowie des Fugenstils und das von Raffael in seiner Verwendung der einfachsten bzw. kon-

\footnotetext{
11 WS 131, KSA 2, S. 610.

12 WS 10, KSA 2, S. 546. Vgl. auch WS 9, KSA 2, S. 545. Goethe verwies in dem von Nietzsche 1879 als bestes deutsches Buch gelobte Gespräche mit Goethe in den letzten Jahren seines Lebens auf einen Brief Mozarts. Mozart kritisiert darin einen Baron, der gerade dort, wo er in seinem Anspruch auf Originalität eigene Gedanken hervorbringen wollte, diletantisch wirke (vgl. Eckermann 2011, S. 183f.).

13 WS 159, KSA 2, S. 618.

14 Vgl. WS 150, KSA 2, S. 615.
} 
ventionellsten Farben. ${ }^{15}$ Wielands Gedanken gäben nichts zu denken. Er habe jedoch schlicht «besser als irgend jemand deutsch geschrieben», weshalb seine Übersetzungen von Cicero und Lukian von höchster Qualität seien. ${ }^{16}$ Die Beherrschung der Konvention - die deutsche Sprache - und nicht die individuell eigenen Gedanken werden hervorgehoben. Weiter werden im Wanderer Autoren gelobt, die Wörtern ausweichen können, welche ein mittelmässiger Schriftsteller nicht hätte vermeiden können. ${ }^{17}$ Lessing sei bekannt geworden, weil er für seine Gedanken einen schönen Putz gewählt habe: «er versteht seine Dinge im Schauladen gut zu ordnen und aufzustellen: ohne diese wirkliche Ku n st würden seine Gedanken, so wie deren Gegenstände, ziemlich im Dunkel geblieben sein, und ohne dass die allgemeine Einbusse gross wäre.» ${ }^{18} \mathrm{Zu}$ sagen, es wäre nicht schlimm gewesen, wären Lessings Gedanken unbekannt geblieben, heisst so viel als zu behaupten, es hätten sich andere gefunden, welche Ähnliches vermutlich besser vorgetragen hätten. Und auch Herder sei «kein großer Denker und Erfinder» gewesen. ${ }^{19}$ Vielmehr sei er stets ruhelos, umtriebig und dank seiner guten Witterung an den richtigen Orten gewesen. Indem Nietzsche auf die Technik des Herder'schen Schaffens verweist, relativiert er dessen Ansprüche originaler Produktion. Im selben Stile entlarvt Nietzsche Jean Paul: Waren Herders Verdienste vor allem auf seine Witterung und Umtriebigkeit zurückzuführen, so sind es bei Jean Paul sein künstlerisches Laientum und der durch Schiller und Goethe bereitete Boden, auf dem er erst wachsen konnte - als «Unkraut». ${ }^{20}$ Überhaupt seien die originalen Eigenschaften der deutschen Prosa misslungen, weil sie nicht «nach einem Muster» bzw. nach strengen Konventionen gebildet wurden. Nietzsche zeichnet ein Bild der Literaturwertschätzung fernab der Genieästhetik. Der Genius wird durch die Entstehungskontexte sowie die Auflösung der klassischen Hierarchie des Autors gegenüber von Stil und Schreiben relativiert.

Indem Nietzsche die Produktionsprozesse thematisiert, verärgert er ebenso die Künstler wie das Publikum. Denn überall, wo man das Werden sehe, kühle sich die Bewunderung ab. ${ }^{21}$ So verstecken die Genies ihren «Leierkasten», um

\footnotetext{
15 Vgl. WS 159, KSA 2, S. 618.

16 WS 107, KSA 2, S. 599.

17 WS 97, KSA 2, S. 596.

18 WS 103, KSA 2, S. 597 f.

19 WS 118, KSA 2, S. 602.

20 WS 99, KSA 2, S. 597. Vgl. auch Schubert, der den grössten « Erbre ich thu m an Musik» besitze (WS 155, KSA 2, S. 617). Die Bezeichnung «Unkraut» könnte eine Verschärfung von Hillebrands Argumentation in seiner Rezension zu Nietzsches erster Unzeitgemässen Betrachtung sein, vgl. Hillebrand 1875, S. 296. 
als komplexer zu gelten, als sie angesichts der «alten sieben Stücke» eigentlich seien. ${ }^{22}$ In dieselbe Richtung geht das provokative Argument, es gebe in Kunstwerken nur wenige wichtige Hauptstränge und viele sekundäre Feinheiten: «Der Bildhauer kann viele kleine Züge hinzuthun oder weglassen: ebenso der Darsteller, sei es ein Schauspieler oder, in Betreff der Musik, ein Virtuos oder Dirigent.» ${ }^{23}$ Aber in der «Darstellung des Hauptgedankens» bedürfe es «Strenge und Selbstbezwingung». ${ }^{24}$ Künstler und Publikum bilden sich jedoch sehr viel auf die kleinen Züge ein und schmeicheln dadurch sich selbst. Denn in den kleinen Feinheiten können sich die Künstler frei fühlen und nicht allzu viel falsch machen.

Nietzsche stellt das Festhalten der Künstler an metaphysischen Selbstinszenierungen wie einen Überlebenskampf der Kunst dar. Die starken Wirkstoffe wie das «Phantastische, Mythische, Unsichere, Extreme», aber auch der Geniekult, könnten von den Künstlern nicht aufgegeben werden. Die Kunst wolle sich nicht einem wissenschaftlichen Denken preisgeben, weil sie ohne metaphysische Kräfte ihren Zweck als Lebensspenderin der Kultur verliere. Neue Vermittlerin von lebensfördernden Kräften werde die Wissenschaft: «Der wissenschaftliche Mensch ist die Weiterentwickelung des künstlerischen.» ${ }^{25}$

\section{Handwerker-Autor}

Es wurde gezeigt, dass Künstler und Rezipienten die Genieästhetik wechselseitig aufrechterhalten und die metaphysischen Inszenierungen der Kunst einst eine lebenserhaltende Funktion für die Kultur erfüllten. Offen bleibt noch, wie Nietzsche das künstlerische Schaffen fernab der Genieästhetik konzipiert.

Aber von jenen Einflüsterungen unserer Eitelkeit abgesehen, so erscheint die Thätigkeit des Genie's durchaus nicht als etwas Grundverschiedenes von der Thätigkeit des mechanischen Erfinders, des astronomischen oder historischen Gelehrten, des Meisters der Taktik. Alle diese Thätigkeiten erklären sich, wenn man sich Menschen vergegenwärtigt, deren Denken in Einer Richtung thätig ist, die Alles als Stoff benützen, die immer ihrem innern Leben und dem Anderer mit Eifer zusehen, die überall Vorbilder, Anreizungen erblicken, die in der Combination ihrer Mittel nicht müde werden. Das Genie thut auch Nichts, als dass es erst Steine setzen, dann bauen lernt, dass es immer nach Stoff sucht und immer an ihm herumformt. ${ }^{26}$

\footnotetext{
22 VM 155, KSA 2, S. 442.

23 MA 171, KSA 2, S. 159.

24 Ebd.

25 MA 222, KSA 2, S. 186.

26 MA 162, KSA 2, S. 151f. Im Rahmen seiner Metaphysikkritik gilt die Hervorhebung eines stofflichen Schaffensprozesses nicht nur für die Kunst, sondern als Grundbedingung des menschlichen Schaffens überhaupt. Vgl. dazu auch Lichtenberg 1971, G 118, S. 155: «Es gibt
} 
Nietzsche versteht menschliche Schaffensprozesse als Handwerk: Er sieht im Verfahren und dem Willen, ständig Stoff zu gewinnen und umzuarbeiten, das verbindende Merkmal zwischen Genie, mechanischem Erfinder und historischem Gelehrten. Damit bestreitet er substanzielle Unterschiede zwischen wissenschaftlicher und künstlerischer Arbeit (wie das etwa die Gegenüberstellung von Gelehrten und Genies voraussetzt). Nietzsche beschreibt Schaffensprozesse durch die Art und Weise, wie mit Stoff umgegangen wird, d.h. durch das Handwerk. Das gemeinsame Element von Schaffensprozessen sei, dass in ihnen etwas «als Stoff» genutzt wird. So wie ein Gelehrter seine Quellen «als Stoff» seiner Feststellungen behandelt, so kann dies beim Philosophen ein Gedanke sein. Wichtig ist nur, dass die Quelle, der Gedanke, die historische Vermutung als Stoff, das heisst als Material für einen Produktionsprozess dienen. Es geht um die Tätigkeit, einen Stoff zu suchen und an ihm «herumzuformen». Auch das Genie müsse wie der Handwerker zuerst lernen, «die Theile vollkommen zu bilden, bis er es wagt, ein grosses Ganzes zu machen». ${ }^{27} \mathrm{Ob}$ dabei eine Chronik, eine Maschine oder ein philosophisches Buch entsteht, ändert nichts an dieser Tatsache. Damit stellt sich Nietzsche gegen Kant, der das Genie in der Kritik der Urteilskraft klar von lernbaren Bereichen wie der Wissenschaft abgrenzt. ${ }^{28}$ Entsprechend benutzt Nietzsche ein Produktionsvokabular: Es geht um das Handwerk, die Werkstätte, die Rezepte, das Herumformen und die Fabrikation. ${ }^{29}$

Wie können aber Produktionsprozesse von Werken analysiert werden? Diese Frage ist schwierig für Kunst und Philosophie vergangener Jahrhunderte zu beantworten, da man es meistens mit fertigen Werken zu tun hat und die entsprechenden Produktionsprozesse wenig materielles Substrat zurückliessen. Und wenn doch, wurde dieses von den Künstlern gemeinhin vernichtet. ${ }^{30}$ Nietzsche fokussiert in seiner Geniekritik nicht auf Produktionsmaterialien, sondern auf die Praktiken und Techniken, welche am Entstehungsprozess beteiligt sind. Es soll im Folgenden anhand zweier Aphorismen aus Menschliches gezeigt werden, welche konkreten Techniken der Produktion in

keine Art von Gelehrsamkeit, und keine Art literärischer Beschäftigung, die man nicht mit irgend einem Handwerk oder sonst einer Handarbeit vergleichen könnte.»

$27 \quad$ MA 163, KSA 2, S. 153.

28 Vgl. den Abschnitt $\$ 47$ in Kant, AA, Bd. V, S. 308-310.

29 MA 162, KSA 2, S. 151f.; MA 163, KSA 2, S. 152-154; Vorstufe von MA 196 in KGW IV 4, S. 196.

3o Handschriften sind unvollendet und widersprechen daher dem geniehaft Vollendeten, vgl. Grésillon 1999, S. 110: «Das sicherste Mittel, sich nicht öffentlich bloßzustellen, war die Vernichtung aller Vorstufen des Werks.» 
Kunst und Philosophie zum Einsatz kommen. Das erste Beispiel sind die Notizbücher Beethovens (die Nietzsche kaum je gesehen hat): ${ }^{31}$

In Wahrheit producirt die Phantasie des guten Künstlers oder Denkers fortwährend, Gutes, Mittelmässiges und Schlechtes, aber seine Ur th e ils k raft, höchst geschärft und geübt, verwirft, wählt aus, knüpft zusammen; wie man jetzt aus den Notizbüchern Beethoven's ersieht, dass er die herrlichsten Melodien allmählich zusammengetragen und aus vielfachen Ansätzen gewissermaassen ausgelesen hat. [...] Alle Grossen waren grosse Arbeiter, unermüdlich nicht nur im Erfinden, sondern auch im Verwerfen, Sichten, Umgestalten, Ordnen. ${ }^{32}$

Nietzsche benennt konkrete Praktiken wie «allmähliches Zusammentragen», «Auswählen», «Verwerfen», «Sichten», «Umgestalten» und «Ordnen». Diese oft übersehenen Praktiken seien materiale Arbeitsprozesse der Urteilskraft. Nietzsche versteht also die Urteilskraft keineswegs als rein geistige Tätigkeit, sondern als materialen Prozess der Gedankenentwicklung. Im Medium des Notizbuchs werden diese Techniken als Arbeit sichtbar. Eine Auswahl zu treffen oder eine Wortwahl zu verwerfen sind Arbeitspraktiken des Denkens. Die Arbeit der Urteilskraft geschieht am und mit dem Material: Schreiben ist darum eine Sammeltechnik des Denkens, etwa für Zusammentragen (Notizbuch), Auswählen (Umschreiben) und Verwerfen (Durchstreichen). Nietzsche verneint nicht, dass es auch plötzliche Schaffensprozesse gebe, doch seien diese nur «scheinbare Inspiration». So könne sich die «Productionskraft» bei einem Künstler durch ein Hindernis stauen und sich später umso plötzlicher ergiessen. Das vorausgehende lange «innere[ ] Arbeiten» sei zwar unscheinbar, aber eben doch vollzogen worden. ${ }^{33}$ Die Notizbücher Beethovens stehen hier als Zeugen für die materiale Genese von Gedanken und Werken. Sie veranschaulichen das Handwerk des Komponierens. Um Beethovens Notizbücher entzündete sich eine breite, öffentliche Debatte über künstlerische Inspiration. Richard Wagners Beethoven-Schrift war mitunter eine Reaktion

31 Es ist fraglich, ob Nietzsche die einschlägigen Schriften Gustav Nottebohms zu Beethovens Notizbüchern kannte. Jedenfalls trifft man einige Aspekte der damaligen Debatte in Menschliches an. Vgl. etwa Nottebohms folgende Feststellung über Beethovens Notizbücher mit MA 163 (KSA 2, S. 152-154): «überall sehen wir Ansätze, nirgends ein Ganzes; ein Ganzes tritt uns erst ausserhalb des Skizzenbuchs entgegen, in der gedruckt vorliegenden Composition, wo dann die Theile, die im Skizzenbuche zerstreut auseinander liegen, zusammengestellt erscheinen.» (Nottebohm 1865, S. 6) Er betont auch die Verschiedenheit der unstrukturierten Notizen, welche kaum zielgerichtet einem im Voraus bekannten Projekt dienten.

32 MA 155, KSA 2, S. 146f. Zudem heisst es im Wanderer von Beethoven, er trage seine Melodien «wie eine Biene» zusammen (WS 152, KSA 2, S. 616). 
gegen die aufkommende musikwissenschaftliche Beethovenrezeption. ${ }^{34}$ Laut Wagner gehören Notizbücher nicht in die Sphäre der «Inspiration», sondern fallen unter die «Gesetze der Konvention». ${ }^{35}$

Im zweiten Beispiel aus Menschliches wird das Schreibhandwerk unter dem Titel «D er Ernst d es Handwerks » anhand eines fiktiven Novellenschreibers veranschaulicht:

\begin{abstract}
Das Recept zum Beispiel, wie Einer ein guter Novellist werden kann, ist leicht zu geben, aber die Ausführung setzt Eigenschaften voraus, über die man hinwegzusehen pflegt, wenn man sagt «ich habe nicht genug Talent». Man mache nur hundert und mehr Entwürfe zu Novellen, keinen länger als zwei Seiten, doch von solcher Deutlichkeit, dass jedes Wort darin nothwendig ist; man schreibe täglich Anekdoten nieder, bis man es lernt, ihre prägnanteste, wirkungsvollste Form zu finden, man sei unermüdlich im Sammeln und Ausmalen menschlicher Typen und Charaktere, man erzähle vor Allem so oft es möglich ist und höre erzählen, mit scharfem Auge und Ohr für die Wirkung auf die anderen Anwesenden, man reise wie ein Landschaftsmaler und Costümzeichner, man excerpire sich aus einzelnen Wissenschaften alles Das, was künstlerische Wirkungen macht, wenn es gut dargestellt wird, man denke endlich über die Motive der menschlichen Handlungen nach, verschmähe keinen Fingerzeig der Belehrung hierüber und sei ein Sammler von dergleichen Dingen bei Tag und Nacht. ${ }^{36}$
\end{abstract}

Bemerkenswert ist bereits die Wortwahl des Rezepts. Nietzsche versucht die Technizität und den handwerklichen Charakter des Novellenschreibens herauszustellen. Die Techniken des handwerklichen Schreibens sind Folgende: über einige Jahrzehnte an kurzen und prägnanten Entwürfen zu üben (Schreibtechnik); täglich Anekdoten, Exzerpte und menschliche Charaktere aufzuschreiben (Sammeln von Material); möglichst viel zu erzählen (Erzähltechnik); die Wirkung von Erzähltem auf die anderen Personen zu beobachten (Wirkungsästhetik); zu reisen (Selbsttechnik) usw.: «Man sei ein Sammler

34 Vgl. Walton 2014, S. 15f. Cosima Wagner berichtet in ihrem Tagebuch über Nottebohms Ausgabe von Beethovens Notizbücher: «Wir beschäftigen uns mit den Skizzen von Beethoven zu der 9ten Symphonie, von Nottebohm herausgegeben, sehr merkwürdig, wie nichtssagend fast, gewöhnlich zuerst die bedeutendsten Themen aufgesetzt; R. sagt, ihm ging es ähnlich, was er zuerst aufschrieb, könne er fast nie so gebrauchen, es ist wie ein Zeichen, dass man etwas im Sinn hatte, aber ganz anderes, dann findet man es wieder.» (Wagner 1976, S. 917) Richard Wagner nannte den Versuch, Beethovens Werke zu erklären, ein «thörichtes Unternehmen» (Wagner 1870, S. 28).

35 Wagner 1976, S. 319.

36 MA 163, KSA 2, S. 153. Im Entwurfsstadium diente Walter Scott als Beispiel für den «Novellisten», vgl. KGW IV 4, S. 195. Es ist unklar, woher Nietzsche diese Information über Scotts Arbeitsweise hatte. Interessanterweise kommentiert Nietzsche mit dem Ablauf des guten Novellenschreibens teilweise seine eigene Arbeitsweise zur Zeit der ersten Aphorismenbücher (Kap. 4.1). 
von dergleichen Dingen bei Tag und Nacht. In dieser mannichfachen Uebung lasse man einige zehn Jahre vorübergehen: was dann aber in der Werkstätte geschaffen wird, darf auch hinaus in das Licht der Strasse.» ${ }^{37}$ Die Produktionstechniken werden somit auch auf Gebiete erweitert, die vom konkreten Schreibprozess losgelöst sind: Das «Viel-Erzählen» oder das «Reisen» sind ungewohnt in diesem Kontext.

Am wichtigsten in diesem Beispiel ist die «mannichfache Uebung», also die konstante Wiederholung dieser Techniken. Der gute Novellist unterscheidet sich dann vom Laienschriftsteller durch seinen «Handwerker-Ernst», d.h. indem er seine Novellen als Handwerk begreift und dieses Handwerk durch fleissige und ausdauernde Übung erlernt. Diese unscheinbaren Charaktereigenschaften sind es, über die man «hinwegzusehen pflegt». Talent wird von Nietzsche aus dem Diskurs der Genialität in jenen des Handwerks überführt bzw. aus dem Bereich irrationaler Bewunderung in jenen der (Selbst-)Techniken und Praktiken. Auf den ersten Blick besteht die Provokation dieses Aphorismus im nicht personalisierten Novellisten. Es könnte offenbar jeder, der durch genügend Fleiss und Ernst die jahrzehntelangen Übungen durchsteht, gute Novellen schreiben. Die Pointe liegt jedoch darin, dass jene vermeintlich simplen Tugenden wie Ernst, Ausdauer und Fleiss das eigentlich Schwierige und Seltene sind. Genie und Talent beziehen sich deshalb nicht auf eine natürliche Anlage, sondern auf ein Rezept, zu dessen Ausführung es keiner Genialität, sondern «Handwerker-Ernst» bedarf:

Redet nur nicht von Begabung, angeborenen Talenten! Es sind grosse Männer aller Art zu nennen, welche wenig begabt waren. Aber sie b ek a m e n Grösse, wurden 〈Genie's $\rangle$ (wie man sagt), durch Eigenschaften, von deren Mangel Niemand gern redet, der sich ihrer bewusst ist: sie hatten Alle jenen tüchtigen Handwerker-Ernst $[\ldots] .^{38}$

Diese Auffassung wendet sich gegen Schopenhauer, der ausdrücklich zwischen Genie und Talent unterscheidet. ${ }^{39}$ Es verwundert nicht, dass Nietzsche den «Handwerker-Ernst» an einem Notizbuch exemplifiziert. Das Notizbuch ist das Modell von Nietzsches philosophischen Überlegungen zu Werk und Autorschaft. Sie sind das Mittel, um «Alles als Stoff [zu] benützen», um dem eigenen Leben und jenem anderer mit Eifer zuzusehen, um überall Anreizun-

$37 \quad$ MA 163, KSA 2, S. 153.

38 MA 163, KSA 2, S. $15^{2}$ f.

39 Vgl. Schopenhauer 1986, Bd. 2, Kap. 31, Vom Genie, S. 484-514. «Auch macht sich schon hier die Verschiedenheit des Genies vom bloßen Talent bemerkbar, als welches ein Vorzug ist, der mehr in der größern Gewandtheit und Schärfe der diskursiven als der intuitiven Erkenntnis liegt.» (ebd. S. 485). 
gen zu sehen, und vor allem, um ständig am Stoff zu arbeiten. Am Modell des Handwerks zeigt sich, dass am Schreiben ein Ensemble von Faktoren beteiligt ist. So können in Literatur und Philosophie namentlich die Schreibinstrumente, Produktionsumstände, Wirkungsabsichten und Stile am Schaffensprozess teilhaben.

\section{Material, Handwerk und Genius}

Über Menschliches heisst es in Ecce Homo: «Hier zum Beispiel erfriert <das Genie> [...].» ${ }^{40}$ Sieht Nietzsche demnach den Künstler als unfrei und alle Kunstwerke als Resultate ihrer Produktionstechniken? Keineswegs. Nietzsche betont einige Male die Existenz von Talenten und vom Genius. Er kritisiert nicht den Genius als Talent, ausserordentliche Schaffenskraft und meisterhaftes Handwerk, sondern den «Cultus des Genius», also die religiöse Verehrung und Stilisierung, welche um den Genius herum inszeniert wird. So spricht Nietzsche weiterhin von einem Genius des Wissens (Kepler, Spinoza), des Könnens, des Erkennens, der Moral. Es sei zudem fruchtbar, wenn es auf einem Gebiete mehrere Genies zugleich gebe, die sich gegenseitig in Schranken hielten. ${ }^{41}$ Das Handwerker-Modell wendet sich gegen die Genieästhetik der Inspiration und der Regellosigkeit, nicht aber gegen die Vorstellung von ungleich verteilten Talenten, gutem Geschmack und Virtuosität.

Nietzsche führt also nicht alles künstlerische Schaffen auf die Produktionssituation zurück, er nimmt ihm jedoch die individuelle Exklusivität, mit der etwa das Genie sein Können inszeniert. So behauptet er im Wanderer: «Fast alle Zustände und Lebensweisen haben einen seligen Moment. Den wissen die guten Künstler herauszufischen.» ${ }^{42}$ Der Künstler hat keine exklusiven Erfahrungen. Selige, spezielle und herausragende Momente gehören zu allen Lebensweisen. Der Künstler verwertet diese Momente jedoch «als Stoff» für seine Kunst. Dazu muss er einerseits Techniken erlernen und beherrschen, andererseits Ausdauer, Fleiss und Ernst besitzen. Diese Techniken und Tugenden fasst Nietzsche unter dem Begriff «Handwerker-Ernst» zusammen, den er als die eigentliche Ressource von Talenten und Genies ansieht. Es kann auf den ganzen Arbeitsprozess bezogen deshalb von Talent und Genie gesprochen werden, jedoch nicht mehr als exklusive Attribute des Autors. Der «Handwerker-Ernst» ist an Praktiken, Dinge und Materialien geknüpft. Da das Genie für

$40 \quad$ EH, KSA 6, S. 322.

41 Vgl. MA 157, KSA 2, S. 147f.; MA 158, KSA 2, S. 148. Liest man sich durch Nietzsches Lesespuren dieser Zeit, so gibt es alleine schon bei Emerson, La Rochefoucauld und Stendhal ein durchgehendes Interesse an Reflexionen zur Thematik herausragender Menschen, Genies, grossen Geistern etc. 
Nietzsche eine handwerkliche Meisterschaft bezeichnet, kann Genie auch dort entdeckt werden, wo es nicht einer metaphysisch begründeten Intention entspricht. Christian Benne schreibt dazu: «Alternativ wird eine Ästhetik entworfen, die in jeder Tätigkeit Genie und Intuition anerkennt und «alles Werdende>, das Machen und Herstellen, gegenüber dem Fertigen und vorgeblich Vollkommenen herausstreicht.» ${ }^{43}$ Diese Produktionsästhetik interessiert sich nicht mehr primär für die intentio auctoris.

Indem Nietzsche den «Handwerker-Ernst» hervorhebt, verweist er nicht nur auf die letztlich handwerkliche Produktion des Genies, sondern auch ganz wörtlich auf die materialen Produktionsumstände. Der Fokus auf das Material eines künstlerischen Prozesses führt weg vom geistigen Geniegedanken und hin zum Handwerk. So spricht Richard Sennett von einem «material consciousness», das jedem Handwerker eigen sei. ${ }^{44}$ Dieses materiale Bewusstsein ist für Sennett eine Ressource der Kreativität und vollkommen gleichwertig zu eher geistigen Kreativitätsformen. Auf den Autor bezogen heisst dies, dass das materiale Bewusstsein für Typografie, Layout, Papier und Notizbücher hinsichtlich der Schreibtechniken und Schreibsituationen kreativ eingesetzt werden kann. Karin Krauthausen hat ausgehend von Hans-Jörg Rheinbergers Studien zur Verwicklung des Forschers in die materialen Praktiken der Wissensgewinnung vorgeschlagen, von «Kunstfertigkeit» und «Virtuosität» zu sprechen. ${ }^{45}$ Beide Begriffe betonen Materialität, Prozessualität und Abhängigkeit des künstlerischen Schaffens.

\subsubsection{Der Wanderer-Autor und die Schatten-Schrift}

Nachdem bereits einige Techniken und Praktiken des künstlerischen Schaffens thematisiert wurden, soll nun spezifisch auf das Schreiben eingegangen werden. Die wohl wichtigsten Bedeutungen des Schattens im Kontext vom Wanderer sind denn auch die Schrift und die Schreibsituation. Das Bild der Schrift als Schatten ist angesichts des weissen Papiers und der dunklen Tinte (bzw. den schwarz gedruckten Lettern) eine sehr anschauliche Metapher, welche seit Platon zur Abgrenzung der leblosen Schrift von der lebendigen Rede dient. Deshalb muss zunächst das Verhältnis von Sprechen und Schreiben bei

\footnotetext{
43 Benne 2015b, S. 48 mit Bezugnahme auf MA 162, KSA 2, S. 151f.

44 Sennett 2008, S. 119-146. Vgl. für die Gegenüberstellung «von inspiriertem Genie und poetischem Handwerker oder Ingenieur» auch Bohnenkamp 2002, S. 62.

45 Die Virtuosität als Praxis verstanden verunmöglicht eine rein technische Sicht auf Schaffensprozesse: «Als Praxis hat die Virtuosität des Experimentators dann ebenso Anteil am Entwurf neuen Wissens wie die Instrumente und Materialitäten des Experimentes.» (Krauthausen 2010, S. 15) Vgl. auch Rheinberger 2001.
} 
Nietzsche geklärt werden. Denn dieses ist der Ausgangspunkt für die Entwicklung einer Schreib- und Lesekunst.

\section{Schreibkunst als Gebärdenkunst}

Die Unterscheidung von Schreiben und Sprechen im Wanderer stützt sich auf die Schriftkritik Platons. Im Phaidros-Dialog führte Sokrates aus, dass die kunstvolle und schöne Rede die Bedingung für die Wahrheit des Gesagten sei. Wie der Körper müsse auch die wahre Rede eine Seele bzw. einen wahren Sinn besitzen. Phaidros fragte daraufhin Sokrates: «Phaidros. Du meinst die lebende und beseelte Rede des wahrhaft Wissenden, von der man die geschriebene mit Recht wie ein Schattenbild ansehn könnte. Sokrates. Allerdings eben sie.» ${ }^{46}$ Die negative Deutung der Schrift als Schattenbild gegenüber der lebendigen Rede hat sich lange gehalten. Überträgt man die Metaphorik von Schrift und Schatten nun auf den Anfangsdialog des Wanderers, so ergibt sich eine interessante Konstellation: Der Wanderer führt dann nämlich weniger einen Dialog mit sich selbst, als mit der Schrift!

Die Kompensation der Mündlichkeit in der Schrift ist durch alle Werkphasen hindurch ein wichtiger Topos für Nietzsche. ${ }^{47}$ Im Nachlass von 1876 brachte Nietzsche diese Problematik auf den Punkt und legte zugleich eine Fährte zum Wanderer:

Die Schriftsprache entbehrt der Be to n ung und dadurch eines außerordentlichen Mittels, Verständniß zu erlangen. Sie muß sich also bemühen, dies zu ersetzen: hier ist ein Hauptunterschied der geschriebenen und gesprochenen Rede. Die letztere darf sich auf Betonung verlassen: die Schriftsprache muß übersichtlicher kürzer unzweideutiger sein, ihre größte Mühe ist es aber, die Leidenschaften der Betonung ungefähr nachfühlen zu lassen. Frage: wie hebt man ein Wort heraus, ohne den Ton zu Hülfe zu nehmen (da man keine Tonzeichen hat)? Zweitens: wie hebt man ein Satzglied heraus? Vielfach muß anders geschrieben als gesprochen werden. Deutlichkeit ist Vereinigung von Licht und Schatten..$^{48}$

46 Platon 1855, S. 111 (Schleiermacher-Werkausgabe). Die Werkausgabe von Ernst Heitsch übersetzt ohne Schatten-Bezug: «Du meinst die Rede des Wissenden, die lebt und beseelt ist, von der die geschriebene zurecht eine Art Abbild genannt werden könnte. - Genau.» (Phaidros 276a-276b, Platon 1997, S. 62f.) Nietzsche kannte die Schatten-Metaphorik vermutlich auch von Schopenhauer: Dieser sah in der Musik das «Abbild des Willens selbst, dessen Objektivität auch die Ideen sind: deshalb eben ist die Wirkung der Musik so sehr viel mächtiger und eindringlicher als die der andern Künste: denn diese reden nur vom Schatten, sie aber vom Wesen.» (Schopenhauer 1986, Bd. 1, § 52, S. 359).

47 Vgl. Langer 2005, S. 50-64; Schlaffer 2007, S. 78-86; Benne 2013. Vgl. insb. DW 4, KSA 1, S. 572; MA 216, KSA 2, S. 176f.; NL 1882, 3[1], Nr. 296, KSA 10, S. 89.

48 NL $1876,15[27]$, KSA 8, S. 286. 
Das Gebärdenproblem bezieht sich auf die Produktions- und Rezeptionspraktiken der Schrift, welche zwar in einem lebendigen Schreibprozess entsteht, jedoch im Unterschied zur Rede ein totes Buchstabensubstrat hinterlässt. Nur deshalb bedarf die Schrift einer Gebärdenkunst und gerade nicht, weil der Akt des Redens lebendiger als jener des Schreibens ist. Dass am Ende des Notats die «Deutlichkeit» als «Vereinigung von Licht und Schatten» bezeichnet wird, gibt einen ersten Hinweis darauf, dass die Figur des Schattens bei Nietzsche schon früher mit der Sprech- und Schreibweise konnotiert war. Gleich im Anfangsdialog spricht der Wanderer diesen Gedanken aus: «Damit es Schönheit des Gesichts, Deutlichkeit der Rede, Güte und Festigkeit des Charakters gebe, ist der Schatten so nöthig wie das Licht.» ${ }^{49}$ Der Aphorismus «S chreibstil und Sprechstil» im Wanderer bringt die Thematik schlüssig auf den Punkt: «Die Kunst, zu schreiben, verlangt vor Allem Ers at z mittel für die Ausdrucksarten, welche nur der Redende hat: also für Gebärden, Accente, Töne, Blicke.» ${ }^{50}$ Die Schrift ist für sich genommen mangelhaft, wobei die «Kunst, zu schreiben» die Fähigkeit bezeichnet, diese Mängel der Schrift wettzumachen - und zwar durch Beherrschung des Schreibhandwerks. Die Schreibkunst führt Nietzsche zum Vergleich, «an einer Seite Prosa wie an einer Bildsäule» zu arbeiten. ${ }^{51} \mathrm{Er}$ weist darauf hin, dass Demosthenes seine Reden zum Gelesenwerden immer überarbeitet habe. ${ }^{52}$

Der Schriftsteller muss sich also konkrete Ersatzmittel für die weggefallenen Gebärden erarbeiten. Dabei bedient er sich auch poetischer Ausdrucksmittel: «Um Vers, Bild, Rhythmus und Reim hat man sich redlich zu bemühen, [...].»53 Diese Gebärden der Schrift sind klassische Bestandteile des Stils: «Der Stil ist der Ersatz der Gebärde und des Tones, in der Schrift.» ${ }^{54}$ Die sorgfältig gewähl-

49 WS Rahmendialog, KSA 2, S. 538. Die Gedankenfigur des Schattens als Deutlichkeit lässt sich bis zur Beschreibung des Apollinischen zurückverfolgen: «Dies ist der apollinische Traumeszustand, in dem die Welt des Tages sich verschleiert und eine neue Welt, deutlicher, verständlicher, ergreifender als jene und doch schattengleicher, in fortwährendem Wechsel sich unserem Auge neu gebiert.» (GT 8, KSA 1, S. 64).

50 WS 110, KSA 2, S. 6oo. Es ist hier das Schreiben als Handwerk im Sinne des 4. Hauptstücks von Menschliches gemeint.

51 WS 95, KSA 2, S. 595. Auch später wird Nietzsche das Schreiben wieder mit Bildhauer-Vokabular bezeichnen, vgl. N. an von Salomé, 27./28.6.1882, Nr. 251, KGB III 1, S. 213; sowie: «Nach Demosthenes muß die Rede sculpta <ausgemeißelt> sein.» (NL 1878, 30[10], KSA 8, S. 524) Die Metapher der Bildhauerei für das Schreiben ist im 19. Jh. ein Gemeinplatz, vgl. etwa Taine 1878, Bd. 1, S. 660 .

$5^{2}$ WS 110, KSA 2, S. 600.

53 WS 95, KSA 2, S. 595. Vgl. zur Annäherung von Prosa und Poesie bei Nietzsche, Schlaffer 2007, S. 49-58.

KGW IV 4, S. 323. Es handelt sich um die Vorstufe von WS 110, KSA 2, S. 600. 
ten schriftlichen Gebärden erzeugen einen persönlichen Stil. Durch die Kultivierung der schriftlichen Gebärden wie der Metrik, des Rhythmus oder der Tonlage entsteht also auch eine Autorpersönlichkeit, mit der ein Leser in Dialog treten kann. ${ }^{55}$ Diese Gebärdenkunst will die körperliche und persönliche Dimension der Stimme in den Akt des Schreibens und Lesens einbringen. Dies gelingt jedoch nur dann, wenn die Leser die Gebärden als solche erkennen können. Ein St. Moritzer Notat zeigt, wie technisch und körperlich Nietzsche es mit den «Ersatzmittel[n]» meint: «Kommata, Frage- und Ausrufezeichen, und der Leser sollte seinen Körper dazu geben und zeigen, daß das Bewegende auch bewegt.» ${ }^{56}$ Die Interpunktion ist, gezielt eingesetzt, ein Ersatzmittel für Gebärden, sofern der Leser die Lesekunst beherrscht. Deshalb gibt es für Nietzsche mehr und weniger lebendige Schreibweisen. Dies bewertet er anhand der Gebärden, welche beim Schreiben eingesetzt und beim Lesen hervorgerufen werden.

Das Problem der toten Schrift löst Nietzsche durch den Versuch eines lebendigen Schreibens, das den Leser aktivieren und die Gebärden der mündlichen Rede durch stilistische Mittel ersetzt. Nietzsche denkt das Schreiben vom Sprechen aus und stellte sich mit seinem Fokus auf Gebärden gegen die Tilgung des Körperbezugs, den die Sprechsituation hauptsächlich durch die Stimme bewahrt. ${ }^{57}$ Die Dialogsituation zwischen Wanderer und Schatten reflektiert ebenso die Körperlichkeit der beiden sprechenden Akteure wie auch die Überführung des mündlichen Gesprächs in die verschriftlichten Aphorismen. Das zeigt sich hier umso mehr, als es Nietzsche spezifisch um Gebärden des Sprechens geht. Nietzsche löst Platons Unterscheidung zwischen Schrift und Rede nicht auf, sondern überführt sie in eine auf den Leser ausgerichtete Schreibpraktik. Die Schrift ist nicht entkoppelt von Schreiben und Lesen. Deshalb braucht es eine Schreibkunst und eine Lesekunst.

\section{Schreiben für ein Lesepublikum}

Die erhöhte Sensibilität für Rede und Schrift ist auch eine Konsequenz der Wirkungsästhetik des Frühwerks, welche sich auf die Tragödie bezog. In der Geburt der Tragödie beschreibt Nietzsche nämlich das Auseinanderfallen von Produktion und Rezeption durch die Auflösung der antiken Kultgemeinde, welche v.a. in Form der attischen Tragödie nicht zwischen Produzent (Satyrn) und Rezipient (Chor) unterschied. ${ }^{58}$ Friedrich Kittler folgert für diese 
Verschmelzung von Bühne und Publikum: «Dieser Kreis erübrigt eine abgetrennte Wirkungspoetik.» ${ }^{59}$ Noch 1874 versucht Nietzsche mit literarischen Mitteln das Ideal der antiken Wirkungspoetik wiederherzustellen: «Eine gute Schrift wird, wo sie w irkt, vergessen machen, dass sie litterarisch ist; sie wirkt als Wort und Handlung eines Freundes; wer möchte darüber etwas drucken lassen!» ${ }^{60}$ Wenn die Medialität des gedruckten Buches zurücktritt, hat man eine direkte Interaktion, wie es beim Sprechen unter Freunden der Fall ist. Im Zeitalter des Buchdrucks ist laut Heinrich Bosse das Gegenteil der Fall: «Aus dem Redner ist ein abwesender Sprecher geworden, der nunmehr den Mangel an rednerischer Aktion, seine fehlende Präsenz, zu beheben hat.» ${ }^{61}$ Schreiben und Lesen sind im Buchmarkt durch die Anonymität voneinander isoliert. Deshalb bedarf es einer Wirkungsästhetik, welche strategisch zwischen Schreiben und Lesen vermittelt. Dieser Wechsel wird gut ersichtlich in der Kritik am Sentenzenleser: «Die schlechtesten Leser von Sentenzen sind die Freunde ihres Urhebers, im Fall sie beflissen sind, aus dem Allgemeinen wieder auf das Besondere zurückzurathen, dem die Sentenz ihren Ursprung verdankt: [...].» ${ }^{62}$ Hier wird nun gerade der Freund als schlechtester Leser ausgewiesen, da er das Literarische durch das Biografische untergräbt. Oder medientheoretisch formuliert: Der schlechte Leser hört seinem Freund zu, anstatt den Text zu lesen. Der gute Leser beim mittleren Nietzsche ist ein Leser der Schrift; sowie der gute Autor nun ein Autor von Texten ist. Nietzsche fordert also auch von seinen Freunden, was für die anonymen Leser im Buchmarkt des 19. Jahrhunderts galt: Ein Buch so zu lesen, als ob man den Autor nicht kenne; und damit zu lesen, was geschrieben steht.

Der Unterschied zwischen einem Lesepublikum und einem vertrauten Adressatenkreis kann anhand von Platons Phaidros-Dialog präzisiert werden, gemäss dem die Schrift dem Leser kein Wissen übertragen könne. Platon sieht jedoch in verschriftlichten Dialogen ein Ersatzmittel, um die Intentionen der Sprecher einem breiteren Publikum zu vermitteln. Schleiermacher schreibt, dass die schriftliche Dialogform die mündliche Situation auf eine Weise nachahme, dass die «beabsichtigte[ ] Idee» beim Leser ebenso erzeugt werde. ${ }^{63}$

\footnotetext{
59 Kittler 2013a, S. 34.

6o NL 1874, 37[4], KSA 7, S. 830.

61 Bosse 1981, S. 23, insb. das Kap. «Sprechen und Schreiben», S. 17-24.

62 VM 129, KSA 2, S. 432. Und gemäss Wanderer setzen sich die Menschen treuer für Staat, Kirche und Gott ein, wenn diese Institutionen für sie unpersönlich bleiben (vgl. WS 8o, KSA 2, S. 588).

63 Schleiermacher 1996, S. 41. Es bleibt anzufügen, dass Nietzsche wie auch Schleiermacher die mehrschichtigen Reflexionen über das Geschriebene bei Platon übersehen (vgl. Moser 2010, S. 151-153). Stegmaier behandelt die Platonkritik in seiner Interpretation des Rah-
} 
Während Platon also nach dem am besten geeigneten schriftlichen Ersatz für die Intentionen suchte, löst Nietzsche den philosophischen Text von der Vermittlungsaufgabe auktorialer Intentionen los. Aphorismen und Sentenzen versuchen auf möglichst vielfältige Weise das aktive Lesen anzuregen (Kap. 3.2.3). Mit dieser Lektürepolitik folgt Nietzsche der Einsicht Schillers, dass der Schriftsteller den Nachteil habe, dass ihm der lebendige Ausdruck der Rede fehle, jedoch den Vorteil, «seinem Leser eben deswegen eine größere Gemüthsfreyheit zu lassen, als im lebendigen Umgang möglich ist, u.s.f.» ${ }^{64}$ Damit reagiert Nietzsche spielerisch auf die Problematik des Buchdrucks, inwieweit der Autor dem Leser etwas so mitteilen könne, wie er es gedacht habe. ${ }^{65}$ Nietzsche interessieren die Ersatzmittel für die Gebärden, nicht jene für die Intentionen.

\section{Wanderer-Autor und Schatten-Schrift}

Die Motive des Wanderers als Philosoph, Autor und Dichter sowie des Wanderns als Denken, Lesen und Schreiben sind charakteristisch für Nietzsches Denken. ${ }^{66}$ Im Gedicht «Der Wanderer» von 1876 wird ein Wanderer durch den Gesang eines Vogels zum Innehalten verführt. Bezeichnenderweise wird diese Situation im späteren Gedicht «Dichters Berufung» wieder aufgenommen und in vielfacher Weise auf die Schreibsituation des Dichters (sowie auf den

mendialogs zu pauschal (2012, S. 104), während Zittel anhand von Nietzsches Frühwerk die ambivalente Platonkritik rekonstruiert (2016, S. 88-91).

64 Schiller an Garve, 25.1.1795, in: Schiller 1958, S. 124f.

65 Vgl. Bosse 1981, S. 50-64.

66 Vgl. etwa den Entwurf zu Ueber Wahrheit und Lüge im aussermoralischen Sinne: «Der Philosoph als Abnormität. Daher als einsamer Wanderer.» (KSA 14, S. 114) Vgl. auch SE 7, KSA 1, S. 406; Z III, KSA 4, S. 204 sowie zum Wanderer-Motiv bei Nietzsche auch Zittel 1996, S. 203-206. Zu Lesen und Wandern vgl. Benne 2005, S. 162-170. Noch ausstehend ist eine Untersuchung über die Bedeutung des Wanderers für die frühen 1880er Jahre und damit auch für Also sprach Zarathustra. So finden sich im Nachlass Pläne für Gedichtbände, welche den Wanderer mit der Yorick-Figur verbinden, vgl. KSA 14, S. 708-716. Dieser Plan müsste vor dem Hintergrund des lockeren Stils und Nietzsches Sterne-Verehrung in den Vermischten Meinungen sowie im Wanderer gründlich untersucht werden. Auch eine Untersuchung zum Wanderer und zu Goethes Wilhelm Meisters Wanderjahre wäre angesichts der vielen aphoristischen und spruchartigen Stellen sowie der mehrschichtigen Wandermetaphorik in Goethes Roman wünschenswert. Am Ende des zweiten Buches sind unter dem Titel «Betrachtungen im Sinne der Wanderer» verschiedene Gedanken $\mathrm{zu}$ «Kunst, Ethisches, Natur» in Aphorismenform versammelt (Goethe 1950, S. 283-309). Eckermann hat nach dem Tod Goethes diesen Aphorismenteil für die weiteren Auflagen entfernt, weshalb auch in Nietzsches Exemplar dieser Abschnitt fehlt (vgl. die Anmerkungen in Goethe 1950, S. 682f.). Bis auf ein Lob Overbecks im Dezember 1876 konnte keine zeitnahe Verbindung zu Nietzsches Wanderer gefunden werden (vgl. Overbeck an N., 18.12.1876, Nr. 849, KGB II 6/2, S. 456). 
Leser) bezogen. ${ }^{67}$ Auch im Gedicht «Mit dem Fusse schreiben» aus Scherz, List und Rache wird die Engführung von Dichten und «physischer Fortbewegung» rhythmisch umgesetzt. ${ }^{68}$ Viele Forschungsarbeiten setzen die Bezeichnungen Wanderer und Freigeist oder Wanderer und Philosoph synonym, womit sie sich den Blick auf spezifische Bedeutungen des Wanderer-Motivs verwehren. ${ }^{69}$

Die Schlussaphorismen von Menschliches und den Vermischten Meinungen kontrastieren die spezifische Bedeutung des Wanderns im Wanderer: Im Aphorismus «Der Wanderer» wird das Wanderer-Motiv als Gefühlszustand beschrieben. Der Wanderer verfolge kein bestimmtes Ziel und empfinde ebenso Leid und Freude am «Wechsel und der Vergänglichkeit». ${ }^{70}$ Dieser Aphorismus bleibt durch den metaphorischen und unpersonalisierten Wanderer sehr allgemein und allegorisch. Vom Wandern als Gefühlszustand geht es dann in den Vermischten Meinungen zum Wandern als Lektüre und Studium. Im Schlussaphorismus «Die Ha d e sfahrt» berichtet ein Ich-Erzähler über seinen Gang in die Unterwelt und seinen Totengesprächen. ${ }^{71}$ Gemeint ist die Lektüre von acht Autoren: «Epikur und Montaigne, Goethe und Spinoza, Plato und Rousseau, Pascal und Schopenhauer. Mit diesen muss ich mich auseinandersetzen, wenn ich lange allein gewandert bin, $[\ldots] .{ }^{72}$ Lesen bedeutet hier, einen Dialog zu führen. Das einsame Wandern bezöge sich dann auf die durch Nachdenken ausgelösten Veränderungen. Dieses eigene Werden will der Ich-Erzähler den genannten Autoren präsentieren und sich von ihnen «Recht und Unrecht geben lassen».73 Die «Lebenden» kommen dem Ich-Erzähler wie «Schatten» vor, während die verstorbenen Autoren ihm lebendig erscheinen. ${ }^{74}$

67 Für das Gedicht «Der Wanderer» vgl. Grundlehner 1986, S. 64-70; Zittel 1996; Labhart 2006, S. 44-50. Für eine ausführliche Interpretation von «Dichters Berufung» vgl. Forrer 2014, S. 109-122. Im Lichte von Forrers Erkenntnissen ist Labharts Interpretation des Vogels als Metapher für die Natur, welche man nicht verstehen kann (es aber will), simplifizierend.

68 Vgl. dazu Benne 2015b, S. 38 f.

69 Vgl. beispielsweise die lesenswerte Studie von Labhart 2006, der den Wanderer mit dem «freien Geist», dem «Freigeist», «Kolumbus» gleichsetzt (S. 107). Fortier 2016 simplifiziert und psychologisiert den Schatten als das, was der Wanderer negiert (S. 211).

$70 \quad$ MA 638, KSA 2, S. 362 f.

71 VM 408, KSA 2, S. 533 f.

72 Ebd.

73 Ebd. Vgl. für den Zusammenhang mit der Tradition der Totengespräche Lupo 2004, S. $102 f$.

74 VM 408, KSA 2, S. 534. Lupos Interpretation des Schattens als gesamte Geschichte und Vergangenheit widerspricht Nietzsches Umkehrung der toten Autoren als eigentlich Lebendige, vgl. Lupo 2004, S. 103. 
Im Wanderer sind die Motive des Wanderns und des Schattens auf die Schreibsituation bezogen. Im ersten Satz des Rahmendialogs anerbietet sich der Schatten bzw. die Schrift dem Autor zu reden bzw. zu schreiben: «Der Schatten: Da ich dich so lange nicht reden hörte, so möchte ich dir eine Gelegenheit geben.» ${ }^{75}$ Dadurch ist das Geschriebene aber anders als bei Platon nicht etwa tot, sondern führt ein Eigenleben. Die Schrift macht es möglich, dass der Autor sich selbst begegnen kann - in der Praktik des Schreibens. Damit wird die Schrift als eigenständiger Akteur neben dem Autor wahrgenommen. Die Schrift wird von ihrem Schattendasein gegenüber der lebendigen Rede emanzipiert, weil sie im Akt des Schreibens (und Lesens) lebendig wird. Das zeigt sich plastisch an der Figur des sprechenden bzw. lebenden Schattens: «Der Wanderer: Er redet - wo? und wer? Fast ist es mir, als hörte ich mich selber reden, nur mit noch schwächerer Stimme als die meine ist. / Der Schatten: (nach einer Weile): Freut es dich nicht, Gelegenheit zum Reden zu haben?» 76 Hier wird die Urszene des Schreibens inszeniert: Der Autor (Wanderer) hört in der Schrift (Schatten) seine eigene Stimme, die zugleich nicht mehr die seine ist. Durch diesen dramaturgischen Kniff wird in den Blick gerückt, dass man im Schreibakt die eigene Stimme ins Geschriebene hineinlegt und dieses fortan für sich selbst spricht. So wird die Frage nach der Autorschaft bei der Schrift problematisch, weil der körperliche und situative Bezug der Rede wegfällt. Diese Frage stellt sich gleichermassen für Autor und Leser. So kann auch der Leser glauben, er höre seine eigene Stimme. Sobald man liest oder schreibt, wird aufgrund der medialen Eigengesetzlichkeiten unklar, ob man die bewusste Kontrolle und Urheberschaft bei diesen Vorgängen hat.

Anders als in Platons Höhlengleichnis dient der Schatten nicht als Symbol der Gefangenschaft in der sinnlichen Welt gegenüber der geistigen Ideenwelt. Bei Platon ist die Abwendung von den falschen Schatten die Bedingung, um der Höhle zu entkommen; während bei Nietzsche die philosophische Erkenntnis dann beginnt, wenn der Wanderer seinen sprechenden Schatten akzeptiert und sich auf das Gespräch einlässt. Dies wird auch im Buchaufbau artikuliert, indem der Anfangsdialog zwischen Wanderer und Schatten aus der Sicht des Lesers den Eintritt in die Aphorismen, also die Erkenntnis, vorbereitet. Bei Nietzsche führt die Hinwendung zum Schatten zur Erkenntnis. Die Dualität von der finsteren Höhle und der strahlenden Ideenwelt Platons wird aufgehoben, denn der Schatten sei «so nöthig wie das Licht». ${ }^{77}$ Es findet also eine provokante Umkehrung statt.

\footnotetext{
75 WS Rahmendialog, KSA 2, S. 537.

76 Ebd.

77 Ebd., S. 538.
} 
Das Ergebnis des Gesprächs zwischen Wanderer-Autor und Schatten-Schrift ist ein Buch. Denn mit Blick auf den Leser wollen Wanderer und Schatten nur die Ergebnisse ihres Gesprächs in die Schrift übertragen - ohne weitere Erwähnung des Schattens:

Der Wanderer: Wie wir zusammen gesprochen haben? Der Himmel behüte mich vor langgesponnenen schriftlichen Gesprächen! Wenn Plato weniger Lust am Spinnen gehabt hätte, würden seine Leser mehr Lust an Plato haben. Ein Gespräch, das in der Wirklichkeit ergötzt, ist, in Schrift verwandelt und gelesen, ein Gemälde mit lauter falschen Perspectiven: Alles ist zu lang oder zu kurz. - Doch werde ich vielleicht mittheilen dürfen, w o r ü b er wir übereingekommen sind?

Der Schatten: Damit bin ich zufrieden; denn Alle werden darin nur deine Ansichten wiedererkennen: des Schattens wird Niemand gedenken. ${ }^{78}$

Das Buch Der Wanderer und sein Schatten ist eine schriftliche Zusammenfassung, worin der Wanderer und sein Schatten übereingekommen sind. Der fertige Text verdeckt die dialogische Entstehungssituation. Zudem wird beim Lesen das Gelesene nur der Fiktion einer einzigen Instanz, dem Autor, zugerechnet: «des Schattens wird Niemand gedenken». Die Pointe liegt darin, dass durch den Rahmendialog jeder Leser der dialogischen Entstehungssituation gedenken muss. Dafür sorgt Nietzsche auch durch das Layout, indem er folgende Anweisung ins Druckmanuskript schreibt: «Durch Druck und Spatien als Vorwort zu charakterisiren! Drei Sterne darüber und darunter!» ${ }^{79}$ Diese typographische Abhebung zusammen mit den drei Sternen $(* * *)$ verleiht dem Rahmendialog zusätzliche Bedeutung.

In Nietzsches zeitnaher Lektüre um 1879 finden sich weitere Hinweise, dass das Gespräch zwischen Wanderer und Schatten als Allegorie von Autor und Schrift, die sich im Schreiben treffen, verstanden werden kann. ${ }^{80}$ Nietzsche sieht in auffälliger Ähnlichkeit zu Laurence Sterne und Jonathan Swift das Schreiben als ebenbürtige Gesprächsform an. Laurence Sterne schreibt in Tristram Shandy über das Schreiben: «Writing, when properly managed, (as you may be sure I think mine is) is but a different name for conversation [...].» ${ }^{81}$ Weiter heisst es analog zum Bündnis zwischen Wanderer und Schatten, dass nicht das ganze Gespräch, sondern nur Teile davon ins Geschriebene einflies-

78 Ebd., S. 539. Nietzsche bezieht sich bei dieser Platonkritik vermutlich auch auf Montaigne, der Platons Dialoge als «müde» und ermüdend bezeichnete (Montaigne 1965, Bd. 2, S. 112). Vgl. dazu ausführlich Vivarelli 2014. Vgl. auch die Stilkritik an Platon in der Götzen-Dämmerung, GD, KSA 6, S. 155 .

$79 \quad \mathrm{D}_{13}$, Blatt 3 recto.

8o Vgl. auch Emerson (1876, S. 269), bei dem die Unterhaltung zwar als Denktechnik identifiziert, jedoch auf das mündliche Gespräch bezogen wird.

81 Sterne 1978, Bd. 1, S. 125 . 
sen. In Nietzsches Swift-Lektüre findet sich wiederum ein angestrichener Brief, in dem Swift von seinem einsamen Spazierleben berichtet: «Vergeben Sie diese Langweiligkeit der Feder, die ich ansetze, weil ich sie nicht gesprächsweis absetzen kann; [...].» ${ }^{82}$ Die Formulierung ist in mehrerer Hinsicht bemerkenswert: Zunächst wird die Langeweile von der Feder aus formuliert und damit eine Personifikation des Schreibzeugs vorgenommen. Der Autor wird ausschliesslich durch das Ansetzen der Feder charakterisiert, als würde diese einmal angesetzt selber schreiben. Der Grund, dass der Autor seiner Feder freien Lauf lässt, ist das in der Einsamkeit fehlende Zwiegespräch. Die Formulierung suggeriert einen anhaltenden Gesprächstrieb, der sich entweder im menschlichen Zwiegespräch oder behelfsweise im Schreiben entladen muss.

In einem weiteren Beispiel aus Nietzsches Swift-Lektüre kommen Spaziergänge, Dialoge und Aphorismen beispielhaft zusammen: Swift und Alexander Pope haben einige Gedanken publiziert, die aus Gesprächen während gemeinsamen Spaziergängen resultierten. Nietzsche besitzt ab Mitte Juli 1878 ein Exemplar des Swift-Büchleins, einer deutschen Swift-Anthologie. ${ }^{83}$ Dort wird die besondere Entstehungsweise von Swifts und Popes Gedankensammlung vom Herausgeber Gottlob Regis durch eine Klammerbemerkung dem Leser erläutert: «[,Pope und Swift hatten damals, während eines Aufenthaltes auf dem Lande verabredet, die zufälligen Gedanken, die Beide auf ihren Spaziergängen hätten, niederzuschreiben.']» ${ }^{84}$ Nietzsche markierte sich diese Herausgeber-Angabe durch zwei waagrechte Striche am Seitenrand. Dieses Beispiel enthält nicht nur die für den Wanderer spezifische Rahmung einer Gedankensammlung durch die Angabe der spazierenden Schreibsituation, sondern auch die Tilgung der Dialogsituation in den gedruckten Sentenzen und Aphorismen. Auch der Wanderer teilt dem Lesepublikum in Form von Aphorismen mit, «w or über» er und sein Schatten «übereingekommen sind». ${ }^{55}$ Die Aphorismensammlung, die der Wanderer zu lesen gibt, wird als Resultat des Gesprächs zwischen Wanderer und Schatten inszeniert. Der zentrale Unterschied liegt darin, dass es bei Swift und Pope um einen Dialog unter Menschen, bei Nietzsche um einen Dialog zwischen Denker und Schreibsituation geht. Nietzsche inszeniert die Tätigkeit des Schreibens als Gespräch zwischen Wanderer-Autor und Schatten-Schrift.

\footnotetext{
$82 \quad$ Swift 1847, S. 375 .

83 Swift 1847. Gemäss BN, S. 596: «Gebunden am 20. Juli 1878 bei: M. J. Memmel-Tripet, Basel, laut Rechnung vom 31. Dezember 1878.»

84 Gottlob Regis übersetzte diesen editorischen Hinweis des Swift-Herausgebers Thomas Roscoe zit. n. Swift 1845, S. 13 .

85 WS Rahmendialog, KSA 2, S. 539.
} 
Schreiben als eigenständige Praktik

Nietzsche rührt mit der Schreibsituation an einer tiefer liegenden philosophischen Grundüberzeugung, jener von den intentionalen Möglichkeiten eines Individuums. Das souveräne Subjekt wird auch vom mittleren Nietzsche immer wieder in Frage gestellt. Schreiben bedeutet in seinem Autorschaftsverständnis, Kontrolle abzugeben und sich dem Schreiben sowie der Freiheit des späteren Lesers zu überlassen. Viele der von Nietzsche genannten Produktionspraktiken werden nicht ausschliesslich von den intentionalen Entscheidungen des Autors geleitet, sondern finden unbewusst statt. Indem man etwas durchstreicht, ändert man den Sinn und trifft eine Auswahl, ohne dass man sich dieser Handlungen als Techniken bewusst sein müsste. Daher gebe es eine Unfähigkeit seitens der Autoren und Künstler, die Gründe für ihr Handeln anzugeben. So beschreibt Nietzsche in einem Entwurf zu Menschliches, dass Erfolgsautoren gar nicht wüssten, weshalb sie erfolgreich schreiben, weil sie ihr Handwerk intuitiv beherrschen. ${ }^{86}$

Im Sommer 1879 findet sich folgendes Notat, in dem die intendierte Zweckmässigkeit von Handlungen radikal verneint wird: «Durch die Zwecke wird das Leben ganz unsinnig / u unwahr. Man arbeitet, um sich zu nähren. Man nährt sich, um zu leben? [...] Vielmehr ist im Arbeiten Essen usw immer auch das Ende da: mit dem Zweck knüpfen wir 2 Enden aneinander. Ich esse, um zu essen und um zu leben dh um wieder zu essen». ${ }^{87}$ Die von Maria Fornari auf 1880 datierte Wende weg von einer utilitaristischen Moralvorstellung (wie noch in Menschliches) geschieht bereits $1879 .{ }^{88}$ Es interessiert hier jedoch, dass Nietzsche den Gedanken auf der gegenüberliegenden Seite wie folgt fortsetzt (Abb. 13):

Die Handlung will wiederholt werden, weil sie angenehm ist. Alles Angenehme ist das Ende Sind die Pflanzen da, $\underline{u m}$ von den Thieren verspeist zu werden? Es giebt keinen Zweck. Wir täuschen uns. - Ich tauche die Feder ein $\underline{\mathrm{um}}^{89}$

86 Vorstufe zu MA 196, vgl. KGW IV 4, S. 198: «Man findet oft bei mässigen Dichtern, bei Fabrikanten von Sensationsromanen (Miss Braddon) die grösste psychologische Sicherheit, vielleicht mit Unfähigkeit, die Gründe der Handlungen anzugeben.» Ähnlich ergehe es dem grossen Pianisten, welcher wenig über die Technizität und Erziehung seiner Finger nachgedacht habe.

$87 \quad$ N IV 1, S. 7 ; vgl. NL 1879, 41[5], KSA 8, S. 584.

88 Vgl. auch Fornari 2005, S. 319. Die von Fornari angeführten Nachlassstellen von 1880 finden sich inhaltlich fast identisch bereits im Sommer 1879. Nietzsches spätere Ablehnung von Spencers Utilitarismus ist deshalb ab 1879 gewissermassen vorprogrammiert.

N IV 1, S. 8; vgl. NL 1879, 41[5], KSA 8, S. 584 . 


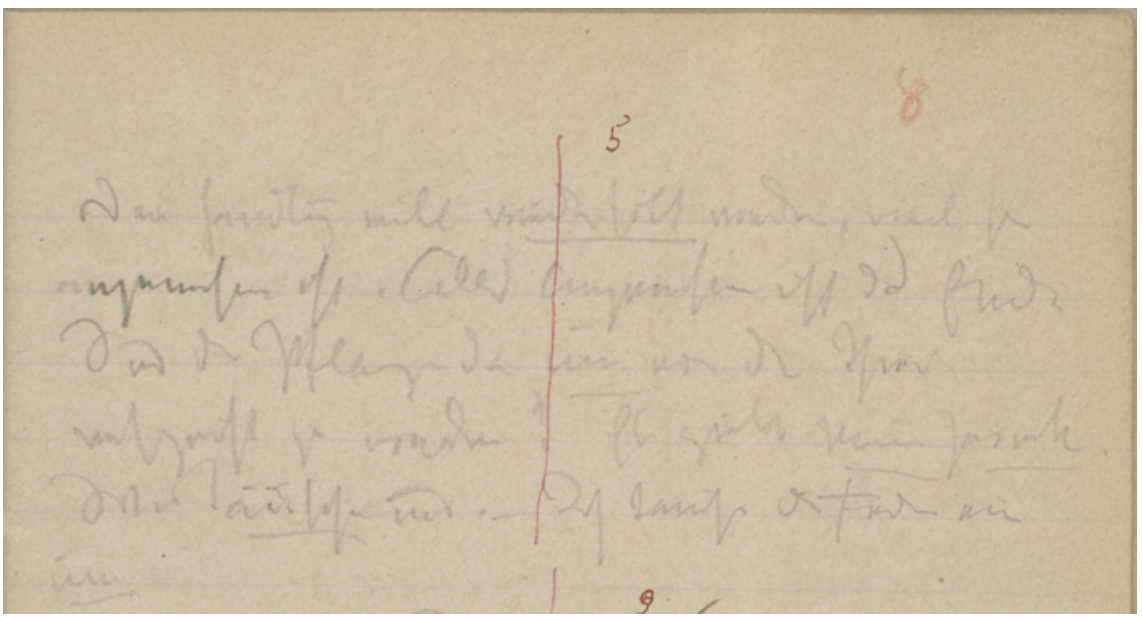

Abb. 13 Ausschnitt aus dem Notizbuch N IV 1, S. 8

Der letzte Satz liesse sich auf zwei naheliegende Weisen fortspinnen: Die Feder in Tinte tauchen, um entweder die Feder in Tinte zu tauchen, oder um zu schreiben. Letzteres ersetzt die utilitaristische Sicht auf das Schreiben durch den Verweis auf die dem Schreiben inhärente Eigenständigkeit. Man schreibt nicht, weil man bestimmte Gründe durch das Schreiben ausdrücken will, sondern man schreibt, um zu schreiben; so wie man isst, um zu essen und lebt, um zu leben. Die Intentionen erfinden sich so gesehen immer erst im Nachhinein dazu. Es sind begriffliche Reaktionen a posteriori eines vorausgehenden eigenwertigen Triebs. Schreiben ist ein «intransitives Verb», wie Roland Barthes feststellte und sich dabei fragte, «zu welchem Zeitpunkt man begonnen hat, das Verb schreiben intransitiv zu verwenden, und der Schriftsteller nicht mehr der war, der etwas schreibt, sondern jemand, der schlechterdings schreibt». ${ }^{90}$ Der jeder Schreibtätigkeit inhärente Antrieb wird nicht zufällig in einem Notizbuch manifest, das zu einem lose strukturierten Aphorismenbuch führt. Das Spiel des Schreibens (um zu schreiben) wird im eigenen Notieren sichtbar, weil sich immer wieder etwas Neues in die Notizen hineindrängt, das man nicht intendierte.

Eine spekulative Interpretation ergibt sich für mich aus dem andern Fall, dass man die Feder in Tinte taucht, um sie in Tinte zu tauchen. Obwohl von

9o Barthes 2012, S. 247. Das Schreiben wird dann intransitiv, wenn es «nicht in einer Gattung, einem Konzept oder einem Werk seine Bestimmung und sein Ende findet, sondern sich als Tun in der Sprache, durch den Körper und mit Hilfe eines Instruments vollzieht.» (Campe 2010, S. 78) Wie Barthes selbst ausführt, verschwindet durch das eigenständige Schreiben nicht das zweckgeleitete. Vielmehr werden Buch und Text anders verstanden, was bei Nietzsche exemplarisch der Fall ist. 
Tinte und Tintenfass die Rede ist, wird diese Reflexion mit Bleistift notiert. Da Nietzsche das Notat just beim Wort «um» abbricht, ist zu vermuten, dass er den Bleistift zur Seite legte, um seine Feder in Tinte zu tauchen. Für den Nietzsche von St. Moritz heisst dies vorwiegend einen Brief oder eine Umschrift zu verfassen. Die Lust am Umschreiben drang in den Notierprozess ein und beendete diesen. Es scheint, als ob ein Schreibprozess zum nächsten drängt, das Bleistift zur Tinte, die Tinte zum Druck usw. Der Autor will durch den Medienwechsel vom Notizbuch ins Arbeitsheft keine Botschaft für eine Leserschaft formulieren, sondern ein ihm angenehmes Schreibverfahren ausüben.

Aus beiden Interpretationen kann geschlossen werden: Nietzsche versteht das Schreiben 1879 in St. Moritz als eigenständige Praktik. Ein solches Schreiben kann vom Autor nicht augenblicklich durch seine Intentionen oder Schreibkunst beeinflusst werden. Es ist deshalb naheliegend, dass die Schreibsituation in den Blick rückt, weil der Autor die Umstände des Schreibens strategisch arrangieren kann.

\subsubsection{Der Wanderer-Autor und die Schreibsituation}

Im Handwerk widerspiegelt sich Nietzsches neues Verständnis von Autorschaft, gemäss dem ein Philosoph seine Gedanken nicht durch Worte darstellt, sondern innerhalb von literarischen Stilen, Wirkungsabsichten und Schreibpraktiken denkt. Bereits der frühe Nietzsche problematisiert in der Geburt der Tragödie die intentionale Autorschaft. Er verweist jedoch auf metaphysische Kräfte ausserhalb des Autorsubjekts. ${ }^{91}$ Indem in Menschliches die Kunst auf das Handwerk zurückgeführt wird, verlagert sich der Fokus auf die Produktion. Von Menschliches bis zum Wanderer rücken deshalb die Schreibtechniken sowie die physisch-materiale Umgebung des Schreibenden in den Mittelpunkt, womit die Autorschaft auf die Schreibsituation als ganze verteilt wird. Nietzsche wählt für die Erarbeitung vom Wanderer gezielt das Oberengadin als Ort, Notizbuch und Bleistift als Schreibgerät, das Wandern als Schreibverfahren sowie die dort verbrachten Sommermonate als Zeitabschnitt für seine Gedanken-Spaziergänge aus: «Alles ist, wenige Zeilen ausgenommen, unterwegs erdacht und in 6 kleine Hefte mit Bleistift skizziert worden: [...] Hinterher verliere ich den Zusammenhang der Gedanken aus dem Gedächtniß: [...].» ${ }^{92}$

91 Der Dichter werde vom «Ur-Einen» durchtönt, in dessen musikalischer Stimmung lyrische Verse entstehen. So kann es weder eine geistige Urheberschaft noch eine Verantwortung für das durch ihn sich Schreibende geben (vgl. GT 5, KSA 1, S. 42-48).

92 N. an Gast, 5.10.1879, KGB II 5, S. 450. Die Sperrung ist hier wie weiter unten absichtlich durch eine Unterstreichung ersetzt worden, weil es sich um eine Korrespondenz und nicht um eine Publikation handelt. Im Übrigen sind nicht alle Notizen von St. Moritz (vgl. Kap. 2.3.4). 
Nietzsche sieht den «Zusammenhang der Gedanken» verbunden mit der mobilen Schreibsituation. Sobald sich Letztere verändere, verliere sich auch der Zusammenhang. An dieser Klage zeigt sich einmal mehr, dass der Wanderer Nietzsches erstes Buch ist, das in einer räumlich-zeitlich begrenzten Situation erarbeitet wird (Kap. 2.2). Nietzsche hat das bei Swift und Pope angelegte Konzept einer kollektiven Autorschaft auf Dinge, Praktiken und Umgebungen ausgeweitet. Diese Gesamtheit der an einem Schreibverfahren beteiligten Faktoren ist mit dem Begriff der Schreibsituation gemeint (Kap. 2.3).

Es werden im Folgenden die Ausweitung der Autorschaft auf St. Moritz, das mobile Schreibverfahren des Wanderns sowie der philosophische Einbezug von St. Moritz dargelegt. Es geht dabei primär um die philosophische Bedeutung des mobilen Schreibverfahrens, während im Diätetikkapitel (Kap. 3.3) die Zusammenhänge zwischen zeitgenössischer Diätetik und Schreibsituation sowie die Auffassung von Philosophie als Diät ausgeführt werden. In beiden Fällen wird gezeigt, dass die Schreibsituation bei Nietzsche mitphilosophiert.

\section{Autorschaft, Gedanken und Schreibsituation}

Die Schreibsituation im Wanderer ist philosophisch an der stets wiederkehrenden Frage nach der Urheberschaft nachvollziehbar. Im Aphorismus «D er Werth der Arbeit» wird das Verhältnis von Arbeiter und Produkt reflektiert. Wie schon bei der Schuldfrage wird auch hier die Verantwortung und Urheberschaft des Arbeiterindividuums durch die nicht-intentionalen Umstände und Konstellationen relativiert. Es sei ebenso unmöglich, den Wert einer Arbeit zu bestimmen, wie einen Menschen zu richten.

Denkt man weiter, so findet man jede Persönlichkeit unverantwortlich für ihr Product, die Arbeit: ein Verdienst ist also niemals daraus abzuleiten, jede Arbeit ist so gut oder schlecht, wie sie bei der und der nothwendigen Constellation von Kräften und Schwächen, Kenntnissen und Begehrungen sein muss. Es steht nicht im Belieben des Arbeiters, o b er arbeitet; auch nicht, wi e er arbeitet. Nur die Gesichtspuncte des Nutzen s, engere und weitere, haben Werthschätzung der Arbeit geschaffen. ${ }^{93}$

Die Urheberschaft eines Produkts ist unbestimmbar, weil die je persönliche Handlungskonstellation nie adäquat abgeschätzt werden kann. Die Eigenschaften «Zeit, Fleiss, guter oder schlechter Wille, Zwang, Erfindsamkeit oder

93 WS 286, KSA 2, S. 681. Parallel zur Urheberschaft der Arbeit problematisiert Nietzsche die Rechtmässigkeit von richterlichen Urteilen. Immer wieder insistiert er auf die komplexen Abhängigkeiten des Verbrecherindividuums, um die Richtbarkeit von kriminellen Handlungen anzuzweifeln. 
Faulheit» ähneln auffällig jenen der Schriftsteller in Menschliches ${ }^{94}$ Nietzsches Arbeitsweise mit der Schreibsituation und sein neuer Autorschaftsbegriff verweisen auf eine veränderte Verantwortungsethik. Wenn die notwendigen Konstellationen das Produkt des Arbeiters bestimmen, so macht es Sinn, die Arbeitsprozesse für den Nachvollzug des Produkts in die Analyse einzubeziehen. Und auf die Produktion bezogen ist es ergiebiger, sich Gedanken über die Schreibsituation zu machen, als über die eigene Gedankenentwicklung verfügen zu wollen. Die Frage ist nicht mehr, wie man zu immer besseren Gedanken kommt (beispielsweise durch noch mehr Lektüre, durch Weiterbildung etc.), sondern wie man konstellationsspezifische Gedanken sammeln kann. Das zeigt sich schön an einer unverwendeten Notiz aus St. Moritz, in der das Aufkommen von Gedanken als Naturvorgang beschrieben wird: «An den Tagesstunden, wo der Geist seinen Fluthstand hat, wer wird da nach einem Buche greifen! Da wollen wir unsre eigenen Bootsmänner und Lootsen sein.»95 Auf die Schreibsituation übertragen hiesse dies, dass man in gedankenreichen Stunden zum Notizbuch und in gedankenarmen Stunden zu einem Buch greift. Das antizipiert auffällig nahe die bekannte Aussage in Jenseits von Gut und Böse, gemäss der «der Gedanke kommt, wenn «er» will und nicht wenn 〈ich〉 will». .6

Die zeitliche Dimension der Schreibsituation kommt auch im Rahmendialog des Wanderers zur Sprache. Die Gesprächszeit zwischen Wanderer und Schatten ist nämlich begrenzt durch das Tageslicht der Sonne: «Der Schatten: Nehmen wir es hin und denken wir nicht weiter darüber nach, in einer Stunde ist Alles vorbei.» ${ }^{97}$ Der Schatten spricht von einer Stunde, weil dann die Dämmerung anbricht und keine Schatten mehr zu sehen sind. Die Dämmerung wird unabhängig vom Wanderer-Autor anbrechen. Er kann nicht alleine darüber verfügen, wann die Schatten-Schrift mit ihm in einen Dialog tritt. Auf das Schreiben bezogen wird hier nicht die auktoriale Verfügbarkeit der Zeit, sondern deren Begrenztheit exponiert. Der Autor und sein Schreiben sind dem natürlichen Rhythmus von Tag und Nacht unterworfen.

\section{«unterwegs » schreiben}

Die Bezugnahme auf das Schreiben und Denken «unterwegg » ist zentral für die Produktionsästhetik und die diätetische Dimension des schreibenden Phi-

\footnotetext{
94 Ebd.

95 NL 1879, 42[43], KSA 8, S. 603.

96 JGB 17, KSA 5, S. 31. Es sei eine Fälschung zu sagen, dass das Subjekt «ich» die Bedingung des Prädikats «denke» sei. Bereits «es denkt» sei eine Auslegung und daher immer schon mehr als der blosse Vorgang.

WS Rahmendialog, KSA 2, S. 537.
} 
losophierens. Schon 1876 in Sorrent begann Nietzsche seine Spaziergänge zum Sammeln von Notizen zu benutzen. ${ }^{98}$ Da er mehrfach Schreibtischgedanken von seinen auf Wanderungen gesammelten Gedanken unterscheidet, wird in der Rezeption gerne von «Geh-danken» gesprochen. ${ }^{99}$ Der Unterschied des St. Moritzer Schreibverfahrens zu früheren Schreibaufenthalten in Kurorten wird deutlich, wenn man folgende Selbstbeschreibung von 1872, aus Nietzsches erster Begegnung mit Graubünden, liest: «Auf meinem Zimmerchen arbeite ich mit frischer Kraft dh. ich notire und sammle einzelne Einfälle zu meinem jetzigen Hauptthema 〈Zukunft der Bildungsanstalten〉.» ${ }^{100}$ Nietzsche spazierte zur Erholung und Kräftigung, um dann im Zimmer Einfälle zu einem bestimmten Thema zu sammeln. Sieben Jahre später notiert er spazierend und sammelt seine wechselnden Gedanken zu verschiedensten Themen.

Das Schreibverfahren des Spazierens hat eine eigene Kulturgeschichte, auf die hier nicht weiter eingegangen wird.101 Zum Verständnis der doppelten Bedeutung des Wanderns als philosophische Praktik und körperliche Fortbewegung sollen jedoch fünf von Nietzsche rezipierte Exponenten des spazierenden Schreibens kurz beschrieben werden: Jean-Jacques Rousseau, Michel de Montaigne, Ludwig van Beethoven, Jonathan Swift und Stendhal (alias Marie-Henri Beyle).

Der für das 19. Jahrhundert einflussreichste Spaziergänger, der den Gang in die offene Landschaft zum Nachdenken benutzte, war Rousseau. Er unternahm lange Spaziergänge und betrieb damit eine Selbststilisierung. Erst in Kombination mit der offenen Landschaft liegt das philosophische Potenzial von Rousseaus Spaziergängen: «It is Rousseau who laid the groundwork for the ideological edifice within which walking itself would be enshrined - not the walking that took Wittgenstein back and forth in Russell's room, but the walking that took Nietzsche out into the landscape.» ${ }^{102}$ Noch zu Lebzeiten

98 So berichtet Malwida von Meysenbug 1905, S. 66: «Eines Tages kam Nietzsche mit einem großen Paket beschriebener Blätter in der Hand und sagte mir, ich möge sie doch einmal lesen, es seien Gedanken, welche ihm auf seinen einsamen Spaziergängen gekommen wären, besonders bezeichnete er mir einen Baum, wenn er unter dem stände, fiele ihm immer ein Gedanke herunter.»

99 Es handelt sich nicht wie vielfach behauptet um ein Zitat von Nietzsche, sondern um eine Erfindung des populären Diskurses, der vor allem in therapeutischen, religiösen und spirituellen Zeitschriften, Websites und Seminarausschreibungen verwendet wird. Vgl. beispielsweise Fischill 2005 .

$100 \quad$ N. an Franziska N., 01.10.1872, Nr. 257, KGB II 3, S. 56.

101 Vgl. dazu Bausinger/Beyrer/Korff 1991; Wellmann 1991; Wallace 1993; König 1996, v.a. Kap. 5, «Der Spaziergang als kulturelle Praktik», S. 214-257; Albes 1999; Landry 2001, v.a. der Schlussteil «Walking in the Countryside», S. 203-244; Mayer 2013; Solnit 2014.

102 Vgl. Solnit 2014, S. 17; vgl. zu Rousseau auch S. 12-22. 
Rousseaus wurden Spaziergänge vermehrt mit Einsamkeit, Einfachheit, Kontemplation und wilder Natur assoziiert. ${ }^{103}$ Rousseau hatte die Spaziergänge als Denktechnik nicht nur für seine Schriften benutzt, sondern auch über sie geschrieben: «Je ne fais rien qu'à la promenade, la campagne est mon cabinet; l'aspect d'une table, du papier et des livres me donne de l'ennui; l'appareil du travail me décourage.»104 In seinen Confessions bemerkt Rousseau: «Das Gehen hat etwas, das meine Gedanken weckt und belebt; ich kann, wenn ich auf der Stelle bleibe, fast nicht denken; mein Körper muß in Schwung gesetzt werden, wenn mein Geist hinein kommen soll.»105 Rousseau sah darum die Philosophie und die Bewegung zu Fuss als optimale Kombination: «Zu Fuß reisen heißt reisen wie Thales, Platon und Pythagoras. Ich vermag kaum zu begreifen, wie ein Philosoph sich entschließen kann, anders zu reisen [...].» ${ }^{106}$ Für das Verständnis der spezifischen Akzentuierung der Schreibsituation im Wanderer bietet sich ein Vergleich mit Rousseaus Les Rêveries du promeneur solitaire an: Wie der Wanderer trägt dieses Buch die Schreibsituation im Titel. Weder die Aphorismen im Wanderer noch die einzelnen «Promenades» enthalten jedoch Hinweise auf die konkreten Spaziergänge. Es geht bei beiden Titeln nicht um Erlebnisberichte, sondern um den Verweis auf die Schreibsituation und damit auf die Entstehungsumstände, der im jeweiligen Buch publizierten Gedanken.

Auch der von Nietzsche geschätzte Michel de Montaigne äusserte sich zu Spazieren und Denken in freier Natur: «Mes pensées dorment si je les assieds. Mon esprit ne va, si les jambes ne l'agitent.» ${ }^{107}$ Montaigne hat den Zusammenhang von Bewegung und Denken kultiviert, was Nietzsche in seine Stil- und Schreibideale aufnimmt. ${ }^{108}$

Ebenso weiss Nietzsche, wie gezeigt, dass Beethoven intensiv mit Notizbüchern arbeitete. Im Jahr 1887 notiert er zudem: «Beethoven componierte gehend.»109 Angesichts der verbreiteten Beschreibung des in der Natur spazierenden und notierenden Beethovens ist es gut möglich, dass Nietzsche dies schon 1879 weiss. So heisst es in einer populären Beethoven-Biografie von 1861, dass der Direktor des Konservatoriums München Beethoven aufsuchte: «Da sieht er nach einer Weile durch die Felder einen Mann schweifen, der bald stehn bleibt, bald weiter geht [...] und etwas in sein Notizbuch schreibt.

\footnotetext{
103 Ebd., S. 17-19.

104 Rousseau 1861, S. 286.

105 Rousseau 1870, S. 200.

106 Rousseau 1971, S. 451.

107 Montaigne 1965, Bd. 3, S. 72.

108 Vivarelli 2014 hat den Zusammenhang von Nietzsches Schreibidealen mit jenen von Montaigne nachgewiesen.

109 NL 1887, 9[70], KSA 12, S. 372.
} 
[...] Seine Kleidung verrieth, dass er durch Dick und Dünn gegangen. Es war Beethoven.»110

In der von Nietzsche spätestens 1878 erworbenen Swift-Anthologie finden sich wie oben erläutert zwei Reihen von Gedanken, die Swift und Pope auf ihren gemeinsamen Spaziergängen dialogisch entwickelten.

Die wohl direkteste Inspiration stammt indessen von Stendhal. Nietzsche kaufte am 8. Mai 1879 das Buch Promenades dans Rome, dessen Vorwort mit folgendem Satz endet: «Chaque article est le résultat d'une promenade, il fut écrit sur les lieux ou le soir en rentrant.» ${ }^{111}$ Das ist sehr nahe an der Idee von Nietzsches «St. Moritzer Gedanken-Gängen». ${ }^{112}$

Diese fünf Schreibverfahren bilden einen Diskurs, in dem sich Nietzsche als spazierender Autor 1879 befindet. Die Spaziergänge als Schreibverfahren waren ihm also bekannt. Die St. Moritzer Schreibsituation erscheint angesichts von Nietzsches Lektüre wie eine nicht-textuelle Kompilation von Schreibpraktiken und -situationen. Im Wanderer und den darauffolgenden Büchern wird Nietzsche immer wieder die Verbindung von Denken und Bewegung preisen. In der Fröhlichen Wissenschaft widmet er dieser Thematik gleich einen ganzen Aphorismus:

Wir gehören nicht zu Denen, die erst zwischen Büchern, auf den Anstoss von Büchern zu Gedanken kommen - unsre Gewohnheit ist, im Freien zu denken, gehend, springend, steigend, tanzend, am liebsten auf einsamen Bergen oder dicht am Meere, $[. .$.$] oh wie rasch errathen wir's, wie Einer auf seine Gedanken$ gekommen ist, ob sitzend, vor dem Tintenfass, mit zusammengedrücktem Bauche, den Kopf über das Papier gebeugt: oh wie rasch sind wir auch mit seinem Buche fertig! Das geklemmte Eingeweide verräth sich, darauf darf man wetten, ebenso wie sich Stubenluft, Stubendecke, Stubenenge verräth. ${ }^{113}$

110 Marx 1863, S. 263. Diese Episode ist auch bekannt aus Nohl 1861, S. 156f.

111 Stendhal 1853, S. 7 .

112 Vgl. M I 2, S. 91 bzw. NL 1879, 43[Titel], KSA 8, S. 610. Auch andere Gemeinsamkeiten zwischen Stendhal und Nietzsche sind erstaunlich: Vgl. etwa die Bemerkungen zum Stil in Racine et Shakespeare in Stendhal 1854, S. 299-320. Stendhal präsentiert vermischte Meinungen über Schriftsteller und Komponisten seiner Zeit, indem er essayistisch etwas zum Stil schreibt und diesen jeweils immer mit etwas Biografischem, Geografischem, Klimatischem etc. verbindet. Dieses flanierende Nachdenken über Entstehungsweisen von Werken ist ein zentrales Charakteristikum von Nietzsches ersten Aphorismenbüchern.

113 FW 366, KSA 3, S. 614. Vgl. auch die Kritik an Flauberts Votum für die Sitzposition in der Götzen-Dämmerung, GD, KSA 6, S. 64: «Das Sitzfleisch ist gerade die S ü n de wider den heiligen Geist. Nur die e rg a n g e n en Gedanken haben Wert.» Nietzsche war auf die Sitzstellung Flauberts über Guy de Maupassant gestossen (Vgl. KSA 14, S. 412). Vgl. dazu auch den Abschnitt «Von der «Spaziergehe-Existenz zum «Schreibthier-leben»» in Röllin 2012, S. 17-20. 
Mit der Positionierung zu jenen, die «im Freien» denken, verbindet sich eine zeitgenössisch bekannte und oft vorgenommene Distanzierung zu Gelehrten und Viellesern. Für Rebecca Solnit ist das Moralisieren der Schreibsituation ein Merkmal von spazierenden Schriftstellern und Philosophen. ${ }^{114}$ In den 1870er Jahren ein philosophisches Buch zu publizieren, das im Titel und im Text auf ein gehendes Denken anspielt, ist deshalb nicht trivial. Ein solches Buch reiht sich in eine exklusive Gruppe von redlichen, authentischen und freien Philosophen ein (Kap. 4.2). Das «unterwegs»-Schreiben verbürgt seine Qualität nicht durch innerliterarische Zitation, sondern durch Verweise auf die extradiegetische Schreibsituation unterwegs. Einige dieser Verweise werden im Folgenden analysiert.

\title{
«St. Moritzer Gedanken-Gänge»
}

Nietzsches Faszination für St. Moritz äussert sich nicht nur in den Briefen, sondern auch in seiner Philosophie. Man denke an den Entwurfstitel «St. Moritzer Gedanken-Gänge» oder die Aphorismen «D oppelgängerei der Natur» sowie «Et in Arcadia Ego». Sie sollen im Folgenden genauer analysiert werden:

\begin{abstract}
Doppelgängerei der Natur. - In mancher Natur-Gegend entdecken wir uns selber wieder, mit angenehmem Grausen; es ist die schönste Doppelgängerei. - Wie glücklich muss Der sein können, welcher jene Empfindung gerade hier hat, in dieser beständigen sonnigen Octoberluft, in diesem schalkhaft glücklichen Spielen des Windzuges von früh bis Abend, in dieser reinsten Helle und mässigsten Kühle, in dem gesammten anmuthig ernsten Hügel-, Seen- und Wald-Charakter dieser Hochebene, welche sich ohne Furcht neben die Schrecknisse des ewigen Schnees hingelagert hat, hier, wo Italien und Finnland zum Bunde zusammengekommen sind und die Heimath aller silbernen Farbentöne der Natur zu sein scheint: - wie glücklich Der, welcher sagen kann: «es giebt gewiss viel Grösseres und Schöneres in der Natur, di es s aber ist mir innig und vertraut, blutsverwandt, ja noch mehr.»115
\end{abstract}

Nietzsche beschreibt hier sein Erlebnis mit St. Moritz. So liest man im Arbeitsheft folgende Passage: «In mancher Natur-Gegend entdecken wir uns / selber wieder, mit angenehmem Grausen, es ist die / schönste Doppelgängerei. So gieng es mir beiSt. / Moritz - so bin ieht» $(\text { Abb. 14) })^{116}$

114 Vgl. Solnit 2014, S. 120. Shapin 1991 thematisiert zudem die durch Wandern und Einsamkeit verbürgte Individualität und Unabhängigkeit.

115 WS 338, KSA 2, S. 699. Vgl. für eine weitere Engadiner Naturbeschreibung auch WS 138, KSA 2, S. 611 .

116 M I 2, S. 5 o. 


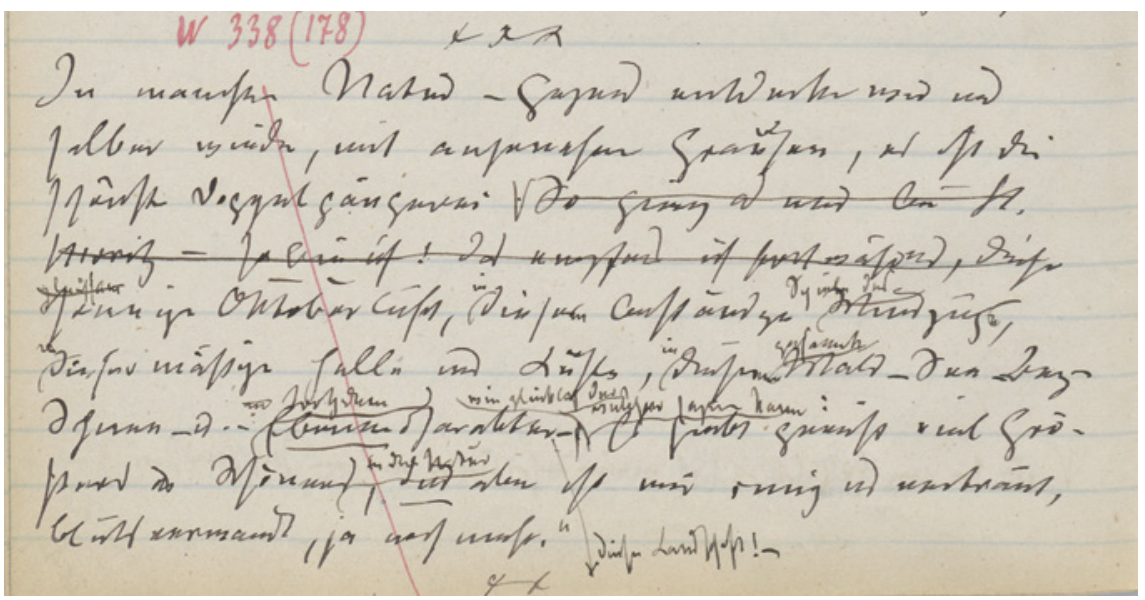

Abb. 14 Die Streichung «St. Moritz» im Arbeitsheft M I 2, S. 50

Die durchstrichene Passage verknüpft also die philosophische Aussage der inneren Verwandtschaft von «Natur-Gegend» und Individuum direkt mit dem persönlichen Erlebnis in St. Moritz. Wie so oft - und wie auch mit dem Entwurfstitel - tilgt Nietzsche die persönlichen und biografischen Angaben und verallgemeinert sie. Jedoch absichtlich unvollständig, indem er weiterhin von einem örtlichen und unterstrichenen «hier» spricht. So wird die durchstrichene Passage wie folgt ersetzt: «[Doppelgängerei.] Wie glücklich muß der sein können, welcher jene Empfindung / gerade hier hat, hier in dieser [sonnigen Oktoberluft]». ${ }^{117}$ Durch dieses «hier» sowie durch die geologischen, klimatischen und geografischen Hinweise können die Alpen, vielleicht sogar die Eigenschaften von Kurorten erahnt werden. Nietzsche tilgt zwar die Verknüpfung zum biografischen Kontext, nicht aber jene zur Schreibsituation. Des Weiteren fügte er ebenfalls im Arbeitsheft ein Zitat in Anführungszeichen ein, das er als direkte Rede bis zur Publikation beliess: «- wie glücklich Der, welcher sagen kann: «es giebt gewiss viel Grösseres und Schöneres in der Natur, diess aber ist mir innig und vertraut, blutsverwandt, ja noch mehr.»»118 Diese Aussage ist wohl angelehnt an Nietzsches briefliche Schwärmereien über St. Moritz, so etwa an diese: «Inzwischen habe ich meine Art Natur gefunden[...]». ${ }^{119}$ Und einige Jahre später schreibt Nietzsche aus dem Oberengadin an Carl von Gersdorff: «Hier wohnen me in e Musen: schon im

117 Arbeitsheft M I 2, S. 51.

118 WS 338, KSA 2, S. 699.

119 N. an Gast, 12.7.1879, Nr. 865, KGB II 5, S. 426. 
<Wanderer und sein Schatten〉 habe ich gesagt, diese Gegend sei mir «blutsverwandt, ja noch mehr.${ }^{\perp 120}$ Dass mit dem Schatten nicht bloss die Schrift, sondern auch die Schreibsituation gemeint ist, legt eine Briefstelle vom Juli 1879 nahe: «Ich habe jetzt die beste und mächtigste Luft Europa's zu athmen und liebe den Ort, an dem ich weile: St. Moritz in Graubünden. Seine Natur ist der meinigen verwandt, wir wundern uns nicht über einander, sondern sind vertraulich zusammen.» ${ }^{121}$ Die Personifizierung von St. Moritz sowie die Vertraulichkeit finden sich im Rahmendialog wieder: Der Wanderer spricht vertraut und freundschaftlich mit seinem Schatten. Die Doppelgängerei bezieht sich auf St. Moritz als «Natur-Gegend», mit welcher der Wanderer in Dialog tritt.

Es finden sich in den Manuskripten jedoch nicht nur Verallgemeinerungen persönlicher Notate, sondern umgekehrt auch eine Personalisierung eines unpersönlichen Notats. Im Aphorismus «Welche Gegenden dauernd erfreuen» berichtet ein Ich-Erzähler Folgendes: «Ich bemerke, dass alle Landschaften, die mir dauernd zusagen, unter aller Mannichfaltigkeit ein einfaches geometrisches Linien-Schema haben.» ${ }^{122}$ Der Entwurf zu diesem Aphorismus im Notizbuch N IV 2 hatte noch keine Ich-Formulierung. ${ }^{123}$ Für die Schreibsituation ist noch ein anderer Zusammenhang interessant: Denn im selben Notizbuch N IV 2 hat Nietzsche den Weg von Wiesen nach Schmitten durch vier Einträge beschrieben. ${ }^{124}$ Die Liste wird durch eine für die Wanderer-Manuskripte seltene Illustration ergänzt (Abb. 15). Diese zeigt eine Aussicht auf mehrere Berggipfel und einige Bäume im Vordergrund. Links von dieser Skizze finden sich drei parallele kurvenförmige Linien, die zunächst durchstrichen wurden, aber in der Ecke links unten nochmals aufgeführt sind. Da Nietzsche im Mai/Juni in Wiesen bei Davos war, ist zu vermuten, dass die illustrierte Liste dem Aphorismenentwurf vorausgeht. Die drei kreisförmigen Linien interpretiere ich als Versuch, ein «geometrisches Linien-Schema» von einer Landschaft zu machen. Es handelt sich um eine unterwegs erlangte Einsicht, die vom publizierten Wanderer aus gelesen durch die Ich-Perspektive die Durchlässigkeit zur spazierenden Schreibsituation anzeigt.

Der Einbau von persönlichen und lokalen Erlebnissen schlägt sich in einer weiteren Textstelle aus dem Rahmendialog nieder. So wird im Anfangsdialog die Anekdote angeführt, dass der Wanderer «in einem Walde bei Pisa erst zwei

\footnotetext{
120 N. an Gersdorff, Ende Juni 1883, Nr. 427, KGB III 1, S. 387.

121 N. an Rée, Ende Juli 1879, Nr. 869, S. 430.

122 WS 115, KSA 2, S. 602.

123 Vgl. N IV 2, S. 4.

124 Ebd., S. 45. Die KGW hat diese Liste im Nachbericht als Gelegenheitsnotiz klassifiziert, diese jedoch in einer Fussnote wörtlich transkribiert (vgl. KGW IV 4, S. 562).
} 


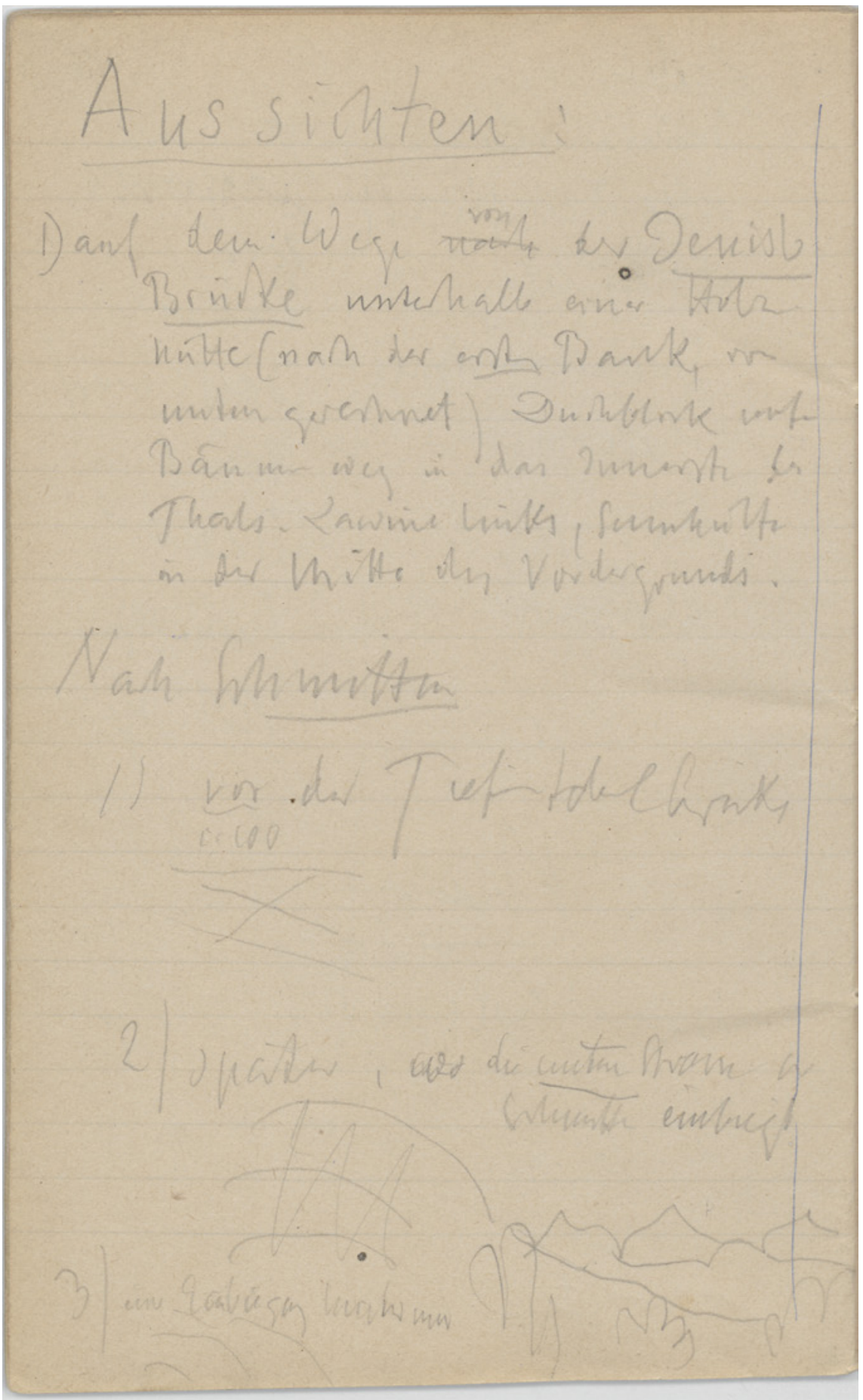

Abb. 15 Notizbuch N IV 2, S. 45 
und dann fünf Kameele sah». ${ }^{125}$ Hinter der kryptischen und zunächst skurrilen Bemerkung steckt ein Erlebnis vom Oktober 1876, als Nietzsche auf dem Weg nach Sorrent einen Zwischenhalt in Pisa einlegte, wo es tatsächlich bei San Rossore Dromedare gab. ${ }^{126}$ Diese für den zeitgenössischen (und heutigen) Leser weitgehend irritierende Aussage des Wanderers hat einen spezifischen Effekt: Sie stört die auf den reinen Text bezogene philosophische Lektüre. Zu genau sind die örtlichen Angaben und zu irritierend der Fakt, dass es bei Pisa Kamele gab. Die Figur des Wanderers kann nicht länger als abstrakte Erzählfigur philosophischer Dialoge wahrgenommen werden, sondern bezeugt durch diese Angaben eine biografische Dimension, die einen anreizt, über den geschriebenen Dialog hinaus an eine konkrete Person zu denken. Das Beispiel zeigt auf, dass man im Wanderer als Leser immer wieder aus der philosophischen Lektüre herausgerissen und auf eine hinter dem Text liegende biografische, lebensweltliche Ebene verwiesen wird.

In dem mit Naturbeschreibungen bestückten Aphorismus «Et in Arcadi a e go » behält Nietzsche dann die erste Person Singular ganz gemäss dem lateinischen Ausspruch - Auch ich bin in Arkadien - bei:

Et in Arcadia ego - Ich sah hinunter, über Hügel-Wellen, gegen einen milchgrünen See hin, durch Tannen und altersernste Fichten hindurch: Felsbrocken aller Art um mich, der Boden bunt von Blumen und Gräsern. Eine Heerde bewegte, streckte und dehnte sich vor mir; einzelne Kühe und Gruppen ferner, im schärfsten Abendlichte, neben dem Nadelgehölz; andere näher, dunkler; Alles in Ruhe und Abendsättigung. Die Uhr zeigte gegen halb sechs. Der Stier der Heerde war in den weissen schäumenden Bach getreten und gieng langsam widerstrebend und nachgebend seinem stürzenden Laufe nach: so hatte er wohl seine Art von grimmigem Behagen. Zwei dunkelbraune Geschöpfe, bergamasker Herkunft, waren die Hirten: das Mädchen fast als Knabe gekleidet. Links Felsenhänge und Schneefelder über breiten Waldgürteln, rechts zwei ungeheure beeiste Zacken, hoch über mir, im Schleier des Sonnenduftes schwimmend, Alles gross, still und hell. Die gesammte Schönheit wirkte zum Schaudern und zur stummen Anbetung des Augenblicks ihrer Offenbarung; unwillkürlich, wie als ob es nichts Natürlicheres gäbe, stellte man sich in diese reine scharfe Lichtwelt (die gar nichts Sehnendes, Erwartendes, Vor- und Zurückblickendes hatte) griechische Heroen hinein; man musste wie Poussin und sein Schüler empfinden: heroisch zugleich und idyllisch. - Und so haben einzelne Menschen auch gelebt, so sich dauernd in der Welt und die Welt in sich gefühlt, und unter ihnen einer der grössten Menschen, der Erfinder einer heroisch-idyllischen Art zu philosophiren: Epikur. ${ }^{127}$

\footnotetext{
125 WS Rahmendialog, KSA 2, S. 537.

126 Vgl. Busellato/Campioni 2013.

127 WS 295, KSA 2, S. 686f. Labhart 2006, S. 65-80, interpretiert diesen Aphorismus als Konglomerat von Referenzen (Epikureismus, Poussins und Lorrains Gemälde, Goethe, Burckhardt, Stifter, Wagner uvm.).
} 
In diesem Aphorismus werden die Eigenheiten alpiner Landschaften (Fichten, Tannen, Wildbäche, Kühe, Bergamasker Schafhirten, Felshänge, Schneefelder, Berggipfel usw.) zu einer Idylle verklärt. Es sind im Übrigen auch die «Fichten», welche die Umgebung des Rahmendialogs am Buchende bilden. ${ }^{128}$ Doch auch in «Et in Arcadia ego» legt Nietzsche trotz aller direkten und persönlichen Beschreibung Wert darauf, dem Ganzen noch eine Entpersönlichung beizufügen, indem er relativ spät, erst im Druckmanuskript, den Schlusssatz mit Epikur hinzufügt. Dies lässt einen Autor vermuten, der nicht mit dem eben noch benutzten «ich» identisch ist. Es ist ein Autor, der hypothetische Gefühle und Landschaften schildert, um diese nun einem Menschentypus wie Epikur zuzuschreiben. Zudem wird auf die Form der Idylle in der Malerei (Poussin) angespielt, wobei sich der ganze Aphorismus durch den Titel als literarische Idylle präsentiert. ${ }^{129}$ Im vorliegenden Fall gibt es zunächst eine zweifache Vermittlung: Erstens berichtet der Ich-Erzähler in der Vergangenheitsform über sein idyllisches Erlebnis und zweitens dessen Projektion auf Epikur. Zugleich versucht der Aphorismus diese Vermitteltheit zu umgehen, in dem auf Empfindungen und Gefühle ausserhalb des literarisch präsentierten Idylls verwiesen wird: erstens auf die Empfindungen (und nicht auf die gemalten Bilder) Poussins, zweitens auf die Gefühle Epikurs. Nietzsche verweist nicht weiter auf die Erfahrung idyllischer Kunst, sondern auf jene der schönen Natur. ${ }^{130}$ Die empfundene Erfahrung findet auf Seiten des Individuums statt, wird hier von Nietzsche aber als Fähigkeit des aktiven Umwertens einer Landschaftsstimmung inszeniert. Das «Heroisch-Idyllische» ist darum zweigeteilt: Der landschaftliche, arkadische Hintergrund ist wirkliche Empfindung, welche die Künstler «unwillkürlich» dazu bringen, die Heroen in diese Landschaft hineinzuprojizieren. Auf die Philosophie Epikurs übertragen führt die ständige Empfindungswirklichkeit einer arkadischen Landschaft «unwillkürlich» zu einer «heroisch-idyllischen Art zu philosophiren». Hier wird einmal mehr ein dialogisches Prinzip zwischen idyllischer Naturempfindung und Philosophie sichtbar, das für den dialogischen Charakter vom Wanderer spezifisch ist. Dieses Spiel mit dem Wirklichen der eigenen

128 Vgl. WS Rahmendialog, KSA 2, S. 704.

129 Vgl. für Nietzsches Verhältnis zur Idylle Kaufmann 2015b, S. 483-49o, hier: 486-489. Nietzsche lehnte die Idylle als Form grundsätzlich ab: «Bei allem freigeistigen Heroismus nahm der «mittlere〉 $\mathrm{N}$. in der Tat Anteil am Idyllischen, das er früher als das Romanisch-Moderne ablehnte.» (ebd., S. 489) Es wäre deshalb zumindest für den Wanderer genauer zu erörtern, in welchem Sinne Nietzsche die Idylle hier einsetzt und wie sie mit seiner Vorstellung von Landschaften und Spaziergängen zusammenhängt. In einer Notiz von 1871 ist bezüglich Idyllen die Rede vom «Schillersche[n] S p a zi erg a ng (NL 1871, $9[76], \mathrm{KSA}_{7}$, S. 302). Zumindest der späte Nietzsche kritisiert die antike und neuzeitliche Idylle auf komplexe Weise, vgl. Forrer 2017.

130 Vgl. Kaufmann 2015b, S. 489. 

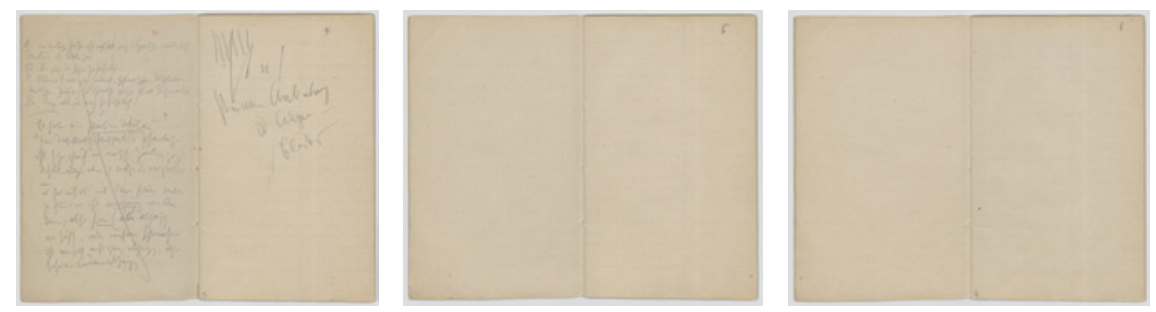

Abb. 16 Die zwei leeren Doppelseiten nach dem Eintrag «IIIIII / stu / stumme Anbetung / des Augen- / Blicks» im Notizbuch N IV 5 (S. 4-8)

Empfindungen - vermittelt durch literarische Beschreibung - findet sich in einem durchstrichenen Entwurf zu «Et in Arcadia ego»: «Ich hatte nicht gewußt, daß die Erde dies zeige und meinte, die guten Maler hätten es erfunden. Das Heroisch-Idyllische ist jetzt die Entdeckung meiner Seele: und alles Bukolische der Alten ist mit einem Schlage jetzt vor mir entschleiert und offenbar geworden - bis jetzt begriff ich nichts davon.» ${ }^{131}$ Wenn Nietzsche schreibt, dass alles Bukolische vor ihm «entschleiert» liege und er trotz seiner bisheriger Kenntnisse von Idyllen nichts davon begriff, so suggeriert er, dass er Idyllen nicht in der zeitgenössischen Auffassung von Nachahmungen versteht - sondern in einem mystischen Sinne als Offenbarungsmomente der Natur. Sebastian Kaufmann folgert deshalb: «Das Idyllische erscheint nicht mehr als Grundzug der «sentimentalischen〉 Moderne, sondern der «naiven〉 griechischen Antike, [...].» ${ }^{132}$ Da Nietzsche diese Stelle gestrichen hat, ist davon auszugehen, dass er für die Publikation die persönliche Beglaubigung von Idyllen tilgen wollte oder es nicht für möglich hielt, im Buchmedium eine «naive» Idyllenerfahrung wiederzugeben.

Auf Letzteres deuten Nietzsches private Notizbücher. Die «stumme Anbetung» findet sich nämlich nicht bloss im Aphorismentext von «Et in Arcadia ego», sondern auch im Notizbuch N IV 5 . Dort steht ein grossgeschriebenes Notat: «stumme Anbetung des Augenblicks».133 Das ansonsten auf jeder Seite beschriebene Notizbuch N IV 5 enthält in der Folge auf dieses Notat gleich vier leere Seiten (Abb. 16). Nietzsche inszeniert mit den leeren Notizbuchseiten performativ die «stumme Anbetung», indem er sein Schreibzeug verstummen lässt. Es gibt in keinem der erhaltenen St. Moritzer Notizbücher mehrere leere Seiten, weshalb der vorliegende Fall besonders auffällig

\footnotetext{
131 NL 1879, 43[3], KSA 8, S. 610.

132 Kaufmann 2015b, S. 489; vgl. auch Forrer 2017, S. $169 f$.

133 N IV 5, S. 4.
} 
und fragwürdig ist. Es vermischen sich hier materiale Schreibreflexionen (leere Notizbuchseiten) und mystische Empfindungen (Anbetung). Die im Entwurfstitel genannten «St. Moritzer Gedanken-Gänge» werden auf dem Papier fortgeführt. ${ }^{134}$

Es wäre einseitig, würde man in diesem Beispiel nur das poetologische Spiel mit dem Notizbuchformat sehen. Vielmehr spielt das erhabene Empfinden in der Engadiner Landschaft eine tragende Rolle für die Schreibsituation. Die augenblicklichen Empfindungen sind zugleich erhaben und vergänglich, weil man sie einerseits nicht im Text bannen kann, andererseits durch den Schreibverzicht bewahren will. ${ }^{135}$ Nietzsche nimmt hier im Notizbuch N IV 5 auf performative Weise die Thematik der Unbeschreiblichkeit vorweg, welche ihn durch sein ganzes Schaffen hindurch begleitet und der er ebenso den Aphorismus «I m g ross en S ch we i g e $\mathrm{n}$ » in der Morgenröte wie auch den Schlussaphorismus von Jenseits von Gut und Böse widmet. ${ }^{136}$ Zwei Aphorismen nach «Et in Arcadia ego» kommentiert Nietzsche das Verhältnis von Erlebnis und Aufzeichnung: «So lange man Etwas erlebt, muss man dem Erlebniss sich hingeben und die Augen schliessen, also nicht darin schon den Beobachter machen.» ${ }^{137}$ Dieser Aphorismus verweist auf ein Erlebnis ausserhalb des Schreibens und Lesens. Er weist als Reflexion auf ein Erlebnis hin, das im gedruckten Buch nicht artikulierbar ist. Der Aphorismus «Et in Arcadia e go 0 » ist von den Manuskripten her betrachtet nicht die stilistische Essenz von Nietzsches Engadin-Erlebnis, sondern die nachträgliche Beobachtung, welche bestenfalls auf das Erlebte hinweist. Im Vergleich zum Drucktext erreicht die Unbeschreiblichkeit durch die leeren Seiten im Notizbuch performative Evidenz. Nur in der sich ausnehmenden Leere des ansonsten dicht beschriebenen Notizbuchs ist das Erlebnis als Spur sichtbar. ${ }^{138}$ Erst in diesem wechselseitigen

134 Vgl. M I 2, S. 91 bzw. NL 1879, 43[Titel], KSA 8, S. 610.

135 Indem Nietzsche seine Entzückung nicht verschriftlicht, erhält er gewissermassen die Idylle. Forrer 2013, S. 334, weist daraufhin, dass das memento mori des Ausspruchs «Et in Arcadia Ego» nicht für die schriftlosen Hirten gelte, sondern der schriftlichen Tradierung der idyllischen Welt und daher den Nachkommen.

136 Vgl. JGB 296, KSA 5, S. 239f. sowie Benne 2013. Im Aphorismus «Im gros sen Schweig en» wird ebenfalls das Verhältnis von der Stummheit der schönsten Natur und dem Verstummen des Autors verhandelt, das wiederum für Also sprach Zarathustra charakteristisch sein wird (vgl. M 423, KSA 3, S. 259f.) Labhart hat in seiner Interpretation den Zusammenhang mit dem Wanderer anhand der Deiktika überzeugend dargelegt (vgl. 2006, S. 112-117).

137 WS 297, KSA 2, S. 687 .

138 Ein ähnlicher Fall findet sich bei Heinrich Jung-Stilling, dessen Biografie Nietzsche aufgrund des im Wanderer ausgesprochenen Lobs um 1879 gelesen haben könnte (vgl. 
Spiel von Aphorismen, Notizbuch und Erlebnis kommt die Motivik von Arkadien zur Geltung, welche in der Kunstgeschichte immer auf das Vergangene hinweist, das jedem Erlebnis durch die Erinnerung, Beobachtung und Verschriftlichung anhaftet.

Der Nietzsche der späten 1870er Jahre ist keineswegs nur technisch, kühl und naturwissenschaftlich. Immer wieder erlebt er gleichsam mystische und spirituelle Momente, die ihn in seiner Selbstwahrnehmung massgeblich geprägt haben. Schon während den Arbeiten an Menschliches wurde der persönliche Kontext eines ekstatischen Reiseerlebnisses getilgt: So erinnert sich Malwida von Meysenbug, dass Nietzsche vom Anblick des Golfs von Neapel verzückt war und sich dabei nur die Musik von Beethoven (Benedictus) vorstellen konnte. ${ }^{139}$ Beethoven, der mit seiner notierenden Arbeitsweise für das Handwerk Pate steht, prägt zugleich die spirituellen Erlebnisse Nietzsches: In Menschliches kommt selbst der Freigeist in metaphysische Stimmung und Wehmut, wenn er Beethovens neunte Symphonie hört. ${ }^{140}$

Die Philosophie ist mit der Landschaftsempfindung verbunden: Die Wortreihe «gross, still und hell» von «Et in Arcadia ego»entspricht den drei Grundelementen von Nietzsches Vorstellung der guten Philosophie:

«Ruhe, Grösse, Sonnenlicht, - diese drei umfassen Alles, was ein Denker wünscht und auch von sich fordert: seine Hoffnungen und Pflichten, seine Ansprüche im Intellectuellen und Moralischen, sogar in der täglichen Lebensweise und selbst im Landschaftlichen seines Wohnsitzes. Ihnen entsprechen einmal e rh eb e nd e Gedanken, sodann b e ru hi gen de, drittens a u fhell en de,- viertens aber Gedanken, welche an allen drei Eigenschaften Antheil haben, in denen alles Ir-

WS 109, KSA 2, S. 599). Der Protagonist erlebt auf einer Wanderung einen Moment höchster Naturidylle: «So brach er in Tränen aus, setzte sich eine Weile auf die Rasen nieder und ergötzte sich an der herrlichen Aussicht. Hier fing er zuerst an, ein Lied zu versuchen, es gelung ihm auch so ziemlich, denn er hatte eine natürliche Anlage dazu. Ich habe es unter seinen Papieren nachgesucht, aber nicht finden können.» (Jung-Stilling 1982, S. 118f.; vgl. dazu auch Benne 2015a, S. 259f.) Da das Lied unauffindbar ist, bleibt einem vorenthalten, welch hohe Entzückung der Protagonist erlebte. Das unauffindbare Papier weist auf die jenseits des Buches liegende Natur, in deren Angesicht die erlebte Entzückung allein sich einstellen kann. Das Lied, welches die Natur so grossartig pries, bleibt für den Biografieleser stumm. Die Unmöglickeit der Aufzeichnung wird materiell inszeniert und dem Leser über die Medialität mitgeteilt.

139 Vgl. von Meysenbug 1926, S. 66. Der Zusammenhang wird nur in den Manuskripten sichtbar, vgl. KSA 14, S. 134; Ponton 2001, S. 55 f.

140 Vgl. MA 153, KSA 2, S. 145. 
dische zur Verklärung kommt: es ist das Reich, wo die grosse Dreifaltigkeit der Freude herrscht.» ${ }^{141}$

Auch dieser Aphorismus wurde entpersönlicht, hiess es doch ursprünglich statt «ein Denker» nämlich «ich». ${ }^{142}$ Es kommt hier auf die Denkfigur der diätetisch-philosophischen Verbundenheit an. Gedanken eines Philosophen entsprechen einer Landschaft, einer täglichen Lebensweise, den Hoffnungen, der Moral etc. Der Einbezug der Lebensweise und der Landschaft ist also auch hier von der St. Moritzer Schreibsituation in die Philosophie übersetzt worden. Wäre es Nietzsche nur um einen biographisch-örtlichen Einblick in die Entstehung des Buches gegangen, so hätte er die Schreibsituation nicht so aufwendig in Titel, Rahmendialog und Aphorismen eingeflochten.

Die Beispiele zeigen, wie viel Nietzsche daran lag, dass die Schreibsituation als selbstverständlicher Bestandteil seines philosophischen Buches zu betrachten ist. Sein Empfinden ist mit einer bestimmten Umgebung verbunden und entsprechend erklärt sich sein spazierendes Schreibverfahren sowie Teile seiner damaligen Philosophie. Gemäss Lukas Labhart fällt durch die Tilgung persönlicher Angaben im Wanderer das «autobiographische Bekenntnis zum geographischen Ort» zu Gunsten einer «ästhetische[n] 〈Objektivität»» weg. ${ }^{143}$ Die inkonsequenten Tilgungen der biografischen Schreibsituation deuten jedoch eher auf ein Spiel mit der Entstehungsgeschichte, der Landschaft und dem Autor. Deshalb geht es weniger um ästhetische Objektivität idyllischer Naturerlebnisse, sondern um die philosophische Relevanz von Schreibsituationen: Dass Nietzsche einige Passagen entpersönlicht, zeigt, dass er die entsprechenden Abschnitte als Teile seiner Philosophie ansieht.

Der Entwurfstitel «St. Moritzer Gedanken-Gänge» macht diese Verbindung von Philosophie und Schreibsituation explizit (Abb. 17). ${ }^{144}$ In diesem Titel verbindet sich das mobile Schreibverfahren, die St. Moritzer Schreibsituation sowie die darin entstandenen Gedanken. Und auch der Titelzusatz «1879» zeigt, dass Nietzsche die Datierung der Schreibsituation und damit deren räumlichzeitliche Kohärenz hervorheben will.

141 WS 332, KSA 2, S. 697f. Dieselbe Aufzählung nennt Nietzsche auch später noch als Charakterisierung des Oberengadins, vgl. N. an Gast, 5.7.1886, Nr. 719, KGB III 3, S. 202.

142 Vgl. Arbeitsheft M I 2, S. 56.

143 Labhart 2006, S. 85. Hingegen wäre Labharts Hinweis über die Verbindung von landschaftlichen Glückszuständen und ästhetischen Urteilen mit Blick auf ästhetische Existenzformen weiter nachzugehen (vgl. ebd.).

144 M I 2, S. 91 bzw. NL 1879, 43[Titel], KSA 8, S. 610. 


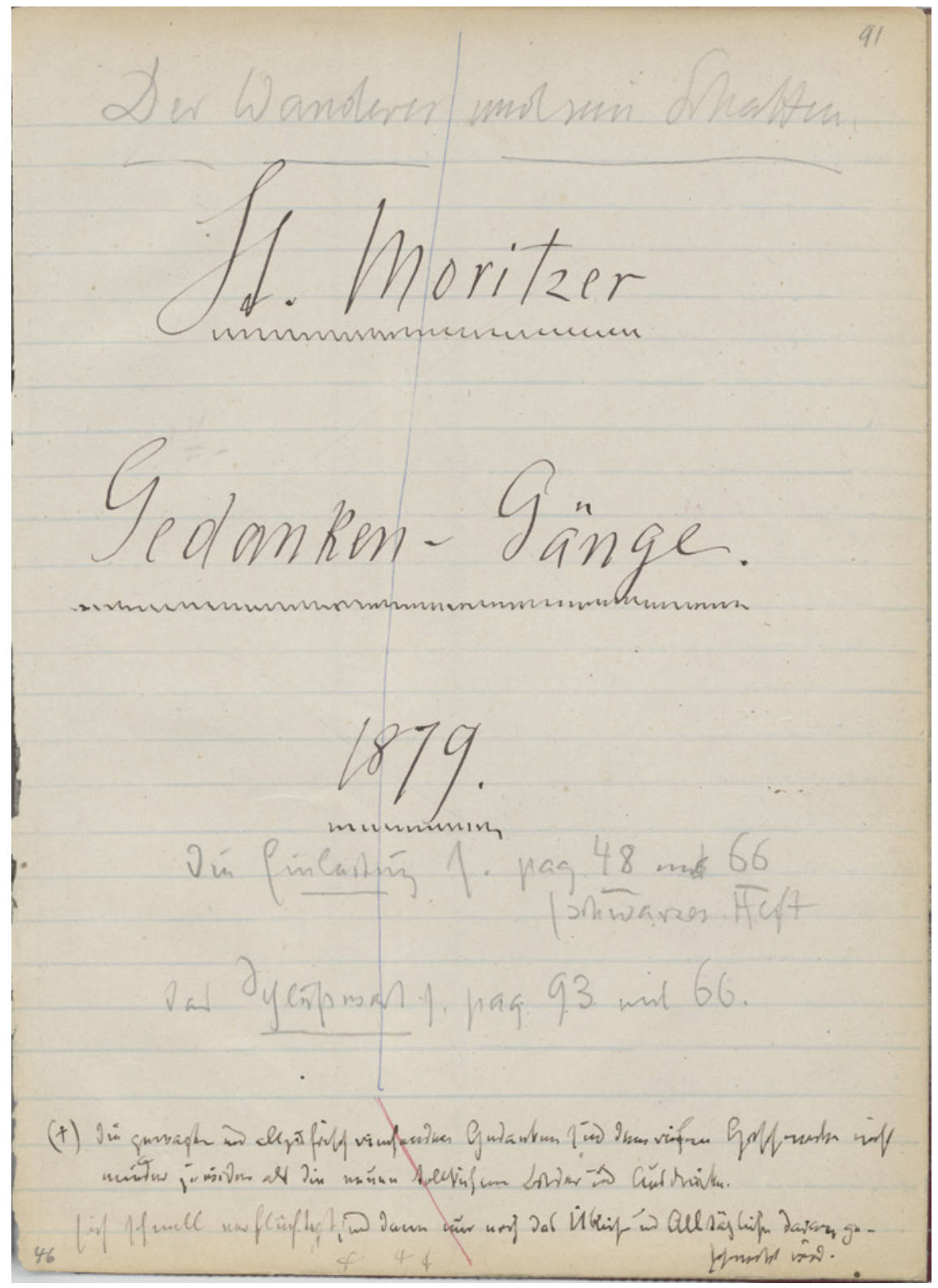

Abb. 17 Gelayouteter Arbeitstitel der Umschrift aus dem Arbeitsheft M I 2, S. 91 bzw. der ersten Seite von Nietzsches Umschrift (Nietzsche beschreibt seine Hefte rückwärts) 


\subsubsection{Fazit}

Nietzsche ist dem Genie als talentierten und arbeitenden Menschen nicht abgeneigt, sondern nur dessen Selbstinszenierungen, namentlich der Inspiration, Vollkommenheit und Originalität - kurz: der Genieästhetik. Demgegenüber zeigen Nietzsches Beispiele die Vielfalt von menschlichen Anlagen sowie deren allmähliches Wachsen durch Techniken der Übung und Hervorbringung. Die Geniekritik und Produktionsphilosophie von Menschliches ist trotz aller Parallelen noch nicht jene vom Wanderer. Sie ist integriert in eine kulturpolitische Aufklärung gegen die Metaphysik und positioniert sich in einem zeitgenössischen Diskurs, der anhand Beethoven, Kant, Lichtenberg, Mach, Nottebohm, Schopenhauer, Stendhal, Taine und Wagner grob skizziert wurde. Davon zeugt auch Nietzsches Orientierung an den französischen Moralisten und ihrer «Entlarvungspsychologie» sowie der provokative Titel des vierten Hauptstücks, gemäss dem man einen Blick in die «Seele» der Künstler werfe. ${ }^{145}$ Dieses kulturpolitische Vorhaben lockert sich in den Vermischten Meinungen und wird im Wanderer zu Gunsten einer Hinwendung zum räumlich-zeitlich konkreten Individuum in seinem je eigenen Alltag aufgelöst.

Die Hinwendung zum Individuum bedeutet im Kontext der Produktion aber auch jene zur Schreibsituation, die Text abwirft. Für die Autorschaft heisst dies, dass man es nicht mit einem klassischen Selbstverständnis zu tun hat, das sich von seinen «materiellen und körperlichen Voraussetzungen» frei glaubt. ${ }^{146}$ Der Wanderer scheint sich in Nietzsches Augen gleich einem Naturvorgang ereignet zu haben. Nachdem ihn am 18. Dezember die fertige Publikation in Naumburg erreichte, schrieb er an Schmeitzner: «Der vollendete <Wanderer > ist mir fast etwas Unglaubliches - am 21 Juni [sic] kam ich nach St. Moritz - und heute - !» ${ }^{147}$ Und 1880 , also kurz nach Fertigstellung vom Wanderer, schreibt Nietzsche: «Ich habe meine Schriften jederzeit mit meinem ganzen Leib und Leben geschrieben: ich weiß nicht, was «rein geistige〉 Probleme sind.» ${ }^{148}$ Und zwei Jahre nach dem St. Moritzer Sommer heisst es: «ich selber als Ganzes komme mir so oft wie der Krikelkrakel vor, den eine unbekannte Macht über's Papier zieht, um eine ne ue Fe der zu probiren.» ${ }^{149}$ Diese Aussagen zeigen, wie sehr Nietzsche sich mit den materialen Bedingungen seines Schreibens - vom Schreibgerät bis zur ihn umgebenden Landschaft - verhaftet

\footnotetext{
145 Lütkehaus 2001, S. 24. Lütkehaus betont zurecht, dass Nietzsches Stil nicht kühl, nüchtern und wissenschaftlich ist. Vgl. auch Zimmer 2016.

146 Stingelin 2004, S. 10.

147 N. an Schmeitzner, 18.12.1879, Nr. 915, KGB II 5, S. 471.

148 NL 1880, 4[285], KSA 9, S. 170.

149 N. an Gast, Ende August 1881, Nr. 143, KGB III 1, S. 122.
} 
sieht. Im Notizbuch N IV 2 findet sich ein nicht weiter verwendetes Notat, das diesen Zusammenhang anspricht: «Der Faden, auf dem die Gedanken manches Denkers laufen, ist so fein, daß wir ihn nicht sehen und daß wir vermeinen, jener fliege oder schwebe oder treibe die Kunst der beflügelten Dichter. Aber wie die S p in n e oft an einem zarten Fädchen herabläuft $-\gg .{ }^{150}$ Ein Philosoph hat keine losgelösten geistigen Gedanken. Ebensowenig hat er die alleinige Kontrolle über die Schreibsituation. Er kann aber seine Autorschaft für die Bestimmung der Umstände reklamieren. Die Verschmelzung von Autor und Schreibsituation, welche oft erst im Spätwerk von Nietzsche und verbunden mit dem Wahnsinn angesetzt wird, ist also schon weit früher zu beobachten. ${ }^{151}$ Der diätetische Autor ist der Vorläufer des späteren Konzepts eines Urhebers als «psycho-physiologischer Komplex».152 Daraus resultiert dann auch die Fokussierung auf eine Leibphilosophie, da der Leib als wesentlicher Teil von Nietzsches Schreibsituation mit all seinen Besonderheiten und gesundheitlichen Eigenschaften massgeblich für die Textproduktion wird. Aus dem Freigeist-Autor wird ein diätetisch und material gebundener Wanderer-Autor.

Die Hinwendung zu den Produktionstechniken macht sich auch in den Buchtiteln bemerkbar. Fokussiert Menschliches, Allzumenschliches. Ein Buch für freie Geister mit Verweis auf die Buchform noch auf den Inhalt, so weist Vermischte Meinungen und Sprüche hauptsächlich auf die literarische Gattung und schliesslich Der Wanderer und sein Schatten auf die Schreibsituation. Letztere wird im Entwurfstitel noch schlichter als «St. Moritzer Gedanken-Gänge» umschrieben. Der Rahmendialog des Wanderers ist weniger ein Experiment mit «Gattungsgrenzen» als eine Reflexion über die Schreibsituation. ${ }^{153}$ So geht es im Wanderer nicht bloss um den Stil, sondern um die von Nietzsche selbst auferlegten Prinzipien (Wandern, Diät, Landschaft, Klima etc.) der Schreibsituation. Es ist deshalb die Akzentuierung auf Schreibtechniken in Menschliches zu unterscheiden von Selbsttechniken der Lebensführung im Wanderer. Es wird sich im Kapitel 3.3 zur zentralen Rolle der Diätetik zeigen, dass Nietzsches Hinweis, Philosophen könnten im Unterschied zu Gelehrten nur «in ihrer eigenen Luft, auf ihrem eigenen Boden leben», wörtlich gemeint ist. ${ }^{154}$

In St. Moritz nimmt die starke Verbindung von Schreibsituation, Schreibprozessen und Philosophie erstmals kohärente und konzeptuelle Gestalt an.

\footnotetext{
$150 \quad$ NL 1879, 40[25], KSA 8, S. 583 .

151 Vgl. auch Brücker 2014; Derrida/Kittler 2000.

152 Heit 2013, S. 139.

153 Vgl. Zittel 2016, S. 98.

154 WS 171 , KSA 2, S. 625.
} 
Die Regulierung der Schreibsituation und das Experimentieren an derselben zu Gunsten einer vielseitigen und sich weiter entwickelnden Philosophie zeugt von einem besonderen Verständnis des Schreibens. Durch die Schreibsituation verflechten sich die handwerkliche Schreibkunst und die Lebenspraktiken. Nietzsches Interesse für das Handwerk, die «Werkstätte» und die Schreibsituation überträgt sich zunehmend auf seine eigene Arbeitsweise. In diesem Sinne erprobt Nietzsche nicht nur einen neuen Stil, sondern auch eine neue Schreibsituation. Exemplarisch wird dies am wandernden Notieren sichtbar, bei dem sich eine körperliche Bewegungsform, eine gesundheitliche Massnahme, eine Alltagsgewohnheit und eine Aufzeichnungsform miteinander vermischen. Das heisst, dass Nietzsches Schreibverständnis über das Schreibhandwerk hinausgeht. Es ist daher im Falle des Wanderers zu eng gedacht, wenn Thomas Schestag die «Denkmaschine» nur an den Elementen «Feder, Tinte und Papier zueinander» festmacht. ${ }^{155}$ Nietzsche selbst sprach im 1886 publizierten Vorwort zu Menschliches II von «Diätetik und Zucht, welche es dem Geiste so leicht als möglich machen wollte, weit zu laufen, hoch zu fliegen, vor Allem immer wieder fort zu fliegen.» ${ }^{156}$

Der Topos der raumzeitlichen Gebundenheit von Gedanken ist ein bleibendes Thema in Nietzsches Selbstinszenierung als Autor. Der Wanderer mit seinen deiktischen Textstellen und dem Rahmendialog bildet sein erstes Werk, in welchem eine ganze Gedankensammlung in ihrer Durchlässigkeit zur Schreibsituation präsentiert wird. Dies bahnte sich jedoch schon früher an: Ein unverwendeter Vorredenentwurf aus den Arbeiten an Menschliches ist unterzeichnet mit Raum- und Zeitangaben: «Rosenlaui-Bad, am 26. Juli / Sommersonnenwende 1877».157 Zudem gab es im Druckmanuskript von Menschliches einen Epilog über ein Genueser Glockenspiel in der Ich-Form. Erst nach Erhalt der Druckfahnen änderte Nietzsche dieses Buchende und verschob den vormaligen Genueser Schlussaphorismus. ${ }^{158}$ Auch nach dem Wanderer geht die Vermischung von Umgebung und Philosophie nahtlos weiter. Im Jahr

155 Schestag ist in seiner Interpretation vom Wanderer nur auf den reinen Schreibakt fokussiert und geht nicht auf die Klimatologie, Bewegungslehre und Diätetik ein, welche ins Schreiben miteinfliessen (vgl. Schestag 2008, S. 118).

156 MA II, Vorrede 5, KSA 2, S. 375.

157 NL 1876/1877, 23[196], KSA 8, S. 474.

158 Vgl. MA 628, KSA 2, S. 354. Dennoch finden sich im finalen Schlussaphorismus ebenso eine Anspielung auf den Glockenschlag sowie die Landschaft, vgl. MA 638, KSA 2, S. 363 . Vgl. dazu D'Iorio 2012, S. 157-220; Labhart 2006, S. 99-111. Auch D'Iorio interpretiert dies als Vermischung von biografischen, literarischen und philosophischen Ebenen: «Trois niveaux sémantiques au moins se mêlent dans cette illumination soudaine: un niveau biographique, un niveau littéraire et un niveau plus proprement philosophique.» (ebd., S. 178). 
1880 verstärkt Nietzsche seinen Genua-Kult, der wiederum später durch Ecce Homo als Teil der Philosophie präsentiert wird: «Zuletzt war ich's selbst, dieses Seegethier: fast jeder Satz des Buchs ist erdacht, erschlüpft in jenem Felsen-Wirrwarr nahe bei Genua, wo ich allein war und noch mit dem Meere Heimlichkeiten hatte.» ${ }^{159}$ Die Betonung auf «erschlüpft» inszeniert eine organische Bindung von Gedanken und Landschaft. Bekannt wurde auch die genau datierte Aufzeichnung des Gedankens der ewigen Wiederkunft: «Anfang August 1881 in Sils-Maria, 6ooo Fuss über dem Meere und viel höher über allen menschlichen Dingen!» ${ }^{160}$ Nietzsche hat dies später in Ecce Homo auch der Öffentlichkeit mitgeteilt und damit einmal mehr die Durchlässigkeit zwischen seinen Schreibsituationen und seinen Werken hervorgehoben:

Ich erzähle nunmehr die Geschichte des Zarathustra. Die Grundconception des Werks, der Ewige-Wi ed erk un ft s-Ged a n ke, diese höchste Formel der Bejahung, die überhaupt erreicht werden kann -, gehört in den August des Jahres 1881: er ist auf ein Blatt hingeworfen, mit der Unterschrift: «6ooo Fuss jenseits von Mensch und Zeit>. Ich gieng an jenem Tage am See von Silvaplana durch die Wälder; bei einem mächtigen pyramidal aufgethürmten Block unweit Surlei machte ich Halt. Da kam mir dieser Gedanke. ${ }^{161}$

Die raum-zeitliche Datierung eines Gedankens ist die konsequente Weiterführung einer schreib-diätetischen Autorschaft, bei der Zeitpunkt und Umgebung - bzw. die Schreibsituation - sich an der Philosophie beteiligen. Weitere Beispiele sind die Entstehung eines Zarathustra-Teiles, den Nietzsche in «zehn vollkommen hellen Tagen» geschrieben haben will; oder das datierte Lenzerheide-Fragment mit dem Titel «Der europäische Nihili s m u s. Lenzer Heide den 10. Juni 1887»; und zu guter Letzt der gelayoutete und datierte Werkplan zu «der Wille zur Macht». ${ }^{162}$ Die raum-zeitliche Kohärenz wurde so wichtig, dass Nietzsche im Falle des Druckmanuskripts zu Jenseits von Gut und Böse dessen Entstehung auf den Silser Sommer von

159 Vgl. EH, KSA 6, S. 329. Für einen zeitnahen Beleg vgl. folgende Briefstelle: «und Genova scheint mir der rechte Ort, drei Mal jedes Tages ist mir hier das Herz übergegangen, bei dieser in die Ferne weisenden Größe und unternehmenden Mächtigkeit. Hier habe ich Gewühl und Ruhe und hohe Bergpfade und das, was schöner ist als mein Traum davon, das campo santo.» (N. an Gast, 24.11.188o, Nr. 67, KGB III 1, S. 5of.).

16o NL 1881, 11[141], KSA 9, S. 494.

161 EH, KSA 6, S. 335. Es charakterisiert EH im Ganzen, dass Nietzsche seine Werke mit Orts-, Zeit- und Stimmungsangaben beschreibt.

162 N. an Hillebrand, 24.5.1883, Nr. 420, KGB III 1, S. 380; NL 1887, 5[71], KSA 12, S. 211; und NL 1888, 18[17], KSA 13, S. 537: «Entwurf des / Plans zu: / d e r Wille zur Macht / Versuch / einer Umwerthung aller Werthe. / - Sils Maria / am letzten Sonntag des / Monat August 1888». 
1885 zurückdatierte. ${ }^{163}$ Nietzsche begann sogar die Auswirkung von Zeit und Raum auf seine Philosophie umzukehren: So erschütterte ihn der Gedanke, dass die Insel Ischia, welche er als Motiv in seinen Zarathustra eingeflochten hatte, nach Abschluss der Schreibarbeiten von einem Erdbeben erschüttert wurde; oder «daß in der Stunde, in der ich den ersten Zarath[ustra] im DruckManuscript vollendete - Wagner gestorben ist.» ${ }^{164}$ All diese Beispiele sollen veranschaulichen, dass in Nietzsches Werken nach dem Wanderer die Philosophie durch die Schreibsituation bedingt produziert, inszeniert und auch im Werk sichtbar gemacht wird.

\subsection{Schreiben und Lesen}

Die Lesethematik zieht sich prominent durch Nietzsches Schaffen. In der Rezeption findet sich vorwiegend das Ideal eines ernsthaften und philologischen Lesens - sei es als philosophische Methode, als auktoriale Leseanweisung oder Leseideal, den Texten Nietzsches philosophisch beizukommen. Die Nietzsche-Leser sollen exakt, langsam und repetitiv lesen. Mazzino Montinari forderte eine «philologisch-historisch fundierte Lektüre» und verwies auf eine Reihe bis heute vielzitierter Textstellen, die das philologische Leseideal nahelegen. ${ }^{165}$ Dabei übersieht man aber eine wichtige alternative Schreibund Leseanleitung, die ich das lockere Schreiben und Lesen nenne und in der Folge am Wanderer, an den Manuskripten sowie an unverwendeten Vorreden zu Menschliches exemplifizieren möchte. Das Kapitel soll aufzeigen, dass die Autor-Inszenierung, die Leseanleitungen, die Lesereflexionen und die Buchkomposition eine «Lektürepolitik» bilden, an welcher ebenso der Autor wie die historischen Umstände teilhaben. ${ }^{166}$

In einem ersten Schritt wird deshalb Nietzsches Ideal des philologischen Lesens sowie dessen Einbettung in die Sentenzenkunst der französischen

\footnotetext{
163 Vgl. Röllin 2012, S. 178f.

164 N. an Gast, 16.08.1883, Nr. 452, KGB III 1, S. 429. Nietzsches Beziehung zur Insel Ischia und ihrem Schicksal hatte biografisch und philosophisch nachgewirkt, vgl. D'Iorio 2012, S. $136-156$.

165 Montinari 1982, S. 4. Dieses Ideal hat auch historische Gründe, da Nietzsches Texte verschiedentlich für politische Zwecke instrumentalisiert wurden.

166 Den Begriff «Lektürepolitik» verwende ich angelehnt an Michel de Certeau (1988, S. 305). Eine «Lektürepolitik» zeigt an, dass sich Lesepraktiken entlang einem politischen System und historischen Umständen bilden. In diesem Kapitel fokussiere ich mich auf die Leseideale des Autors sowie auf die Buchmaterialität, während später der politische und historische Zusammenhang von Aphorismenbüchern und demokratischen Lesepraktiken analysiert wird (Kap. 3.4.3).
} 
Moralisten ausgeführt (3.2.1). Die geschliffene und knappe Schreibweise wandelt sich im Wanderer zu einem lockeren und digressiven Stil, der alternative Lesepraktiken nahelegt (3.2.2). Diese Neuorientierung kann exemplarisch am Stil der englischsprachigen Humoristen nachvollzogen werden. Es ist dem philologischen und dem lockeren Lesen aber gemeinsam, dass sie die Aktivität des Lesers anregen (3.2.3). Dadurch gewinnt man einen neuen Blick auf die Schreibstrategien des Rätselhaften und Unvollständigen, welche die Grundlage des aktiven Lesens bilden. Es wird sich dabei herausstellen, dass lockere und philologische Lesepraktiken gleichzeitig in einem Text angelegt sein können.

\subsubsection{Philologisches Lesen und Schreiben}

Nietzsches philologische Ausbildung und Berufstätigkeit prägte ebenso seine Schreibweise, seine Leseideale wie auch seine Werkpolitik. Philologie bedeutet nicht nur die Herstellung von Texten. Sie ist laut Christian Benne auch die Kunst des «richtigen, d.h. langsamen, zyklischen, perspektivenreichen und genauen Lesens als Voraussetzung und Ziel der Kritik, als Grundlage und Ergebnis des Kommentars.» ${ }^{167}$ Deshalb ist in der Folge mit philologischem Lesen die Praxis des langsamen Lesens und langen Nachdenkens gemeint. Zum philologischen Leseideal gibt es viele einschlägige Textstellen, von denen folgende besonders repräsentativ geworden sind:

Der Philologe liest noch Worte, wir Modernen nur noch Gedanken. ${ }^{168}$

Philologie ist die Kunst, in einer Zeit, welche zu viel liest, lesen zu lernen und zu lehren. Allein der Philologe liest langsam und denkt über sechs Zeilen eine halbe Stunde nach. Nicht sein Resultat, sondern diese seine Gewöhnung ist sein Verdienst. ${ }^{169}$

Ein solches Buch, ein solches Problem hat keine Eile; überdies sind wir Beide Freunde des lento, ich ebensowohl als mein Buch. Man ist nicht umsonst Philologe gewesen, man ist es vielleicht noch, das will sagen, ein Lehrer des langsamen Lesens: [...] Philologie nämlich ist jene ehrwürdige Kunst, welche von ihrem Verehrer vor Allem Eins heischt, bei Seite gehn, sich Zeit lassen, still werden, langsam werden -, als eine Goldschmiedekunst und -kennerschaft des Worte s [...] - sie selbst wird nicht so leicht irgend womit fertig, sie lehrt gut lesen, das heisst langsam, tief, rück- und vorsichtig, mit Hintergedanken, mit offen gelassenen Thüren, mit zarten Fingern und Augen lesen... Meine geduldigen

167 Benne 2005, S. 354. Vgl. ausführlich zur Methode des philologischen Lesens, ebd., Kap. 4, «Philologische Methode II: Lesen statt Interpretieren», S. 151-237.

168 Vgl. BAW 5, S. 268. Nietzsche betont dies in seiner Basler Einführungsvorlesung in Abgrenzung zu zeitgenössischen Lesepraktiken.

169 NL 1876, 19[1], KSA 8, S. 332. 
Freunde, dies Buch wünscht sich nur vollkommene Leser und Philologen: l e rn t mich gut lesen! - 170

Ein Aphorismus, rechtschaffen geprägt und ausgegossen, ist damit, dass er abgelesen ist, noch nicht <entziffert`; vielmehr hat nun erst dessen A u sl e g u n g zu beginnen, zu der es einer Kunst der Auslegung bedarf. [...] Freilich thut, um dergestalt das Lesen als Kunst zu üben, Eins vor Allem noth, was heutzutage gerade am Besten verlernt worden ist - und darum hat es noch Zeit bis zur «Lesbarkeit> meiner Schriften -, zu dem man beinahe Kuh und jedenfalls nicht «moderner Mensch〉 sein muss: da s Wi e derkäu en ... ${ }^{171}$

[...] ein Leser, wie ich ihn verdiene, der mich liest, wie gute alte Philologen ihren Horaz lasen. ${ }^{172}$

Die meisten dieser Zitate beziehen sich auf Aphorismenbücher, die sich nicht an Philologen, sondern an eine breite Leserschaft wenden. Es handelt sich beim philologischen Lesen also nicht um eine wissenschaftliche Methode, sondern um eine Lektürepraxis. Offenbar bedürfen die Aphorismenbücher einer Leseanleitung, weil sie auf verschiedene und aus Sicht des Autors falsche Weise gelesen werden können. Den kulturellen Kontext dieser Sorge bildet die industrialisierte Gesellschaft der Arbeitsamen.

Die Kunst in der Zeit der Arbeit. - Wir haben das Gewissen eines a rb e it s a m e n Zeitalters: diess erlaubt uns nicht, die besten Stunden und Vormittage der Kunst zu geben, und wenn diese Kunst selber die grösste und würdigste wäre. Sie gilt uns als Sache der Musse, der Erholung: wir weihen ihr die Reste unserer Zeit, unserer Kräfte. [...] sie ist auf die Gewissenlosen und Lässigen angewiesen, welche aber, ihrer Natur nach, gerade der gr o s s e n Kunst nicht zugethan sind und ihre Ansprüche als Anmaassungen empfinden.»173

Im Zeitalter der Industrialisierung mangelt es an Kontemplation. Die arbeitende Elite ist erschöpft und nachlässig geworden: Die «Lässigen» sind der «grossen Kunst» unfähig. Auf die Literatur übertragen kann «grosse» Kunst nur von wachen und kräftigen Lesern gelesen werden. Je mehr also der Aphoristiker seine Prosa als Kunst verstanden haben will, desto mehr muss er die Leser anleiten, seine Texte intensiv und zyklisch zu lesen. Der philologische Lesetyp ist also nicht nur zum Studium antiker Autoren wie Horaz von Nöten, sondern auch für gut geschriebene Prosa, allen voran jene der französischen Moralisten.

170 M, Vorrede $5, \mathrm{KSA}_{3}$, S. 17.

171 GM, Vorrede 8, KSA 5, S. 255 f.; vgl. auch Z IV, KSA 4, S. 334.

172 EH, KSA 6, S. 305 .

173 WS 170, KSA 2, S. 623 . 


\section{Philologisches Lesen und Sentenzenstil}

In den späten 1870er Jahren studiert Nietzsche insbesondere durch seine Freundschaft mit Paul Rée die französischen Moralisten, welche häufig in Sentenzen und Aphorismen schreiben. Der Zusammenhang von philologischem Lesen und Sentenzenstil wurde in Menschliches deutlich formuliert:

Warum liest man nicht einmal die grossen Meister der psychologischen Sentenz mehr? - denn, ohne jede Übertreibung gesprochen: der Gebildete in Europa, der La Rochefoucauld und seine Geistes- und Kunstverwandten gelesen hat, ist selten zu finden; [...] denn selbst der feinste Kopf ist nicht vermögend, die Kunst der Sentenzen-Schleiferei gebührend zu würdigen, wenn er nicht selber zu ihr erzogen ist, in ihr gewetteifert hat. ${ }^{174}$

Die «Sentenzen-Schleiferei» bezieht sich auf den Schreibstil der französischen Moralisten. Sie strebt nach Verknappung und Verdichtung. Es ist ihr Ziel, möglichst geschliffene, stilvolle und klare Sätze zu bilden. Das philologische Leseideal leitet sich aus dieser aufwendigen Verfertigung der Sentenzen ab. Nietzsche nennt in Menschliches als Beispiele für Sentenzenkunst die moralischen Maximen von La Rochefoucauld und die Psychologischen Beobachtungen von Paul Rée. In der Nietzsche bekannten Zeitschrift Revue des Deux Mondes schrieb Sainte-Beuve über La Rochefoucauld, dass einige seiner Maximen dreissig Mal überarbeitet wurden, bis sie den notwendigen Ausdruck als «geschliffene» Aphorismen erhalten haben: «c'est l'aphorisme aiguisé et poli.» ${ }^{175}$ So lobt Nietzsche Voltaire für seinen gedrängten, strengen und schlichten Stil. Voltaire habe seine «Seele durch griechisches Maass» gebändigt. ${ }^{176}$ In dieser wechselseitigen Anspielung von griechischem Mass und französischem Sentenzenstil bezeichnet Nietzsche einen Satz aus Paul Rées Psychologischen Beobachtungen als «hart und schneidig geworden unter dem Hammerschlag der historischen Erkenntniss». ${ }^{177}$

Die Zwänge, Regeln und Formen sind nicht nur Umstände, sondern integrale Essenz künstlerischer Produktivität. Nietzsche geht es um konkrete Regeln

174 MA 35, KSA 2, S. 57f. Vivetta Vivarelli und Olivier Ponton haben aufgezeigt, inwiefern Nietzsche diese Stilvorstellung eines knappen, geschliffenen und konventionellen Stils der französischen Literatur entlehnte, vgl. Vivarelli 1998; Ponton 2007. Für die zeitgenössische Auffassung der französischen Sprachkunst und ihren Konventionen sowie des Sentenzenstils vgl. Hillebrand 1876, S. 297-307. Es sei ferner dahingestellt, ob die Bücher der französischen Moralisten der strengen Definition des Sentenzenstils standhalten.

175 Sainte-Beuve 1840, S. 194.

176 MA 221, KSA 2, S. 182; MA 195, KSA 2, S. 165.

177 MA 37, KSA 2, S. 61. Der Taine-Leser Nietzsche kannte womöglich das Lob an Francis Bacons Aphorismenstil, der sich durch «Knappheit und Glanz» auszeichne, vgl. Taine 1878, Bd. 1, S. 346. 
des Schreibens wie Stil, Rhetorik oder Erzähltheorie. Es sind diese Konventionen, welche dem Künstler zwar als «strenge Zwänge», jedoch als «allerstärkste» Mittel des Ausdrucks zur Verfügung stehen:

Der strenge Zwang, welchen sich die französischen Dramatiker auferlegten, in Hinsicht auf Einheit der Handlung, des Ortes und der Zeit, auf Stil, Vers- und Satzbau, Auswahl der Worte und Gedanken, war eine so wichtige Schule, wie die des Contrapuncts und der Fuge in der Entwickelung der modernen Musik oder wie die Gorgianischen Figuren in der griechischen Beredtsamkeit. Sich so zu binden, kann absurd erscheinen; trotzdem giebt es kein anderes Mittel, um aus dem Naturalisiren herauszukommen, als sich zuerst auf das allerstärkste (vielleicht allerwillkürlichste) zu beschränken. ${ }^{178}$

Der Sentenzenstil ist das Produkt einer kunstvoll gefesselten Sprache. Durch die strengen Prinzipien, nach denen sich alle Aspekte von Form und Stil richten, wirkt der Sentenzenstil künstlich und konstruiert. Nietzsches Ideal des philologischen Lesens entspringt dem Schreibideal der Fessel, das er in der antiken Kunst und der französischen Literatur verortet.

\section{Literarische Unsterblichkeit}

Die Prämisse des Sentenzenstils ist der Wille nach literarischer Unsterblichkeit, also möglichst lange haltbar, d.h. lesbar und auslegbar, zu bleiben. Der Autor will dauerhaft lesbar bleiben und muss sich darum der stabilsten Sprachgebäude, der einstmalig herrschenden Stile, bedienen. Es geht um den «Stil der Unsterblichkeit»:

Der Stil der Unsterblichkeit. - Thukydides sowohl wie Tacitus, - beide haben beim Ausarbeiten ihrer Werke an eine unsterbliche Dauer derselben gedacht: diess würde, wenn man es sonst nicht wüsste, schon aus ihrem Stile zu errathen sein. [...] und Beide, scheint es, haben sich nicht verrechnet. ${ }^{179}$

Will eine Philosophie also überleben, darf sie stilistisch weder zu originell noch zu zeitgemäss sein. Deshalb lobt Nietzsche die Sentenzenform: «Eine gute Sentenz ist zu hart für den Zahn der Zeit und wird von allen Jahrtausenden nicht aufgezehrt [...].» ${ }^{180}$ Zuviel Originalität und Individualität gereichen

178 MA 221, KSA 2, S. 181. Zur Wichtigkeit des Zwangs bei Voltaire, Montaigne und in der Antike vgl. Vivarelli 1998, S. 44-47; Ponton 2007, S. 219-244. Dies, während etwa Gottfried Herder die französischen Moralisten für ihre künstliche Sprache hart kritisiert, insbesondere Voltaire. Für Herder ist gerade der Fakt verwerflich, dass Voltaire so gut schreibt, vgl. Bertino 2011, S. 264-273.

179 WS 144, KSA 2, S. 613 .

180 VM 168, KSA 2, S. 446. 
dem literarischen Nachleben zum Nachteil: So wie dem Rennpferd ein grosses Gewicht nachteilig sei, so dem Schreibenden die Fülle. ${ }^{181}$ Es ist davon auszugehen, dass sich die Fülle im letzteren Fall auf die Gedanken, Gefühle und Erlebnisse des Autors bezieht. Konsequent konstatiert darum Nietzsche, dass wer viel «gelten» wolle, eine Taxe haben müsse: «Aber nur das Gewöhnliche hat eine Taxe.» ${ }^{182}$ Der Künstler, der etwas gelten will, müsse sich der Konventionen und Regeln bedienen, um Geltung zu erlangen. Was man gewöhnlich als 〈Inhalt` über die Form setzt, nämlich die gewählten Gedanken und Worte, verortet Nietzsche im Bereich des Vergänglichen, während die Form das Erhabene und Überdauernde mitbringt. Dies wird im Wanderer im Gewand der religiösen Reflexionen vorgeführt:

Was ist das Vergänglichere, der Geist oder der Körper? - In den rechtlichen, moralischen und religiösen Dingen hat das Äusserlichste, das Anschauliche, also der Brauch, die Gebärde, die Ceremonie am meisten D a u e r: sie ist der Leib, zu dem immer eine ne ue Seele hinzukommt. Der Cultus wird wie ein fester Wort-Text immer neu ausgedeutet; die Begriffe und Empfindungen sind das Flüssige, die Sitten das Harte. ${ }^{183}$

Das Äusserlichste, das Oberflächliche, das Anschauliche, die Gebärde, die Richtlinien von Brauch und Ritual - analog zur Funktion des Stils in der Schrift - sind der Leib. Es ist keine versteckte Poetologie, da sie gleich ausgeführt wird: Der Cultus sei der Text, welcher immer neu ausgedeutet wird. Statt neue «Seelen» kommen bei den guten Texten neue Leser hinzu. Die Gebärden des Schreibens sind dauerhaft, während die Auslegung des Textes sich stets ändert. Nietzsche macht hier eine Umkehrung von Form und Inhalt, indem er die Form zum eigentlich Wichtigen erhebt, während sich die Inhalte stets wechselnd zu dieser Form hinzugesellen. Das Erfolgsrezept der Religionen wird auf die Textproduktion übertragen.

Die literarische Unsterblichkeit ist ein kulturpolitisches Ziel: «Es ist ein hoher Zustand der Menschheit möglich, wo das Europa der Völker eine dunkle Vergessenheit ist, wo Europa aber noch in dreissig sehr alten, nie veralteten Büchern le bt: in den Classikern.» ${ }^{184}$ Der Gedanke, dass von Völkern nur wenige Bücher überdauern und rezipiert werden, ist der Altertumswissenschaft geschuldet, die sich im Gefolge von Friedrich August Wolf ausschliesslich einem Kanon antiker Literatur widmete. Dies, weil man die griechische und römische

\footnotetext{
181 Vgl. WS 141, KSA 2, S. 613.

182 WS 334, KSA 2, S. 698.

183 WS 77 , KSA 2, S. 587 .

184 WS ${ }_{125}$, KSA 2, S. 608.
} 
Kultur aufgrund ihrer Literatur als höchste Kulturzustände der Menschheit ansah. ${ }^{185}$ Der philologische Diskurs um die Unsterblichkeit von Literatur war das Thema von Nietzsches Basler Antrittsvorlesung, in der es mitunter um die Frage ging, wie sich der Autorenname Homer trotz bzw. wegen der ungesicherten Existenz und inkohärenten Quellenlage als Fiktion durchsetzen konnte. ${ }^{186}$ Auch für Jacob Burckhardt gehört das Schaffen eines klassischen Kulturguts zu den höchsten Zielen eines guten Staatswesens. Zudem hält Burckhardt explizit fest, dass das «wie» in der antiken Kunst wichtiger sei als das «was», weil es dauerhafter sei und die Bedingung zu klassischer Kunst erfülle. ${ }^{187}$ Gut zu schreiben ist deshalb in Nietzsches philologischer Sicht tatsächlich eine Erhöhung der Kultur und eine Sicherung des Ruhms in der Nachwelt.

\section{Das Layout des Sentenzenstils}

Die Sentenzenkunst lässt sich am Layout der Sentenzen von La Rochefoucauld und Paul Rée veranschaulichen (Abb. 18). Denn es handelt sich hier um eine Technik des gedruckten bzw. gesetzten Wortes, welche ebenso durch die Verfasstheit wie durch das Drucklayout aufgewertet wird. Wenn Nietzsche das Verfassen einer Seite Prosa mit der Arbeit eines Bildhauers vergleicht, trifft das eher auf den Sentenzen- als auf seinen Aphorismenstil und eher auf die gedruckte Seite als auf das Manuskript zu. Dies zeigt nicht zuletzt eine Briefstelle aus der Zeit der Drucklegung der Fröhlichen Wissenschaft: «die letzte Entscheidung über den Text zwingt zum scrupulösesten «Hören〉 von Wort und Satz. Die Bildhauer nennen diese letzte Arbeit $\left\langle\right.$ ad unguem $>.{ }^{188}$ Rée akzentuiert das in Stein Gemeisselte seiner Sentenzen durch einen Rahmen, welcher den

185 Vgl. Wolf 1986, S. 16-18, insb. S. 18: «A si a te n und A frik a n er werden als litterarisch nicht cultivirte, nur civilisirte Völker, unbedenklich von unsern Grenzen ausgeschlossen; [...].»

186 Vgl. Homer und die klassische Philologie in KGW II 1, S. 247-269; Benne/Müller 2014, S. 2022 insb. S. 26: So seien die von Diogenes Laertius abgeschriebenen und umgearbeiteten Epigramme auch eine Praktik der «Überlebenschancen» dieser Texte im «Überlieferungsstrom» der Literatur. Vgl. auch Benne 2015a, S. 254: «Gefragt waren nicht länger vollendete Werke, die einer rhetorischen Analyse zu unterziehen wären, sondern unvollständige Überlieferung, schwierig zu deutende Spuren, die für die zeitgenössische Literatur ebensolche intellektuellen Herausforderungen boten wie die antike oder die mittelalterliche Tradition $[\ldots] . »$

187 Burckhardt 1984, S. 432, 384. Dieser Gedanke findet sich auch in Stendhals Reisebericht Promenades dans Rome, welchen Nietzsche im Mai 1879 gekauft und zumindest teilweise gelesen hat. Stendhal lobt darin die Architektur des Kolosseums für seine «simplicité et solidité» bzw. für seine Einfachheit und Haltbarkeit. Er bemerkt zudem, dass durch den Verzicht auf Ornamente und sonstige Verzierungen das Gebäude einen «caractère étonnant et grandiose» erhalte, der sich dem Gedächtnis des Zuschauers einpräge, vgl. Stendhal 1853 , Bd. 1, S. 30.

188 N. an von Salomé, 27./28.6.1882, Nr. 251, KGB III 1, S. 213. 
Buchseiten den Ausdruck von Texttafeln verleiht. Auch Thomas Rahn kommt in seiner Typografie-Studie zum Schluss, dass einige von Nietzsches Schriftgebärden auf die «gesetzte Schrift» der Druckbuchstaben bezogen sind. 189

Das philologische Lektüreideal findet sich auch in der Materialität der Buchgestaltung wieder. Nietzsche will durch die Wahl von Typografie und Layout das langsame Lesen fördern. ${ }^{190}$ So sollte auf Wunsch Nietzsches die damals eher unbequem lesbare Antiqua anstelle der schnell lesbaren Fraktur-Schrift verwendet werden. Wie sehr die Schriftart bei den Aphorismenbüchern zu einem Politikum wurde, zeigte insbesondere Otto von Bismarcks Antwort auf die $\mathrm{Zu}$ sendung von Menschliches: «daß sich aber deutscher Text in lateinischen Lettern gerade so schwer lese, als wie französischer Text in deutschen Lettern...»191 Auch beim Wanderer besteht Nietzsche auf der Antiqua und auf ein spatiöses Layout. In einem Brief an Schmeitzner vom 27. Oktober 1879 äussert sich Nietzsche durch den Einblick in die Korrekturbogen zu formalen Fragen: «Die Vorrede (oder vielmehr der Dialog) stellt mich nicht zufrieden. Ich bitte sehr darum, dieselben Zwischenräume wie beim Texte herstellen zu lassen: so daß Dialog und Aphorismen ganz g l e i ch gedruckt erscheinen.» ${ }^{122} \mathrm{Da}$ für den Anfangsdialog vom Wanderer ein kleiner Zeilenabstand gewählt wurde, umfasst die Druckseite 39 Zeilen im Vergleich zu den 32 Zeilen des Aphorismentextes (Abb. 19). Das spatiöse Textbild bedient auch standardisierte Erwartungshorizonte des Lesers. Es lässt auf eine Werkausgabe klassischer Lyrik oder Prosa schliessen, was wiederum zum langsamen Lesen verführen sollte. Anstatt die Effekte der Typografie und des Layouts zu minimieren, sieht Nietzsche diese als produktive Widerstände zur Gestaltung und Ausübung seiner Philosophie.

189 Rahn 2015, S. 202.

190 Zeit seines Lebens beschäftigt Nietzsche die Ausstattung seiner Bücher. 1886 schreibt er an seinen Verleger Hermann Credner bezüglich der «Form-Fragen»: «dies [Buch] soll sehr langsam gelesen werden, es muß viel weniger auf einer Seite stehen, [...] Ich wollte vorschlagen: Wenig Zeilen: c. 26, bequeme Intervalle (worin wesentlich der vornehme Eindruck eines Buches liegt) Mittelgroßes Format Feines Velin» (N. an Credner, 27.3.1886, Nr. 679, KGB III 3, S. 164). Und im Folgebrief erklärt Nietzsche, dass «Form und Ausstattung» seiner Bücher mit der durch sie «repräsentirten Denkungsweise» zusammengehören (N. an Credner, Ende März 1886, Nr. 682, KGB III 3, S. 169).

191 Dies berichtet Schmeitzner Gast, zit. n. KSA 15, S. 91 (das Original ist nicht erhalten). Schmeitzner denkt auf Bismarcks Brief hin über den zukünftigen Schriftartengebrauch in seinem Verlag nach. Er fragt dazu auch Nietzsche, der ihm antwortet: «Ich bin Bismarck's Meinung, so lange die deutschen Zeitungen wie bisher gedruckt werden. Für gewisse Bücher sind latein[ische] Lettern gut, weil sie dem allzuschnellen Lesen entgegen sind.» (N. an Schmeitzner, 3.9.1878, Nr. 751, KGB II 5, S. 350).

192 N. an Schmeitzner, 27.10.1879, Nr. 897, KGB II 5, S. 458 f. 
18

\section{MAXIMEs}

XLI.

Ceux qu s'appliquent trop aux petites choses doviennent ordinairement incapables des grandes ${ }^{2}$.

$$
\text { - XLII. }
$$

Nous n'avons pas assez de force pour suivre toule notre raison.

$$
\text { XLIII. }
$$

L'homme croit souvent se conduire lorsqu'il est conduit; et, pendant que par son esprit il tend à un but, son cour l'entraine insensiblement à un autre

$$
\text { - xLIV. }
$$

La force et la foiblesse de l'esprit sont mal nommics; elles ne sont en effet que la bonne ou la mauvaise dis. position des organes du corps.

\section{XLV.}

Le caprice de notre humeur est encore plus bizarre que celui de la fortune.

XLVI.

L'attachement ou l'indifférence que les philosophes avoient pour la vie n'étoient qu'un goat de leur amour. propre, dont on ne doit non plus disputer que du goût de la langue ou du choix des couleurs?

1. Var. La complesion quil tait lo talent pour les petites ebsues est contraire a celle qeili faut pour le taleat des grandes (1665- $0^{*} 51$ ).

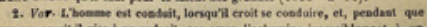

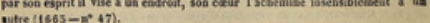

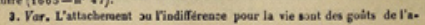

(E) liegt in ber menjकliden शatur, zu

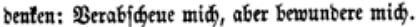

ఇan will fid lieber burdy gajter vor an. beren शenjळen auşzeidnen, als fids gar nidbt por ifnen aubjeidnnen.

Serwante finb unbarmberziger gegen ein. anber, alo grembe.

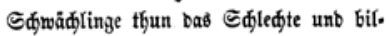
ben fid ein, gut zu jein.

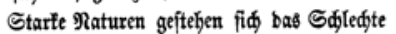
3u, was fie thun.

Ueber ben Tob berwanbter \$erjonen finb wir jo lange unb jo tief betrübt, wie eş jđiđiđllidi ift.

Wir fint nirgenbs fo beideiten, wie ba, wo unjere Borzunge im voljten Mage aner. fannt und befannt fint.

33

Abb. 18 Links das Layout der Maximen von La Rochefoucauld und rechts jenes von Rées Psychologischen Beobachtungen
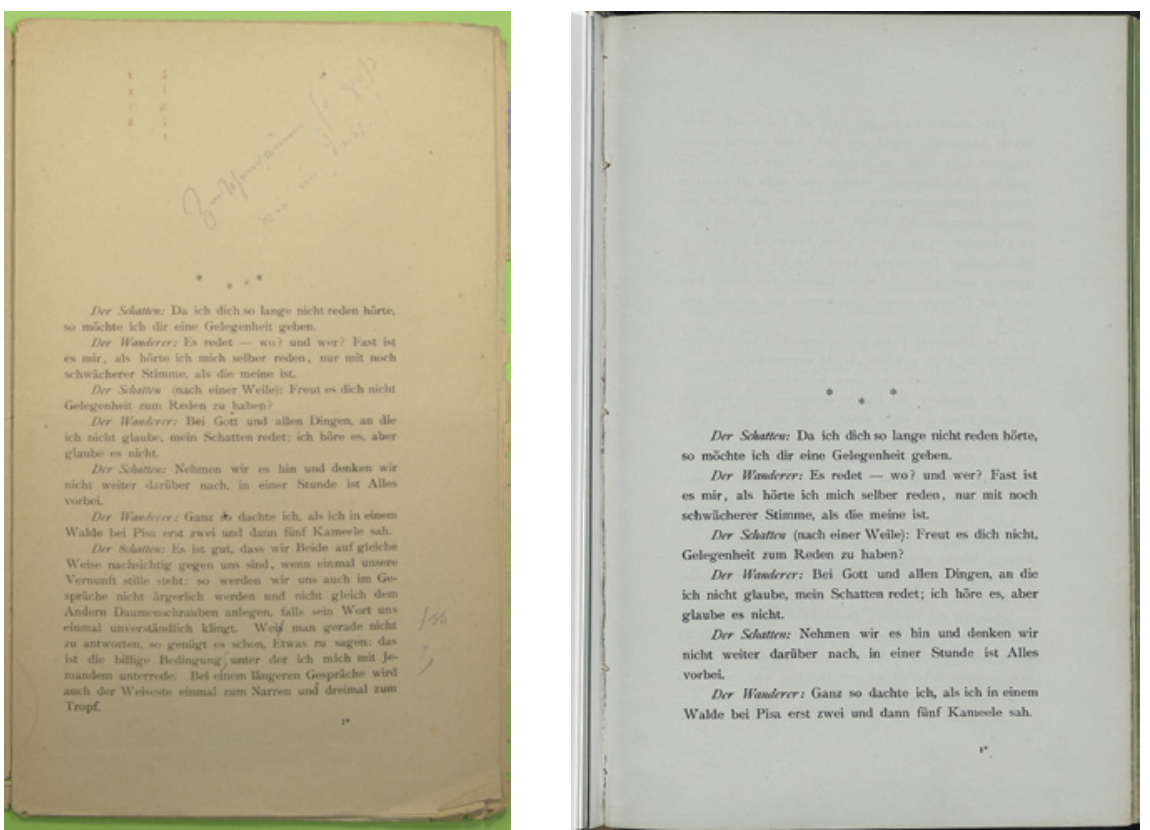

Abb. 19 Das auf Nietzsches Intervention hin spatiösere Layout des Wanderers 
Es stellt sich nun die Frage, inwiefern das referierte Stilverständnis des Kettentanzes auf den Wanderer zutrifft? Das beschriebene Ideal soll zu einer bestimmten Lektüre anleiten, sagt jedoch noch nichts darüber aus, wie die Aphorismenprosa tatsächlich verfasst ist, sondern nur, wie sie der Autor gelesen haben will.

\section{Aphorismenbücher vs. Sentenzenstil}

Nietzsche thematisiert die Ambivalenz im philologischen Leseideal in den Vermischten Meinungen. Dort heisst es, dass Sentenzen beim Leser bestenfalls eine «philosophische[] Stimmung und Belehrung» auslösen. ${ }^{193}$ Das sind zwei Wirkungen, die einen sehr unterschiedlichen Anspruch erheben. Eine philosophische Stimmung auszulösen, heisst, den Leser in irgendeiner Weise zum Denken anzuregen, was sehr bescheiden anmutet und auch von anderen literarischen Gattungen - vom Roman zum Ratgeber - geleistet wird. Die philosophische Belehrung hingegen korreliert mit einem genauen Lesen und einem Lehrplan. Das Buch ist in diesem zweiten Fall nicht einfach zur Anregung, sondern zur Anleitung und Durchführung eines Lernprozesses gedacht. Offenbar sucht Nietzsche zwei Leseideale zu vereinen, was folgende Aufforderung zur Durchmischung von guten und mittelmässigen Gedanken zeigt: «Es ist ein Nachtheil für gute Gedanken, wenn sie zu rasch auf einander folgen; sie verdecken sich gegenseitig die Aussicht. - Deshalb haben die grössten Künstler und Schriftsteller reichlichen Gebrauch vom Mittelmässigen gemacht.»194 Konnten die Leser vorher nicht genug erfahren sein im Wertschätzen und Rekonstruieren der Gedankenketten, so scheinen sie es hier wieder mit viel «Mittelmässigem» zu tun zu haben.

Betrachtet man die Textgestalt von Nietzsches ersten drei Aphorismenbüchern fällt auf, dass Nietzsche eher selten knappe, strenge und pointierte Sentenzen schreibt. ${ }^{195}$ Das zweite Aphorismenbuch, Vermischte Meinungen und Sprüche, ist trotz seines Titels und einigen Sprüchen mehr eine Aphorismenals eine Spruchsammlung. Ganz zu schweigen vom Wanderer, dem im Textbild, im Ton und Schliff nicht an einem Sentenzenstil gelegen ist. Der Sentenzenstil ist ein Schreibideal des mittleren Nietzsches, jedoch nicht sein Schreibstil. Die Sentenzenkunst und die Produktionsästhetik des Kettentanzes stehen im Kontext der Geniekritik, welche sich gegen Wagner und Schopenhauer richtete,

\footnotetext{
193 VM 129, KSA 2, S. 433.

194 VM 120, KSA 2, S. 429.

195 Ein gutes Beispiel sind «Sprüche und Zwischenspiele» in Jenseits von Gut und Böse (JGB, KSA 5, S. 85-104) sowie die «Sprüche und Pfeile» in der Götzen-Dämmerung (GD, KSA 6, S. 59-66).
} 
deren Kunstideale in der Überwindung und Befreiung von Konventionen bestanden (Kap. 3.1.1). ${ }^{196}$ Es sei in diesem Kontext auch auf den Sorrentiner Winter 1876/77 verwiesen, in dem Nietzsche und Rée so eng zusammengearbeitet hatten, dass Rée sein dort entstandenes Buch Über den Ursprung der moralischen Empfindungen (1877) mit einer besonderen Widmung an Nietzsche sandte: «Dem Vater dieser Schrift dankbarst deren Mutter.» ${ }^{197}$ Es ist auffällig, dass dieses zweite Buch Rées viel längere Textabschnitte als die Psychologischen Beobachtungen hat und ungleich weniger Wert auf Verknappung legt. Dies, während Nietzsches in Sorrent erarbeitetes Menschliches ebenfalls wenig spruchhafte, jedoch viele lange Aphorismen enthält. Ein exemplarisches Beispiel dafür ist eine kurze Sentenz aus Rées Psychologischen Beobachtungen über die «schweren Fesseln» der «französischen Dramatiker». ${ }^{198}$ Nietzsche stellt Rées Feststellung an den Anfang seines langen Aphorismus «Die Revolution in der Po e si e» in Menschliches. ${ }^{199}$ Im Unterschied zu Rée wirkt Nietzsches Aphorismus wie ein Mosaik aus Anspielungen, Beispielen und Einschüben, wodurch das Sentenzenhafte vollends getilgt wird. Nietzsche fügt dem französischen Sentenzenstil mehr Individualität, Abschweifungen, Details und Empfindungen hinzu.

Im Schreibverfahren und im Stil des Wanderers setzt sich die Vorstellung vom lockeren Stil durch, der sich weniger den französischen Moralisten, sondern der englischsprachigen Prosa entlehnt. Es ist sogar fraglich, ob Nietzsche die bei den Franzosen bewunderte «Sentenzen-Schleiferei» in der deutschen Sprache für möglich hielt: «Wer in der deutschen Sprache Sentenzen bildet, hat die Schwierigkeit, daß sie gerade am Ende nicht scharf und streng abgeschliffen werden können, sondern daß Hülfszeitwörter hinterdrein stürzen wie Schutt und Gerümpel einem rollenden Steine.»200

196 Vgl. Ponton 2007, S. 230-232; Heller 1972, S. 97: «[...] Nietzsches Vorstellung von einem neuen Stil, der durch Knappheit, Sparsamkeit der Mittel bis zur bloßen Andeutung, usw. in allem umgekehrt wirken soll als die wort-, ton-, farbenreiche Wagner'sche Kunst, bzw. der damals auch in Architektur und Malerei im Schwange stehende Stil der Überladung.» Und laut Schopenhauer sollen die Fesseln wie beispielsweise das Metrum oder der Reim aufgelöst werden: «Alors que pour Schopenhauer, les conventions poètiques sont un lien que le véritable poète dénoue [...].» (Ponton 2007, S. 237).

197 Die Widmung befindet sich auf dem Schmutztitel von Nietzsches Exemplar, zit. n. BN, S. 503 .

198 Rée 1875, S. 11.

199 MA 221, KSA 2, S. 180-184. Auf die inhaltliche Parallele wurde ich durch Rachele Salerno aufmerksam.

$200 \mathrm{NL} 1876 / 77,23[132]$, KSA 8, S. 450. 


\subsubsection{Lockeres Lesen und Schreiben}

Als Nietzsche 1876 beginnt, aphoristisch zu schreiben, schwankt er zwischen zwei Lesetypen, dem philologischen und dem lockeren Lesen. Einerseits will er einen philologischen Leser, andererseits einen promenierenden Leser von Gedankensammlungen. Es gibt in dieser Phase eine ständig kippende Nähe von repetitivem Lesen und einem kurzweiligen Blättern. Beiden Lesetypen entspricht auch eine Autorschaftsvorstellung: dem ersten Typus ein talentierter und virtuoser Schreibkünstler, dem zweiten ein geschwätziger, lockerer und humorvoller Autor.

In der Folge verwende ich das Adjektiv «locker» als Gegenpol zum kunstvollen Schreiben in Zwängen, Konventionen, Ketten und Fesseln. Der Ausdruck «locker» ist für Nietzsche besonders treffend, weil sein früherer Mentor ihm 1869 versagte, als junger Gelehrter im «lockern, kaleidoskopischen Genre» zu schreiben, anstatt «Zusammenhängendes, Einheitliches» hervorzubringen. ${ }^{201}$ Der Begriff des Lockeren verweist auf das Ungezwungene, Ungebundene und Freie. Deshalb werden in Menschliches beim geübten Schreibkünstler «Schritt vor Schritt die Fesseln lockerer». ${ }^{202}$ Anstatt eines virtuosen Kettentanzes, ist hier jedoch das Lockern und Ablegen von stilistischen Fesseln gemeint, wodurch neue Freiheitspotenziale entstehen: So notierte Nietzsche über Darwins Evolutionstheorie, dass es nötig sei, die «stabilen Elemente» zu «lockern», um Veränderung zu ermöglichen. ${ }^{203}$ Dies ist auch für philosophische Aphorismen nötig, da sie die Ansichten der Leser ändern sollen. Nietzsche hat 1874 auch von der «Stimmung» gesprochen, welche ein Buch in sich trage: «Ich verlange von einem Buche Stim m ung als Einheit und Maass; das bestimmt Wortwahl, Gleichniss-Art und -Zahl, Gang und Ende.» ${ }^{204}$ Dies macht die Bezeichnung «lockerer Stil» auch aus heutiger Sprachverwendung nützlich, weil mit «locker» eine Stimmung gemeint ist («gut drauf sein», «gemütlich» oder «ungezwungen»). Das zweite Adjektiv, welches in Frage käme, ist «lässig». Nietzsche nutzte es beispielsweise in seinem Vortrag Ueber die Zukunft unserer Bildungsanstalten, um dem «Ernste» sowie der «strengen Zucht» der lateinischen und griechischen Sprache die «lässige Gemüthlichkeit» der Mutterspra-

201 Ritschl an N., 5.11.1869, Nr. 38, KGB II 2, S. 75. Vgl. auch Goethes auf die Buchkomposition bezogene Verwendung von «locker», die Spoerhase (2018, S. 544f.) analysiert. Vgl. für Lektürepraktiken bei Goethe (stückweises Lesen) sowie generell zum wechselseitigen Verhältnis von Bucheinteilung und Lektürerhythmen ebd., S. 547-557.

202 MA 221, KSA 2, S. 181. Vgl. auch die Formulierung «die Sitten sich lo cke rn » (NL 1880, 4[16], KSA 9, S. 105); oder «Ruhe-Bewegung, fest-locker: alles Gegensätze» (NL 1887, 9[91], KSA 12, S. 284).

203 NL 1875, 12[22], KSA 8, S. 258.

204 NL 1874, 37[8], KSA 7, S. 834. 
che gegenüberzustellen. Noch zentraler für den Schreibkontext ist jedoch die zeitnahe Verwendung in den Vermischten Meinungen: «Ein Werk, das den Eindruck des Gesunden machen soll, darf höchstens mit dreiviertel der Kraft seines Urhebers hervorgebracht sein. [...] Alle guten Dinge haben etwas Lässiges und liegen wie Kühe auf der Wiese.» ${ }^{205}$ Offenbar kann ein Autor seine Anspannung im Werk nicht verbergen. Das Lässige ist ein stilistischer Beweis für die Lockerheit des Autors beim Schreiben. Man könnte einwenden, dass beide diskutierten Adjektive bei Nietzsche wie auch im zeitgenössischen Diskurs mehrheitlich negativ auftauchen. Dies ist hier jedoch kein Nachteil, weil in der Folge ein Schreib- und Lesemodus beschrieben wird, der nicht über Umwege und Hintertüren wieder zu einer «höheren» Kunst stilisiert werden soll.

\section{Lockeres Lesen und und kursorische Lektüre}

Die deutlichste und früheste Adressierung eines lockeren Lesens findet sich 1876. Nietzsche beschreibt in einer unverwendeten Vorrede zu Menschliches das vorliegende Aphorismenbuch als Reisebuch, das man hin und wieder aufschlage:

\section{Reisebuch \\ unterwegs zu lesen}

[...] Es müssen Bücher sein, welche man nicht durchliest, aber häufig aufschlägt: an irgend einem Satze bleibt man heute, an einem anderen morgen hängen und denkt einmal wieder aus Herzensgrunde nach: für und wider, hinein und drüber hinaus, wie einen der Geist treibt, so dass es einem dabei jedesmal heiter und wohl im Kopfe wird. [...] Man hat mit Nutzen gereist. ${ }^{206}$

Diese 1876 geschriebene Passage steht in krassem Kontrast zur eben skizzierten Lektürepolitik der Sentenzenkunst. Hier geht es nicht um das philologisch langsame und wiederkäuende Lesen, sondern um einen lockeren, flanierenden und blätternden Leser, der 〈heute hier, morgen dort〉 hängen bleibt. Hauptsache ist, «aus Herzensgrund» nachdenken zu können; und weniger die

205 VM 107, KSA 2, S. 422. Nietzsche selbst hat «Spannung» und «Locker-werden» als Gegensätze verwendet, vgl. NL 1888, 22 [18], KSA 13, S. 591.

206 NL 1876/1877, 23[196], KSA 8, S. 473f. Diese unverwendete Vorrede wird wenig später wiederaufgenommen, und kann deshalb als Vorstufe des Aphorismus 454 der Morgenröte gelten: «Zwischenrede. - Ein Buch, wie dieses, ist nicht zum Durchlesen und Vorlesen, sondern zum Aufschlagen, namentlich im Spazierengehen und auf Reisen, man muss den Kopf hinein- und immer wieder hinausstecken können und nichts Gewohntes um sich finden.» (M 454, KSA 3, S. 274). 
tiefgründigen Inhalte des Autors zu verstehen. ${ }^{207}$ Das Aphorismenbuch dient nunmehr dazu, den Lesenden Denkstoff zu liefern - als geistige Anregung und Erholung. Das lockere Lesen entspricht nicht der Vorstellung, wie ein durchdachtes philosophisches Buch zu lesen sei. Die Leser halten sich weder an die vom Autor gewollte Reihenfolge noch an seine Denkart. Das ist beispielsweise die gegenteilige Leseanleitung zu Schopenhauers Die Welt als Wille und Vorstellung, das man zweimal, linear und chronologisch, von vorne nach hinten lesen müsse - ganz zu schweigen von den unverzichtbaren Vorkenntnissen. ${ }^{208}$ Nietzsche setzt demgegenüber auf das «Ungezwungene». Dazu passt denn auch der unverwendete Entwurfstitel «Menschliches und Allzumenschliches. Gesellige Sprüche». ${ }^{209}$

Durch den Fokus auf «Erholung» adressiert sich die unverwendete Vorrede an die demokratische Leserschaft im «arbeitsamen» Zeitalter. ${ }^{210}$ Man kann den lockeren Stil und die mögliche Erholung noch anders wenden: Die Forderung nach einer philologischen Lektüre ist eine Machtausübung des Autors, indem er die Leser zu einem Setting anleitet, in dem das Geschriebene seine Wirkungen im Sinne des Autors entfalten soll. Dies ist aber auch eine Hierarchisierung, der man sich mit dem lockeren und blätternden Lesen entzieht. So schreibt Roland Barthes über seine Lust am Text, dass sie zuweilen die Form des Treibens annehme, was auch für die blätternde Lektüre gilt: «Ein solches Treiben [ «dérive»] geschieht immer dann, wenn ich nicht das Ganze respektiere [...].» ${ }^{211}$ Und Michel de Montaigne sieht seinen Lektüreprofit nicht als «fremdes Eigentum», weil er die Bücher nur durchblättere, sie jedoch nicht eingehend studiere. ${ }^{212}$ Es ist bezeichnend für die Freiheit des lockeren Lesens, dass Montaigne sich mehr Leseraktivität zuspricht, wenn er ein Buch nur blätternd und oberflächlich liest. Er wünscht sich konsequenterweise Leser, welche ihn «zerpflücken».213 Durch die Aufforderung zur blätternden Lektüre schwächt

207 Diese Leseempfehlung macht Nietzsche auch seinem Freund Rohde: «Grüble nicht über die Entstehung eines solchen Buches nach, sondern fahre fort, dies und jenes Dir herauszulangen.» (N. an Rohde, kurz nach 16.6.1878, Nr. 727, KGB II 5, S. 333).

208 Vgl. Schopenhauer 1986, Bd. 1, S. 8f.

209 NL 1876, 19[118], KSA 8, S. 359.

210 WS 170, KSA 2, S. 623. Auch deshalb ist Vorsicht geboten, wenn man Nietzsches Äusserungen zu Sentenzen, Aphorismen und Prosa zu einem rein philologischen Leseideal generalisiert.

211 Barthes 1974, S. 29.

212 Vgl. Montaigne 1965, Bd. 2, S. 411: «Je feuillette les livres, je ne les étudie pas : ce qui m’en demeure, c'est chose que je ne reconnais plus être d'autrui; [...]». Gemäss Elisabeth Décultot liegt in dieser Lektürepraxis jedoch kein Wille zum Diebstahl, sondern vielmehr ein Zeichen der Bewunderung (vgl. 2014b, S. 156).

213 Vgl. Montaigne 1965, Bd. 2, S. 105: «J'aimerais quelqu'un qui me sache déplumer [...].» 
Nietzsche seine Textautorität und fördert die Autonomie der Leser. Christoph B. Schulz sieht im Blättern ein befreiendes Potenzial: «Das Blättern, als Manipulation des Buches verstanden, macht die Abhängigkeit des Textes von seinen Lesern deutlich. Der publizierte Text ist in diesem Sinne kein autonomes Produkt seines Verfassers, sondern vielmehr ein Gegenstand, mit dem der Leser dank dem Buch verfahren kann, wie es ihm beliebt.» ${ }^{214}$ Das lockere Lesen enthält einen emanzipierenden Gestus, der sich auffällig in die Demokratisierung des Lesens und Schreibens im 19. Jahrhundert eingliedert (Kap. 3.4.3). Jakob Tanner hat aufgezeigt, dass das Blättern massgeblich von der aufklärerischen Literatur, der Ratgeber-Literatur und der Enzyklopädie geprägt war. ${ }^{215}$ Es war in der Idee dieser Literatur von Beginn weg inbegriffen, dass es keine kontrollierte und enggeführte Lektüre mehr gab. Dieses Phänomen nenne ich das «lockere Lesen» im Unterschied zum «philologischen Lesen» bzw. den «lockeren Stil» im Unterschied zum strengen Stil der Sentenzenkunst. Aphorismenbände bieten sich beiden Leseweisen an. Deshalb muss sich der Autor Nietzsche zur Lektüre seiner Bücher äussern.

\section{Der lockere Stil vom Wanderer}

Der Wanderer ist besonders gesprächig, ja zuweilen geschwätzig. Noch im 1886 geschriebenen Vorwort verweist Nietzsche auf den lockeren Stil vom Wanderer, wenn er diese Zeit mit folgenden Stichworten charakterisiert: «etwas Cynismus vielleicht, etwas 〈Tonne〉, aber ebenso gewiss viel Grillen-Glück, Grillen-Munterkeit, viel Stille, Licht, feinere Thorheit, verborgenes Schwärmen [...].» ${ }^{216}$ Kaum ein Beispiel aus den Arbeitsprozessen widerspiegelt das besser und relevanter als der Titelentwurf: «Der Wanderer und sein Schatten. Ein Geschwätz unterwegs.» ${ }^{217}$ (Abb. 20) Gleich zu Beginn im Rahmendialog zwischen Wanderer und Schatten wird mehrmals die ungezwungene Art des Gesprächs betont:

Es ist gut, dass wir Beide auf gleiche Weise nachsichtig gegen uns sind, wenn einmal unsere Vernunft stille steht: so werden wir uns auch im Gespräche nicht ärgerlich werden und nicht gleich dem Andern Daumenschrauben anlegen, falls sein Wort uns einmal unverständlich klingt. [...] Bei einem längeren Gespräche wird auch der Weiseste einmal zum Narren und dreimal zum Tropf. ${ }^{218}$

\footnotetext{
214 Schulz 2015, S. 28.

215 Tanner 2002, S. 260.

216 MA II, Vorrede 5, KSA 2, S. 375.

217 NL 1879, 41[72], KSA 8, S. 594 bzw. N IV 1, S. 49.

218 WS Rahmendialog, KSA 2, S. 537.
} 


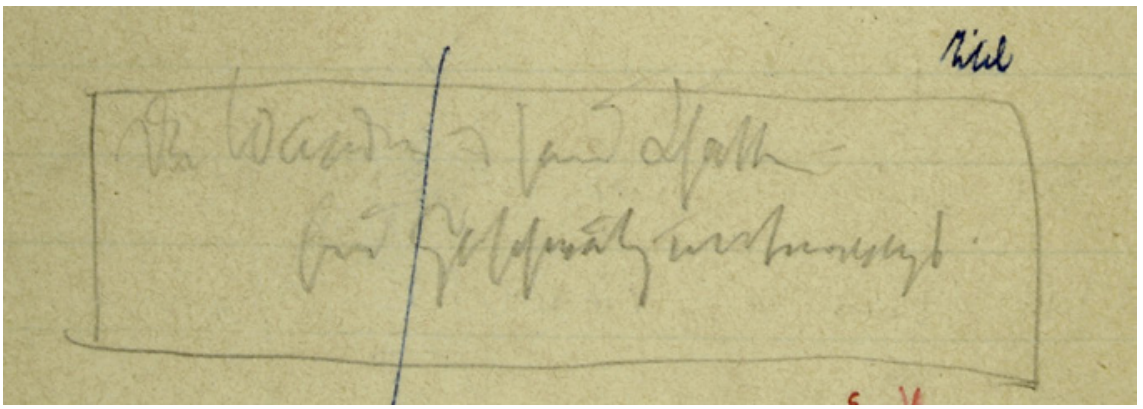

Abb. 20 Das von Nietzsche eingerahmte Notat N IV 1, S. 49: «Der Wanderer und sein Schatten / Ein Geschwätz unterwegs.»

Es geht hier um die Konfrontation zwischen einem philosophischen Dialog und einem lockeren Geschwätz. ${ }^{219}$ Beim lockeren Gespräch kann die Vernunft auch mal «stille» stehen und das Gesagte unverständlich sein. Es müsse noch nicht mal auf die Aussagen des Anderen eingegangen werden: «Etwas zu sagen: das ist die billige Bedingung» einer Unterhaltung. Diese lockere Form des Gesprächs, dessen einzige Bedingung die Anschlusskommunikation ist, steht im Gegensatz zu Platons oft beschworenem Ernst und Fleiss, den die dialektische Methode erfordert. Wenn der Schatten im Schlussdialog - also nach den 350 Aphorismen - bemerkt, dass ihm «Nichts mehr gefallen» habe, als die Lehre der «nächsten Dinge», dann personifiziert er einen lockeren Leser, der nach seinem persönlichen Genussempfinden die Aphorismen durchgegangen ist. ${ }^{220}$

Der lockere Stil manifestiert sich im Wanderer auch an der Wortwahl und dem 〈Ton〉. Dass im Rahmendialog der Weiseste zum «Narren» und «Tropf» wird, zeugt nicht von einem gehobenen und kunstvollen Stil. ${ }^{221}$ Im Aphorismus über Jesus im Gefängnis fällt neben dem Zynismus der Mitgefangenen der umgangssprachliche Ton auf: «Holla, schrien Mehrere durcheinander, holla! Herr Sohn, Herr Sohn, wie steht es mit der Erbschaft?»222 Gut vorstellbar, dass der durch Cosima Wagner bezeugte Ärger ihres Gatten bei der Lektüre des Wanderers insbesondere auf den lockeren Stil zurückzuführen ist. Denn die Stellen zu Goethes Faust, über die sich der Faust-Verehrer Wagner offenbar echauffierte, sind besonders angriffig und salopp formuliert. ${ }^{223}$

219 Für die Arten philosophischer Dialoge bei Nietzsche vgl. Zittel 2016.

220 WS Rahmendialog, KSA 2, S. 703.

221 WS Rahmendialog, KSA 2, S. 537.

222 WS 84, KSA 2, S. 591.

223 Zu Wagner vgl. Janz 1978, S. 41f.; zu Faust vgl. WS 42, KSA 2, S. 572; WS 124, KSA 2, S. 6o6; WS 168, KSA 2, S. $621 f$. 


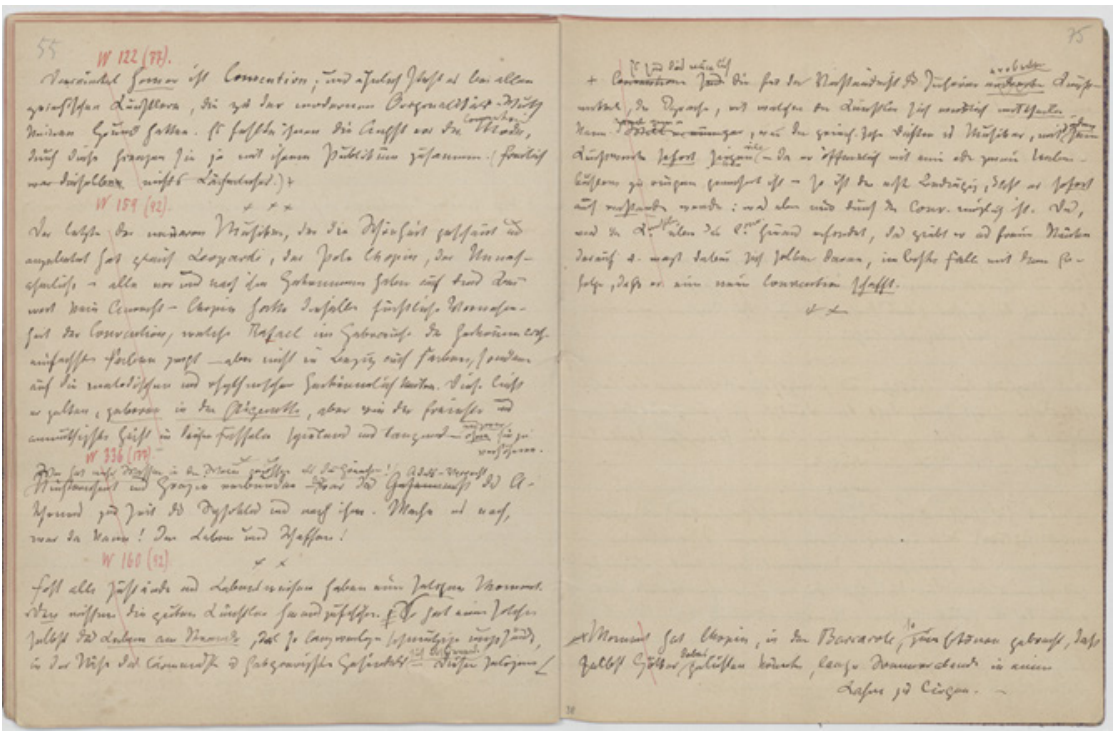

Abb. 21 Die Doppelseite S. 74/75 aus dem Arbeitsheft M I 3

Zuweilen ging es wohl selbst Nietzsche zu weit: So überklebt er den Anfang des von Gast bereits reingeschriebenen Aphorismus über Schopenhauer: «Ein drolliges Beispiel davon, wie der metaphysische Trieb, [...] dem Philosophen hinter die Ohren schlagen und ihn zum schlechten Beobachter machen kann, bieten die Gedanken Schopenhauers über die Schwangerschaft der Weiber.» 224 Die Wortwahl «drollig» oder «hinter die Ohren schlagen» zeugen von einem ungehobelten und lässigen Stil, der sich auch durch den weiteren Aphorismus zieht.

Der knappe und kurze Stil ist im Wanderer nicht vorherrschend. Das lässt sich insbesondere an Nietzsches Schreibverfahren zeigen, welches auf Relektüre und Einschübe hin angelegt ist. So nutzt er beim Umschreiben, wie in Kap. 2.3.4 erläutert, bloss die geraden Seiten seiner Arbeitshefte, um auf den ungeraden Seiten später Ergänzungen vorzunehmen. Die Umschriften werden also mittels der leergelassenen rechten Heftseite erweitert und ausgebaut. Zuweilen sind die Umschriften noch unvollständig, obwohl sie bereits mit drei Kreuzchen räumlich begrenzt wurden. So endet im Arbeitsheft (Abb. 21, links oben) die Umschrift des späteren Aphorismus 122 über die Wichtigkeit der Konventionen bei den Griechen mit einer durchstrichenen Klammerbemerkung:

224 KGW IV 4, S. 306f. Vgl. dazu die Umschrift M I 3, S. 64 sowie die überklebte Stelle D 13, Blatt 10 recto. 
Dreiviertel Homer ist Convention; und ähnlich steht es bei allen griechischen Künstlern, die zu der modernen Originalitäts-Wuth keinen Grund hatten. Es fehlte ihnen die Angst vor der Hode, Convention durch diese hiengen sie ja mit ihrem Publikum zusammen. (Freilich war dieselbe nichts Läeherliches.) $)^{225}$

Die Klammerbemerkung fungiert hier als Schreibanweisung für die spätere Bearbeitung. Diese kann aufgrund der weiter beschriebenen linken Heftseite nur als Erweiterung auf der leergelassenen rechten Heftseite erfolgen. Dort (Abb. 21, rechts oben) ergänzt Nietzsche den heute bekannten Hauptteil dieses Aphorismus, der u.a. die zentrale Definition der Konvention enthält. In einem weiteren Beispiel, dem Aphorismus 41, ist das Erweitern selbst noch im Drucktext spürbar: So hat Nietzsche im Arbeitsheft zunächst auf der linken Seite seine Gedanken zum «moralischen Erbreichthum» dargelegt, um bei der Relektüre auf der rechten Seite wie folgt fortzufahren: «- So wie hier geschehen ist, lässt sich etwa die herrschende Ansicht über den moralischen Erbreichthum zusammenfassen $[. .]. »{ }^{226}$ Nietzsche hat seine erste umgeschriebene Ansicht nach der Relektüre als «herrschende Ansicht» genommen, um diese weiter zu modifizieren. In der Überarbeitung stellt er sich als Leser der Meinung des früher Geschriebenen entgegen und führt auf diese Weise einen Dialog mit sich selbst. Ähnlich geschieht es auch in anderen Fällen. ${ }^{227}$ Nietzsche provoziert den Schreibprozess des Erweiterns, indem er dem Publikationsprozess zuweilen ungeachtet dessen folgt, ob ihm für umgeschriebene Notate bereits eine aphoristische Idee eingefallen ist. Offenbar vertraut Nietzsche einerseits seinem Witz bei der Relektüre so sehr, dass er unvollständige Umschriften belässt und erst später erweitert; andererseits legt er durch dieses Schreibverfahren den Wanderer auf den lockeren Stil hin an.

Auch Peter Gast ist der lockere Stil bei der Reinschrift von Nietzsches Wanderer nicht entgangen: «Einige Stellen, namentlich in den Aphorismen, in denen eine längere Erörterung nöthig war, werden meines Erachtens etwas strenger und geschlossner zu fassen sein, damit die schöne Lässigkeit des Sprechstils nicht in den Anschein der Nachlässigkeit verfalle.»228 Doch anstatt diesem

\footnotetext{
225 KGW IV 4, S. 325 bzw. M I 3, S. 74.

226 M I 3, S. 14/15; WS 41, KSA 2, S. 571.

227 Vgl. beispielsweise die Überarbeitung zum anfänglich kurzen Entwurf für WS 107, KSA 2, S. 599 in M I 3, S. 76.

228 Gast an N., 1./2.10.1879, Nr. 1235, KGB II 6/2, S. 1173 .
} 
Vorschlag zu folgen, finden sich in der zum Zettel-Manuskript verarbeiteten Reinschrift Gasts primär Erweiterungen im Sinne der adiectio und digressio. ${ }^{229}$

Des Weiteren hat Nietzsche sich bei der Buchherstellung des Wanderers gegen eine Kapitelstruktur entschieden und ordnete die ausgeschnittenen Aphorismenzettel in sehr ungleicher Menge zu thematischen Blöcken (Kap. 2.2.5). Die fehlende Kapitelstruktur und die unausgewogene Aphorismenmischung laden zu zwei Interpretationen ein: Die Erste ist wie beschrieben jene der Nietzscherezeption, dass es den Lesern obliege, die verborgene Aufteilung zu rekonstruieren. Die zweite Interpretation wäre, dass die fehlende Kapitelstruktur zu einem freien Lesen und Blättern einlädt. ${ }^{230}$ Im Wanderer beziehen die Leser die Aphorismen nicht auf die Hauptstücke. Es steht ihnen frei, ob sie Zusammenhänge im Buch suchen oder durch dasselbe flanieren. Das ist zwar in der aphoristischen Schreibweise angelegt, jedoch wird es durch die fehlende Kapitelstruktur verstärkt. Der lockere Lese- und Schreibtyp ist also auch Teil der Buchgestaltung.

Der lockere Stil des Wanderers ist durch zahlreiche zeitgenössische Reaktionen belegt (Kap. 4.2.4). Sieht man nämlich ab von wagnerianisch geprägten Lesern, die sich in ihren Erwartungen getäuscht sahen, bieten die Rückmeldungen eine Fundgrube historischer Leseeindrücke, die exemplarisch Nietzsches Verstoss gegen das ernsthafte, ausgereifte und systematische Philosophieren belegen. So berichtet Malwida von Meysenbug an Heinrich von Stein:

Was haben Sie zu Nietzsches letztem Buch gesagt? Alle seine nächsten Freunde sind empört darüber, und mir mißfällt es auch durch den leichtfertigen Ton, mit dem es sich auf einem Gebiet bewegt, auf welchem N. nie einheimisch war und wo er daher inkompetent und oberflächlich ist. ${ }^{231}$

Wenn von Meysenbug sich über den leichtfertigen Ton und die Laienhaftigkeit Nietzsches ärgert, liegt sie aus zeitgenössischer Sicht richtig. Auch Nietzsches Freund Erwin Rohde kritisiert ähnlich, wenn er Menschliches vorwirft, es sei im Gefolge von Rée «leicht eine Reihe geistreich aussehender Sentenzen (die im Grund immer wesentlich dasselbe sagen) zu schmieden.» ${ }^{232}$ Es muss für den Altphilologen Rohde ernüchternd gewesen sein, als er sah, wie einfach Nietzsche vorbei am Korsett der philologischen Methoden zu eindrücklichen

229 Vgl. Benne 2015a, S. 429-431. Nietzsche entspricht mit seiner digressiven Prosa einer historischen Entwicklung der Schreibproduktion, welche vom horazischen knappen Stil zur Erweiterung wechselte (vgl. ebd., S. 430).

230 Vgl. auch den bereits erwähnten, fehlenden Verweis auf Menschliches auf dem Titelblatt (Kap. 2.2).

231 Malwida von Meysenbug an Heinrich von Stein, 11.9.1878, zit. n. Reich 2013, S. 539 .

232 Erwin Rohde an Franz Overbeck, 31.5.1879, zit. n. Reich 2013, S. 544. 
und gut klingenden Erkenntnissen kam. So hat dann der Wanderer auch den Leipziger Theologie-Professor Christoph Ernst Luthardt ordentlich geärgert: «Ein recht charakteristisches Beispiel dieser eitlen Blasirtheit, die sich bis zu geistreich sein sollenden Blasphemien steigert, ist z.B. Nietzsche's «Der Wanderer und sein Schatten> (Chemnitz 1880).» ${ }^{233}$ Es störten ihn wohl nicht primär die Textstellen zur Gottes- und Kirchenkritik, sondern vielmehr der lockere Stil, in dem über diese Gegenstände geschrieben wird: eitel, blasiert und pseudo-geistreich.

Sternes Tristram Shandy und die englischsprachigen Humoristen In der Lektüre des mittleren Nietzsches finden sich einige Autoren, welche digressiv, locker und ungezwungen schreiben. Hillebrand, Lichtenberg, Montaigne, Stendhal, Swift oder Taine geben sich gerne abschweifend und geschwätzig. Anstatt einer systematischen Bewertung wird der originelle Standpunkt, das unerwartete Werturteil oder ein gewagter Zusammenhang bevorzugt. Das plaudernde und digressive Schreiben über Schriftsteller, Maler, Komponisten und Nationalitäten demonstriert eine lässige Virtuosität und Weltgewandtheit. Im Kontext der späten $1870 e r$ Jahre fällt besonders Nietzsches intensive Lektüre englischsprachiger Literatur auf. ${ }^{234}$ Drei Bücher, die Nietzsche im Jahr 1879 kennt und lobt, sind für diese Thematik wichtig und genauer zu analysieren: Mark Twains Tom Sawyer, Laurence Sternes Tristram Shandy und Jonathan Swifts Humoristische Werke.

Nietzsche besass viele Bände der im Friedrich Wilhelm Grunow Verlag in Leipzig erschienenen Reihe «Amerikanische Humoristen» (13 Bände zwischen 1874-1877). ${ }^{235}$ Aus dieser Reihe kaufte er im Dezember 1875 in der Basler Buchhandlung «Felix Schneider» einige Bücher von Mark Twain. Twain schrieb nicht nur über die Ärgernisse der deutschen Sprache, sondern äusserte sich verschiedentlich gegen einen ernsthaften Stil. Im Jahr 1877 schreibt Nietzsche an Paul Rée, er habe in seinen Kuraufenthalt nur drei Bücher mitgenommen, eines davon Tom Sawyer: «etwas Neues von Mark Twain dem Amerikaner (ich

233 Luthardt 1880, S. 258.

234 Vgl. Brobjer 2004, S. 35 sowie 2008a, S. 36. Brobjer hat für die Jahre 1875-188o aufwendige Lektüreverzeichnisse erstellt. Zurecht spricht er angesichts der Menge an Nachweisen von Nietzsches «Love» zu englischsprachiger Literatur. Neben Sterne und Twain könnte man viele weitere aufzählen und genauer analysieren, allen voran Walter Scott und Jonathan Swift.

235 Für die deutsche Rezeption humoristischer Literatur vgl. Kersten 2002 und Wuster 2016, Kap. 1, S. 35-73. Die Bezeichnung «Humoristen» wurde damals hauptsächlich für amerikanische Literaten verwendet. Das Adjektiv «humoristisch» findet sich jedoch als Bezeichnung in Werkausgaben, vgl. etwa «Swift's Humoristische Werke» (1844). 
liebe dessen Albernheiten mehr als die deutschen Gescheutheiten) [...].»236 Tatsächlich war Tom Sawyer damals (wie heute) ein aussergewöhnliches Buch, das die Alltagssprache samt Schimpf und Schande, Dialekt und Abkürzungen benutzte. Kaum kehrt Nietzsche von St. Moritz nach Naumburg zurück, lässt er sich von der Mutter aus Tom Sawyer vorlesen. ${ }^{237}$ Tom Sawyer ist das Gegenstück zu einer Coming-of-Age-Geschichte, welche Nietzsche 1879 ebenfalls lobt, Adalbert Stifters Nachsommer. Haben wir es im Nachsommer mit einer geistigen Veredelung in einer klaren und gehobenen (beinahe biederen) Prosa zu tun, so sind es bei Tom Sawyer alberne Lausbuben-Abenteuer. ${ }^{238}$ Stifters poetische Strategien der Klarheit und Einfachheit sind ein Statement gegen metaphysische und irrationale Poetik. ${ }^{239}$ Die Bücher der Humoristen hingegen sind mit ihrem lockeren Stil für Nietzsche eine neue Erfahrung. So kann es kaum verwundern, dass sich 1880 die folgende, vielsagende Notiz im Nachlass findet: «Mir thut das amerikanische Lachen wohl, diese Art von derben Seeleuten wie Marc Twain. Ich habe über nichts Deutsches mehr lachen können.» 240 Die Erfahrung, ein albernes, lustiges und umgangssprachliches Buch zu lesen, hat Nietzsche viel Vergnügen bereitet. Nietzsche wird dieses erfrischende Buch seinen treuesten Freunden Ida und Franz Overbeck zu Weihnachten 1879 schenken - in der gleichen Sendung befindet sich der Wanderer. ${ }^{241}$ Diese Anekdote zeigt, wie nachhaltig Nietzsche vom lockeren Stil beeindruckt war.

Die Faszination für einen lockeren Stil schlug sich schon in den Vermischten Meinungen nieder, in denen Nietzsche Laurence Sterne als den «freieste $[n]$ Schriftsteller» aller Zeiten anpreist (einem Lob Goethes folgend). Nietzsche lobt Sternes unkonventionellen Schreibstil, der gegen alle Normen verstosse, so etwa gegen «Zucht, Geschlossenheit, Charakter, Beständigkeit der Absichten, Ueberschaulichkeit, Schlichtheit, Haltung in Gang und Miene.» ${ }^{242}$ Sterne wisse «den Tiefsinn und die Posse zu verknäueln», weshalb er jede Ernsthaftigkeit ironisch untergrabe: «seine Sentenzen enthalten zugleich eine Ironie auf alles Sentenziöse, sein Widerwille gegen das Ernsthafte ist einem Hange

236 N. an Rée, zweite Junihälfte 1877, Nr. 627, KGB II 5, S. 245 f.

237 Vgl. N. an Overbeck, 14.11.1879, Nr. 904, KGB II 5, S. 463.

238 Die von Nietzsche in Menschliches gelobten Schriften - Eckermanns Gespräche, Stifters Nachsommer oder Gotthelfs Leute von Seydwilla - bilden v.a. den Gegenpol zur leidenschaftlichen und überspannten Literatur der Romantik. Im Grunde - das zeigt sein Faible für Sterne, Swift oder Twain - hat Nietzsche an lockerer Prosa grosse Freude.

239 Vgl. Giuriato 2015, bes. S. 289-332.

240 NL 1880, 7 [229], KSA 8, S. 365.

241 Vgl. N. an Overbeck, 11.12.1879, Nr. 913, KGB II 5, S. 470.

242 VM 113, KSA 2, S. 426. 
angeknüpft, keine Sache nur flach und äusserlich nehmen zu können.» 243 Nietzsche verbindet hier gleich selbst das Sentenziöse mit dem Ernsthaften. Die an Sterne gelobten Eigenschaften sind dem Sentenzenstil mit seiner Kürze, Knappheit, Präzision und Kühle diametral entgegengesetzt. Der spielerische, unsystematische und exzessiv abschweifende Roman Tristram Shandy müsste nach Nietzsches Regeln des prosaischen Erzählens für seine Langfädigkeit, Unordnung und Anachronie scharf kritisiert werden. ${ }^{244}$ Die durchmischten Gattungen, Rollen und Erzählungen verwirren die Leser. Dadurch verunmöglicht Sterne zwar das Nachspüren eindeutiger Intentionen, ermöglicht aber eine individualisierte, selbstständige und anregende Lektüre. Dies wird an selbiger Stelle ausgeführt:

Der Leser ist verloren zu geben, der jederzeit genau wissen will, was Sterne eigentlich über eine Sache denkt, ob er bei ihr ein ernsthaftes oder ein lächelndes Gesicht macht: denn er versteht sich auf Beides in Einer Faltung seines Gesichtes; [...] So bringt er bei dem rechten Leser ein Gefühl von Unsicherheit darüber hervor, ob man gehe, stehe oder liege: ein Gefühl, welches dem des Schwebens am verwandtesten ist. ${ }^{245}$

Sterne sei der «Meister der Zweideutigkeit», weil sich in seinen Texten unzählige Ambivalenzen versammeln: ernst und «lächelnd», wahr und unwahr, erfunden und historisch belegt etc. Die Zweideutigkeit - die Ambivalenz von ernst und locker - bewirkt beim Leser eine «Unsicherheit», die Nietzsche als hohe Kunst würdigt. Die entscheidende Eigenschaft von Sternes Texten besteht darin, dass sie den Lesern die Freiheit für eine lockere oder ernsthafte Lektüre lassen. Noch 1878 kritisiert Nietzsche Heinrich Heine für seine Stilvielfalt. ${ }^{246}$ Nun verbindet Nietzsche das unsichere Schweben mit dem Gefühl der Freiheit: Sterne sei wie niemand vor ihm «in jede Faser und Muskel

243 Ebd., S. 425. In Tristram Shandy heisst es, Yorick habe einen unüberwindlichen «dislike and opposition in his nature to gravity;----not to gravity as such; [...] but he was an enemy to the affectation of it, and declared open war against it [...].» (Sterne 1978, Bd. 1, S. 29) Im Übrigen wird noch im Roman der Schreibstil als «digressive» bezeichnet (ebd., S. 8of.).

244 Vgl. Benne 2015a, S. 430.

245 VM 113, KSA 2, S. 424f. Im Wanderer ist selbst das xenophontische Sokrates-Lob entlang des Ernsten und Lockeren ausgesprochen: «Vor dem Stifter des Christenthums hat Sokrates die fröhliche Art des Ernstes und jene Weisheit voller Schelmenstreiche voraus, welche den besten Seelenzustand des Menschen ausmacht.» (WS 86, KSA 2, S. 592$)$.

246 NL 1876, 15[10], KSA 8, S. 281: «er liebt die bunte Hanswurstjacke.» Folgerichtig empfindet Nietzsche nach seiner Sterne-Faszination laut unsicherer Lesart Heine 1880 als einen redlichen Autor, vgl. NL 1880, 7[40], KSA 9, S. 326. 
des Leibes hinein» ein Freigeist. In Menschliches sah Nietzsche im Stil Voltaires noch den Inbegriff von Freigeistigkeit, weil er «aus dem Zwange zu jenem Scheine der Freiheit» kam, das heisst durch strikte Auferlegung stilistischer Regeln (Stil, Vers- und Satzbau, Auswahl der Worte etc.). ${ }^{247}$ Kaum ist der Freigeist verblasst, wird nun Sterne als der «freieste Schriftsteller» gelobt.

Im Frühjahr 1876, also noch zwei Jahre vor der Publikation von Menschliches, kaufte Nietzsche die dreibändige Ausgabe von Swift's Humoristischen Werken (1844). ${ }^{248}$ Nietzsche zitiert in Menschliches gleich zwei Mal daraus. ${ }^{249}$ Er inszeniert Swift als Sentenzenschreiber, wenn er das Zitat wie folgt einleitet: «Swift hat den Satz hingeworfen, dass Menschen in dem selben Verhältniss dankbar sind, wie sie Rache hegen.» ${ }^{250}$ Schaut man sich die Humoristischen Werke genauer an, finden sich dort nur wenige Sentenzen. Die beiden von Nietzsche zitierten Sätze stammen aus einem Buchabschnitt, das mit «Aphorismen» überschrieben ist und hauptsächlich längere und digressive Aphorismen enthält (Abb. 22). Vergleicht man das oben besprochene Layout des Sentenzenbuchs von La Rochefoucauld mit den Aphorismen Swifts, so wird die unterschiedliche Ausrichtung der Knappheit sichtbar. Von der Länge, vom Layout und vom lockeren Stil her sind nicht die französischen Sentenzenbücher das Vorbild für Nietzsches erste Aphorismenbücher, sondern die Aphorismen Swifts.

In der englischsprachigen-humoristischen Literatur um Twain, Sterne und Swift entdeckt Nietzsche eine Lockerheit, die sich von den französischen Moralisten abhebt. So heisst es im Sterne-Aphorismus: «Die Franzosen sind eben zum Humor - und namentlich zu diesem humoristisch-Nehmen des Humors selber - zu ernsthaft.» ${ }^{251} \mathrm{Im}$ Wanderer wird diese Kritik nochmals verschärft: Es sei die «Unart geistreicher Franzosen», «lässig» zu wirken, jedoch stilistisch stets hochnäsig («dédain») zu schreiben. ${ }^{252}$ Das ernsthafte Schreiben kommt

247 MA 221, KSA 2, S. 181.

248 Die Werkausgabe wurde am 10. Februar 1876 gekauft, während für die Anthologie (Swift 1847) nur das Datum der Buchbindung, der 20. Juli 1878, bekannt ist, vgl. BN, S. 596. Leider ging die Werkausgabe verloren, weshalb auch keine Lektürespuren vorliegen.

249 Vgl. MA 44, KSA 2, S. 66f. und MA 54, KSA 2, S. 73 f. Die KGW gibt fälschlicherweise als Quelle für MA 44 das Swift-Büchlein an: «eigentlich Pope; vgl. das Swift-Büchlein, Berlin $1847,17, B N »(\mathrm{KGW}$ IV 4, S. 179).

$250 \quad$ MA 44, KSA 2, S. 67.

251 VM 113, KSA 2, S. 425.

252 Vgl. WS 93, KSA 2, S. 595: «Jene Unart geistreicher Franzosen, ihren besten Einfällen einen Zug von dédain beizugeben, hat ihren Ursprung in der Absicht, für reicher zu gelten, als sie sind: sie wollen lässig schenken, gleichsam ermüdet vom beständigen Spenden aus übervollen Schatzhäusern.» 


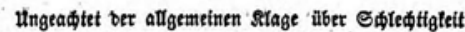
Der Berwaltbaber babe th teine शinifter ober anbere

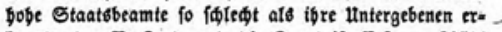

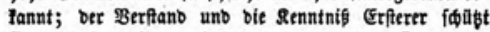

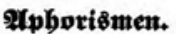

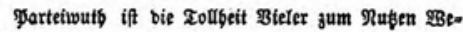
niger.

Riemals gab es eine Yartel ober Sette, worin bie utnviffenften niфt zugieid bie Seftigften waren, benn bie Biene if tein gefíâftigeres rofer, als ein Dumm-

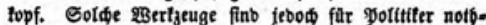
wenbig. Bielleidt verbäit es fid mit Staaten eben fo, wie mit 2 Banbubren, an benen ein tobtes Getwidt berabbăngen muf, um bie Bewegung ber feineren unb nüß̨Ii

Ein sönig if vietleiøt ein Berhigeug, ein Strobmann; bient er jebod baju, unjere feinbe ju f申́reden unb unfer Eigentbum gu fidern, fo if er gut genug;

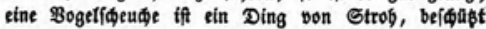
tebod unfer seorn.

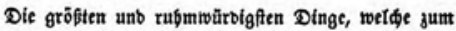

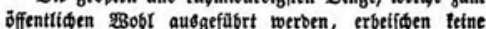
grofen Iñagen, fonbern grofe Reøtliфiteit. Dêfbalb brauфt ein Sönig nur bie Riebe feiner Itntertbanen ju verbienen, nur ein Rann von alfgemeiner Redttidteit unb gut beraţ̧en gu fein. fie bor einer Renge Sdelmereien; merben fie foledt, fo gefdiebt bies gewöbntid mebr burd ibre sage, als

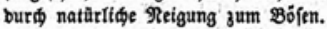

*

Gin Mann, ber an ber \$oemie in einem befudten Theife ber sauptfabt fpasieren gebt, wirb bon einer SRaffe פReniden umtingt; 3eber ift boffid, 3ever bietet ibm feine Dienfte an; ber ganze gärm bes Drtes f́deint jur wegen feiner ju entfteben. (5)bt berielbe Mann-fort,

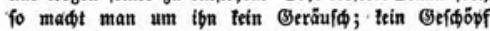
nimmt - शrotiz bon ibm, unb alle Iaffen ibn-botflommen vernaфtäfïgt vorùbergebn. Dies tft gan bas Bito eines Miniffers, wenn er fein Amt antritt unb wenn er baffetbe wieber abgibt.

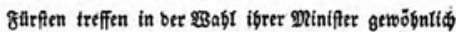

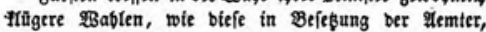
soelde zu tbrer Berfügung feben. DRebr als einmal babe i申 ben Rönig einen verftänbigen शRinifter wäb̆en fç̣en, aber nod niemals bemertt, baß seßterer feinen Einflup auf bie Befeßsung ber Stellen mit benjenigen 'Yetionen berwanbte, bie er felbft für bie pafientften biett. Einer ber gröjten Staat\$männer unferer Beit geftanb bie Sađe

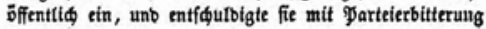
unb bie unbernünftigen forberungen feiner \$arteimit= gliteber.

Abb. 22 Die ersten beiden Seiten der «Aphorismen» aus Swift's Humoristischen Werken (1844, Bd. 2, S. 176/177)

also in Konflikt mit der Lässigkeit, welche wie oben gezeigt für das dynamische, emanzipierte und freie Autor-Leser-Verhältnis verantwortlich ist.

\section{Ambivalenz zwischen philologischem und lockerem Lesen im Notizbuch N IV 5}

Auch im Sommer 1879 kreuzen sich die beiden Lese- und Schreibideale: Einerseits wird das Aphorismenbuch als schriftliche Bildhauerei inszeniert, andererseits das Geschriebene in einem Titelentwurf als «Geschwätz» bezeichnet (Abb. 20). Es soll deshalb gezeigt werden, wie sich in den Arbeitsprozessen das eine Ideal aus dem anderen speist und umgekehrt. Auf der Doppelseite 29/30 des Notizbuchs N IV 5 finden sich in einer Folge von Einträgen ebenso lockere wie philologische Leseanleitungen:253

253 Die KGW hat diese Folge von Einträgen konsequent als ein «Fragment» gelistet, da sich die einzelnen Bestandteile tatsächlich ebenso wenig voneinander trennen wie als einen schlüssigen Entwurf identifizieren lassen, vgl. NL 1879, 47[7], KSA 8, S. 618f. (eigene Darstellung der räumlichen Aufteilung sowie Sperrungen durch Unterstreichungen ersetzt). 
O über diesen erhabenen halb blödsinnigen Ernst!

Giebt es denn kein Fältchen um dein Auge? Kannst du nicht einen Gedanken auf die Fingerspitzen nehmen und ihn emporschnellen? Hat dein Mund nur diesen einen verkniffenen verdrießlichen Zug? Giebt es keine Gelegenheit, die Achseln emporzuwerfen? Ich wollte, du pfiffest einmal und benähmst dich wie in schlechter Gesellschaft, als daß du so achtbar und unausstehlich sittsam mit deinem Autor zusammensitzest.

Ein Autor hat immer seinen Worten Bewegung mitzutheilen.

Hier ist ein Leser; er merkt nicht, daß ich ihn beobachte. Er ist mir von ehemals her bekannt - ein gescheuter Kopf: es schadet nicht, von ihm gelesen zu werden. - Aber er ist ja ganz verwandelt: bin ich es, der ihn verwandelt hat?

Kommata, Frage- und Ausrufezeichen, und der Leser sollte seinen Körper dazu geben und zeigen, daß das Bewegende auch bewegt.
Da ist er. Er ist ganz verwandelt.

Moral: man soll gutlesen lernen; man soll gutlesen lehren.

Die Moral ist: man soll nicht für seine Leser schreiben. Sie meinen, man soll nicht schreiben. Womöglich für sich - - -

Beachten Sie wie schnell er liest, wie er die Seiten umschlägt - genau nach der gleichen Sekundenzahl Seite für Seite. Nehmen Sie die Uhr zur Hand.

Es sind lauter einzelne wohlüberdenkbare Gedanken schwerere leichtere - und er hat für alle Einen Genuß! Er liest sie durch, der Unglückliche, als ob man je Gedanken-Sammlungen durchlesen dürfte!

Diese Doppelseite dokumentiert keine kohärente Haltung zum Lesen. Sie ist ein experimenteller Schreibraum, in dem Nietzsche ausprobiert, wie er sein Aphorismenbuch gelesen haben möchte.

Zum ersten Ideal eines philologischen Lesers, der in langer Arbeit die ertragreichen Sentenzen liest und immer wieder neu interpretiert, gehört wie gezeigt die Forderung nach einer Lesekunst. So liest man rechts oben: «Man soll gut lesen lernen, man soll gut lesen lehren.» Es gibt offenbar eine Moral des Lesens und daher auch Moralverstösse. So heisst es auf der unteren rechten Seite: «als ob man je Gedanken-Sammlungen durchlesen dürfte!» Und was die Genauigkeit angeht, mit der zu lesen ist, wird Nietzsche im Notat links unten sehr konkret: «Kommata, Frage- und Ausrufezeichen, und der Leser sollte seinen Körper dazu geben und zeigen, daß das Bewegende auch bewegt». Lesen ist hier körperliche Praxis. Der Leser muss 〈jedes Komma〉 beachten und die Ersatzmittel für die im Schreibmedium verlorenen Gebärden 
durch körperliche Sensibilität kompensieren. Dem wiederum entspricht die auf intensive Lektüre zielende Autorinszenierung, «an einer Seite Prosa wie an einer Bildsäule» zu arbeiten. ${ }^{254}$

Das zweite Ideal des lockeren Lesens zeigt sich im Notat links oben. Wiederum spielt die körperliche Dimension eine wichtige Rolle, weil Finger, Mund und Achseln bewegt werden sollen: Nietzsche kritisiert die Praktik des Stillsitzens, stillen Lesens und regungslosen Nachdenkens - allesamt historische Folgen der Entkörperlichung des Lesens. ${ }^{255}$ Philologisches und lockeres Lesen sind nicht kompatibel: Denn wie, wenn nicht stillsitzend, soll man philologisch lesen und sich auf die Syntax eines Textes konzentrieren?

Eine weitere Forderung des Notats links oben ist der Ungehorsam gegenüber dem Autor. Neben der körperlichen Lektüre wird der Leser aufgefordert, sich die Gedanken lust- und humorvoll anzueignen. Da Nietzsche das Notizbuch N IV 5 für die finale Phase des Druckmanuskripts vom Wanderer benutzt, kann kaum Zweifel daran bestehen, dass mit dem «halbblödsinnigen Ernst!» das vorliegende Buch bzw. die vorliegenden Aphorismen gemeint sind. Dem wiederum entspricht der Entwurfstitel vom «Geschwätz unterwegs». Hier meldet sich ein kumpelhafter Autor zu Wort, der lieber einen lockeren als einen «ernsten» Leser will. Das heisst aber auch: ein Autor, der mit seinem Leser freundschaftlich vertraut ist. Unter Freunden spricht man nicht «ernst», sondern darf scherzen und lachen. Dies kommt im Anfangsdialog zwischen Wanderer und Schatten zum Ausdruck: «Aber du hattest recht: gute Freunde geben einander hier und da ein dunkles Wort als Zeichen des Einverständnisses, welches für jeden dritten ein Rätsel sein soll. Und wir sind gute Freunde. Desshalb genug des Vorredens!» ${ }^{256}$ Interpretiert man Autor und Leser als Wanderer und Schatten, so bedarf es wegen der freundschaftlichen Vertrautheit keiner Vorrede.

Nietzsche entwirft keine Theorie des Lesens, vielmehr experimentiert er mit verschiedenen Leseanleitungen. Die Doppelseite 29/30 zeigt einerseits die Ambivalenz zwischen philologischem und lockerem Lesen, andererseits, wie eng die Leseanleitungen mit dem Material und der materialen Verfasstheit eines Aphorismenbuches zusammenhängen. Nietzsche versteht Lesen nicht nur als geistigen Prozess und auktorial geplante Wirkungsästhetik, sondern als körperliche Praktik entlang der Materialität von Text und Buch, demnach im Sinne von Klaus Müller-Wille als «Leseszene»: «Wie das Schreiben wird somit auch das Lesen durch eine Spannung zwischen Sprache, Instrumentali-

254 WS 95, KSA 2, S. 595 .

255 Vgl. dazu allgemein Schön 1987.

256 WS Rahmendialog, KSA 2, S. 538 . 
tät und Körperpraktiken bestimmt.» ${ }^{257}$ Lockeres und philologisches Lesen haben aufgrund der körperlichen Dimension ein gemeinsames Feindbild: das Durchlesen. Dies bestätigt ebenso die unverwendete Vorrede zum kursorischen Lesen («nicht durchliest, aber häufig aufschlägt») wie auch der Hinweis auf der rechten Heftseite («als ob man je Gedanken-Sammlungen durchlesen dürfte!»): Das mechanische Durchlesen beachtet weder das persönliche Wohlgefallen, die Materialität des Aphorismenbuches noch die körperlichen Gebärden des Stils. ${ }^{258}$

Gerade weil das Format des Aphorismenbuchs den Lesern keine eindeutige Leseszene nahelegt, ist es für Nietzsche umso wichtiger, wie er sich zu den praktischen Lektüremöglichkeiten positioniert. Schreibt man sehr kurze philosophische Texte, besteht die Gefahr, dass sie zu schnell und zu oberflächlich gelesen und entsprechend auch nicht als Philosophie aufgefasst werden; umgekehrt ist es aufgrund der Menge von Aphorismen nicht möglich, alle gleichermassen intensiv zu lesen. Es ist ein grosser Unterschied, ob man jeden Eintrag als «wohlüberdenkbar» betrachtet, oder ob man philosophische Kurztexte wie ein Geschwätz liest. ${ }^{259}$ Auf der einen Seite steht ein raffinierter Autor, der die Tugenden des philologischen Lesens hochhält, auf der anderen ein locker schreibender Autor, der sich blätternd Material für weitere Gedanken verschafft. Je nach Autorschaftsverständnis bietet sich das eine oder andere Lektüreverhalten an. Das Autorschaftsverständnis der Leser formiert deren Lektürepraktiken.

\subsubsection{Aktives Lesen}

Es soll hier weder das eine, noch das andere Lektüreideal als das Richtige befürwortet werden. Sie sind nicht trennscharf zu unterscheiden und haben ein gemeinsames Ziel: den aktiven Leser. Im Wanderer heisst es über sechs französische Moralisten - Montaigne, La Rochefoucauld, Labruyère, Fontenelle, Vauvenargues und Chamfort - ihre Bücher enthielten «mehr wirkliche Gedanken, als alle Bücher deutscher Philosophen zusammengenommen: Gedanken von der Art, welche Gedanken macht, und die - ich bin in Verlegenheit zu Ende zu definiren». ${ }^{260}$ Das zentrale Kriterium ist also die Anregung

257 Müller-Wille 2017, S. 42. Vgl. für den Begriff der «Leseszene» ebd., S. 41-50.

258 NL 1876/1877, 23[196], KSA 8, S. 473f. und obige Doppelseite 29/30. Vgl. auch den durchstrichenen Zusatz beim Entwurf von WS 6, KSA 2, S. 542f.: «daß Gedanken-Sammlungen nicht durchgelesen, geschweige denn vorgelesen werden dürfen, wenn sie nicht unschmackhaft werden sollen.» (KGW IV 4, S. 303 bzw. M I 3, S. 73).

259 NL 1879, 47[7], KSA 8, S. 619.

26o WS 214, KSA 2, S. 647. Vgl. zum aktiven Lesen u.a. NL 1876/77, 20[3], KSA 8, S. 361: «Eine Sentenz ist ein Glied aus einer Gedankenkette; sie verlangt, dass der Leser diese Kette aus 
des Denkens durch aktives Lesen. Nietzsche bleibt am Ende kryptisch und lässt offen, worin die Anregungskraft dieser Bücher bestehe - und regt damit performativ zum Nachdenken an. Aber der Hinweis der «Gedanken von der Art, welche Gedanken macht» sagt einiges über diese Buchtypen aus. Denn das aktive Lesen bezeichnet nicht nur eine Lese-, sondern auch eine philosophische Schreibtechnik. Es geht um Schreibweisen, welche die Leser anregen, miteinbeziehen und verführen, die nicht erklären, sondern vielfach interpretiert und ausgelegt werden können. Dass damit Aphorismenbücher zumindest mitgemeint sind, kann angesichts der vielen Maximen, Sprüche, Aphorismen und Essays bei den genannten Autoren nicht bezweifelt werden. Jost A. Müller schreibt über Lichtenberg: «Der Aphorismus wendet sich an aktive Leser. Hauptsächlich durch das aussparende Verfahren schafft sich der Aphorismus dieses Publikum, das er umgekehrt gerade auch deswegen benötigt.» ${ }^{261}$

Das aktive Lesen war eine bekannte Strategie, die auch Johann A. Bergk in seiner Kunst, Bücher zu lesen beschreibt und als Beispiel dazu Lichtenbergs «zerstreuete Aufsätze» nennt: «Wir müssen muthigere, kraftvollere Selbstdenker zu werden suchen». ${ }^{262}$ Gute Bücher sind Materiallieferanten, an welchen sich die Leser bedienen können, um eigene Gedanken anzuregen. Karl Hillebrand schreibt über die Grundaufgabe der Prosa: «Die oberste Tugend aber eines Prosaikers der den Namen verdient ist: zum Denken anzuregen, uns zu wecken, nicht uns einzuschläfern.» ${ }^{263}$ Und Hippolyte Taine konstatiert anhand der breitgefächerten Leserinteressen, dass die Hauptsache sei, man werde angeregt und könne diskutieren: «man denkt, um zu denken [...].» ${ }^{264}$ So loben wiederum zeitgenössische Rezensenten den Stil von Taines Geschichte der englischen Literatur - die Nietzsche ungeduldig Band für Band bestellte wie folgt: «wo sie [Taine's Darstellung] zum Widerspruch reizt oder eine Lücke lässt, zwingt sie jeden ernsten Leser zum selbständigen Erkennen.» ${ }^{265}$ In diesem Sinne bezeichnet Nietzsche in den Vermischten Meinungen eine Sentenz

eigenen Mitteln wiederherstelle: dies heisst sehr viel verlangen. Eine Sentenz ist eine Anmaassung. [...] Eine Sentenz muss, um geniessbar zu sein, erst aufgerührt und mit anderem Stoff (Beispiel, Erfahrungen, Geschichten) versetzt werden.» Vgl. auch VM 127, KSA 2, S. 432; N. an Overbeck, 23.6.1879, Nr. 859, KGB II 5, S. 420: «Nur Worte, lieber Freund! Die Gedanken wirst Du suppliren.» Die Formulierung erinnert an Reé 1875, S. 3.

261 Müller 1967, S. 99.

262 Bergk 1799, S. $363,366$.

263 Hillebrand 1875 , S. 295 .

264 Taine 1878 , Bd. 2, S. 212.

265 Chaulieu/Gosche 1870, S. 131. Ebenso findet sich bei Taine eine intensive Auseinandersetzung über die Beziehung zwischen Theaterbühne und Aktivierung der Phantasie beim Publikum (vgl. Taine 1878, Bd. 1, S. 356-359). 
von Homer als «Text ohne Ende für den Denkenden». ${ }^{266}$ Der Optimalfall einer Sentenz liegt im Auslösen einer unaufhörlichen Anregung und Reflexion.

Aphorismenbücher zielen auf das aktive Lesen. Das zeigt etwa die Rückmeldung von Paul Rée zu Menschliches, welche Nietzsche im Mai 1878 in einem Brief an Peter Gast referiert:

Rée sagt, er habe eigentlich nur Einmal durch ein Buch eine gleiche Stimmung produktiven Genießens erfahren, durch Eckermann's Gespräche; ganze Hefte von Reflexionen seien schon entstanden. Das aber ist das Beste, was ich erhoffte - die Erregung der Produktivität anderer und die «Vermehrung der Unabhängigkeit in der Welt» (wie J. Burckhardt sagte). ${ }^{267}$

Aktives Lesen leitet an zu eigenem Denken, Schreiben und zu Unabhängigkeit. Damit ist einmal mehr das emanzipatorische Potenzial vom Lesen vermischter Gedankensammlungen angesprochen, welches im Kapitel 3.4.3 zur Selbstaufklärung besprochen wird. Aphorismen regen an zu eigenen Notizen, Gedanken, Reflexionen bzw. zu Schreibzeug, Notizbüchern und Heften. Damit reiht sich das aktive Lesen in die antike Tradition der Selbsttechniken ein, gemäss denen sich Lesen und Schreiben abwechseln sollen. ${ }^{268}$ Die Herausforderung für den Autor besteht darin, sein Buch besonders fruchtbar zu gestalten.

\section{Das Unvollständige und das Rätselhafte}

Laut Vivetta Vivarelli zielen Nietzsches stilistische Vielfalt, die Leichtigkeit ebenso wie die Strenge auf die Leserverführung und damit auf das aktive Lesen. ${ }^{269}$ Im Wanderer werden zwei zusammenhängende Strategien hervorgehoben: Das Unvollständige und das Rätselhafte. So notiert Nietzsche 1876 über die «Kunst des Novellisten», dass sie versuche, auf «jede Weise die erfindende Fähigkeit des Lesers zu erregen, als ob er ein Räthsel rathen sollte; dieses aber dann so zu lösen, daß es den Leser doch noch überrascht.» ${ }^{270}$ Anstatt das Fragmentarische eines philosophischen Textes zu einer höheren Kunst zu

\footnotetext{
266 VM 212, KSA 2, S. 469.

267 N. an Gast, 31.5.1878, Nr. 723, KGB II 5, S. 329.

268 Foucault 2001, Bd. 4, S. 509. Die Stelle findet sich in «Über sich selbst schreiben» (ebd., S. 503-521).

269 Vivarelli 1998, S. 162: «In Wirklichkeit erscheinen die Masken der Leichtigkeit, der schneidenden Dichte und der stilistischen contrainte, die zwar untereinander so verschieden, doch einig in ihrer Abneigung gegen die zur Schau gestellte und simulierte Tiefe eines emphatischen Stils sind, als ein Köder, um den Leser zu verführen.» Vgl. auch Greiner 1972, S. 16: Nietzsche nenne «implizit als Voraussetzung für einen geglückten Aphorismus dessen Vermögen, den Leser zu eigenem Nachdenken anzuregen.»

270 NL 1876, 23[91], KSA 8, S. 435f.
} 
stilisieren, fokussiert Nietzsche auf dessen philosophische Wirksamkeit. Dies wird in Menschliches beschrieben:

Das Unvollständige als das Wirksame. - Wie Relieffiguren dadurch so stark auf die Phantasie wirken, dass sie gleichsam auf dem Wege sind, aus der Wand herauszutreten und plötzlich, irgend wodurch gehemmt, Halt machen: so ist mitunter die reliefartig unvollständige Darstellung eines Gedankens, einer ganzen Philosophie wirksamer, als die erschöpfende Ausführung: man überlässt der Arbeit des Beschauers mehr, er wird aufgeregt, das, was in so starkem Licht und Dunkel vor ihm sich abhebt, fortzubilden, zu Ende zu denken und jenes Hemmniss selber zu überwinden, welches ihrem völligen Heraustreten bis dahin hinderlich war. ${ }^{271}$

Der Autor überlässt also die Wertschätzung und sogar das Verständnis einer Rede, eines Textes oder eines Kunstwerks der «Arbeit des Beschauers» bzw. der Arbeit des Lesers. Die Leser ernten Stolz für ihre Bemühungen und eine angenehme Aufregung. Das «Unvollständige» ist eine philosophische Technik der Wirksamkeit. Dass diese Erkenntnis im ersten Aphorismenbuch Nietzsches auftaucht, ist kein Zufall, denn Aphorismenbücher können unmöglich «vollständig» verstanden werden. Stets bleiben die Lektüren bruchstückhaft und die Auslegungsvarianten unzählig. Das hängt auch mit dem vergleichsweise digressiven Aphorismenstil zusammen, welcher gemäss Jost A. Müller «die denkbaren Beziehungen» vervielfältige. ${ }^{272}$ Die Leser werden zu Mitschöpfern der Gedanken, weil sie dieselben aus dem Text heraus erdenken müssen. Selbiges gilt von einem rätselhaften Stil, der die Leser anregt, den Text zu klären. So verführen rätselhafte Worte, Texte, Werke, Verweise etc. die Leser dazu, sich anzustrengen. Das wird bei Nietzsche auch typografisch artikuliert, hauptsächlich durch die seinen Stil kennzeichnenden vielen Gedankenstriche und Sperrungen, welche sich mitunter an den Aphorismenenden finden und Einsatzstellen für die Leseraktivität bilden. ${ }^{273}$

271 MA 178, KSA 2, S. 161f. Es handelt sich um den Vorgänger vom Aphorismus «Reiz der Unvoll ko m me nhe it » aus der Fröhlichen Wissenschaft (FW 79, KSA 3, S. 434f.).

272 Müller 1967, S. 101.

273 Daniela Langer schreibt dazu: «Widersprüche und Wortspiele schaffen semantische Leerstellen, die vom Leser gefüllt werden müssen, und auch die graphische Rahmung von Sätzen durch Punkte und Gedankenstriche führt den Leser über den Text hinaus und in das eigene Denken hinein. Schreibverfahren und Leserbezug sind also kaum voneinander zu trennen.» (Langer 2005, S. 75) Vgl. für den denkaktivierenden Gebrauch von Gedankenstrichen beispielsweise WS 182, KSA 2, S. 502; WS 213, KSA 2, S. 508; WS 317, KSA 2, S. $549 f$. 
In einem unverwendeten Entwurf des Rahmendialogs hat Nietzsche den Genuss dieses Ratespiels inszeniert, indem die metaphorische Bedeutung des Schattens auf die Leser gesetzt wird:

D er S ch at te n. Wahr oder unwahr, deine Worte thun mir wohl: waren sie auch aufrichtig gesprochen? fast klang mir's, als ob deine Eitelkeit dir sie eingeflüstert hätte. Ein redender Schatten ist aber eine Seltenheit, auf welche es erlaubt ist eitel zu sein; deshalb halte ich deine Freude für aufrichtig. Der Wand e re r. Du kannst also nicht im Herzen lesen, aber liebst es, Vermuthungen zu machen, was darauf geschrieben steht? Das liebe ich auch. Der Schatten. Jetzt bist du es, der eine Gleichheit zwischen uns wahrnimmt. ${ }^{274}$

Zunächst ist da die Einsicht, dass Worte auch dann guttun können, wenn sie nicht aufrichtig sind, das heisst weder der Intention noch der Redlichkeit des Autors entsprechen. Umso mehr kann der Schatten-Leser Vermutungen anstellen: In diesem Beispiel vermutet er die Eitelkeit als Grund. Oder allgemein gefasst: Er interpretiert den Autor. Der Wanderer-Autor wiederum bemerkt dies und macht sich darüber lustig, indem er auf die Unmöglichkeit «im Herzen zu lesen» hinweist. Die eigentliche Autorintention, so redlich das Geschriebene sein mag, kann vom Leser nie sicher festgestellt werden. Diese Unergründlichkeit und die gleichzeitige Lust, «Vermuthungen» anzustellen, sind zwei grundlegende Merkmale der Aphorismenlektüre. Wenn der Wanderer als Autorfiguration nun zugibt, dass auch er das liebt, so heisst dies schlicht, dass auch er gerne liest und - dass auch er Leser seines Geschriebenen ist. Die Gemeinsamkeit von Autor und Leser besteht also gerade nicht im gemeinsamen und einheitlichen Verständnis, sondern in der Lesepraxis.

Mit der Unvollständigkeit übernimmt Nietzsche eine traditionsreiche wirkungsästhetische Strategie. Schon Montaigne lobte Maler, welche durch Verdunkelung zum Rätsel verführen und schalt Autoren, welche «alles» sagen wollen, weil sie einen überdrüssig machten. ${ }^{275}$ Und das Nietzsche wohlbekannte Handorakel von Balthasar Gracian empfiehlt, «Keinen allzu deutlichen Vortrag haben»: «Die Meisten schätzen nicht was sie verstehn; aber was sie nicht fassen können, verehren sie. Um geschätzt zu werden, müssen die Sachen Mühe kosten: daher wird gerühmt, wer nicht verstanden wird.» ${ }^{276}$ Womöglich kannte Nietzsche sogar die folgende Stelle aus Tristram Shandy, welche grosse Nähe zum Reiz des Unvollständigen aufweist: «The truest respect which you can pay to the reader's understanding, is to halve this matter amicably, and

274 KGW IV 4, S. 302 bzw. im Arbeitsheft M I 3, S. 88, 89.

275 Montaigne 1985, Bd. 3, Kap. V, S. 134 f.

276 Vgl. Gracian 1871, S. 162. 
leave him something to imagine, in his turn, as well as yourself.» 277 Es ist bezeichnend, dass in Rées Definition von Sentenzen, welche gleich zu Beginn der Psychologischen Beobachtungen gegeben wird, den Lesern bloss eine rekonstruierende Aktivität zugestanden wird: «Sentenzen sind Gedankenextract, den sich jeder nach seinem Geschmack verlängern kann. Eine solche Schreibweise ist zu empfehlen.» ${ }^{278}$ Der Sentenzenstil hat den Anspruch, dass das Gelesene in der Kontinuität («Verlängerung») des vom Autor bereitgestellten Textes («Extract») steht. Dieser Anspruch wird beim lockeren Lesen zunehmend unkontrollierbar.

\section{Witz und Konversation}

Die Vereinigung von philologischer und lockerer Lektüre im aktiven Lesen kann anhand der traditionsreichen Unterteilung in Urteilskraft und Witz illustriert werden. ${ }^{279}$ Der lockere Stil regt den Witz der Leser an, bringt sie auf neue Gedanken oder dazu, vermeintlich Verschiedenes zusammenzudenken. Das philosophische Potenzial des Witzes für Schreiben und Lesen beschreibt Lichtenberg in seinen Sudelbüchern: «Der Witz hascht näher oder ferner vom Ende eine Ähnlichkeit, und der Verstand prüft sie und findet sie richtig, das ist Erfindung. So war Sir Isaac Newton.» ${ }^{280}$ Dies ist mitunter eine versteckte Geniekritik. So schreibt Lessing über den Witz: «das Genie liebt Einfalt; der Witz, Verwicklung.» ${ }^{281}$ Petra McGillen hat die erfinderische Wirkung des Witzes an Lichtenbergs Vorlesungsweise analysiert. Anstatt von einem fertigen Manuskript abzulesen, benutzte Lichtenberg immer wieder Sudel-Notizen und Anmerkungen, was zu einem freien und unterhaltsamen Unterrichtsstil führte. ${ }^{282}$ Die lockere Anordnung der Notizen ermöglichte Lichtenberg, seinen Witz einzusetzen und dessen Stärke, das schnelle Kombinieren und Schliessen zu nutzen.

Wusste Nietzsche, dass sein Konzept des aktiven Lesens - ein anregender Stil und ein findiger Leser - nicht weit entfernt von der neuen Konversationsdefinition des Brockhaus von 1875 war? Dort steht: «Aber eine Unterhaltung

277 Sterne 1978, Bd. 1, S. 126.

278 Rée 1875 , S. 3.

279 Vgl. allgemein Winkler/Goulding 2010; Knörer 2007.

$280 \quad$ Lichtenberg 1968, Bd. 1, F 1195, S. 633.

281 Lessing 1973, S. 369.

282 Vgl. McGillen 2016. Dies regte auch den Witz der Studierenden an: In den studentischen Abschriften finden sich pointierte Zuspitzungen, die in den Vorlesungsunterlagen von Lichtenberg nicht zu finden sind. Andere Studierende fanden das offenbar nicht so <witzig〉 wie Lichtenberg selbst. Sie kritisierten, dass Lichtenberg die «hohen Schlüsse der tiefsten Vernunft» in «artige ganz allerliebste Einfälle» umwandelte (zit. n. ebd., S. 524; McGillen verweist ihrerseits auf die studentischen Testimonials). 
soll nichts ergründen, nichts erledigen, sondern alles nur leicht berühren und anregen; es kommt dabei nicht darauf an, viel Witz zu zeigen, als andere solchen finden zu lassen, und wer andere so zu stimmen weiss, dass sie sich und der Gesellschaft gefallen, der besitzt das Geheimnis des feinsten Conversationstons.» ${ }^{283}$ Der geschwätzige Rahmendialog zwischen Wanderer und Schatten entspricht einer zeitgleichen historischen Veränderung des Konversationsbegriffs, unter dem man nicht mehr die gelehrte Unterhaltung, sondern zunehmend das lockere und anregende Gespräch verstand. Die geschwätzige Konversation wurde im 18. Jahrhundert in Frankreich als lockere Form der Verständigung über gesellschaftliche Themen genutzt. ${ }^{284}$ Über Yorick heisst es in Tristram Shandy, dass dieser sich kaum vor Gelegenheiten retten kann, «his wit and his humour» zu verteilen. ${ }^{285}$ Die philosophische Auslegung des Anfangsdialogs als Platon-Kritik bekommt hier einen zeitgenössisch historischen Rahmen. Die Leser werden unartig gegenüber den Autoren, weil dem lockeren, gewitzten Lesen der grosse Respekt vor Text und Autor sowie der beständige Wille, im Andenken an die intentio auctoris, den Sinngehalt zu ermessen, fehlt. Gemäss Angelika Linke geht es beim neuen Konversationsverständnis darum, «durch eine flüchtige Vielfalt von Gesprächsinhalten den Gesprächspartnern und -partnerinnen genügend Raum und Anknüpfungspunkte zur Selbstdarstellung zu geben.» ${ }^{286}$ Das lockere Lesen birgt deshalb die Gefahr (und das Potenzial), dass die intentio auctoris sekundär wird.

\section{Aktives Lesen vs. intentio auctoris}

Je freier geblättert, gelesen und exzerpiert wird, desto weniger spielt die Projektion auf den Autor eine Rolle. Deshalb müssen mit Blick auf Nietzsches Werkpolitik folgende zwei Lektüremodi unterschieden werden: a) der Autor als Urheber des aktiven Lesens und der vielfältigen Interpretationsmöglichkeiten; b) die aktiven Leser, welche sich über den Stil und die Verfasstheit eines Buches hinwegsetzen. Für beide Varianten gibt es Hinweise.

(a) In den Vermischten Meinungen wird die Leseanweisung gegeben, dass der Leser aktiv sein und Einwände vorbringen soll.

Es giebt gewiss manchen kraft- und sinnvollen Leser, der hier einen guten Einwand zu machen versteht. Der Plumpen und Böswilligen halber soll es doch einmal gesagt werden, dass es hier wie so oft in diesem Buche, dem Autor eben auf

283 Brockhaus 1876, Bd. 4, S. 964.

284 Vgl. Naumann 2016.

285 Sterne 1978, Bd. 1, S. 29.

286 Linke 1996, S. 146. 
den Einwand ankommt, und dass manches in ihm zu lesen ist, was nicht gerade darin geschrieben steht. ${ }^{287}$

Der Hinweis, dass es dem Autor auf Einwände ankäme, zeigt, dass die Lese-Aktivität zum auktorialen Konzept gehört. Der Autor reklamiert mit dieser Leseanweisung nicht den konkreten Einwand für sich, sondern die Tatsache, dass Einwände gemacht werden. Diese Autorschaft rühmt sich nicht mehr durch die Systematik und Verstehbarkeit des Geschriebenen, sondern durch das möglichst häufige Anregen des Lesers. Dass die Leser viele Einwände machen können, ist so gesehen ein Verdienst des Autors und seines Textes (kein Mangel!).

In diesem Sinne lobt Nietzsche Raffael, der seiner Sixtinischen Madonna zwei Figuren, Papst Sixtus II. und die heilige Barbara, an die Seite stellt, um einerseits verschiedene Publika zu erreichen und andererseits die Betrachter zu eigenen Deutungen anzuregen:

Mögen die Alten, die an das Beten und Anbeten gewöhnt sind, hier, gleich dem ehrwürdigen Greise zur Linken, etwas Uebermenschliches verehren: wir Jüngeren wollen es, so scheint Raffael uns zuzurufen, mit dem schönen Mädchen zur Rechten halten, welche mit ihrem auffordernden, durchaus nicht devoten Blicke den Betrachtern des Bildes sagt: «Nicht wahr? diese Mutter und ihr Kind - das ist ein angenehmer einladender Anblick?» [...] so wie es der Künstler von ihrer Kunst des Deutens und Hineinlegens auch erwarten durfte. ${ }^{288}$

Das komplexe Spiel von Autorschaft und Rezeption sieht Nietzsche hier vorbildhaft umgesetzt. Während die Gläubigen sich tendenziell im «ehrwürdigen Greise zur Linken» wiederfinden, der die Madonna und und ihr Kind als «etwas Uebermenschliches» verehrt; identifizieren sich die «edlen jungen Männer» mit der heiligen Barbara, welche durch ihren Blick die Madonna weniger im göttlichen Lichte, denn als irdisches Idealbild einer Wunschgattin erscheinen lässt. Die Vieldeutigkeit des Gemäldes erlaubt verschiedene Interpretationen und Sichtweisen, welche ebenso dem Autor, dem Gläubigen oder dem Kunstkritiker einen Genuss ermöglichen. Wichtig ist der Hinweis, dass der Künstler Raffael dies so erwarten durfte, also auf die Rezipierbarkeit und Wirkungsästhetik hin gemalt habe. ${ }^{289}$

(b) Während Raffael als Künstler für seine Publika präsent bleibt, können sich aktive Rezipienten auch über die Autorschaft hinwegsetzen. So findet

287 VM 175, KSA 2, S. 455.

288 WS 73, KSA 2, S. 585 f.

289 Vgl. ebd., S. 586. Dieselbe Konstellation behauptet Nietzsche im Wanderer auch für Rousseau, vgl. WS 216, KSA 2, S. 651. 
man bei Laurence Sterne, in dessen Buch Tristram Shandy, den Hinweis, dass die aktive Lektüre sich über schlechtgeschriebene Bücher hinwegsetzen kann und soll: «The mind should be accustomed to make wise reflections, and draw curious conclusions as it goes along; the habitude of which made Pliny the younger affirm, «That he never read a book so bad, but he drew some profit from it.»» 290 Plinius setzt sich über die Qualität der Bücher hinweg, indem er dank dem aktiven Lesen selbst aus schlechten Büchern eine ertragreiche Lektüre erntet. Der aktive Leser kann sich also durchaus Bücher nutzbringend aneignen, die ihn nicht verführen. Die intentio auctoris ist für dieses Anregungsspiel nur noch sekundär. Es ist diese Einsicht, welche im Wanderer unter dem Titel «Irrthum der Philosophen» ebenso humorvoll wie material simpel zugespitzt wird: «Der Philosoph glaubt, der Wert seiner Philosophie liege im Ganzen, im Bau: die Nachwelt findet ihn im Stein, mit dem er baute und mit dem, von da an, noch oft und besser gebaut wird: also darin, daß jener Bau zerstört werden kann und d o ch n o ch als Material Wert hat.» ${ }^{291}$ Die aktiven Leser betrachten Texte und Gedanken als Material, d.h. als Stoff für weitere Werke. Sie verehren nicht den Bau einer Philosophie bzw. die Autoren, sondern bedienen sich am Baumaterial. Dieses unabhängige, lockere Lesen funktioniert durch eine strukturelle Eigenheit von Texten, die Chladenius treffend beschreibt:

Eine Stelle, in so ferne sie allerhand Gedancken in uns zu erwecken im Stande ist, wird fruchtbar genennet. [...] Weil die Stellen offters mehrere Gedancken veranlassen, als der Verfasser gehabt, und dabey gedacht wissen will, so sind die Stellen offters fruchtbarer, als es der Verfasser sich einbildet. ${ }^{292}$

Jede Textstelle ist potenzielles Material für weitere Gedanken. Dieses Potenzial kann zwar wie gesehen durch den Schreibstil befördert werden, ist aber auch durch aktives Lesen realisierbar. So hält Novalis fest: «Der Leser sezt den Accent willkührlich - er macht eigentlich aus einem Buche, was er will. [...] Es giebt kein allgemeingeltendes Lesen, im gewöhnlichen Sinn. Lesen ist eine freye Operation. Wie und was ich lesen soll, kann mir keiner vorschreiben.»293 Es geht nunmehr darum, die Leser in produktive Zustände zu versetzen, in denen sie dem Text ihre eigenen Meinungen und Interpretationen angedeihen lassen können - sei es in Form von Gedanken, Gesprächen, Notizen,

290 Sterne 1977, Bd. 1, S. 65.

291 WS 201, KSA 2, S. 466.

292 Chladenius 1969, S. 90.

293 Novalis 1981, S. 6og. Es handelt sich um das Teplitzer Fragment Nr. 79 von 1798. 
Exzerpten etc. ${ }^{294}$ Doch trifft dies für Nietzsche zu? Ein Autor, der bloss noch das Anregungspotenzial seines Buches für sich reklamieren kann? Gewiss nicht: Die philologischen Leseanweisungen, das Spiel mit Schreibsituation und Persönlichkeit oder die Reflexionen über den Text als Material deuten auf eine Werkpolitik, die dem Autor letztlich ebenso zum Ruhm verhelfen soll wie seinen Texten (vgl. Kap. 4.2.3).

\section{Reisen und Lesen: «Interessant, aber nicht schön»}

Christian Benne hat bereits auf die Parallelen zwischen Lese- und Reisekunst bei Nietzsche hingewiesen. ${ }^{295}$ Für die Analyse des Wanderers dient diese Analogie zum Nachvollzug der Synthese zwischen dem lockeren und philologischen Lesen. In folgendem Beispiel geht die Kritik am touristischen Reisen nahtlos in jene am Lesen über:

Interessant, aber nicht schön.--Diese Gegend verbirgt ihren Sinn, aber sie hat einen, den man errathen möchte: wohin ich sehe, lese ich Worte und Winke zu Worten, aber ich weiss nicht, wo der Satz beginnt, der das Räthsel aller dieser Winke löst, und werde zum Wendehals darüber, zu untersuchen, ob von hier oder von dort aus zu lesen ist. ${ }^{296}$

Nietzsche vergleicht hier den Genuss von Landschaften und Texten. Beide Tätigkeiten vermischen sich mitten im Satz: «wohin ich sehe, lese ich [...].» Das Betrachten einer Gegend geht direkt über ins Lesen derselben. Beiden Praktiken ist gemeinsam, dass sie von der rätselhaften Sinnsuche geleitet werden. Die Analogie von Landschaftsbetrachtung und Textlektüre repräsentiert bei genauerem Hinsehen die Lektürepolitik von Nietzsches Aphorismenbüchern. Der Entwurf zum obigen Aphorismus 126 steht im Notizbuch N IV 1. Richtet man dort den Blick auf die gegenüberliegende Seite, liest man folgende Notiz: «Montblanc bei Genf / Gehirnfreude / fälschlich vikarirend». ${ }^{297}$ Es handelt

294 So spricht Elisabeth Décultot in ihrem historischen Abriss von Exzerpierpraktiken von einer «subjektive[n] Wende der Exzerpierkunst», nach welcher die eigene Anregung und Produktivität in den Vordergrund rückte (2014a, S. 31). Während fest klassifizierte Exzerptsammlungen («collectanea») eher dem philologischen Lesen entsprechen; verfahren die vermischten Aufzeichnungen in freier Ordnung («miscellanea») mehr wie das lockere Lesen (vgl. ebd., S. 29). Geht es im einen Fall v.a. um die Suche zitierbarer Sentenzen, kann im anderen Fall jede Textsorte als Material dienen (vgl. dazu auch Blair 2010, S. 86).

295 Vgl. Kap. «4.1 Lesekunst und Reisekunst» in Benne 2005, S. 151-170.

296 WS 126, KSA 2, S. 6o8. Vgl. auch den Entwurf in KGW IV 4, S. 326.

297 N IV 1, S. 24 (eigene Darstellung einer Transkription der früheren HyperNietzscheEdition). 
sich um den Entwurf zum Aphorismus 207, in dem diese Stichwortliste verständlich wird:

Falsche Berühmtheit. - Ich hasse jene angeblichen Naturschönheiten, welche im Grunde nur durch das Wissen, namentlich das geographische, Etwas bedeuten, an sich aber dem schönheitsdurstigen Sinne dürftig bleiben: zum Beispiel die Ansicht des Montblanc von Genf aus - etwas Unbedeutendes ohne die zu Hülfe eilende Gehirnfreude des Wissens; die näheren Berge dort sind alle schöner und ausdrucksvoller, - aber «lange nicht so hoch», wie jenes absurde Wissen, zur Abschwächung, hinzufügt. Das Auge widerspricht dabei dem Wissen: wie soll es sich im Widersprechen wahrhaft freuen können!

Nietzsche beschreibt, wie eine Landschaftsaussicht durch ein geografisches Wissen zwar enträtselt werden kann - indem man den Mont Blanc sieht wie man aber dadurch die schöneren und ausdrucksvolleren Berge verpasst: Das Wissen schaut mit. Erst dem touristischen Blick gelingt es, eine Landschaft auf einen einzigen und erschliessbaren Sinn hin zu betrachten und damit gemäss Nietzsche die restliche Vielfalt zu verpassen. Mit dem Mont Blanc exemplifiziert Nietzsche seine These an einem Prototyp der touristischen Sehenswürdigkeit. ${ }^{298}$

Nimmt man die Tourismuskritik zu obiger Lektüreanweisung hinzu, bietet sich folgende Interpretation an: Texte sollen sich wie Landschaften präsentieren, welche einen verborgenen Sinn haben. Dies regt die Leser an, die Landschaft und ihre Vielfalt zu erkunden und über den vielen «Winken» und neuen «Rätseln» zum «Wendehals» zu werden. Die Leser sollen durch einen rätselhaften Sinn zu einer möglichst vielfältigen Lektüre angeregt werden. Die Tourismuskritik fliesst hier nicht rein negativ ins Lektüreverständnis ein. Vielmehr soll die Leseraktivität sich am scheinbar verborgenen Sinn entzünden gleichsam als 〈Trigger〉 - um sich dann auf der Suche in den zahlreichen Hinweisen, Details und Lesarten zu verstricken. Der Unterschied zum touristischen Blick besteht also darin, dass es den eindeutigen Sinn - die Sehenswürdigkeit nicht gibt. Das trifft besonders auf den gesprächigen Stil vom Wanderer zu. Die Leser bekommen durch den «mal〉 ernsten und «mal〉 lockeren Stil sowie durch die verminderte paratextuelle Leserführung keine Anhaltspunkte über den verborgenen Sinn. Sie müssen selbst Überschriften und zusammenfassende Erkenntnisse herauslesen, werden sich aber nie sicher sein können, ob damit nun die Textgegend «enträtselt» ist. Es ist sehr treffend, wenn Nietzsche diese Tätigkeit zwar als «interessant, aber nicht schön» betitelt. Es handelt sich nämlich um eine Anstrengung, um eine angeregte Suche ohne klares Ziel.

298 Vgl. für den Blick auf die Alpen Seger 2005, S. 15-36. 
Damit ist einmal mehr die Praktik des Wanderns angesprochen, weil in ihr Genuss und Anstrengung, Bewegung und Zielabwesenheit sowie Aussichten und Blickverengungen zusammenkommen.

Aus diesen Gründen findet sich auch die Kritik am modernen Lesen als Tourismuskritik wieder: «Bei der ungeheuren Beschleunigung des Lebens wird Geist und Auge an ein halbes oder falsches Sehen und Urtheilen gewöhnt, und Jedermann gleicht den Reisenden, welche Land und Volk von der Eisenbahn aus kennen lernen.» ${ }^{299}$ Hier wird die moderne Hast in Form der touristischen Reisegeschwindigkeit mit der sich mechanisch fortbewegenden Eisenbahn kritisiert. Auf das Problem des Lesens übertragen, ist die Fortbewegung per Eisenbahn das mechanische Durchlesen.

Stendhal beschreibt in den Promenades dans Rome die verschiedenen Stadien eines Romreisenden. Wer als Neuling nach Rom gehe, sei aufgrund der Überfülle an Sehenswürdigkeiten überfordert. Erst nach und nach kommt Stendhal ins höhere Stadium des Dérive:

Sortis de chez nous, ce matin, pour voir un monument célèbre, nous avons été arrêtés en route par une belle ruine, et ensuite par l'aspect d'un joli palais où nous sommes montés. Nous avons fini par errer presque à l'aventure. Nous avons goûté le bonheur d'êtreà Rome en toute liberté, et sans songer au devoir de voir. ${ }^{300}$

Ohne die Pflicht, etwas Bestimmtes anzuschauen, lässt sich Stendhal treiben und flaniert durch die Stadt. Erst aus dieser Freiheit heraus beginnt er wieder mit dem ernsthaften Studium einzelner Objekte. ${ }^{301}$ In der höchsten Form des Reisens lässt man sich gelegentlich treiben, um dann aus angeregter Freiheit ein Detailstudium zu betreiben. Beide Praktiken ergeben zusammen das optimale Reiseerlebnis. Übertragen auf die Textgegenden ist das Aphorismenbuch wie die Stadt Rom: Man kann eine Gedankensammlung kursorisch lesen und an interessanten Stellen verweilen, um sich einer detaillierten Lektüre zu widmen. Die Bedingung beider Strategien ist die Zeit, welche man dem Buch bzw. der Stadt Rom widmen muss, um ins höchste Stadium zu gelangen. Josef Hofmiller beschreibt dies treffend: «Das einzige Mittel freilich, sich in Rom einzuleben, ist:lange zu bleiben (das einzige und kein schlechtes Surrogat, nebenbei gesagt: immer wieder hinzugehen [sic].» ${ }^{302}$ Wiederum auf das Buch bezogen

\footnotetext{
299 MA 282, KSA 2, S. 231.

300 Stendhal 1853 , S. 16; vgl. auch S. 15.

301 So nimmt er sich vor, das Kolosseum anzuschauen und dieses erst zu verlassen, wenn er alles genau studiert habe, vgl. Stendhal 1853, S. 166 .

302 Hofmiller 1928, S. 105.
} 
bedeutet das: zyklische Relektüre. Die Synthese von lockerem und philologischem Lesen findet sich in der Tourismuskritik.

Dies kann auch an Jacob Burckhardts vielfach neu aufgelegtem Buch Der Cicerone: Eine Anleitung zum Genuss der Kunstwerke Italiens illustriert werden. Die Vorrede beginnt wie folgt:

Die Absicht des Verfassers ging dahin, eine Übersicht der wichtigern Kunstwerke Italiens zu geben, welche dem flüchtig Reisenden rasche und bequeme Auskunft über das Vorhandene, dem länger Verweilenden die nothwendigen Stylparallelen und die Grundlagen zur jedesmaligen Local-Kunstgeschichte, dem in Italien Gewesenen aber eine angenehme Erinnerung gewähren sollte. ${ }^{303}$

Burckhardt adressiert sein Buch gleichzeitig an die flüchtigen und intensiven Leser. Anstatt sich für einen Lesertypus zu entscheiden, schreibt man besser gleich für beide. Auch Stendhals Promenades dans Rome bedient beide Lesetypen. Sein Reisebericht ist eine ungezwungene Mischung aus philosophischen Gedanken, Alltagserlebnissen und persönlichen Eindrücken. ${ }^{304}$ Stendhal schreibt unaufgeregt und locker, so dass er sich im Vorwort sogar für das Buch entschuldigt. Der von den Lesespuren her zu schliessen am intensivsten gelesene erste Band von Nietzsches Lichtenberg-Ausgabe preist im Vorwort folgende Eigenschaften: «Witz und Laune mit Menschenkenntniß, philosophischer Geist mit Gelehrsamkeit, Scharfsinn mit Geschmack verbunden!» 305 Und Gerhard Hess sieht in der Neugier, der Zerstreuung und dem Lernpotenzial die wichtigsten zeitgenössischen Leser-Erwartungen an die Aphoristik von La Rochefoucauld. ${ }^{306}$ Nun war es der soeben zitierte Jacob Burckhardt, der seine eigene Lektüre von Nietzsches Schriften wie folgt kommentierte: «Es wird nun seine Zeit dauern, bis ich vom eiligen Durchkosten bis zum allmäligen Lesen des Buches vordringe, so wie es von jeher sich mit Ihren Schriften verhalte hat.» ${ }^{307}$ Burckhardt spricht hier offen die beiden Lesetypen an, mit denen

303 Burckhardt 1855, S. V.

304 Nietzsches Exemplar enthält Lesespuren und ist erhalten, vgl. HAAB C 682.

305 Lichtenberg/Kries 1867, Bd. 1, S. VIII.

306 Vgl. Hess 1957, S. 9: «das sachliche Interesse an der analytischen Leistung der Desillusionierung, auf dem Untergrund der Neugier und der Bestürzung über das eigene Innere; die Bereitschaft, daraus für sich zu lernen und seine «conduite` nach den neuen Erkenntnissen einzurichten; die Orientierung des Verhaltens an der sozialen Wirkung, die den Lebensaltern ihre gemäßen Eigenschaften zuweist; das Vergnügen, die Aufschlüsse über das menschliche Herz, die das Alltägliche als das Unbekannte offenbaren, im Austausch der Gedanken und in der Unterhaltung zum öffentlichen Thema zu machen und sie zur Zerstreuung und zum Vertreiben der Langeweile zu benutzen.»

307 Burckhardt an N., 13.9.1882, Nr. 144, KGB III 2, S. 289. Ähnlich reagierte Burckhardt schon auf die Zusendung der Vermischten Meinungen: «In den Tempel des eigentlichen Denkens 
sich «von jeher» Nietzsches Aphorismenbücher lesen lassen - kursorisch und intensiv.

Titel und Arbeitstitel des Wanderers - Der Wanderer und sein Schatten sowie «St. Moritzer Gedanken-Gänge» - enthalten die Ambivalenz des Wanderns, welches am Ende des 19. Jahrhunderts einerseits in die lustvolle, vergnügliche und gemütliche Tätigkeit des Spazierens übergeht, andererseits noch im Kontext des berufsbedingten oder gelehrten Reisens steht. ${ }^{308} \mathrm{Im}$ Wanderer ist deshalb mit Wandern ebenso das philologisch ernsthafte Lesen (bzw. die Bildungsreise) wie auch das lockere Lesen (bzw. das flanierende Reisen) gemeint. Die Analogie zwischen aktivem Lesen und Reisen vervollständigt sich in den Vermischten Meinungen: Denn aktives Lesen und Reisen regen zu eigenen «Handlungen und Werken» an. So heisst es im Aphorismus «R e is en de und ihre Grade»:

die vierten leben das Erlebte in sich hinein und tragen es mit sich fort; endlich giebt es einige Menschen der höchsten Kraft, welche alles Gesehene, nachdem es erlebt und eingelebt worden ist, endlich auch nothwendig wieder aus sich herausleben müssen, in Handlungen und Werken, sobald sie nach Hause zurückgekehrt sind. ${ }^{309}$

Das Aphorismenbuch kann wie die Stadt Rom von verschiedensten Touristen genutzt werden. Auch wenn nur die Leser «der höchsten Kraft» wiederum zu Schriftstellern werden, gibt es zahlreiche andere Weisen, das Aphorismenbuch zu lesen. Denn Aphorismen bieten gleichzeitig Erholung und philosophische Tiefgründigkeit, Weitblick und Detailstudium sowie blätterndes und philologisches Lesen. Es ist die doppelte Herausforderung von lockerem und philologischem Lesen, von Wandern und Flanieren sowie von Reisen und Tourismus, welche Nietzsches ersten Aphorismenbüchern abzulesen ist.

\subsubsection{Fazit}

Nietzsches Schreibideal ist nicht sein Schreibstil. Sein Lese- und Schreibideal von Menschliches basiert hauptsächlich auf dem Ideal des Sentenzenstils der französischen Moralisten. Im weiteren Fortgang zum Wanderer wird jedoch der lockere Stil als Schreibideal und -praxis immer wichtiger, was sich exem-

bin ich bekanntlich nie eingedrungen, sondern habe mich zeitlebens in Hof und Hallen des Peribolos ergötzt, wo das Bildliche im weitesten Sinne des Wortes regiert. Und nun ist in Ihrem Buche gerade auch für so nachlässige Pilger wie ich bin, nach allen Seiten hin auf das Reichlichste gesorgt.» (Burckhardt an N., 5.4.1879, Nr. 1176, KGW II 6/2, S. 1071).

308 Für das «Wandern als Bild der mühsamen wissenschaftlichen (philologisch geprägten) Arbeit», vgl. Benne 2005, S. 162-165, hier S. 164.

309 VM 228, KSA 2, S. 483. 
plarisch in den unverwendeten Vorreden sowie in Nietzsches Faszination für Mark Twain, Laurence Sterne und Jonathan Swift zeigt. Der Freigeist befreite sich aus dem engen Kothurn Voltaires und gesellte sich zu den lässigen Albernheiten Sternes. Freiheit ist nicht mehr die virtuose Illusionstechnik einer gefesselten Sprache, sondern ein verwirrtes Schwebegefühl der Leser. Gerade Sternes ungeordneter und lockerer Stil besitzt die gegenteiligen Eigenschaften des Sentenzenstils. 310

Innerhalb eines lockeren Stils lassen sich komplexe Autor-Leser-Dynamiken erzeugen. Dazu dient auch die Unvollständigkeit als Mittel, den Lesern mehr Anteil an der Lektüre zu geben. Die Rätselhaftigkeit eines skizzierten, aber nie klar fassbaren Sinns, regt die Leser zu aktiver und wiederholter Lektüre an. An Nietzsches Reflexionen zeigt sich, dass das zyklische Gelesenwerden nicht in erster Linie von dem einen dauerhaften Stil, sondern von den vielfältigen Lesepraktiken abhängt. Frei nach Friedrich Schlegel: «Classisch ist alles was cyclisch studirt werden muß.» ${ }^{311}$ Die materialen Buchobjekte und Wortreihen sind immer schon auf Dauerhaftigkeit angelegt: «Was sich aber nicht vorherbestimmen oder gar künstlich auf Dauer stellen lässt, ist die Art, wie etwas tatsächlich rezipiert wird (wenn dies denn geschieht).» ${ }^{312}$ Und weil man dieses «wie» nicht kontrollieren kann, wird es reizvoll, durch Schreibstrategien möglichst viele Rezeptionsweisen zu ermöglichen. Es steht den Lesenden frei, ob sie den Wanderer als kohärente Komposition oder als anregendes Allerlei lesen. Lockeres und philologisches Lesen kommen in Aphorismenbüchern zusammen und fördern das aktive Lesen: «Gedanken von der Art, welche Gedanken macht». ${ }^{313}$ Solche Gedanken sind an einen Stil, an ein Layout, an eine Werk- und Lektürepolitik gebunden. Nietzsches Denken findet nahe an der Buchmaterialität statt. An seinen Reflexionen zum Lesen lässt sich ein «kalkulierte[r] Umgang[ ] mit der Rezeptionssituation» beobachten. ${ }^{314}$

Die in der Nietzscheforschung immer wieder referierte philologische Leseanleitung für Nietzsches Schriften vermittelt ein simplifiziertes Bild der mittleren Schaffensphase. Das gilt mitunter für die besten Nietzschestudien. So stellt

\footnotetext{
310 Wie René Wellek feststellt, verkörpert Sterne und sein Rousseauismus vieles, was Nietzsche eigentlich ablehnte (vgl. 1977, S. 326).

311 Fragment 640 in Schlegel 1981, S. 139. Vgl. Nietzsches Charakteristika guter Prosa, nämlich «wieder und wieder gelesen zu werden» (WS 109, KSA 2, S. 599).

312 Heine/Zanetti 2017, S. 15. In diesem Sammelband werden die Strategien, einem Kunstwerk Dauerhaftigkeit zu verleihen, unter dem Begriff Transaktualität verstanden.

313 WS 214, KSA 2, S. 647.

314 Zanetti 2012a, S. 49. Dies sei auf das durch den Buchdruck nicht länger kontrollierbare «Rezeptionsverhalten» sowie auf die schwindende «Bindekraft von Regelpoetiken» zurückzuführen (ebd.).
} 
Wolfgang Müller-Lauter zwar die Ambivalenz der Leseanweisungen des mittleren Nietzsches fest, will jedoch gerade die blätternde Lektüre nicht als ernst gemeinte Aufforderung auffassen: «Wir würden uns freilich täuschen, wenn wir aus dieser oder ähnlichen Bemerkungen die Aufforderung zu einer unverbindlichen Lektüre entnehmen wollten.»315 Aus dieser einseitigen Haltung reproduziert sich das elitäre und kryptische Ideal einer auserwählten Leserschaft von höheren Menschen. Nietzsches eigene Entwürfe sowie die damals bevorzugte Lektüre der späten 187oer Jahre zeigen eine Ambivalenz von lockerem und philologischem Lesen. Diese Ambivalenz speist sich zumindest im Wanderer daraus, dass man das Buch praktisch gesehen «locker» lesen kann: Man kann darin blättern und schmökern. Das ernsthafte Lesen ist im Wanderer keineswegs als Zwang angelegt. Zu Recht schreibt Richard Schacht über die Nietzsche-Lektüre: «The difficulty is not (as in the case of Kant, or Hegel, or Heidegger) that he is so hard to read. On the contrary: unlike them he reads easily. But that only makes it all too easy to read him superficially».316 Deshalb muss auch Christoph Windgätter zumindest für die Aphorismenbände der mittleren Phase widersprochen werden, wenn er behauptet, dass Nietzsches Bücher dem flüchtigen, sinnsuchenden Leser im Wege stehen: «Nicht nur, weil sie sich mit anspruchsvollen Themen beschäftigen, sondern auch und vor allem, weil ihre druckgraphischen Inszenierungen einer ebenso flüchtigen wie bloß sinnsuchenden Lektüre im Wege stehen». ${ }^{317}$ Wie Nietzsches unverwendete Vorrede zeigte, lassen sich die mittleren Aphorismenbände bestens flüchtig und sinnsuchend durchkämmen (sonst hätte Nietzsche gar nicht paratextuell darauf reagieren müssen). Die medientheoretische Ausrichtung auf die philologische Lektüre ist übertrieben: Das physische Buchstabenlesen, der Buchstabe als «Körper der Schrift» (Rudolf Fietz) oder die Schrift als «autarkes Medium» (Windgätter), das «genuin graphematisch» funktioniere, mag für die Bonner Textkritik, nicht aber für Nietzsches mittlere Aphorismenbücher gelten. ${ }^{318}$ Windgätter glaubt Nietzsche zu sehr aufs Wort, wenn er schreibt bzw. zitiert, dass Nietzsches Bücher «ein Komplex voneinander abgesetzter Texte sind; zwar «kurz〉 geschrieben, aber «lang〉 zu lesen; zwar «in Stücken gegeben〉, aber deshalb kein «Stückwerk»». ${ }^{319}$ Von der Produktion her gesehen ist der Wanderer ein abgedruckter Zettelstapel, also durchaus ein Stückwerk.

\footnotetext{
315 Müller-Lauter 1991, S. 836. Vgl. auch Kofman 2014, S. 167: «Wie der Gebrauch der Metapher, zielt auch die aphoristische Schreibweise, indem sie eine philologisch unerbittliche Lektüre unternimmt, darauf, das Gemeine abzuschrecken.»

316 Schacht 1995 , S. XI.

317 Windgätter 2004, S. 16.

318 Fietz 1992, S. 393; Windgätter 2004, S. 18.

319 Windgätter 2004, S. 20. Die zitierten Wörter finden sich in VM 128, KSA 2, S. 432.
} 
Vivetta Vivarellis Ansicht, dass Nietzsches Aphorismen das «Ergebnis einer Straffungs- und Eliminierungsarbeit» seien, gilt für den Wanderer grösstenteils nicht. ${ }^{320}$ Für Vivarellis Beispiele, in denen Nietzsche längere Textstellen von Montaigne auf wenige Sätze verkürzt, mag dies als Exzerpiertechnik sicher gelten. ${ }^{321}$ In den Notizen aus dem Engadin gibt es jedoch fast keine Exzerpte. Vielmehr ist Nietzsches Schreibverfahren auf Einschübe hin angelegt. Er erweitert gesamthaft gesehen beim Wanderer seine knappen Notizen durch zwei, drei Überarbeitungsschritte zu kurzen Texten. Dies tut er meistens mit eingeschobenen Teilsätzen, was die Sprache im Vergleich zu einigen Sprüchen aus den Vermischten Meinungen und Menschliches gerade nicht knapp macht, sondern gesprächig und reichhaltig. Angesichts der vielen digressiven Aphorismen in den ersten drei Aphorismenbüchern, kann Nietzsches Stilideal eines Sentenzenstils nicht als Gattungsform für seine Prosa gelten. Wie gezeigt sind Nietzsches Aphorismen stilistisch gesehen näher an den englischsprachigen Humoristen als am französischen Sentenzenstils La Rochefoucaulds. Insofern ist auch Friedrich Kittlers These, den von Nietzsche 1879 benannten «Telegrammstil» mit der puren Verknappungsökonomie einer «Signifikantenlogik» gleichzusetzen, gerade für den Wanderer falsch. ${ }^{322}$ Die Bezeichnung «Telegrammstil» stammt aus der Korrekturkorrespondenz von $1879 .{ }^{323}$ Kittler schliesst fälschlicherweise von seiner Medientheorie auf Nietzsches Schreibverfahren und setzt deshalb Nietzsches Aphorismen mit kurzen und prägnanten Telegrammen gleich: «Der Wanderer und sein Schatten heißt demgemäß das Buch, darin Nietzsche zum erstenmal Telegrammstil probt.» ${ }^{324}$ Der Wanderer enthält keine Telegramme, sondern digressive, stilisierte und informelle

320 Vivarelli 1998, S. 48, Fussnote 33 .

321 Vgl. ebd., S. 83: «Wir sahen bislang, daß Nietzsche die Gedanken Montaignes verwertete, indem er sie drastisch verkürzte. Was bei jenem angenehm, liebenswürdig und mitteilsam ist, wird zugunsten eines konzisen Ausdrucks eliminiert, der die Kontrastwirkungen verstärkt.»

322 Kittler 2003, S. 230. Vgl. N. an Gast, 5.11.1879, Nr. 900, KGB II 5, S. 461: «Fahren Sie fort, bei der Corr[ektur] zu winken und zu warnen. Der Boden des Mißverständnisses ist bei dieser Schrift so oft in der Nähe; die Kürze, der verwünschte Telegrammstil, zu dem mich Kopf und Auge nöthigt ist die Ursache.» Während den Korrekturarbeiten am Wanderer kritisierte Gast, dass Nietzsche die Frauen im Aphorismus «Im Verkehr mit den Thieren» als Haustiere bezeichnete (WS 57 , KSA 2, S. 577f.). Nietzsche strich den Satz aufgrund der möglichen Irritation. Der Ausdruck «Telegrammstil» hat seither eine eigene Karriere in der Nietzscheforschung erlebt. D'Iorio hat darauf hingewiesen, dass Nietzsche einige Briefe in einem abgehackten telegrammartigen Stil verfasste, vgl. D'Iorio 2012, S. 28.

323 N. an Gast, 5.11.1879, Nr. 900, KGB II 5, S. 461.

324 Kittler 2003, S. 231. Vgl. ebd., S. 230: «Aus schlicht ökonomischen Gründen fordern Telegramme jene Wortverknappung, die bei Nietzsche den physiologischen Grund vierzehn kurzsichtiger Dioptrien hat.» 
Aphorismen. Ebenso wenig wie ein «Telegrammstil» lässt sich im Wanderer eine «mnemotechnische Prägnanz» (Friedrich Balke) von Inschriften beobachten. ${ }^{325}$ Wie Balke eigens hervorhebt, hat Nietzsche zwar den Wunsch einer leiblichen Gebärdenschrift, muss aber wie alle anderen Schriftsteller mit jenen zweidimensionalen Papierflächen arbeiten, die gerade nicht besonders einprägsam sind. Die Produktionsästhetik der kunstvollen Bildhauerei unterscheidet sich hier von der Schreibsituation. Nietzsche schliesst mit seiner Bildhauermetaphorik an den breiten Diskurs der «Feile» an, mit welcher man schreiben soll. ${ }^{326}$ Der ständige Verweis auf philologisches Lesen und bildhauerisches Schreiben ist auf eine moderne Werkpolitik zurückzuführen, welche durch die Inszenierung der Schreibarbeit zur gewünschten Lesepraktik anleiten will: «Hat die Arbeit am Text dem Autor genügend Schwierigkeiten gemacht und ihn entsprechend Zeit gekostet, darf er im Gegenzug auch erwarten, dass sich das Publikum darauf einlässt, anstatt nur eine schnelle und einmalige Unterhaltung zu avisieren.» ${ }^{327}$ Der Wunsch seitens der Autoren, intensiv gelesen zu werden, steht im Kontext der veränderten Lesepraktiken: Die bis ins 18. Jahrhundert vorherrschende «intensive Lektüre» konkurriert mit der im 19. Jahrhundert aufstrebenden «extensiven Lektüre». ${ }^{328}$ So sehr man aber die intensive Lektüre idealisierte, so wenig widerspiegelte sie die reale Lesepraxis. Nietzsches Leseanleitungen sind deshalb mitunter eine zeitgenössische Reaktion:

Während für den ungeübten Leser schnelles und flüchtiges Lesen tatsächlich zusammenfallen, da er zu einer effektiven kursorischen Lektüre nicht fähig ist, vermag der geübte Leser durch kursorische Lektüre viel mehr zu erreichen als

325 Balke 2011, S. 25: «Nietzsches aphoristischer Schreibstrategie als Vorbild dient: das «Epigramm als Stil〉, wobei neben der Kürze und Einprägsamkeit, also der mnemotechnischen Prägnanz dieses Stilmittels, seine Erscheinung in Form der Inschrift z.B. auf kultischen Gegenständen oder Grabmälern für Nietzsche die Wirksamkeit einer Schrift verbürgt, die sich nicht einer zweidimensionalen, mobilen und leicht zerstörbaren Schreibfläche anvertraut, sondern sich den Körpern, deren Bedeutung oder Funktion sie aussagt, dauerhaft aufprägt.»

326 Vgl. dazu Benne 2015a, Kap. «3.4.2. Feile und Fragment», S. 374-409.

327 Vgl. ebd., S. 350 und S. 349: «Eine gute Lektüre ist jene, die von ihrem eigenen zeitlichen Aufwand Rückschlüsse auf den zeitlichen Produktionsaufwand zieht. Zu diesem Zweck müssen Texte ihre Komplexität werkpolitisch anzeigen und ihre Entstehung in einer Weise zum Ausdruck bringen, dass der Leser sich zur intensiven Beschäftigung mit ihnen bemüßigt fühlt.»

328 Vgl. Engelsing 1978, S. 122: «Bis zum Ende des 18. Jahrhunderts war der typische Gewohnheitsleser ein intensiver Leser, der eine kleine Auswahl von Büchern oder ein einziges Buch immer wieder las, seit dem Ende des 18. Jahrhunderts ein extensiver Leser, der zahlreiche Bücher las und ein einzelnes selten oder überhaupt nicht wieder vornahm.» Generell provoziere die «Druckschriftlichkeit ein prinzipiell unkontrollierbares Rezeptionsverhalten» (Zanetti 2012a, S. 49). 
der ungeübte durch gründliche. [...] Damit wird, wenigstens zu einem guten Teil, die Vormeinung hinfällig, dass Qualität und Quantität der Lektüre miteinander konkurrieren und einander ausschließen müssen. Unter bestimmten Voraussetzungen kann es so sein. Aber unter anderen Voraussetzungen geschieht es ebensowohl, daß sie ineinandergreifen und sich wechselweise steigern. ${ }^{329}$

Ein Buch zu schreiben, das man vorzüglich kursorisch lesen kann und gleichzeitig von philologischer Lesekunst zu schwärmen, ist kein Widerspruch, sondern zeigt den historisch längst antizipierten Wandel der Lesementalität. Nietzsche bedient mit seinen Aphorismen gerade jene Leser am besten, welche seine Bücher intensiv und extensiv zugleich lesen. Gewinnt man einem Aphorismus nichts ab, wechselt man ohne grossen Zeitverlust zu einem anderen. Und wird man umgekehrt von einem Aphorismus stark angeregt, bleibt die intensive Lektüre gut machbar, weil die Aphorismenabschnitte nicht lang sind. Auf diese Weise verschränkt sich die kursorische mit der intensiven Lektüre. Das ist besonders für ein nicht fachliches Publikum komfortabel, das mit der Lektüre keinen systematischen Gewinn anstrebt. Eine solche «Stellenlektüre» «blättert, sie sucht sich heraus, was ihr paßt, fixiert sich auf die ansprechende, auf Anhieb überzeugende Passage.» ${ }^{330}$ Dies entspricht wiederum der Praktik des Wanderns, bei der man nicht alle Gegenden eingehend studiert, jedoch bei Interesse innehält und verweilt. Die digressive Prosa ist seit Montaigne ein Topos für die Gangart des Spazierens, weshalb das spazierende Notieren auch auf stilistischer Ebene umgesetzt ist. 331

Das aktive Lesen zeitigt viele Folgen in Nietzsches Werk. Im lockeren Stil des Wanderers entwickelt sich, was viele Textstellen in Also sprach Zarathustra charakterisiert: So ist Heinz Schlaffer aufgefallen, dass viele Sätze inkorrekt oder unvollständig seien, wodurch das Gefühl beim Leser erzeugt wird, man habe es im Unterschied zur abgeschliffenen Rede eines Rhetors mit einer vertraulichen Mitteilung unter Freunden zu tun. ${ }^{332}$ Die vielen Erzählstimmen, Literatursorten und rätselhaften Passagen maximieren bei konzentrierter Lektüre die Deutungsmöglichkeiten. Der mittlere Nietzsche versucht die Leser zu eigenen Gedanken und allenfalls zum eigenen Schreiben anzuregen. Je unabhängiger die Leser aber vom Textmaterial sind, desto weniger formbar werden sie für den Autor. Der Ruhm des Autornamens bedarf einer minimalen Passivität der Lesenden, damit sie ihr Leseerlebnis auf den Autor projizieren und sich

\footnotetext{
329 Engelsing 1978, S. 114. Vgl. zu kursorischer und blätternder Lektüre auch ausführlich Schulz 2015.

330 Stanitzek 1999, S. 254; vgl. auch Maye 2015, S. 144.

331 Vgl. Müller 1981, S. 37. Auch Rebecca Solnit (2014, S. 106) sieht im digressiven Stil die Übertragung der Bewegung des Wanderns in die Prosa.

332 Vgl. Schlaffer 2007, S. 81.
} 
für ein Werk die Chancen erhöhen, ein immer wieder gelesener Klassiker zu werden. So nahe Nietzsche an einem lockeren Stil und einer digressiven Prosa ist, so wenig will er den Anspruch aufgeben, dass seine Bücher philosophisch ernsthaft gelesen werden können. ${ }^{333}$ Aus den Manuskripten wird sichtbar, dass Nietzsche hin und her gerissen ist, mit welchen Schreib- und Leseidealen er seine Bücher inszenieren soll. Es gibt eine Spannung zwischen erwünschtem und gefürchtetem Umgang mit den entstehenden Büchern. Daher verwundert es nicht, dass die vielzitierten Leseanleitungen des philologischen Lesens die publizierten Vorreden und Schriften prägen; während sich im Wanderer eine ambivalente Lesehaltung zeigt, die Ernst und Vergnügen auf Seiten der Leser sowie Schliff und Lockerheit auf Seiten des Autors miteinschliesst. Das Aphorismenbuch ist die Lösung, diese beiden Ansprüche zusammenzuführen, wodurch jedoch ein Bedarf an vermittelnden Leseanleitungen entsteht, um die möglichen Lesepraktiken zu moderieren.

\subsection{Schreiben und Diätetik}

Nietzsche wandte sich in der kurzen Zeit zwischen Menschliches (erschienen am 14. April 1878) und dem Wanderer (erschienen Ende Dezember 1879) von der freigeistigen Kulturpolitik zum individuellen Alltag. Ging es in Menschliches noch um die Erhöhung einer ganzen Kultur durch philosophische Freigeister, so geht es im Wanderer um das Wohlergehen des Einzelnen im alltäglichen Leben. Zu diesem Zweck formuliert Nietzsche im Wanderer «Die Lehre von den nächsten Dingen», eine Diätetik, nach der man sich von Politik und Wissenschaft abwenden und dem eigenen Alltag zuwenden soll. ${ }^{334}$ Einfache Dinge wie Essen, Wohnen, Heizen oder Kleiden werden so zur primären Angelegenheit der philosophischen Selbstbeschäftigung. Nietzsches Botschaft lautet: «Wir müssen wieder gute Nachbarn der nächsten D in ge werden [...].» ${ }^{335}$ Die Diätetik prägt dabei nicht nur Nietzsches Philosophie, sondern auch seine Vorstellungen von Lesen, Schreiben und Autorschaft. Es sollen im Folgenden die Kulturpolitik der Freigeister und die Wissenschaftseuphorie in Menschliches dargelegt werden, um die zunehmende Politik- und Wissenschaftsskepsis im Wanderer nachzuvollziehen (3.3.1). Dann soll die an-

333 Eine produktive Ambivalenz, die weiterhin in seinen Werken zu finden sein wird. Beispielsweise 1887: «Ein Buch zum Denken, nichts weiter: es gehört Denen, welchen Denken Vergn ü gen macht, nichts weiter ...» (NL 1887, 9[188], KSA 12, S. 450).

334 NL 1879, 40[16], KSA 8, S. 581.

335 WS 16, KSA 2, S. 551 . 
stelle der Kulturpolitik eingesetzte Lehre der «nächsten Dinge» ausgeführt werden (3.3.2), um anschliessend den Vorrang dieser Diätetik vor der Kulturpolitik im Wanderer zu konstatieren (3.3.3). Im Zuge dieses Vorrangs erfolgt auch eine temporäre Abwendung vom Freigeist, was die kohärente Form einer freigeistigen Denkphase Nietzsches problematisiert. Mit der Lehre der «nächsten Dinge» kehrt Nietzsche einerseits wieder zu den antiken Lebensschulen, ihrem Fokus auf den Alltag, die Selbstsorge und die Freude am Leben zurück, andererseits zum diätetischen Zeitgeist des 19. Jahrhunderts (3.3.4). Anhand einiger von Nietzsche benutzten populären Diätetikratgebern kann die diskursive Verflechtung der «nächsten Dinge» und der zeitgenössischen Diätetik nachgewiesen werden. An der St. Moritzer Schreibsituation wird gezeigt, inwiefern Nietzsche dieses Verständnis von Schreibpraktiken in die Arbeiten am Wanderer einbezog (3.3.5). So findet sich die Diätetik ebenso in der Organisation seines Schreibverfahrens wie als philosophisches Modell seiner Lehre der «nächsten Dinge».

\subsubsection{Von der Kulturpolitik zur Diätetik}

Die Lehre der «nächsten Dinge» ist spezifisch für den Wanderer und richtet sich in bemerkenswerter Weise gegen Menschliches. Durch die separate Lektüre von Menschliches und dem Wanderer wird diese Umorientierung sichtbar.

\section{Wissenschaft und Kulturpolitik in Menschliches}

In Menschliches kommt die Wissenschaft erstmals zu einer eigenständigen und positiven Bedeutung. Nietzsche verwendet in der Erstausgabe als Motto ein Zitat aus dem Discours de la méthode von René Descartes, in dem dieser sein Leben der Erkenntnis widmet. ${ }^{336}$ Im Frühwerk war die Wissenschaft noch der Kunst unterstellt. Wissenschaft sei eine sokratische «Wahnvorstellung», eine Überschätzung des Denkens gegenüber dem Sein, welches nur durch Kunst verändert werden könne. ${ }^{337}$ In Menschliches kehrt sich dieses Verhältnis um und kulminiert in der Behauptung, der «wissenschaftliche Mensch ist die Weiterentwicklung des künstlerischen».338

Diese Neubewertung der Wissenschaften geschieht vor dem Hintergrund der kulturpolitischen Frage nach «Nutzen und Nachteil für das Leben» bzw. für die Kultur. Diese Frage bildet den Massstab, an dem sich Philosophie, Wissenschaft und Kunst zu messen haben. Und gerade hier hat Nietzsche

\footnotetext{
336 MA, KSA 2, S. 11.

337 GT 15, KSA 1, S. 99. Die Natur selbst dränge durch Staat und Gesellschaft zum Genius, weil sie sich nur im grossen Individuum verwirklichen könne (vgl. CV 3, KSA 1, S. $766 f$.).

338 MA 222, KSA 2, S. 186.
} 
seine Meinung über die Kunst vollkommen geändert. Denn die Kunst könne für die moderne Kultur keine lebenserhaltenden Funktionen mehr übernehmen. Sie sei auf ein mythisch-religiöses Weltbild angewiesen, das durch die moderne Wissenschaft widerlegt sei und nicht länger gebraucht werde. Die Kunst sei durch die Aufklärung unzeitgemäss geworden und verhindere das Fortschreiten der Kultur zu höheren Entwicklungsstufen. Nietzsche bezeichnet die Kunst als eine «To d te n b e s chwör rerin» abergläubischer und primitiver Zeitalter. ${ }^{339}$ Sie suche nach Tiefe, Bedeutung und Glück, während die Wissenschaft nur nach Erkenntnis strebe und daher zu einer reiferen Kultur führe. ${ }^{340}$ So sei es das «Merkmal einer höhern Cultur», dass man wissenschaftliche Wahrheiten höher schätze als die «beglückenden und blendenden Irrthümer, welche metaphysischen und künstlerischen Zeitaltern und Menschen entstammen.» ${ }^{341}$

Da es in der Wissenschaft aber auch Irrtümer gebe, liege der kulturelle Nutzen nicht in den Ergebnissen, sondern in den wissenschaftlichen Methoden: «Im Ganzen sind die wissenschaftlichen Methoden mindestens ein ebenso wichtiges Ergebniss der Forschung als irgend ein sonstiges Resultat [...].» ${ }^{342}$ So ist die in Menschliches angekündigte «historische Philosophie» - im Gegensatz zur metaphysischen Philosophie - weniger durch ihre objektiven Erkenntnisse als durch ihre Methoden wissenschaftlich. Nietzsche denkt besonders an die Naturwissenschaften und spricht im ersten Aphorismus von Menschliches von einer «Chemie der Begriffe und Empfindungen».343 Das Zusammenspiel von Begriffen und Empfindungen soll analog zu jenem von organischen Stoffen in der Chemie betrachtet werden. Die Methode der Chemie und die damit verbundenen Haltungen sind wichtiger als die Resultate. Nietzsche wirbt also weder für eine interesselose Erkenntnisliebe noch für einen Wissenschaftspositivismus. Er versteht laut Gianni Vattimo «die Wissenschaft nicht als objektive Erkenntnis der Wirklichkeit, sondern bewertet sie aufgrund der geistigen Einstellungen, die sie mit sich bringt.» ${ }^{344}$ Diese durch wissenschaftliche Methoden erworbenen Einstellungen wirken sich auf die Kultur aus. So verbreite die Wissenschaft eine wertvolle Skepsis gegen unbegründete und gewalttätige Meinungen, das Interesse für das Unbedeutende und Unschein-

\footnotetext{
339 MA 147, KSA 2, S. 142.

340 Vgl. MA 6, KSA 2, S. 27f.; MA 7, KSA 2, S. 28.

341 MA $_{3}, \mathrm{KSA}_{2}, \mathrm{~S} .25$.

342 MA 635, KSA 2, S. 360.

343 MA 1, KSA 2, S. 24. Insofern übernimmt Nietzsche nur Descartes' Motto, sein Leben der Suche nach Erkenntnismethoden zu widmen, aber weniger dessen naturphilosophische Gegenstandsbereiche im Sinne der Naturwissenschaften.
}

Vattimo 1992, S. 34 . 
bare sowie einen «Zuwachs an Energie, an Schlussvermögen, an Zähigkeit der Ausdauer». ${ }^{345}$

Die aufgewertete Wissenschaft bringt für Nietzsches Vorstellung der Kultur zwei grosse Probleme mit sich: Erstens fehlen durch den Wegfall von Religion und Kunst die lebensfördernden Energien aus Glaube, Leidenschaft und Metaphysik. Die Antriebsenergien für die Erkenntnis bedürfen eines Nährbodens, den die Wissenschaft nicht bieten kann: «Wenn wir nicht in irgend einem Maasse unwissenschaftliche Menschen geblieben wären, was könnte uns auch nur an der Wissenschaft liegen! [...] für ein rein erkennendes Wesen wäre die Erkenntniss gleichgültig. ${ }^{346}$ Es gibt gemäss Nietzsche keine rein wissenschaftliche Tätigkeit, die nicht auf Lust und Leidenschaft angewiesen ist. Die Wissenschaft verhält sich nicht nüchtern und neutral zu ihren Entstehungsbedingungen. Darum unterscheidet sich der Erkennende nur graduell von den Gläubigen. Dieses Problem zeigt sich in Nietzsches skurriler Forderung nach einem «Doppelgehirn»: eines für die rein erkennende Wissenschaft, und eines für die Nicht-Wissenschaft als leidenschaftliche Kraftquelle. ${ }^{347}$ Zweitens kann die Wissenschaft allein noch keine höherentwickelte Kultur erreichen, da der Wissenschaftler zu spezialisiert und unpolitisch sei, um die Kultur auf eine höhere Stufe zu führen.

Beide Probleme versucht Nietzsche im fünften Hauptstück «An ze ich en höherer und niederer Cultur» durch die Figur des «Freigeists» zu lösen. Der Freigeist ist jemand, der «anders denkt, als man von ihm auf Grund seiner Herkunft, Umgebung, seines Standes und Amtes oder auf Grund der herrschenden Zeitansichten erwartet». ${ }^{348}$ Die Freigeister schlagen Wunden ins «Gemeinwesen», um diesem dann das Neue und Edle zu «in oculi[ren]». Die Formel für den Fortschritt in eine höhere Kultur heisst «Veredelung durch Entartung». ${ }^{349}$ Es bleibt zu ergänzen, dass Nietzsches biologische Rhetorik nicht auf eine Züchtung anhand körperlicher Merkmale zielt. ${ }^{350}$ Es zeigte sich aber schon bald, welch gefährliches Potenzial diese Rhetorik barg. ${ }^{351}$

345 MA 256, KSA 2, S. 212; MA 635, KSA 2, S. $360 f$.

346 VM 98, KSA 2, S. 418.

347 Vgl. MA 251, KSA 2, S. 209.

348 MA 225, KSA 2, S. 189 .

349 MA 224, KSA 2, S. 187-189.

350 Vgl. NL 1875, 12[22], KSA 8, S. 257-259; Schank 200o, S. 335-357; Thüring 2012, S. 188-205.

351 So konnte der enge Freund Peter Gast, der den Gestus von Nietzsches Philosophie jeweils verlässlich übertrieben in sich aufnahm, nicht mehr zwischen Kultur- und Biopolitik unterscheiden. Er schrieb in seiner 1893 veröffentlichten Einleitung zu Menschliches: «sein Erforschen der Moral ist nur Mittel, kein Endzweck! er geht auf eine Neuordnung, Neugestaltung des Lebens aus, er ist kein Nihilist; er will instinktiv die Erhöhung des 
Der Freigeist steht im Kontext einer im 19. Jahrhundert populären Übertragung von physikalischen und ökonomischen Modellen auf die Funktionsweise der Kultur. Letztere sei nur durch Gleichgewichte, Energieerhaltung und Harmoniezustände möglich. ${ }^{352}$ In diesem Sinne bedurfte es beim frühen Nietzsche des Genius zur künstlerischen Ablenkung des griechisch-pessimistischen Weltbildes und bei Menschliches den Freigeist als symbiotisches Komplement zum Gesellschafts-Organismus. Gerade weil Freigeister der Gesellschaft auch Wunden zufügen - damit Neues in den Organismus gelangen kann - darf es nur wenige von ihnen geben. Die elitäre Gruppe steht also im Dienste der Aufrechterhaltung einer organisch evolvierenden Kultur.

Im Vergleich zum einseitigen Wissenschaftler, tanze der Freigeist virtuos zwischen Wissenschaft, Kunst, Poesie, Religion und Metaphysik. ${ }^{353}$ Er kompensiert die Mängel der Wissenschaft und könne dadurch jene Führungsaufgaben zu höheren Kulturstufen übernehmen, zu der die Wissenschaft allein nicht fähig ist. Zu stark seien die Gelehrten an die wissenschaftliche Gründlichkeit gebunden, «während er [der Freigeist] die ganz andere und höhere Aufgabe hat, von einem einsam gelegenen Standorte aus den ganzen Heerbann der wissenschaftlichen und gelehrten Menschen zu befehligen und ihnen die Wege und Ziele der Cultur zu zeigen.» ${ }^{354}$ Die kulturpolitische Vision ist hier klar ausgesprochen: Freigeister regieren über die Wissenschaften und bestimmen die Ziele der Kultur. Nietzsches Wissenschaftseuphorie in Menschliches führt zur Entwertung des mythisch-religiösen Weltbildes und der Kunst. Jedoch vermag die Wissenschaft der Kultur nicht genügend Antriebe zu geben, um eine höhere Kulturstufe zu erreichen. Dieses Problem löst Nietzsche durch den Rückgriff auf die Freigeister, welche als kleine Elite über die Kultur und ihre Ziele regieren. Das ist Kulturpolitik: Es wird nämlich eine politische Form des kulturellen Fortschritts bestimmt und die Führung dieses Vorgangs einer kleinen Elite von Freigeistern zugesprochen, während die Mehrheit der gebundenen Geister das gesellschaftliche Material der höheren Ziele ausmacht. ${ }^{355}$ Nietzsche führt im selben Hauptstück aus, dass die «Freigeisterei» ihren Ursprung im Überlegenheitsgefühl einer regierenden Klasse hat, welche das Volk als «Mittel» für ihre Ziele gebraucht. ${ }^{356}$ In den Entwürfen zu

Typus Mensch; [...].» (Gast 1893, S. XVII) Und weiter: «Er [Nietzsche] will an Stelle der moralischen Werthe bi ol o g i s c he Werthe!» (ebd., S. XVIII).

352 Gerhardt 1983; Ottmann 1999, S. 142f. Beide Autoren verweisen auf Dühring, dessen Einfluss auf den Nietzsche von 1879 genauer zu untersuchen wäre.

353 Vgl. MA 278, KSA 2, S. $228 f$.

354 MA 282, KSA 2, S. 231.

355 Der Ausdruck «Kulturpolitik» wurde prägend von Kittler auf Nietzsches Philosophie bezogen, vgl. Kittler 2000, S. 160-163.

356 MA 472, KSA 2, S. 303 . 
den Freigeistpassagen ist deshalb zurecht von einer «Mission» der Freigeister die Rede. ${ }^{357}$ Nur im Sinne einer solchen hierarchisierten Machtverteilung ist hier und im Folgenden von Kulturpolitik die Rede. Obwohl diese kulturpolitische Vision im Wanderer zurückweicht, sind mit der Diätetik, des aktiven Lesens, des lockeren Schreibens zahlreiche politische (insbesondere kulturpolitische) Implikationen verbunden, die im Kapitel 3.4 zur Demokratie noch genauer ausgeführt werden.

\section{Wissenschaftsskepsis im Wanderer}

Im Wanderer verebbt Nietzsches Begeisterung für die Wissenschaft und ihre Erkenntnisliebe. Schon im ersten Aphorismus heisst es vom Baum der Erkenntnis, dass er mit folgenden zwei «Früchten» locke: «Wahrscheinlichkeit, aber keine Wahrheit: Freischeinlichkeit, aber keine Freiheit [...].» ${ }^{358}$ Die «Wahrscheinlichkeit» steht in starkem Kontrast zur methodischen Wahrheitsliebe des wissenschaftlichen Menschen und die «Freischeinlichkeit» zur angepriesenen Freiheit des Freigeists. Dieser Einstieg ist die Umkehrung des Mottos von Menschliches, in dem Descartes sein Leben feierlich den «Früchten» der Erkenntnis widmet: «genug, dass für meinen Theil mir Nichts besser erschien, als wenn ich die ganze Frist des Lebens darauf verwendete, meine Vernunft auszubilden und den Spuren der Wahrheit in der Art und Weise, welche ich mir vorgesetzt hatte, nachzugehen.» ${ }^{359}$ Zwar geht es auch bei Descartes um ein praktisches Ethos, jedoch im Sinne einer wissenschaftlichen Arbeitsweise. ${ }^{360}$

357 NL 1876, 17 [55], KSA 8, S. 306.

358 WS 1, KSA 2, S. 540. Es finden sich aber aufgrund des unsystematischen Erschreibens von Aphorismenbüchern auch im Sommer 1879 noch Textstellen, die im Stile von Menschliches die Wissenschaft lobend der Religion und Kunst entgegenstellen. So lobt etwa Nietzsche die Wissenschaft für ihr Misstrauen gegenüber «Bildern und Gleichnissen», welches «der Prüfstein für das Gold der Gewissheit ist.» (WS 145, KSA 2, S. 614).

359 MA, KSA 2, S. 11. Für eine ausführliche Besprechung des Descartes-Mottos vgl. Rethy 1976.

36o Bei Descartes steht das wissenschaftliche Ethos im Vordergrund: Zwar ist im Discours die Rede von der Ersetzung der metaphysischen Philosophie durch praktisches und nützliches Wissen der Lebensführung, jedoch soll dieses Wissen durch wissenschaftliche Methoden gewonnen werden, vgl. Descartes 2011, S. 107: «anstelle jener spekulativen Philosophie, die man in der Schule lehrt, eine praktische finden kann, durch die wir die Kraft und die Wirkungsweise des Feuers, der Luft, der Gestirne, der Himmelsregionen und aller anderen Dinge, die uns umgeben, genau so deutlich erkennen können wie die verschiedenen Gewerbe unserer Handwerker.» Die wissenschaftliche Ausrichtung zeigt sich auch in den drei naturphilosophischen Abhandlungen, welche auf den Discours folgen. Descartes widmet im angeführten Motto sein Leben also der wissenschaftlichen Erkenntnis und nicht der praktischen Lebenskunst. 
Die Gründe für diese plötzliche Wissenschafts- und Erkenntnisskepsis liegen in der neuen Fokussierung auf den individuellen Alltag. Der Aphorismus 16 aus dem Wanderer enthält neben der prägnanten Wissenschaftsskepsis auch zentrale Passagen zur Lehre der «nächsten Dinge». Doch zunächst zur Wissenschaftsskepsis:

Worin Gleichgültigkeit noth thut - Nichts wäre verkehrter, als abwarten wollen, was die Wissenschaft über die ersten und letzten Dinge einmal endgültig feststellen wird, und bis dahin auf die herkö mmliche Weise denken (und namentlich glauben!) [...] Jetzt nun thut in Hinsicht auf jene letzten Dinge nicht Wissen gegen Glauben noth, sondern Gleich gültig ke it ge gen Glauben und angebliches Wissen auf jenen Gebieten!361

Anders als in Menschliches wird der Wissenschaft mit Skepsis begegnet. Man könne nicht abwarten, bis wissenschaftlich gesichertes Wissen umfassend vorliegt. Nietzsche hebt das Gegensatzpaar von Wissen und Glauben auf, indem er Gleichgültigkeit gegenüber beiden fordert. Es ist daher folgerichtig, wenn Nietzsche die «Förderung der Wissenschaft» als metaphysisches Ziel kritisiert, das sich über die eigentlichen «Bedürfniss[e] des Einzelnen» hinwegsetzt. ${ }^{362}$ Das wissenschaftliche Ethos verhindert die Entwicklung einer individuellen Diätetik im eigenen Alltag. Offenbar ist es dem Menschen möglich, für das alltägliche Leben selbst gute Entscheidungen zu treffen.

Im St. Moritzer Spätsommer schreibt Nietzsche in sein Arbeitsheft: «Nichts verkehrter als abwarten wollen, was die Wis- / senschaft über die ersten $^{\text {und letzten Dinge einmal endgültig / feststellen wird.» }}{ }^{363} \mathrm{Im}$ Oktober verschärft Nietzsche abermals seine Wissenschaftskritik und positioniert sich noch stärker gegen seine eigenen Aussagen in Menschliches. Er ergänzt in der bereits angefertigten Reinschrift Gasts noch folgenden handgeschriebenen Zusatz mittels eines Zettels (Abb. 23):

Ebensowenig wie diese Fragen der Religiösen gehen uns die Fragen der / philosophischen Dogmatiker an, mögen sie nun Idealisten oder Materi- / alisten oder Realisten sein. Sie allesammt sind darauf aus, uns zu einer Ent- / scheidung auf Gebieten zu drängen, wo weder Glauben noch Wissen noth thut; / selbst für die wissenschaftlichsten Menschen ist es wünschenswerth, daß um alles / Erforschbare und der Vernunft Zugängliche ein umnebelter OzeanGürtel ohne ferne Küsten sich lege, / ein Streifen des Undurchdringlichen, Ewig-Flüssigen und Unbestimmbaren. Gerade / durch die Vergleichung mit

361 WS 16, KSA 2, S. 550 .

362 WS 6, KSA 2, S. 542.

363 M I 2, S. 28. 


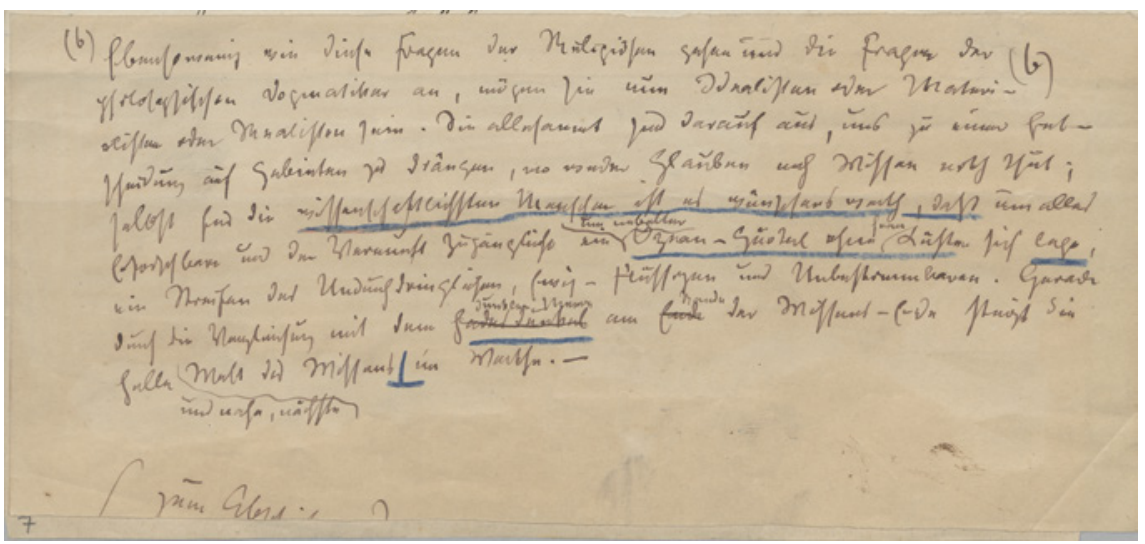

Abb. 23 Der Zettel, den Nietzsche dem reingeschriebenen Aphorismus 16 hinzufügt

dem Hades Đunket dunklen Meere am Ende Rande der Wissens-Erde steigt die / helle und nahe, nächste Welt des Wissens im Werthe. -364

Das Erforschbare d.h. das wissenschaftlich erreichbare Wissen soll umnebelt sein. Es soll der Vernunft unzugänglich bleiben. Der Wissenschaftler profitiere sogar davon, dass er das Erforschbare aufgrund der Umnebelung nicht erforschen kann. Nietzsche behauptet also, dass Unklarheit und Unsicherheit in Bezug auf wissenschaftliche Fragen förderlich seien, weil dadurch der Blick auf den nahen Alltag gelenkt werde, der uns umgibt.

Im Wanderer zählt Nietzsche im Vergleich zu Menschliches auch Wissenschaft und Politik zum metaphysischen Paar Kunst und Religion. Selbst die Philosophie gerät ins Visier der Kritik. ${ }^{365}$ Auch sie lenkt ab vom eigenen Alltag und seinen konkreten Problemen:

Priester und Lehrer, und die sublime Herrschsucht der Idealisten jeder Art, der gröberen und feineren, reden schon dem Kinde ein, es komme auf etwas ganz Anderes an: auf das Heil der Seele, den Staatsdienst, die Förderung der Wissenschaft, oder auf Ansehen und Besitz, als die Mittel, der ganzen Menschheit Dienste zu erweisen, während das Bedürfniss des Einzelnen, seine große und kleine Noth innerhalb der vierundzwanzig Tagesstunden etwas Verächtliches oder Gleichgültiges sei. ${ }^{366}$

364 Eigene Darstellung der Transkription von D 13, Blatt 9 recto.

365 Vgl. WS 16, KSA 2, S. 55 of.

366 WS 6, KSA 2, S. 542f. Schon in Menschliches wurde die Ablenkung durch die Politik kritisiert, jedoch abseits des Alltags als kollektives Problem auf dem Weg zur höheren Kultur: «dass das politische Aufblühen eines Volkes eine geistige Verarmung und Ermattung, eine geringere Leistungsfähigkeit zu Werken [...] nach sich zieht» (MA 481, KSA 2, S. 315). 
Religion, Pädagogik, Politik und Wissenschaft dienen überindividuellen Zwecken. Der Fortschritt der Wissenschaft, das Voranbringen des eigenen Staates oder das Heil der Seele erschliessen sich nicht aus den individuellen Bedürfnissen. Es sind gesellschaftliche Ideale, welche sogenannt höheren Zwecken dienen. Also solchen Zwecken, für die man sein eigenes Wohlergehen vernachlässigen kann und soll. So riskiert man für den Staat das eigene Leben, nimmt für wissenschaftliche Entdeckungen nicht selten Armut in Kauf oder fastet für sein Seelenheil. Essen, Trinken und Wohnen erscheinen als triviale Alltagspraktiken, die hinsichtlich der hohen Ideale nur Mittel zum Zweck sind. Noch in Menschliches unterschied Nietzsche nicht zwischen einer Mutter, die für ihr Kind auf Schlaf verzichte und einem Soldaten, der für den Sieg seines Vaterlandes zu fallen wünscht. ${ }^{367}$ Alltägliche und staatliche bzw. nächste und letzte Bedürfnisse wurden unter dem abstrakten Begriff «N e i g u ng z u E tw as (Wunsch, Trieb, Verlangen)» verallgemeinert. ${ }^{368} \mathrm{Im}$ Wanderer wird der Mensch von ausseralltäglichen Pflichten und Verantwortungen entlastet, während der Erkenntnisliebende von Menschliches die alltäglichen bzw. «gewöhnlichen Fesseln des Lebens» abwirft. ${ }^{369}$

Anders als in der Wissenschaft soll im Wanderer ein Wissen «auf Grund unserer B ed ürfn is se » erworben werden. ${ }^{370}$ Dieses Wissen kann zwar von der Wissenschaft unterstützt werden, muss aber stets auf die individuellen Lebensumstände bezogen und von jedem Einzelnen eigenständig erarbeitet werden. Die Abwägung, «was uns förderlich, was uns schädlich ist», bedarf keiner institutionell autorisierten Absicherung. ${ }^{371}$ Es gebe eine «beschämende Abhängigkeit» von institutionellen Autoritäten wie Ärzten, Lehrern und Seelsorgern. ${ }^{372}$ Religion, Philosophie, Metaphysik und Kunst untergraben durch metaphysische Ideale das selbsttätige Handeln und Denken: «Sie allesamt sind darauf aus, uns zu einer Entscheidung auf Gebieten zu drängen, wo weder Glauben noch Wissen noth thut [...].» ${ }^{373}$ Es ist die Lehre der «nächsten Dinge», welche 1879 im Denken von Nietzsche auftritt und die sukzessive Veränderungen hervorbringt.

\footnotetext{
367 Vgl. MA 57, KSA 2, S. 76.

368 Vgl. ebd.

369 MA 34, KSA 2, S. 55 .

370 NL 1879, 40[3], KSA 8, S. 578.

371 WS 6, KSA 2, S. 542.

372 WS 5 , KSA 2, S. 541.

373 WS 16, KSA 2, S. 551.
} 


\subsubsection{Die Lehre der «nächsten Dinge» als Diätetik}

Die Lehre der «nächsten Dinge» ist alles andere als eine klar definierte «Lehre» mit Definitionen, Regeln und Beispielen. Die verstreuten Notate dieser Lehre fügten sich erst allmählich zum Text. Das Nahe, Nächste und Allernächste bezieht sich dabei auf die Nähe zum Alltag. In einem St. Moritzer Notizbuch findet sich unter der Überschrift «Die Lehre von den nächsten Dingen» eine heterogene Aufzählung:

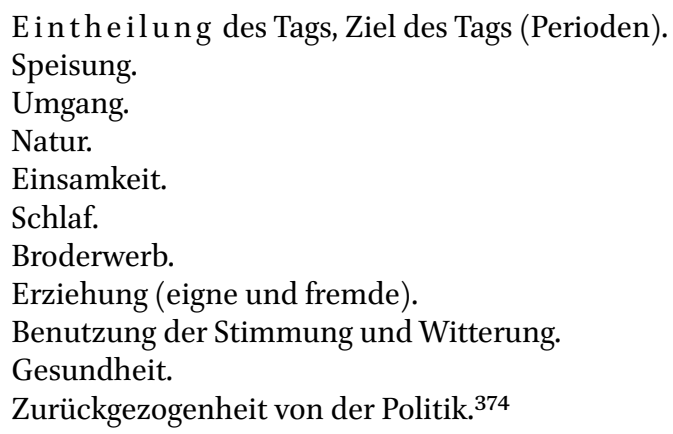

An anderer Stelle im selben Notizbuch nennt Nietzsche noch: «Speisung, Kleidung, Wohnung, Heizung, Clima usw.» ${ }^{375}$ Im publizierten Wanderer finden sich dann «Einrichtung der Lebensweise, Vertheilung des Tages, Zeit und Auswahl des Verkehres, in Beruf und Musse, Befehlen und Gehorchen, Naturund Kunstempfinden, Essen, Schlafen und Nachdenken». ${ }^{376}$ Das verbindende Merkmal dieser Aufzählung ist die Nähe zur eigenen Lebensweise. Damit rekurriert Nietzsche einerseits auf die antiken Diätetiklehren. Die Diätetik bezieht sich auf die ganze Lebensweise (griech. «díaita») und wird seit Hippokrates in Übungen, Speisen, Getränke, Schlaf und Sexualität aufgeteilt. ${ }^{377}$ Diese fünf Bestandteile sind wiederum differenziert in Tageszeiten, Lebensalter, Temperatur, Klima uvm. ${ }^{378}$ Im Unterschied zu Therapie oder Lebenskunst dient die Diätetik weniger zur Heilung des kranken als zur Pflege des eigenen Leibes. Es geht um die Kenntnis von gesundheitsförderlichen (und -schädlichen Faktoren) sowie die dazugehörigen Praktiken. Diese erstrecken sich freilich nicht nur auf den Körper, sondern sind wechselseitig mit dem Zustand der Seele verbunden. Gemäss Michel Foucault charakterisiert die Diätetik «die Weise,

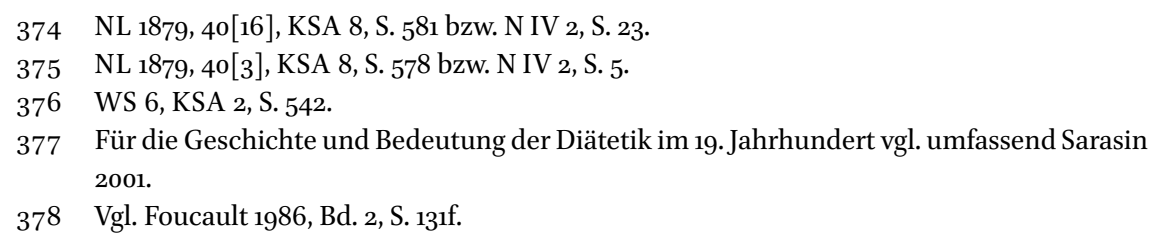


in der man seine Existenz führt, und ermöglicht es, die Lebensführung mit Regeln auszustatten [...]. Die Diät ist eine ganze Lebenskunst.» ${ }^{379}$ Es ist hier in diesem Sinn von Lebenskunst die Rede als bewusste Beherrschung der Techniken und Strategien der Lebensführung, d.h. der Diätetik: «Die Diätetik ist eine strategische Kunst, insofern sie erlauben soll, auf die Umstände in einer ständigen, also nützlichen Weise zu antworten.» ${ }^{380}$ Die Umstände sind aber immer situativ einzigartig und je individuell. Es gibt keine allgemeinen oder festen Regeln, wie Foucault weiter ausführt:

\begin{abstract}
Die Praktik der Diät als Lebenskunst ist also etwas anderes als ein Ensemble von Vorsichtsmaßregeln zur Vermeidung von Krankheiten und zu ihrer Heilung. Es handelt sich darum, wie man sich als ein Subjekt konstituiert, das um seinen Körper die rechte, notwendige und ausreichende Sorge trägt. Eine Sorge, die das Alltagsleben durchläuft; die aus den größeren und kleineren Tätigkeiten der Existenz eine Angelegenheit der Gesundheit und der Moral macht; die zwischen dem Körper und den Elementen, die ihn umgeben, eine «umständliche〉 Strategie definiert; und die schließlich darauf abzielt, das Individuum selbst mit einem verständigen Verhalten zu rüsten. ${ }^{381}$
\end{abstract}

Es wird im Folgenden nur in diesem Sinne der Diät von Lebenskunst gesprochen. Die diätetische Lebenskunst besteht deshalb nicht aus einem allgemeinen Wissen, sondern aus Praktiken, welche auf das eigene Selbst angewendet werden. Nietzsche selbst versteht die Lebenskunst im Sinne von Techniken. So spricht er 1876 mehrmals von «Recepten» der Lebensführung. ${ }^{382}$ Es wird weiter unten mit Blick auf Nietzsches Lektüre und Schreibsituation ausgeführt, dass die Lehre der «nächsten Dinge» von der zeitgenössischen Diätetik des 19. Jahrhunderts geprägt ist.

Nietzsche konstatiert, man sei im «Kleinsten und Alltäglichsten unwissend» und darum abhängig vom Urteil anderer. Deshalb fordert er dazu auf, «Fachkenner» der «nächsten Dinge» zu werden. ${ }^{383}$ Der allgemein schlechte Zustand der Selbstkenntnis sei auch auf den Glauben an den

\footnotetext{
379 Ebd., S. 131.

380 Ebd., S. 137 .

381 Ebd., S. 140.

382 Vgl. etwa NL 1876, 16[7], KSA 8, S. 289: «Jeder Mensch hat seine Recepte, um das Leben zu ertragen [...] Diese überall angewandte Lebenskunst ist zusammenzustellen.» Vgl. weiter: NL 1876, 18[30], KSA 8, S. 321: «Jeder Mensch hat seine eigenen Recepte dafür, wie das Leben zu ertragen ist und zwar wie es leicht zu erhalten ist oder leicht zu machen ist, nachdem es sich einmal als schwer gezeigt hat.»

383 WS 6, KSA 2, S. 542; NL 1879, 40[3], KSA 8, S. 578. Nietzsche formuliert dies in Ueber Wahrheit und Lüge im aussermoralischen Sinne zum ersten Mal prägnant, jedoch unpubliziert: WL 1, KSA 1, S. 877: «Was weiss der Mensch eigentlich von sich selbst!».
} 
freien Willen zurückzuführen. ${ }^{384}$ Dieser führt zur Illusion der völligen Selbstbestimmung, welche die gegebenen und notwendigen Bedürfnisse ignoriert und die Entscheidungshoheit über die «nächsten Dinge» an andere Autoritäten abgibt. Freiheit ist immer situativ und nur dann nutzbar, wenn man seine Abhängigkeiten kennt. Nietzsche will deshalb die alltägliche, praktische und leibliche Existenz in ihr Recht setzen und sie als primäre Entscheidungsgrundlage des Individuums etablieren.

Die Kenntnis der «nächsten Dinge» schützt die Fähigkeit, um sich selbst Sorge tragen zu können. Damit zielt Nietzsche aber nicht auf die totale Unabhängigkeit des Individuums. Vielmehr soll man die unmittelbar alltäglichen Abhängigkeiten ernst nehmen, und dadurch die «überflüssige[n]» relativieren. ${ }^{385}$ Als Beispiel eines aufgeklärten und eigenständigen Menschen verweist Nietzsche im Kontext der «nächsten Dinge» auf den Sophisten Hippias von Elis (5. Jh. v. Chr.), der seine Kleider selbst machte und sich vor Gericht selbst verteidigen konnte. ${ }^{386}$ In diesem Sinne setzt Nietzsche im Wanderer Sokrates in Szene:

Sokrates schon wehrte sich mit allen Kräften gegen diese hochmüthige Vernachlässigung des Menschlichen zu Gunsten des Menschen und liebte es, mit einem Worte Homer's, an den wirklichen Umkreis und Inbegriff alles Sorgens und Nachdenkens zu mahnen: Das ist es und nur Das, sagt er, «was mir zu Hause an Gutem und Schlimmem begegnet. ${ }^{387}$

Das entspricht Nietzsches Abwendung von den «letzten Dingen», welche von den «nächsten Dingen» der eigenen Existenz ablenken. Die Forderung der Selbstaufklärung entspricht wiederum Sokrates' «Erkenne dich selbst». 388 Nietzsche besitzt einige Selbstironie, wenn nun gerade Sokrates, gemäss der Geburt der Tragödie noch der Prototyp des wissenschaftlichen Menschen, als Gewährsmann für die «nächsten Dinge» bürgt. Dies hängt jedoch auch damit

384 WS 9, KSA 2, S. 545 .

385 WS 318, KSA 2, S. 693.

386 Vgl. ebd. Ein Jahr später schreibt er in der Morgenröte, dass man ohne Arzt besser auf die eigene Gesundheit achte (vgl. M 230, KSA 3, S. 231). Vivetta Vivarelli hat Ähnlichkeiten dieser Hippias-Stelle mit jener bei Montaigne nachgewiesen. Während sie diese Hippias-Beschreibung im Wanderer aber als Beispiel für den freien Geist interpretiert, sehe ich ihn mehr als Beispiel für die Lehre der «nächsten Dinge» (vgl. Vivarelli 1998, S. 74f.).

387 WS 6, KSA 2, S. 543 .

388 So will Sokrates im Phaidros allem Rätseln um die Göttermythen entsagen, solange er sich selbst nicht besser kenne: «da scheint es mir lächerlich, wenn ich hier noch ahnungslos bin, mich um Dinge zu kümmern, die mich nichts angehen. Deshalb also lasse ich diese Geschichten auf sich beruhen, folge für sie der allgemeinen Meinung und prüfe, wie gesagt, nicht sie, sondern mich selbst [...].» (Phaidros 229e-230a, Platon 1997, S. 13). 
zusammen, dass Nietzsche sich nun auf den xenophontischen Sokrates aus den Memorabilien beruft. ${ }^{389}$ Also auf jenen Sokrates, den man in der Philologie und Philosophie für eher banal und weniger hochstehend hält. Aber auch jener, den Montaigne schon für seine Nähe zum irdischen Leben lobte, was Nietzsche kaum entgangen sein wird. ${ }^{390}$

Neben Sokrates bezieht sich Nietzsche auf die Selbstsorge des Epikur. Nietzsche fordert die Abwendung von der Wissenschaft und der Politik sowie die Hinwendung zu den «nächsten Dingen» des eigenen Alltags. ${ }^{391}$ Epikur stellte die Sorge um sich selbst über Reichtum, Macht und Bekanntheit. ${ }^{392}$ Er dachte, dass die Selbstsorge die einzige Beschäftigung des Menschen sein sollte. Diese bringe dem Einzelnen Heilung und Freude am Leben, was Nietzsche im Schlussaphorismus erwähnt. Nietzsche fand in der antiken Philosophie die Überzeugung, dass alles, was dem alltäglichen Leben fern ist, nicht Gegenstand der Philosophie sei. Er notiert in St. Moritz, dass «die Trostmittel der antiken Philosophie» wieder neu aufleben würden. ${ }^{393}$

Wie alltagsnah Nietzsche nun zu denken versucht, zeigt sich in seinen Beispielen. Viele Menschen wüssten nicht, dass die länglichen Eier am «wohlschmeckendsten» seien, dass Tischgespräche dem Magen schaden oder dass Handwerker dank eigener fachmännischer Kenntnis besser arbeiten. ${ }^{394}$ Diese kaum verallgemeinerbaren Ratschläge stehen in der Tradition von diätetischen Richtlinien. Im Falle des stillen Essens ist das jedoch besonders komisch, weil u.a. das von Nietzsche gelobte Diätetische Kochbuch empfiehlt, bei Trübsinn und Deprimiertheit immer mit anderen Menschen zusammen zu speisen (welche fröhlich sind). ${ }^{395}$ Es wird aber immerhin sichtbar, wie konkret und praktisch Nietzsche sich dem Alltag zuwendet.

389 Vgl. WS 86, KSA 2, S. 596; vgl. dazu Brusotti 1997, S. 135-138.

390 Die Annäherung an den Sokrates des Xenophon lässt sich durch die Montaigne-Lektüre erklären, vgl. Vivarelli 1998, S. 77 f.

391 Vgl. WS 7, KSA 2, S. 543f.; WS 192, KSA 2, S. 638; WS 227, KSA 2, S. 656; WS 295, KSA 2, S. $686 f$.

392 Vgl. zu Epikur und seiner Lehre Hadot 1987, S. 15-29, bes. S. 25.

393 NL 1879, 41 [32], KSA 8, S. 588 bzw. N IV 1, S. 22. Vgl. auch WS 7, KSA 2, S. 543f.; NL 1878, 28 [40] und 28 [41], KSA 8, S. 367 .

394 WS 6, KSA 2, S. 542; NL 1879, 40[3], KSA 8, S. 578; NL 1879, 42[29], KSA 8, S. 601.

395 Wiel 1876, S. 183. Vgl. auch Meyer-Ahrens 1860, Bd. 1, S. 13f.: «Allein zu speisen ist Jedermann, der nicht durch seine Leiden oder Unpäßlichkeit dazu gezwungen wird, abzurathen, da abgesehen davon, daß die Preise solcher Privatmahlzeiten meistens höher sind, die Unterhaltung, die man an den gemeinsamen Tafeln durch Beobachtung und Konversation genießt, zu den Zerstreuungsmitteln gehört, die jedem Kuristen so nothwendig sind.» 
Nietzsche fasst seine Lehre der «nächsten Dinge» in zwei Grundsätzen zusammen:

Die zwei Grundsätze des neuen Lebens. - Erster Grundsatz: man soll das Leben auf das Sicherste, Beweisbarste hin einrichten: nicht wie bisher auf das Entfernteste, Unbestimmteste, Horizont-Wolkenhafteste hin. Zweiter Grundsatz: man soll sich die Reihenfolge des Nächsten und Nahen, des Sicheren und weniger Sicheren feststellen, bevor man sein Leben einrichtet und in eine endgültige Richtung bringt. ${ }^{396}$

Kennt man sich selbst, ist man auf feste Resultate und klare Ergebnisse nicht mehr angewiesen. Lebenskunst heisst dann: Ohne feste Überzeugungen gut leben zu können. Das entspricht auch der Figur des Wanderers, welcher bei Nietzsche keine letzten Ziele hat. ${ }^{397}$ Im letzten Aphorismus vom Wanderer fordert Nietzsche «Erleichterung des Lebens», «um derFreudigkeit willen» leben und ein «Frieden um mich und ein Wohlgefallen an allen nächsten Dingen $»{ }^{398}$ Obwohl sich Nietzsche von den metaphysischen «letzten» Dingen zu den «nächsten Dingen» wendet, behält er hier eine religiöse Rhetorik bei: Nicht zufällig parodiert er das Grusswort des Erzengels Gabriel bei der Verkündigung von der Geburt Jesu. Die religiöse Rhetorik ist jedoch auch ein Seitenhieb gegen die Wissenschaft und deren Methoden. Nietzsche ersetzt den christlichen Gruss durch eine säkularisierte Diätetik. Es fehlte dem Menschen zu lange an «reiner Luft und freier Bewegung» - beides Grundelemente der diätetischen Kur und der St. Moritzer Schreibsituation. ${ }^{399}$ Und während in der Bibel alle Menschen in den Gruss eingeschlossen werden, adressiert Nietzsche bloss den Einzelnen und seinen individuellen Alltag: Die kulturpolitische «Ersatzreligion» von Bayreuth muss einer diätetischen Ethik weichen. ${ }^{400}$

Einige Beispiele aus den Manuskripten zeigen, wie zentral die «Lehre der nächsten Dinge» für den Wanderer ist. Die ersten zwei Notizbücher von Juni und Juli 1879 enthielten bereits die Idee, dass der abgewandelte Engelsgruss

396 WS 310, KSA 2, S. 691.

397 Vgl. MA 638, KSA 2, S. $362 f$.

398 WS 350, KSA 2, S. 702. Die Bibelstelle findet sich bei Lukas 2,14. Nietzsche verwendete diesen Gruss auch Ende 1878 in einem Brief: ««Friede auf Erden und den Menschen ein Wohlgefallen aneinander!»» (N. an Baumgartner, 23.12.1878, Nr. 785, KGB II 5, S. 374).

399 WS 350, KSA 2, S. 702.

400 Eichberg 2009, S. 22. Es ist bezeichnend, dass die meisten Interpreten dieses Schlussaphorismus den zitierten Wahlspruch unhinterfragt auf den «freien Geist» beziehen und damit den Unterschied zwischen Kulturpolitik und Diätetik ignorieren. So etwa Venturelli 2003, S. 147 f. 
den Schluss des Wanderers bilden soll. ${ }^{401}$ Nietzsche betont übermässig, beinahe pleonastisch die Wichtigkeit der «nächsten Dinge». Nachdem er im ersten Satz des Aphorismus 5 die «nächsten Dinge» als die «wichtigsten» bezeichnet, hebt er dies im zweiten Satz nochmals hervor und fügt im Druckmanuskript sogar noch eine dritte solche Formulierung ein:

Um- / gekehrt ist die Hochschätzung der «wichtigsten Dinge» fast niemals ganz ächt: die Priester / und Metaphysiker haben uns zwar auf diesen Gebieten durchaus an einen heuchlerischen übertreibenden Sprachgebrauch / gewöhnt, aber das Gefühl doch nicht umgestimmt, welches diese wichtigsten Dinge nicht so wichtig nimmt, wie jene verachteten nächsten Dinge 402

Offenbar wollte Nietzsche sichergehen, dass seine Botschaft nicht überlesen wird. Der Schlussdialog zwischen Wanderer und Schatten beginnt denn auch mit den «nächsten Dingen»: «Der Schatten: Von Allem, was du vorgebracht hast, hat mir Nichts m eh $\mathrm{r}$ gefallen, als eine Verheissung: ihr wollt wieder gute Nachbarn der nächsten Dinge werden. Diess wird auch uns armen Schatten zu Gute kommen. Denn, gesteht es nur ein, ihr habt bisher uns allzugern verleumdet.» ${ }^{403}$ Der Schatten selbst gehört zur oft übersehenen Nähe des Menschen: «Der Schatten: Es schien uns, als ob wir euch eben zu nahe wären, um von uns selber reden zu dürfen.» ${ }^{404}$ Der Schatten personifiziert den nahen Alltag, die Diät und die Umgebung. Indem jeder Körper im Licht einen Schatten wirft, verbindet der Schatten den Körper mit der Umgebung und steht dadurch für die diätetische Dimension der Philosophie. Einen Schatten zu haben, heisst, einen Leib zu haben.

\subsubsection{Vorrang der Diätetik vor der Kulturpolitik}

Die Ausrichtung auf die Diätetik im Wanderer ist nicht mehr mit den kulturpolitischen Mandaten der Freigeister zu vereinen. In Menschliches stand mit den Freigeistern die Verbesserung der Kultur im Mittelpunkt, im Wanderer der individuelle Alltag. Ging es in Menschliches noch um die kulturpolitische Forderung einer «alle bisherigen Grade übersteigende Kenntnis s der Bedingungen der Cultur, als wissenschaftlicher Maassstab für ökume-

\footnotetext{
401 Vgl. das Notat N IV 1, S. 21 bzw. NL 1879, 41[31], KSA 8, S. 588 und N IV 2, S. 19 (als Vorstufe kategorisiert und daher nicht ediert).

402 Eigene Darstellung der Transkription von D 13, Blatt 5 recto.

403 WS Rahmendialog, KSA 2, S. 703. Und in einem unverwendeten Dialogstück zwischen Wanderer und Schatten hiess es, der Schatten habe besondere Freude am «Hauptsatze dass die Menschen / wieder gute Nachbarn der nächsten Dinge / werden sollen». (N IV 3 , S. 33).

404 WS Rahmendialog, KSA 2, S. 703.
} 
nische Ziele», geht es im Wanderer um die je individuelle Kenntnis des eigenen Alltags der «nächsten Dinge». ${ }^{405}$ Ralf Eichberg fasste das mit Bezug auf den Wanderer prägnant zusammen: «Die Frage nach der Wahl des Klimas und des menschlichen Umgangs, der dem Leben förderlich ist, wurde wichtiger als die Gegenstände einer kulturellen Ersatzreligion. Es war ein Abschied von der großen kulturellen Vision und ein Hinlenken auf die Lebenswelt.» ${ }^{406}$ Henning Ottmann spricht gar von einer «Neigung zur Apolitie», welche sich ab Menschliches bei Nietzsche bemerkbar mache. ${ }^{407}$ Demgegenüber wird im Kap. $3.4 \mathrm{zu}$ zeigen sein, dass die Diätetik mit den politischen Fragestellungen um Schreiben und Demokratie verknüpft wird. Denn die Abwendung von einer freigeistigen Kulturpolitik führt keineswegs zu einer apolitischen Haltung, sondern zu einer Neukonzeption von Nietzsches Demokratiekritik.

Abwendung vom Freigeist und seiner Kulturpolitik

Indem Nietzsche nicht länger auf einen wissenschaftlichen Menschen fokussiert, relativiert sich das oben beschriebene zweifache Dilemma sowie dessen Lösung, der Freigeist. Die individuelle Diätetik ist nicht nur das Gegenstück zur Wissenschaftsskepsis, sondern auch zur freigeistigen Kulturpolitik. So wundert es nicht, dass der «Freigeist» über die Vermischten Meinungen zum Wanderer fast ganz verschwindet. Im Wanderer wird noch vereinzelt von «freier Geist» gesprochen, jedoch nicht mehr von «Freigeist». Zwar bezeichnen beide Namen ein Streben nach Unabhängigkeit, jedoch auf verschiedene Weisen:Während der «Freigeist» durch eine elitäre Position in der Gesellschaft auf eine Erhöhung der allgemeinen Kultur zielt, steht beim «freien Geist» eher die eigene Unabhängigkeit und Gesundheit durch umfassende Kenntnisse von Körper und Alltag im Mittelpunkt. ${ }^{408}$ Der «freie Geist» im Wanderer ist nicht mehr der

405 MA 25, KSA 2, S. 46; WS 16, KSA 2, S. 551.

406 Eichberg 2009, S. 22.

407 Vgl. Ottmann 1999, S. 125.

408 Es gibt feine Unterschiede und Akzente zwischen «Freigeist» und «freier Geist». Dies bemerkt Vivarelli: «Nietzsches Ausdruck für diese Art von Modell und Gegenfigur seiner selbst, ist zunächst noch der «Freigeist〉. Erst in Vermischte Meinungen und Sprüche und Morgenröte beginnt er, vom 〈freien Geist zu sprechen, als wollte er seine Ablösung von den esprits forts signalisieren.» (Vivarelli 1998, S. 55, vgl. auch ebd., Fussnote 42) Vivarelli gibt zu bedenken, dass der «Freigeist» näher am französischen «Esprit fort» und an der Ablehnung theologischer Werte ist (ebd., S. 57-59). Auch Ottmann unterscheidet: «Aber die historische Belastung des Begriffs «Freigeist〉 und «Freidenker〉 könnte auch verdecken, worauf Nietzsches Philosophie der 〈freien Geister〉 zielte.» (Ottmann 1999, S. 122, vgl. auch S. 121-123) Dies passt zu meinen Thesen, gemäss denen sich Nietzsche im Wanderer von den französischen Moralisten distanziert. Es ist angesichts dieser Hinweise missverständlich, wenn Jochen Schmidt in seinem Kommentar zur Morgenröte behauptet, dass 
kulturpolitische Regent im Zeichen der «Freigeisterei», sondern widmet sich seinem eigenen Alltag. So heisst es in Menschliches, dass die «Freigeisterei» ihren Ursprung im Gefühl der Überlegenheit über die Religion und das Volk habe. ${ }^{409}$ Eine Vorstellung, die für eine demokratische Zukunft unbedeutend ist, weil die Regierung durch den Volkssouverän ersetzt wird. Deshalb bezeichnet Nietzsche die Demokratie im Vergleich zur «Freigeisterei» als «jene ganz verschiedene Auffassung des Begriffs der Regierung».410

Voltaire, der Inbegriff des Freigeists, steht für eine kulturpolitische Aristokratie, welche durch die Diätetik der «nächsten Dinge» nunmehr sekundär ist. Er bleibt aber durch den Fokus auf das Schreiben in Zwängen und Fesseln im Wanderer («Kettentanz») weiterhin präsent. ${ }^{411}$ Dies spricht freilich gegen meine These der Abwendung vom Freigeist. Die Kettenphilosophie korreliert aber, wie in Kap. 3.2 gezeigt, eher mit dem Sentenzenstil als mit dem lockeren Stil im Wanderer. Das grosse Lob der sorgsam gewählten Worte findet im Wanderer seinen Gegenpart in der Aufforderung des Wanderers, man wolle nicht jedes Wort auf die Waage legen. ${ }^{412}$ Der Sentenzenstil stützt sich auf Zwänge (contraintes), während der lockere Stil eine ungezwungene Sprache fordert. Damit entsteht eine Opposition zu den Freigeistern, welche sich wie Voltaire durch die äusserste Leichtigkeit in Zwängen bewegen. Dass Nietzsche die ursprünglich geplante Voltaire-Widmung am Buchende der Vermischten Meinungen durch einen Schlussaphorismus ersetzte, der gerade den Antipoden Rousseau in einer Reihe von Denkern nennt, die Nietzsche sich vornimmt immer wieder zu konsultieren, entbehrt nicht einer gewissen Ironie. ${ }^{413}$

Die Freigeist-Thematik ist zudem noch mit Nietzsches früheren Werken verhaftet. Der «Freigeist» diente damals zur Charakterisierung von Schopenhauer und Kulturvisionen aus Wagners Werken. ${ }^{414}$ Das zeigt sich daran, dass die Entwürfe zu den hier besprochenen Freigeist-Aphorismen von 1876 eigentlich für

Nietzsche sich «von Menschliches, Allzumenschliches über die Morgenröte bis zur Fröhlichen Wissenschaft programmatisch als 〈Freigeist»» verstand (Schmidt 2015, S. 23). MA 472, KSA 2, S. 303. Vgl. demgegenüber WS 182, KSA 2, S. 63 of.

410 MA 472, KSA 2, S. 303.

411 Es ist daher fraglich, ob man mit Ottmann den Bruch mit der Wissenschaft und jenen mit Voltaire parallel sehen kann: «Voltaire war Leitbild für eine gewisse Zeit. Er konnte es nicht mehr sein, als Nietzsche die Synthese von Wissenschaft und Glück, Wissenschaft und Moral zerbrach.» (Ottmann 1999, S. 162) Der Bruch mit der Wissenschaft geschah schon im Wanderer, während Voltaire durch den «Kettentanz» präsent blieb (Kap. 3.1.1 und 3.2.1).

412 Vgl. WS Rahmendialog, KSA 2, S. 537.

413 Vgl. VM 408, KSA 2, S. 534. Ganz zu schweigen davon, dass Rousseau ein grosser Einfluss an der europäischen Kultur zugestanden wird (vgl. WS 216, KSA 2, S. 651).

414 Vgl. Campioni 2000, 235f. 
eine weitere «Unzeitgemässe Betrachtung» geplant waren. ${ }^{415}$ Diese Aphorismen waren also für eine kulturpolitische Buchreihe geplant, in der Nietzsche zuletzt Wagner und Schopenhauer ein Denkmal gesetzt hat. Das sind nun selbstredend jene Figuren, mit denen Nietzsche in Menschliches gebrochen hatte. Zudem stammt die kulturpolitische Formel der «Veredelung» aus der 1876 erschienenen Unzeitgemässen Betrachtung: Richard Wagner in Bayreuth. Dort heisst es: «Der Einzelne soll zu etwas Ueberpersönlichem geweiht werden $[. ..] .{ }^{416}$ Jeremy Fortier hat darauf aufmerksam gemacht, dass Nietzsche offen lässt, wie die von der Politik weitgehend unabhängigen Freigeister eine starke politische Wirkung entfalten sollen. ${ }^{417}$ Die Vorstellung, dass man über Philosophie und Kunst umfassende politische Veränderungen erreichen kann, ist der Glaube Wagners. Zurecht bezeichnet Mazzino Montinari den Nietzsche des Sommers 1876 als «wagnerschen Kulturrevolutionär». ${ }^{418}$ Giuliano Campioni schreibt dazu: «Der Freigeist dient in gewissem Maße noch den Möglichkeiten eines Fortschritts der Gattung». ${ }^{419}$ Und laut Peter Heller dient die wissenschaftliche Haltung der «Erziehung und Züchtung des gesteigerten Menschen».420 In dieser Hinsicht ist Menschliches weniger weit von Bayreuth entfernt, als Nietzsche das von dieser Schrift dachte.

Aus Sicht vom Wanderer und der abgekühlten Kulturpolitik erscheint der Freigeist als eine Verlegenheitslösung der Aporie zwischen Nietzsches Wissenschaftseuphorie und seinen kulturpolitischen Ansprüchen. Mit dem Freigeist nimmt er aber eine kulturpolitische Vorstellung in Kauf, die er mit der wissenschaftlichen Haltung, der Geniekritik und der Abwendung von Wagner und Schopenhauer überwinden wollte. ${ }^{421}$ Im Vergleich zur Wanderer-Figur fehlen dem Freigeist die «nächsten Dinge»: der Leib, der Alltag, die Landschaft, die

\footnotetext{
415 Vgl. KSA 14, S. 115f.; Brücker 2016, S. $168 f$.

416 RWB 4, KSA 1, S. 453.

417 Vgl. Fortier 2016, S. $206 f$.

418 Montinari 1986, S. 201.

419 Campioni 1987, S. 221.

420 Heller 1972, S. 104f. Ich argumentiere deshalb gegen Vivarelli 1998, S. 55 und Fortier 2016, S. 206, welche mit dem «freien Geist» von Menschliches bereits Nietzsches Bruch mit der Vergangenheit konstatieren. Die selbstverständliche Rede eines «Free Spirit Project» (ebd., S. 208) reproduziert Nietzsches werkpolitisches Narrativ einer Gesamtausgabe und degradiert den Wanderer zum sekundären Anhang (vgl. Kap. 2.2).

421 Paolo D'Iorio sieht darin den Grund, weshalb Nietzsche keine 5. Unzeitgemässe Betrachtung mit dem Titel «Der Freigeist» schrieb: «Et le thème de cette cinquième Inactuelle, l'esprit libre, aurait peut-être pu servir de transition vers une nouvelle phase de sa philosophie. Mais Nietzsche n'avait plus ni la force ni l'envie de l'écrire, car le schéma était encore celui de Wagner de la lutte contre l'actualité pour une réforme de la culture allemande et la pensée de Nietzsche sortait maintenant définitivement du cercle magique de cette étrange inactualité, très liée au présent.» (D'Iorio 2012, S. 113).
} 
Geschichte und die Gespräche. Anstatt sich mit den «nächsten Dingen» zu befassen, wird das negiert, was einem nah ist - bis hin zum eigenen Selbst. ${ }^{422}$ Das zeigt sich an einer weiteren Formulierung aus dem Wanderer, die sich auf die «nächsten Dinge» bezieht: «Seine nothwendigen Bedürfnisse so viel wie möglich selber befriedigen, wenn auch unvollkommen, das ist die Richtung auf Freiheit von Ge ist und Pers on.» ${ }^{423}$ Freiheit ist nun auf die Bedürfnisse des Einzelnen ausgelegt und betrifft nicht nur den Geist, sondern auch die Person. Der Freigeist von Menschliches ist so gesehen noch im Denkmodell des cartesianischen Subjekts, das primär aus rationalen Einstellungen, geistigen Haltungen und Theorien besteht. Deshalb charakterisiert Nietzsche die freien Geister durch praktische Handlungsunfähigkeit. ${ }^{424}$ Aus Sicht der «nächsten Dinge» kann gefolgert werden: Der Freigeist hat keinen Schatten. Er tanzt wohl weniger als Virtuose denn als haltloser Geist über Kunst, Metaphysik, Wissenschaft und Religion. Nietzsches Bruch mit Wagner und Schopenhauer wird so gesehen im Wanderer am konsequentesten vollzogen, weil Nietzsche sich durch die Lehre der «nächsten Dinge» von der kulturpolitischen Veredelung entfernt. Dies zeigt sich einmal mehr in der Buchgestaltung. Während bei den Vermischten Meinungen auf dem Titelblatt noch Menschliches, Allzumenschliches. Ein Buch für freie Geister als Haupttitel aufgeführt war, ist dieser Vermerk beim Wanderer nur noch kleingedruckt auf der Rückseite der Titelseite angebracht (Kap. 2.2.3). Bedenkt man Nietzsches sorgfältige Planung von Titelblättern und Layout, kann dies kein Zufall sein.

Im Hinblick auf diese Faktenlage sollte vorsichtiger mit Nietzsches selbst verbreiteter Behauptung umgegangen werden, dass die Freigeisterei erst mit der Fröhlichen Wissenschaft «abgeschlossen» sei (Buchrückseite der Erstausgabe, Abb. 1). Der vielfache Bezug auf Nietzsches Philosophie im Zeichen des Freigeistes müsste zumindest für diese Phase und vor dem Hintergrund der hier präsentierten Konflikte neu bewertet werden. Auch die Rede vom «Bruch» mit Wagner und Schopenhauer erweist sich hier problematisch, weil es für einen aphoristisch arbeitenden Philosophen ein Problem darstellt, seine Ansichten intendiert, ruckartig und konsistent umzustellen. Vielmehr zeigen Nietzsches erste Aphorismenbücher, dass auch einige Meinungen gleich bleiben und sich alte Ideen in neuem Gewand präsentieren. Dieser komplexen Denkentwicklung wird man durch äussere Zäsuren selten gerecht. Gerade in Bezug auf den Freigeist zeigt sich am Wanderer, dass das lineare Verständnis einer freigeistigen Phase, welches selbst noch bei Marco Brusottis «Abschied

422 Vgl. NL 1876, 16[55], KSA 8, S. 295.

423 WS 318, KSA 2, S. 693.

424 MA 230, KSA 2, S. 193. 
von der Freigeisterei» oder Henning Ottmanns Analyse von Nietzsches politischer Philosophie vorherrscht, nicht haltbar ist. ${ }^{425}$

\section{Aufgeschobene Kulturpolitik}

Damit lässt sich festhalten: Aus dem «Kloster für freiere Geister» wurde der einsame Wanderer und aus der Arbeit am «Typus» wurde die Arbeit an sich selbst. ${ }^{426}$ Der Vorrang der Diätetik vor der Kulturpolitik wird im Schlussaphorismus benannt: Zuerst ein «Wahlspruch für Einzelne», dann (allenfalls in ferner Zukunft) ein «Wahlspruch» für alle. ${ }^{427}$ Die allgemeinverbindliche Ethik muss der individuellen Diätetik weichen. ${ }^{428}$ Trotzdem hebt sich die aufgeschobene Kulturpolitik auch im Wanderer nicht auf: So überführt Nietzsche seine zunächst technisch verstandene Philosophie der Ketten am Schluss vom Wanderer wieder in eine kulturpolitische Befreiungsphilosophie veredelter Geister: Der «veredelte[] Mensch[]» dürfe seine «Ketten» abnehmen und um der «Freudig keit willen» leben, womit der Mensch definitiv vom Tier losgelöst sei. ${ }^{429}$ In dieser fernen Zukunft geht es nicht mehr darum, in Ketten zu tanzen, sondern sie abzuwerfen. Es ist kein Zufall, dass in den kulturpolitischen Textpassagen der ansonsten abwesende «freie Geist» wieder auftaucht. ${ }^{430}$ Nietzsche hält also trotz der Lehre der «nächsten Dinge» auch in St. Moritz an einer Erhöhung der Kultur fest. Das Leben des Einzelnen geniesst im Wanderer gegenüber den kulturpolitischen Aufgaben der Gesellschaft nur deshalb einen Vorrang, weil dies dazu dient, dem gesamtkulturellen Ziel einer höheren Kultur näherzukommen. Julian Young hat diese ambivalente Annäherung an eine alltägliche Lebenskunst erkannt. So sei bei Nietzsche nur wenig von Epikurs Demut und Rückzug zu spüren:

The crucial respect in which he [Nietzsche] departs from the Epicurean injunction to live modestly> is his ongoing concern for the regeneration of culture, [...]. Possessing a life-unifying 〈task〉, a life-defining meaning, is, as we know, an essential ingredient of happiness as Nietzsche conceives it, and cultural regeneration - through the writing of his books - is his own life-task. This grandeur

425 Vgl. Brusotti 1997, S. 490-516; Ottmann übersieht die Abwendung vom Freigeist und verbindet auch die kulturpolitische Zurückhaltung mit dem Freigeist (vgl. Ottmann 1999, S. 128).

426 Nietzsche nannte die Sorrentiner Reisegruppe «eine Art Kloster für freiere Geister» (N. an von Seydlitz, 24.og.1876, Nr. 554, KGB 5 II, S. 188).

427 WS 350, KSA 2, S. 702.

428 Vgl. Brusotti 1997, S. 134; Brücker 2016.

429 WS 350, KSA 2, S. 702. Mit Ketten meint Nietzsche «jene schweren und sinnvollen Irrthümer der moralischen, der religiösen, der metaphysischen Vorstellungen.» (ebd.).

430 WS 87 , KSA 2, S. 592 f. 
of ambition that is, in a broad sense, political seems to me something like the opposite of Epicurean inconspicuousness, of Epicurus's recommended inner emigration> from politics. ${ }^{431}$

Das «live unnoticed» kann nur schwerlich für Menschliches und seine «freien Geister» gelten. ${ }^{432}$ Grundsätzlich gilt auch hier: Nietzsche schiebt die Kulturpolitik zeitlich in eine weite Zukunft hinaus und verschafft sich dadurch Raum, über diesseitige, individuelle und körperliche Dinge nachzudenken (Kap. 3.4.1). Diese gleichsam <anwesende Abwesenheit der Kulturpolitik im Wanderer währte aber nur sehr kurz: Schon 1880 rücken kulturpolitische Tendenzen und ein elitäres Menschenbild wieder in den Mittelpunkt von Nietzsches Philosophie; wenn auch das Verhältnis zum Freigeist fortan ambivalent blieb. ${ }^{433}$ Nietzsche wird sich in späteren Schriften auch von Epikur lösen und in ihm sogar eine Dekadenzgefahr sehen. ${ }^{434}$ So sehr Nietzsche sich 1879 dem Ideal eines bescheidenen, gesunden und zurückgezogenen Lebens näherte er war diesem Ideal nie näher als 1879 - so wenig konnte er seine kulturpolitischen Visionen vollends ablegen.

\subsubsection{Nietzsche und die Diätetik des 19.Jahrhunderts}

Woher kommt die «Die Lehre von den nä chsten Di ngen»? Bisher spricht man in der Forschung von einem Rückgriff Nietzsches auf die antike Lebenskunst, wofür bereits gute Gründe genannt wurden. ${ }^{435}$ Es ist angesichts der St. Moritzer Schreibsituation und Nietzsches breiter Lektüre aber einseitig, die «nächsten Dinge» ausschliesslich durch kanonisierte philosophische Texte zu erklären. Ich möchte den Blick auf die populäre Literatur des 19. Jahrhunderts ausweiten. Nietzsches Lehre der «nächsten Dinge» im Jahr 1879 ist ein geeignetes Beispiel, um aufzuzeigen, wie seine Philosophie mit populären Gesundheitsratgebern interagiert.

431 Young 2010, S. 285 .

432 Es gibt wenige Stellen, in denen ein bescheidenes Leben der Freigeister anklingt (vgl. MA 291, KSA 2, S. 234f.). Sie sind jedoch mit der mehrheitlich geforderten Kulturpolitik nicht vereinbar. Hier muss auch Venturelli (2003, S. 153) und Ansell-Pearson (2013, S. 111) widersprochen werden, die diese Spannungen zu sehr glätten und Nietzsches mittlere Phase mit Epikurs Demut kennzeichnen.

433 Vgl. NL 1880, 3[140], KSA 9, S. 93; N. an von Salomé, 24.11.1882, Nr. 335, KGB III 1, S. 282; MA I, Vorrede 2, KSA 2, S. 15; Ottmann 1999, S. 121-123.

434 Vgl. NL 1888, 14[99], KSA 13, S. 276-278.

435 Vgl. Brusotti 1997, S. 133-139; Ottmann 1999, S. 147-163; Young 2010, S. 277-285; Ansell-Pearson 2013; Ders. 2014. 
Nietzsches Lektüre populärer Diätetik

Nach der Abwendung von Wagner und Schopenhauer weitet Nietzsche seine Lektüre insbesondere auf naturwissenschaftliche Bücher aus. ${ }^{436}$ Das entspricht dem Zeitgeist der zweiten Hälfte des 19. Jahrhunderts, als Philosophie und Naturwissenschaften längst zusammen gedacht und der (Natur-)Wissenschaft als Ganzes grosse gesellschaftliche Potenziale zugesprochen wurden. Auch wenn Nietzsche einen individuellen Zugang zu diesen Themen erarbeitet, ist seine Vorgehensweise mitunter der zeitgenössischen Philosophie geschuldet. In den $1870 e r$ Jahren findet ein Boom populärwissenschaftlicher Literatur statt. ${ }^{437}$ Nach der Publikation seines ersten Aphorismenbuchs Menschliches im April 1878 verringert sich Nietzsches Lektüre aufgrund von Gesundheitsproblemen massiv. Gerade zwischen 1877-79, während den Arbeiten an den Vermischten Meinungen und am Wanderer, finden sich im Nachlass nur wenige Lesespuren von wissenschaftlichen Büchern. ${ }^{438}$ Es ist daher umso auffälliger, dass Nietzsche in dieser Zeit diätetische Ratgeber konsultiert und teilweise auch benutzt. Es seien hier einige erworbene und ausgeliehene Bücher aufgeführt: ${ }^{439}$

- Gekauft 1875, vermutlich im Frühjahr:

Carl Ernst Bock: Das Buch vom gesunden und kranken Menschen. Leipzig: Keil 1870.

- Gekauft am 4. Juni 1875, gebunden am 29. Januar 1878: Josef Wiel: Diätetisches Koch-Buch mit besonderer Rücksicht auf den Tisch für Magenkranke von Josef Wiel Arzt in Bonndorf. Zweite, umgearbeitete und vermehrte Auflage. Freiburg i. Br.: Fr. Wagner 1873.

- Gekauft am 22. Februar 1878: Anonym [Adolph Richter]: Dr. Airy's Naturheilmethode. Naturheilmethode oder sichere Anleitung, um die am Meisten vorkommenden Krankheiten der

436 Vgl. Brobjer 2004, S. 21: «His acquisition and reading of scientific books reached a peak during 1875-81.» In Ecce Homo schreibt er rückblickend über Menschliches, er hätte damals nichts anderes «als Physiologie, Medizin und Naturwissenschaften» gelesen (EH MA 3, KSA 6, S. 325). Für Nietzsches Lektüre und Kenntnis der Natur-, Geistes- und Sozialwissenschaften vgl. Heit/Heller (Hg.) 2014.

437 Vgl. Daum 2002, besonders die Beschreibung des letzten Drittels des 19. Jahrhunderts, in dem sich Populärwissenschaften etablieren, S. 324-336, 459-471. Auf Nietzsche bezogen vgl. Moore/Brobjer (Hg.) 2004.

438 «Nietzsche read a large number of books relating to positivism and the philosophy of nature in $1875^{-76}$, but few during the period $1877^{-80}$, mainly because of his poor health.» (Brobjer 2004, S. 36f.) Erst ab 1880 wird er sich wieder vertieft mit den Naturwissenschaften auseinandersetzen, vgl. Zittel 2000. Doch selbst dann ist der Einfluss diätetischer Werke weiterhin gross. So kauft sich Nietzsche 1883 das Populärbuch Discorsi della vita sobria von Luigi Cornaro, vgl. Mahler 2014, S. 428-436.

Vgl. für die Angaben BN; Crescenzi 1994; für weitere Ratgeberliteratur vgl. Moore 2004. 
Menschen durch einfache bewährte Mittel sicher und schnell selbst zu heilen. Mit vielen in den Text gedr. anatom. Holzschn. Abbild. Leipzig: Richter 1877.

- Gekauft am 21. Juni 1878:

Eduard Reich: System der Hygiene, 2 Bde. Leipzig: F. Fleischer 1870-71.

- Gekauft am 10. September 1878:

Daniel Gottlob Moritz Schreber: Aerztliche Zimmergymnastik oder System der ohne Geräth und Beistand überall ausführbaren heilgymnastischen Freiübungen als Mittel der Gesundheit und Lebenstüchtigkeit für beide Geschlechter, jedes Alter und alle Gebrauchszwecke, entworfen von Dr. med. Daniel Gottlob Moritz Schreber. Mit 45 Abbildungen im Texte. Fünfzehnte Auflage, Leipzig: F. Fleischer, 1877.

- Ausgeliehen im Sommersemester 1879 bei der Basler Bibliothek: Otto Ewich: Rationelle Balneologie. Praktisches Handbuch über die vorzüglichsten Heilquellen und Curorte für Aerzte und Badereisende. Berlin: Hirschwald 1862.

- Ausgeliehen im Sommersemester 1879 bei der Basler Bibliothek:

Bernhard M. Lersch: Geschichte der Balneologie, Hydroposie und Pegologie oder des Gebrauches des Wassers zu religiösen, diätetischen und medicinischen Zwecken. Ein Beitrag zur Geschichte des Cultus und der Medicin. Würzburg: Stahel'sche Buch- und Kunsthandlung 1863.

Die Diätetik erlebte im Gefolge der Aufklärung einen grossen Aufschwung. Man verstand unter Diätetik und Hygiene nicht nur Essen und Waschen, sondern alle Aspekte, welche die menschliche Lebensweise konkret betrafen. ${ }^{440}$ Die Diätetik galt im 19. Jahrhundert als praktisch und wenig theorieabhängig, für einige gar als einziges Gebiet der Heilkunst, das nicht den vielen Wechseln der wissenschaftlichen Erkenntnis ausgeliefert war. ${ }^{411}$ Das sah auch Nietzsche so, der in Menschliches als einziges Beispiel einer wissenschaftlichen Wahrheit, die «alle Zersetzungen» überdauert habe, «die Diätetik der Gesundheit» nannte. ${ }^{442}$ Das war zwei Jahre vor den Notizen zur Lehre der «nächsten Dinge», also auf dem Höhepunkt seiner Wissenschaftseuphorie, als die populäre Diätetik für ihn kaum als «harte> Wissenschaft gelten konnte. Trotzdem war es die Diätetik, welche durch ihre praktische Anwendbarkeit die Hoffnung auf untrügliche und zuverlässige Wahrheiten weckte.

Alle von Nietzsche genannten Beispiele für «nächste Dinge» - vom Wohnen, Essen, Kleiden und Heizen - wurden regelmässig und hochdetailliert

440 Für den zeitgenössischen Hygiene- und Diätetikdiskurs des 19. Jahrhunderts vgl. umfassend Sarasin 2001, insb. das Kap. «Eine Kultur des Wissens», S. 118-136.

441 Vgl. ebd., S. 125.

442 MA 22, KSA 2, S. 43. 
Gegenstand von diätetischen Überlegungen und Ratschlägen. Im wachsenden Buchmarkt gab es eine regelrechte diätetische und hygienische Publikationsflut. Die Diätetik hatte auch starken Einfluss auf den philosophischen Diskurs. ${ }^{443}$ So gibt es seit Kants Wortschöpfung einer «Diät im Denken» einen Diskurs über Lebensweisen, die dem Denken förderlich sind. ${ }^{444}$

Die «nächsten Dinge» im Kontext von Zimmergymnastik und Gesundheitslehre

Es wird im Folgenden auf zwei Diätetik-Bestseller, die Nietzsche in dieser Zeit gelesen hat und auf ihre Bezüge zur Lehre der «nächsten Dinge» genauer eingegangen: Auf Die ärztliche Zimmergymnastik von Daniel Gottlob Moritz Schreber und auf Das Buch vom gesunden und kranken Menschen von Carl Ernst Bock.

Die ärztliche Zimmergymnastik von Daniel Gottlob Moritz Schreber erschien $1855{ }^{445}$ Die Zimmer- oder Hausgymnastik bezeichnet geregelte Körperübungen in Wohnräumen, die mehrheitlich ohne zusätzliche Geräte ausgeführt werden. Schrebers Zimmergymnastik war die populärste Anleitung. Sie erreichte bis 1896 eine Gesamtauflage von 16o'ooo Exemplaren und erlebte bis 1907 sagenhafte ${ }_{31}$ Auflagen. ${ }^{446}$ Nun: Nietzsche bestellte dieses Buch am 29. August 1878 in der fünfzehnten Auflage. ${ }^{447}$ Kurz darauf berichtete er seinem Verleger: «Heilgymnastik eingetroffen und schon eifrig benutzt.»48 Und 11 Tage später schreibt er an Mutter und Schwester in einem Brief, er habe eben «Zimmergymnastik» gemacht. Es ist aufgrund der allseits bekannten Zimmergymnastik gar nicht mehr nötig, ein Buch oder einen Autor zu erwähnen.

443 Für eine Skizzierung dieses Zusammenspiels seit der Antike, vgl. Shapin 1998. Vgl. auch Lemke 2007; Hlade 2015.

444 Kant, AA, Bd. VII, S. 109. Kant reagiert auf die Diätetik von Hufeland, der etwa schrieb: «Die erste Ursache des Denkens ist also geistig, aber das Denkgeschäft selbst $[\ldots]$ ist organisch» (Hufeland 1798, S. 143).

445 Schreber selbst war ein deutscher Arzt, Diätetiker und Hochschullehrer (1808-1861). Er schrieb zahlreiche Bücher zu Gesundheit und Erziehung. Die Zimmergymnastik war sein grösster Bestseller. Bekannt geblieben ist Schreber aber weniger als Autor, sondern als Namensgeber der «Schrebergärten», welche er ursprünglich als Spielwiesen für Kinder konzipierte.

446 Vgl. Rethschulte 2007. Verschiedene andere Praktiken der Haus- und Zimmergymnastik waren neben Schreber populär. So etwa jene von Ludwig Seeger oder jene von Eduard Angerstein und Gebhard Eckler.

447 Vgl. Schreber 1877; N. an Schmeitzner, 29.8.1878, Nr. 748, KGB II 5, S. 349. Laut den Angaben der BN trifft das Buch am 10. September 1878 ein. Die Rechnung ist auf den 28. Februar 1879 datiert (vgl. BN, S. 556).

448 N. an Schmeitzner, 10.09.1878, Nr. 754, KGB II 5, S. $35^{2}$. 
Ebenfalls 1855 erschien zum ersten Mal Das Buch vom gesunden und kranken Menschen, eine Aufsatzsammlung von Carl Ernst Bock aus der Massenzeitschrift Die Gartenlaube. Es finden sich darin ausgiebige Kapitel zur Pflege des gesunden Körpers, zur Anatomie, zum Wohnen und gesunden Kleiden etc. Das Buch war ebenfalls sehr erfolgreich und erreichte zwischen 1855 und 1876 bereits eine Gesamtauflage von 10o'ooo Exemplaren. ${ }^{449}$ Nietzsche kauft sich das Buch im Sommer 1875 und hat es intensiv genutzt.

Im Sommer 1879, also während der Arbeit an der Lehre der «nächsten Dinge», findet sich in Nietzsches Notizbuch folgender Eintrag: «Jeden Tag eine Stunde: Gesundheitslehre». ${ }^{450}$ Der Eintrag steht auf der letzten Seite, also dort, wo Nietzsche oft alltägliche und persönliche Dinge notiert. Es ist angesichts des Wortes «Gesundheitslehre» zu vermuten, dass Nietzsche nicht antike Texte zur Lebenskunst, sondern hygienische und diätetische Schriften meint. ${ }^{451}$ Ein ganzes Drittel von Bocks Buch ist mit «Gesundheitslehre» betitelt und auch sonst ist der Begriff in diesem Sinne weit verbreitet. In genau diesem Monat Juli 1879, und teilweise im selben Notizbuch, in dem sich dieser Eintrag zur Gesundheitslehre findet, entwickelt Nietzsche auch die Entwürfe zu den oben zitierten Passagen über die Lehre der «nächsten Dinge». 452 Und von dieser aus kann man erstaunliche Parallelen zu Schreber und Bock ziehen.

Wie auch immer Nietzsche auf die Wörter «nächste» und «allernächste» Dinge kam, sie gehören jedenfalls zum populären zeitgenössischen Diskurs. Gleich im ersten Satz von Schrebers Zimmergymnastik liest man: «Oft im Leben übersehen oder geringschätzen wir das Einfache, Natürliche und Naheliegende und sind gemeint, unser Heil nur in dem Darüberhinausliegenden finden zu können. So auch in Ansehung unserer Gesundheitsverhältnisse.»453 Und im ersten Jahrgang der deutschen Familienzeitschrift Gartenlaube liest man 1853 folgende Aussage: «Und seltsam! vielleicht gerade das Nächste, was uns umgiebt, das Allernächste, sich selbst, kennen die Meisten nicht.»454 Nun vergleiche man dies - samt der Wortwahl «das Allernächste» und «die

449 Moore 2004, S. 72f. Für die Popularisierung der Wissenschaft in der Gartenlaube vgl. Stockinger 2018, bes. S. 329-353.

$45^{\circ}$ NL 1879, 41[75], KSA 8, S. 594 bzw. N IV 1, S. 50.

$45^{1} \mathrm{Zu}$ diesem Schluss kommt auch Moore 2004, S. 72 und $78 \mathrm{f}$.

452 Die meisten Entwürfe zur Lehre der «nächsten Dinge» sind in N IV 2 und N IV 1.

453 Schreber 1862, S. 5. Ich zitiere Schreber hier und in der Folge nach der mir zur Verfügung stehenden 8. Auflage von 1862 .

454 Dr. L-n 1853, S. 91. Es handelt sich um eine anonym publizierte Artikelserie. Bock wiederum sagt schon im Vorwort der «Unkenntniß des menschlichen Körpers» den Kampf an (Bock 1870, S. VIII). Er sieht in dieser Unkenntnis den Hauptgrund für den falschen Umgang mit dem Körper. Die fehlende Selbstkenntnis war ein geläufiger Topos und hat im 18./19. Jahrhundert Hochkonjunktur, vgl. Sarasin 2001, S. 118-124. 
Meisten» - mit Nietzsches ähnlich gebauter Aussage: «um so mehr möge man zugestehen, dass die alle rnächsten Dinge von den Meisten sehr schlecht gesehen, sehr selten beachtet werden.» ${ }^{455}$ Sprach Schreber oben von Geringschätzung, spricht Nietzsche von der «Missachtung [...] aller nächsten Dinge .» ${ }^{456}$ Bei beiden wird das Argument zunächst unabhängig von der Gesundheit formuliert. Die Gewichtung Schrebers auf Geringschätzung und Nietzsches auf Missachtung richtet sich bei beiden gegen die Gebildeten: Diese würden den Alltag und das Studium des eigenen Körpers nämlich fälschlicherweise für etwas Triviales und Niedriges halten. So beklagt Nietzsche an selbiger Stelle, dass man die Ernährung nicht zum Gegenstand des allgemeinen und steten Nachdenkens mache. ${ }^{457}$

Die Reaktion auf diesen Zustand allgemeiner Unwissenheit war bei Schreber und Nietzsche ähnlich: Gemäss Schreber müsse man die «physischen Bedürfnisse» «in ihrem Wesen gründlich erforschen», während Nietzsche eine umfassende Kenntnis der «nächsten Dinge» fordert. ${ }^{458}$ Schrebers hygienische Methoden wie auch Nietzsches Kenntnis der «nächsten Dinge» sind nie abschliessbar, sondern müssen je nach Lebensphase und Ort ständig neu erarbeitet werden. Deshalb gibt es bei Nietzsche und Schreber keine Universalheilmethode, sondern aufgrund der je einzigartigen und komplizierten Lebensverhältnisse nur individuelle Heilmethoden und Gesundheitszustände. ${ }^{459}$ Mit Nachdruck verweist Schreber auf die je individuellen Voraussetzungen von Körper, Zeit und Ort, denen man nur durch ein «selbstthätiges» Kultivieren der eigenen Körperbewegungen gerecht werden kann. ${ }^{460}$ Je nach Geschlecht, Alter, Physis, sozialer Lage, Klima und Ort sind andere Vorkehrungen zu treffen. Das bedeutet zwar ein nicht abschliessbares Lernen - dafür kann man selbst an sich arbeiten. Damit distanzieren sich Nietzsche und die populären Diätetiker u.a. von philosophischen Positionen, wie jener von Hegel, der abseits des Individuums die klimatische Bedingtheit von Völkern in Bezug auf ihren Geist bestimmt. ${ }^{461}$

\footnotetext{
455 WS 6, KSA 2, S. 542.

456 WS 5 , KSA 2, S. 541.

457 Vgl. ebd.

$45^{8}$ Schreber 1862, S. 12; WS 6, KSA 2, S. 542 f.

459 Schreber 1862, S. 13; MA 286, KSA 2, S. 233: «Mit der Freiheit der Meinungen steht es wie mit der Gesundheit: beide sind individuell, von beiden kann kein allgemein gültiger Begriff aufgestellt werden.»

46o Vgl. Schreber 1862, S. 13 f.

461 Vgl. den Abschnitt «Geographische Grundlagen der Weltgeschichte» in Hegel 1986, S. 105-133.
} 
Wie weit diese Selbsterforschung gehen konnte, zeigt etwa Bock, wenn er dutzende Seiten lang über die richtige Weise des Wohnens referiert: über das Heizen, die Wohnlage, das entsprechende Klima, die geologische Umgebung, die Höhenlage und vieles mehr. Schliesslich gibt er Tipps für Auswanderer, welche ihre bestmöglichen Wohnbedingungen finden wollen. Bock beschreibt nicht bloss eine temporäre Klimakur, sondern die Suche nach einem individuell angepassten Wohnort:

Dass die Beschaffenheit der Wohnung, der Gegend und des Klimas, wo der Mensch lebt, Einfluss auf dessen Befinden haben muss, ist wohl selbstverständlich, da sich jene Wohnorte in Hinsicht auf Luft und Licht, Wärme und Kälte, Trockenheit und Feuchtigkeit, vegetabilische und animalische Beziehungen sehr verschieden und oft so verhalten, dass sie nachtheilig auf den menschlichen Körper einwirken. ${ }^{462}$

Wenig überraschend findet sich dann in Nietzsches Wanderer eine diätetische Klimatologie unter dem Titel «Geistige und leibliche Verpflanzung als Heilmittel». Nietzsche fordert darin:

[...] durch eine medicinische Geographie dahinterzukommen, zu welchen Entartungen und Krankheiten jede Gegend der Erde Anlass giebt, und umgekehrt welche Heilfactoren sie bietet: und dann müssen allmählich Völker, Familien und Einzelne so lange und so anhaltend verpflanzt werden, bis man über die angeerbten physischen Gebrechen Herr geworden ist. Die ganze Erde wird endlich eine Summe von Gesundheits-Stationen sein. ${ }^{463}$

Diese philosophische Verlängerung von Bocks Ausführungen (und von der zeitgenössischen Hereditätslehre) ist eine konsequente Umsetzung der diätetischen Selbsterforschung. Immer bessere Selbstkenntnis bringt mehr Kontrolle. Philipp Sarasin bringt dies zusammenfassend für die Diätetik auf den Punkt: «Wer den Reiz kontrolliert, kontrolliert den Körper - und damit den Geist.» ${ }^{464}$ Auch die zeitgenössischen Reiseführer, welche Nietzsche benutzt, sind auf diese je individuelle Verpflanzung ausgerichtet. Die Reisedestinationen werden mit wissenschaftlichen Erklärungen versehen. Im Falle eines geplanten Kuraufenthaltes wählt man dank diesen Informationen entlang der

\footnotetext{
462 Bock 1870, S. 547.

463 WS 188, KSA 2, S. 634f. Vgl. dazu auch Moore 2004, S. 82f. Eine geografische Klimatologie wurde verschiedentlich gefordert und war Nietzsche beispielsweise durch Mohn bekannt: «Für die Interessen des täglichen Lebens ist es von Wichtigkeit, sowohl den allgemeinen Zustand des Wetters in den verschiedenen Jahreszeiten, als auch seinen $\mathrm{Zu}$ stand an den einzelnen Tagen eines bestimmten Jahres zu kennen.» (Mohn 1875, S. 283).

464 Sarasin 2001, S. 20.
} 
eigenen Leiden einen Kurort. Gerade St. Moritz ist ein Kurort für Dauergäste, die sich aus Gründen der diätetischen Klimatologie für das Engadin entschieden haben. Die Besonderheit von Kurorten besteht weniger im Reiseerlebnis der Fremde als im Kultivieren des Alltäglichen. Während einer Kur bekommen die «nächsten Dinge» (Essen, Trinken, Wohnen, Umgebung, Freizeitbeschäftigungen etc.) eine hohe Relevanz. Deshalb sind die Beschreibungen der einzelnen Kurorte entlang der «nächsten Dinge» aufgebaut. So werden im populären und Nietzsche bestens bekannten Kurortführer Die Heilquellen und Kurorte der Schweiz von Conrad Meyer-Ahrens gleich zu Beginn die «mancherlei kleinen Geschäfte und selbst Sorgen, welche uns auch das Reisen auferlegt», positiv angesprochen und es wurde in der Folge auch nicht mit penibelsten Details zur optimalen Einrichtung der kleinen Geschäfte und alltäglichen Bedürfnisse gespart. ${ }^{465}$ In der Kur wird das Individuum auf sich selbst und die «nächsten Dinge» zurückgeworfen, auf das Atmen, Essen, Trinken, Schlafen, Spazieren, Unterhalten, Waschen, Lesen etc. Fast alle Elemente von Nietzsches Aufzählung der «nächsten Dinge» behandelt Meyer-Ahrens in seiner Einleitung zum richtigen Kuren. ${ }^{466}$ Die Lehre der «nächsten Dinge» repräsentiert ein Ideal der Kurorte: Sie entstand im modernen St. Moritz, auf den für Kurgästen angelegten Spazierwegen und inmitten von Diäten, Trink- und Badekuren.

Eine weitere Überzeugung der aufstrebenden Diätetik ist die Verbindung von geistigen und körperlichen Prozessen. ${ }^{467}$ Stellvertretend sei hier ein zweites Motto aus Schrebers Zimmer-Gymnastik zitiert: «Soll geist'ges Leben wohl gedeih'n, / So muss der Leib die Kraft verleih'n!» ${ }^{468}$ Die geistige Tätigkeit könne durch Gymnastik und Nahrung gestärkt werden. Ein Gedanke, der bei Nietzsche auch für das Spätwerk eine tragende Rolle spielt. Nun könnte man einwenden, dass diese Vorstellung aus dem antiken «Mens sana in corpore sano» längst bekannt sei. Nietzsches Umformulierung klingt aber weniger nach antiker Lebenskunst als nach neuzeitlicher Diätetik, wie sie Hufeland, Bock, Schreber und andere Autoren populär gemacht haben. So lesen wir in Nietzsches Nachlass bereits 1877:

465 Meyer-Ahrens 186o, Bd. 1, S. 1. Nietzsche kannte diesen Reiseführer spätestens seit seiner Basler Zeit, als er seinem früheren Lehrer Ritschl eine Kurort-Empfehlung abgab und auf das Buch verwies, vgl. N. an Ritschl, 17.6.1871, Nr. 138, KGB II 1, S. 201.

466 Vgl. die Einleitung unter dem Titel: «Kurze diätetische Regeln, die beim Gebrauche von Kuren zu beobachten sind» (Meyer-Ahrens 186o, S. 1-26); für Nietzsches Aufzählung vgl. Kap. 3.3.2.

467 Stellvertretend und einflussreich für Nietzsche ist Bain 1874.

468 Schreber 1862, S. 9 sowie ebd.: «Der Mensch ist ein Doppelwesen, bestehend aus einer wunderbaren innigen Vereinigung einer geistigen und einer leiblichen Natur.» 
[...] Ge sun dh eit [...] durch Paarung gesunder Eltern, richtige Kräftigung der Weiber, gymnastische Übungen, die so sehr gewöhnlich und begehrt sein müssen wie das tägliche Brod, Prophylaxis der Krankheiten, rationelle Ernährung, Wohnung, überhaupt durch Kenntnisse der Anatomie usw. ${ }^{469}$

Die Forderung einer Paarung gesunder Eltern steht im Kontext der aufkommenden Vererbungslehren und war weit verbreitet. ${ }^{470}$ Die Hervorhebung der gymnastischen Übung als «Prophylaxis der Krankheiten» ist das exakte Ziel von Schrebers Zimmer-Gymnastik, welche sich an die gesunden Menschen richtet. Hygiene gemäss Schreber heisst nämlich Prävention und nicht Heilung. Die rationelle Ernährung gibt es erst im 19. Jahrhundert und ist eine Trendbewegung der Diätetik. Nietzsche kannte sie nicht nur gut, sondern nutzte sie in Form des beliebten Diätetischen Koch-Buchs von Josef Wiel. ${ }^{471}$ Und die Forderung nach Kenntnissen der Anatomie ist wie eben gesehen das Credo von Schreber, Bock und allen Diätetikern. Es finden sich also spezialisierte Aussagen, welche sich nicht auf die antike Lebenskunst, sondern auf den spezifischen Gesundheitsdiskurs des 19. Jahrhunderts beziehen. ${ }^{472}$ Das Lob auf die Ernährung der Griechen, welches oft als Grundlage für die Interpretation von Nietzsches Lebenskunst benutzt wird, soll in diesem Sinne der zeitgenössischen Diätetik einer Relektüre unterzogen werden:

[Die Griechen] lebten ein paar Jahrhunderte hindurch b e s s er, als wir (in jedem Sinne besser, namentlich viel einfacher in Speise und Trank): da wurden endlich die Gehirne so voll und fein zugleich, da floss das Blut so rasch hindurch, einem freudigen hellen Weine gleich, dass das Gute und Beste bei ihnen nicht mehr düster, verzückt und gewaltsam, sondern schön und sonnenhaft heraustrat. ${ }^{473}$

Der Glaube, dass durch gute Ernährung das «Gehirn» besser durchblutet sei und dadurch besser gedacht würde, ist aufgrund der seit dem 18. Jh. aufstrebenden Hirnforschung in den Diätetik-Ratgebern geläufig. Ausgiebig beschreibt etwa Schreber in der Zimmergymnastik den Stoffwechselprozess von Ernährung, Bewegung, Blut und leiblich-geistiger «Frische» und «Kraft».474 Promi-

469 NL 1877, 23[151], KSA 8, S. 459.

470 Vgl. auch WS 197, KSA 2, S. 640 sowie das Kap. «Nietzsche und das Problem der Vererbung in der damaligen Biologie» in Orsucci 1996, S. 53-57.

471 Vgl. Wiel 1873; N. an Franziska und Elisabeth N., 17.7.1875, Nr. 468, KGB II 5, S. 80: «Die Beefsteaks à la Wiel sind schmackhaft und viel weicher und milder als die uns bekannten.»

472 Die konzise Studie von Brusotti erhellt zahlreiche Facetten der Diätetik, versteht letztere jedoch primär «im Sinn der antiken Diätetik» (1997, S. 133).

473 WS 184, KSA 2, S. 632. Vgl. JGB 188, KSA 5, S. 108-110.

474 Schreber 1862, S. 14. 
nent findet sich dieses Argument schon in Hufelands populärer Makrobiotik: Im Gehirn werden «die feinsten und geistigsten Theile der durch Nahrung und Respiration uns zugeführten Kräfte gesammlet, sublimirt und zum höchsten Grad veredelt, und von da aus durch die Nerven dem ganzen Körper in allen seinen Puncten mitgetheilt.» ${ }^{475}$ Für diesen Kontext des 19. Jahrhunderts und den damaligen Bezug zur Antike, ist Johann Joachim Winckelmann hervorzuheben, der die Diätetik einer breiten Rezeption geöffnet hat und neue Ansätze verfolgte. So finden sich in seinen Gedanken über die Nachahmung der griechischen Werke in der Malerey und Bildhauerkunst einige Abschnitte zu Luft, Ernährung, Körperbau und Klima. ${ }^{476}$ Winckelmann prägte damit den eben bei Nietzsche zitierten Glauben, die Griechen seien klimatologisch, geografisch und physiologisch privilegiert gewesen. Diese materialistische Geschichtsschreibung ergibt ein anderes Griechenbild und verschiebt den Fokus auf die Lebenspraktiken und Umweltkontexte. Nietzsches Bezug auf die Lebensweise der Griechen steht also im Zeichen der zeitgenössischen Griechenrezeption und diese wiederum im Zeichen der Diätetik des 19. Jahrhunderts.

Die Diätetik fördert die Eigenständigkeit der Menschen, indem sie durch Ratgeberliteratur eine Unabhängigkeit von Ärzten, Arzneien, Geräten und damit fremden Autoritäten bezweckt. Es wird das Ideal der selbsttätigen und natürlichen Heilung aus eigener Kraft angestrebt. Bock behauptet sogar, dass jeder vernünftige Mensch ein Arzt sei und durch diätetische Selbstbehandlung jede Heilung bedeutend unterstützen könne. ${ }^{477}$ In diesem Sinne verhindert die Einmischung von anderen Autoritäten die Selbstbeschäftigung und das Erkennen der natürlichen Heilkräfte, die jeder Mensch in sich habe. Auch Schreber betont dies ausdrücklich im Motto der Zimmer-Gymnastik: «Es ist sicherer, in den Folgen belohnender und zudem des Menschen würdiger:

475 Hufeland 1798, S. 145. Diese Thematik wurde etwa durch den Briefwechsel zwischen Kant und Hufeland bekannt. Hufeland wollte die Diätetik als eine Leib und Geist umfassende Lehre verstanden haben. Sarasin zeigt jedoch, dass Hufeland keinen kohärenten Materialismus vertrat, weil er paradoxerweise weiterhin an eine von der Materie losgelöste Seele glaubte (vgl. Sarasin 2001, S. 88).

476 Vgl. Winckelmann 1756, S. 105-109: «Unterdessen war die glückselige Lage ihres Landes allezeit die Grundursach, und die Verschiedenheit der Luft und der Nahrung machte unter den Griechen selbst den Unterschied, der zwischen den Atheniensern und ihren nächsten Nachbarn jenseit des Gebürges war. Die Natur eines jeden Landes hat ihren Eingebornen sowohl, als ihren neuen Ankömmlingen eine ihr einige Gestalt, und eine ähnliche Art zu denken gegeben. [...] Wenn die Natur bey dem ganzen Baue des Körpers, wie bey den Werkzeugen der Sprache verfähret, so waren die Griechen aus einem feinen Stoffe gebildet; Nerven und Muskeln waren aufs empfindlichste elastisch, und beförderten die biegsamsten Bewegungen des Körpers.»

Bock 1870, S. VIII. 
durch Selbstthätigkeit die Gesundheit soweit möglich zu entwickeln und zu e rw erb en, als sie, wenn sie verloren, allein im passiven Hilfesuchen von der Natur oder aus der Apotheke zu erwarte n.» ${ }^{478}$ Es soll möglichst wenig Vermittlung geben. Es geht darum, seine Gesundheit selbstständig zu wahren und gemäss Bock sich «aus den Händen unwissender und gewissenloser Heilkünstler und Charlatane befreien zu können.» ${ }^{479}$

Auch Nietzsche sieht in der eigenständigen Alltagskenntnis den Schutz vor Betrügereien aller Art. Er warnt vor Ärzten und Priestern, welche die Menschen an der Nase herumführen und ihre Notwendigkeit durch angebliches Wissen vortäuschen: Die Unkenntnis gegenüber dem eigenen Körper treibt wie oben dargelegt in eine «beschämende Abhängigkeit und Unfreiheit».480 In der später geschriebenen Vorrede zu Menschliches, Allzumenschliches II von 1886 wird Nietzsche sich selbst als «Arzt und Kranker in Einer Person» bezeichnen. ${ }^{481}$ Auch Kant warnt im berühmten Aufsatz «Was ist Aufklärung» vor Ärzten und Seelsorgern, welche den Gebrauch des eigenen Verstandes verhinderten. ${ }^{482}$ Gemäss Sarasin lautete die «biopolitische Botschaft an die aufgeklärten Bürger»: «Die Harmonie der eigenen Körpermaschine durch eigene Regulationsleistungen aufrechtzuerhalten, [...]. Halte Distanz zu den Ärzten und zur Medizin - zum Rat der Ratgeber, wie man mit Kant sagen könnte.» ${ }^{483}$ So propagiert Schreber mit Ausrufezeichen den Kant'schen Ausruf «Sapere aude!» und Nietzsche fordert im Wanderer, an uns selbst «das Werk der Aufklärung fort z u s e t z e $\mathrm{n}$ ».484 Sein eigener Arzt zu werden ist die konsequente Fortsetzung des aufklärerischen Credos, den eigenen Verstand zu benutzen. Ein Detail am Rande sei hier noch erwähnt: Im selben Jahr 1879 schimpft auch Richard Wagner in der Oktoberausgabe der Bayreuther Blätter gegen verwissenschaftlichte Ärzte und fordert eine Medizin auf Basis von praktischen Erfahrungen. ${ }^{485}$

Wie Nietzsche am Schluss vom Wanderer, stilisiert auch Schreber seine Bewegungslehre zu einer kulturpolitischen Vision. Die kultivierte Körperbewegung führe nämlich zu einem veredelten Menschen, der sich dadurch dem natürlichen Urzustand mehr und mehr enthebe.

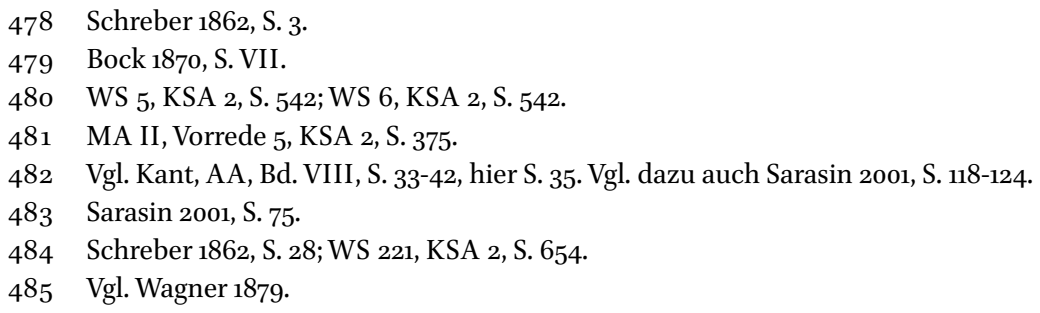


Ebenso wie der höher entwickelte Mensch, mit dem Menschen des Urzustandes verglichen, sich nicht mehr auf unmittelbares und passives Empfangen von Speise und Trank aus den Händen der Natur beschränken und verlassen darf, so liegt es ihm auch ob, seine übrigen physischen Bedürfnisse nicht blos dem Laufe des Lebens zu überlassen, sondern sie in ihrem Wesen gründlich zu erforschen und sie durch eignes Denken und Schaffen in je entsprechender Weise der Natur abzugewinnen und sich zuzurichten, also: das Unbewusst- und Rohnatürliche in das Bewusst- und Edelnatürliche zu verwandeln. Je höher sich das Leben über den unbewussten rohen Naturzustand erhebt, je mehr also der bestimmungsgemäss immer höher und freier sich entwickelnde menschliche Geist auch die Grundbedingungen seiner Existenz unter das Auge der wissenschaftlichen Erkenntniss und der Berechnung nimmt und nehmen muss, um so mehr werden auch die unentbehrlichen physischen Bedürfnisse einer bewussten Harmonisirung mit den allgebietenden Naturgesetzen und mit den höchsten Lebensaufgaben zu unterziehen sein. ${ }^{486}$

Dies entspricht dem Schlussaphorismus vom Wanderer, in dem es nur dem veredelten Menschen möglich wird, die Ketten des Daseins abzuwerfen und sich frei zu bewegen, womit sich der Mensch endgültig von der Tierwelt erhebe. ${ }^{487}$

Wie Nietzsche verbindet auch Schreber die Diätetik mit der Lebenskunst. Schreber verortet seine Zimmer-Gymnastik in einer «hygienischen Gesundheits-Philosophie». Es gehe letztendlich um «Glückseligkeit» und um die wichtigste Kunst überhaupt, um die «Lebenskunst». ${ }^{488}$ Und bei einem weiteren berühmten Vertreter des Diätetik-Genres - Ernst Kapp - heisst es 1845: «Die Heilkunde wird zur allgemeinen Lebenskunst werden.» ${ }^{489}$ Hier wird sichtbar, mit welch hohem Anspruch die populären Gesundheitsratgeber auftreten. Gregory Moore kommt nach seiner Sichtung von Nietzsches populärer Lektüre zu folgendem Schluss: «Nineteenth-century self-help books were not merely concerned with mental and physical well-being. What they attached most importance to - indeed, what ensured the soundness of mind and body was moral hygiene.» 490

Wie unterscheidet sich nun die zeitgenössische Diätetik noch von Nietzsches Lehre der «nächsten Dinge»? Laut Philipp Sarasin habe Nietzsche zusammengefasst, «was die Hygieniker seit rund hundert Jahren schon in ihren

\footnotetext{
486 Schreber 1862, S. 12.

487 Vgl. WS 350, KSA 2, S. 702.

488 Schreber 1862, S. 27. Schreber geht es um weit mehr als die Erhaltung der Gesundheit. Er wollte eine «Orthobiotik» begründen, eine Lehre des richtigen Lebens (bios). So veröffentlichte der junge Schreber 1839 gar ein Buch mit dem Titel Das Buch der Gesundheit oder die Lebenskunst nach der Einrichtung und den Gesetzen der menschlichen Natur.

489 Kapp 1845, S. 444.

490 Moore 2004, S. 86.
} 
populären Ratgebern endlos wiederholt hatten» ${ }^{491}$ Dies ist wie eben gezeigt für die isoliert betrachteten Bestandteile des Wanderers naheliegend. Der Blick auf die Schreibsituation wird jedoch zeigen, dass Nietzsche nicht wie die zeitgenössischen Diätetiker an einer Leib und Geist erfüllenden Gesundheit, sondern an philosophisch ergiebigen Diäten interessiert ist.

\subsubsection{Schreibsituation und diätetische Lebenskunst}

Die Schreibsituation ist eingebettet in eine Lebenskunst im Sinne der Diätetik. In diesem Abschnitt sollen deshalb die in St. Moritz angewandten Selbsttechniken als Schreibsituation kenntlich gemacht werden: Denn die Bandbreite alltäglicher Praktiken erstreckt sich bei Gelehrten nicht nur auf Essen, Kleiden oder Heizen, sondern auch auf Schreiben, Denken und Lesen. Die von Nietzsche im Wanderer als «nächste Dinge» benannten diätetischen Faktoren sind auf die Schreibsituation hin zu optimieren. Doch wie Foucault zeigte, gehört auch das Schreiben selbst zu den zentralen diätetischen Lebenstechniken: «Die gute Führung des Körpers muß, um zur Existenzkunst zu werden, in schriftlicher Form ausgeübt werden, eine Arbeit, die das Subjekt an sich selber zu vollziehen hat [...].» ${ }^{492}$ Die Verwicklung von Lesen und Schreiben in diätetischen Diskursen kann hier nicht behandelt werden. ${ }^{493}$ Es soll jedoch in Bezug auf Nietzsches spazierendes Notieren in St. Moritz der historische Diskurs um Diätetik, Bewegung und Schreiben anhand weniger Beispiele skizziert werden. Nietzsches Konzept auf täglichen Wanderungen und in frischer Bergluft philosophische Gedanken zu sammeln, ist eingebettet in diätetische Ratschläge.

\section{Diätetik des spazierenden Schreibens}

Während Menschliches und die Vermischten Meinungen noch im Zeichen der Resteverwertung standen, basiert der Wanderer auf frei und unterwegs geschriebenen Notizen aus dem Sommer 1879. Die Entscheidung im Freien zu notieren, ist diätetisch motiviert. Viele Ratgeber warnen vor sitzendem Schreiben und Lesen. Die ständige Sitzhaltung gilt als gesundheitsschädigend. Das Gebot des Spazierens, der Aufenthalt im Freien und das Wandern sind Gegenstand unzähliger diätetischer Ratschläge. So gebietet Bock: «Ein Hauptgesetz für den

491 Sarasin 2002, S. 202. Vgl. auch Moore 2004, S. 88: «What seems strange, though, is that Nietzsche's «morality〉, his recommendations in Ecce homo, differ so little from the conventional medical wisdom of the time.»

492 Foucault 1986, Bd. 2, S. 140.

493 Vgl. dazu Butzer 1998 und Campe 1991, S. 765, der anhand einiger Schreibfibeln (u.a. von Erasmus von Rotterdam) beschreibt, wie die Beschäftigung mit der optimalen Schreibsituation zu einer Diätetik des Schreibens führt, in welcher Tageszeit, Wetter, Ernährung, Heizung oder Sexualität ausführlich diskutiert werden. 
Menschen, zumal für den zu sitzender Lebensweise und zum Aufenthalte in düsterer Wohnung gezwungenen ist es: so oft als nur möglich die freie Luft zu geniessen [...].» ${ }^{494}$ Und Schreber richtet seinen Appell zu körperlicher Bewegung besonders an die «Stubengelehrten, Bureaubeamten, Comptoiristen und Alle mit bewegungsloser Berufsthätigkeit». 495 Diese diätetischen Ratschläge sind massgeblich mitverantwortlich für das schiefe Licht, das den sogenannten Stuben- und Büchergelehrten im 19. Jahrhundert nunmehr anhaftet. Zudem gehörte das Spazieren zu den Hauptbeschäftigungen der Kurierenden.

In der Ökonomisch-technologischen Enzyklopädie von $183^{2}$ liest man, dass Spaziergänge in Gärten oder Innenräumen zwar dem Körper dienen können, jedoch nur Spaziergänge im Freien den Geist stärken. ${ }^{496}$ Zudem wird dem Spaziergang ein bewussteres Wahrnehmen von Körper und Umgebung, also der «nächsten Dinge» attestiert. Der Populärphilosoph Karl Gottlob Schelle widmet dem Spaziergang 1802 ein ganzes Buch und dem Zusammenhang von Spaziergang und Geist ein eigenes Kapitel unter dem Titel «Einfluss des einsamen Spatzierengehns im Freyen auf Entwickelung des eigenen Geistes».497 Andreas Mayer hat das in seiner Studie zur Bewegung im 19. Jahrhundert treffend zusammengefasst: «Die Körperbewegung wird damit zur zentralen Bedingung für die geistige Erfassung und Aneignung der Welt durch den Menschen, wobei der Erkenntnisakt untrennbar mit einer spezifischen Stimmungslage gleichgesetzt wird.» ${ }^{498}$ Der Spaziergang wird zur Technik der eigenen Gesundheit, Anregung, geistigen Stärkung und Entwicklung.

Schelle geht jedoch noch einen Schritt weiter: Er betont nicht nur die wechselseitige Anregung von freier, äusserer und innerer Natur in der Gehbewegung, sondern auch die persönliche Affinität eines Denkers zu bestimmten Gegenden: «Endlich hat jede Gegend, jede Parthie, jede Ansicht der Natur ihren besondern Charakter, der sich durch gewisse Gefühle, die sie in uns erregen, zu erkennen giebt.» ${ }^{499}$ Der Spaziergang führt eine Denksituation herbei, in der das eigene Denken und die Umgebung ein individuelles Verhältnis eingehen. Hier erst kommt man Nietzsches Ausspruch, er habe seine «Art Natur g e fun d en», auf die Spur. ${ }^{500}$ Schelle sieht die vielfältigen Bezüge von Spazieren und Denken u.a. in einer Stelle aus Jakob Thomsons Jahreszeiten

\footnotetext{
494 Bock 1870, S. 407.

495 Schreber 1862, S. 35 .

496 Vgl. Korth 1832 , S. 583.

497 Schelle 1802, S. 71-80. Vgl. auch die einschlägigen Texte des überzeugten Wanderers Johann Gottfried Seume, v.a. die Vorrede zu Mein Sommer 1805 in Seume 1806, S. III-XXVIII.

498 Mayer 2013, S. 20.

499 Schelle 1802, S. 126.

$500 \quad$ N. an Gast, 12.7.1879, Nr. 865, KGB II 5, S. 426.
} 
bewiesen. Die kunstvollen Naturbeschreibungen zeugen laut Schelle von eigener «Anschauung» und «einsamer Selbstbetrachtung». ${ }^{501}$ In diesem Kontext sind die beiden intensiv bearbeiteten Aphorismen «D o p pelgängerei der Natur» und «Et in Arcadia ego» auch als Belege für die tiefe Verbundenheit von Nietzsches Philosophie mit St. Moritz anzusehen. ${ }^{502}$ Sie beweisen, dass auch Nietzsche im Engadiner Arkadien war.

\section{Diätetik des Lesens}

Es kann im diätetischen Zusammenhang nicht mehr verwundern, dass just in einem der drei zentralen Aphorismen zu den «nächsten Dingen» die Praktik des Lesens auftaucht. Nietzsche hat den Bezug unkenntlich gemacht und es ist erforderlich, einen Blick in das Arbeitsheft M I 3 zu werfen, um ihn zu rekonstruieren. Im Aphorismus «Die irdische Gebrechlichkeit und ihre $\mathrm{H}$ a u p tursa ch e» formuliert Nietzsche einige Beispiele für die Missachtung der «nächsten Dinge». Die ersten Zeilen lauten:

Man trifft, wenn man sich umsieht, immer auf Menschen, welche ihr Lebenlang Eier gegessen haben, ohne zu bemerken, dass die länglichten die wohlschmeckendsten sind, welche nicht wissen, dass ein Gewitter dem Unterleib förderlich ist, dass Wohlgerüche in kalter klarer Luft am stärksten riechen, dass unser Geschmackssinn an verschiedenen Stellen des Mundes ungleich ist, dass jede Mahlzeit, bei der man gut spricht oder gut hört, dem Magen Nachtheil bringt. ${ }^{503}$

Auf der Doppelseite 72/73 im Arbeitsheft M I 3, wo der Entwurf zum hier zitierten Aphorismus steht, findet sich ein durchstrichener Zusatz: «dass Gedankensammlungen nicht durchgelesen, geschweige vorgelesen werden dürfen, wenn sie nicht unschmackhaft werden sollen.» (Abb. 24) Warum Nietzsche diesen Zusatz wieder gestrichen hat, wird man nie in Erfahrung bringen können. ${ }^{504}$ Offenbar listet Nietzsche das Lesen von «Gedanken-Sammlungen» in derselben Aufzählung mit dem Essen von Eiern und dem Wahrnehmen von Gerüchen auf. Dass dieser Zusatz nicht zufällig hingekritzelt wurde, zeigt sich

\footnotetext{
501 Schelle 1802, S. 77 .

502 WS 338, KSA 2, S. 699; WS 295, KSA 2, S. 686.

503 WS 6, KSA 2, S. 542.

504 Jedenfalls scheint es so, als ob hier die Selbstreflexion über das Schreiben unerwünscht wäre. Eine philosophische Erklärungsmöglichkeit wäre, dass Nietzsche entsprechend dem lockeren Gestus des Wanderers (Kap. 3.2.2) dem Leser keine Leseanleitungen aufdrängen wollte (was er sich in anderen Werken nicht versagen wird).
} 


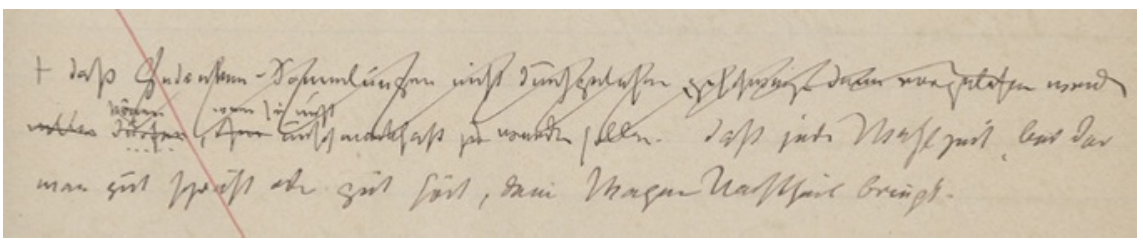

Abb. 24 Arbeitsheft M I 3, S. 73

an der bereits vorgenommenen Bewertung des Lesens als Genuss. ${ }^{505}$ Zudem steht das Beispiel mit der «Mahlzeit» räumlich direkt unter dem Lesen. Die Engführung von leiblichen und geistigen Vorgängen führt zur Frage, in welchem Lesemodus die gelesenen Gedanken schmackhaft bzw. unschmackhaft werden. ${ }^{506}$ Es geht deshalb weniger um ein philologisches Leseideal als um eine je individuelle Lektüre, die weit über den gedruckten Buchstaben hinaus von der Lesesituation formiert wird. Deshalb braucht es eine Diätetik des Lesens.

\section{Philosophie als Diät}

Die Einbettung der Schreibsituation in die Lebensführung wurde ein erstes Mal deutlich in den Vermischten Meinungen dargelegt:

Eine Kunst, wie sie aus Homer, Sophokles, Theokrit, Calderon, Racine, Goethe ausströmt, als Ueberschuss einer weisen und harmonischen Lebensführung - das ist das Rechte, nach dem wir endlich greifen lernen, wenn wir selber weiser und harmonischer geworden sind, nicht jene barbarische, wenngleich noch so entzückende Aussprudelung hitziger und bunter Dinge aus einer ungebändigten chaotischen Seele, welche wir früher als Jünglinge unter Kunst verstanden. ${ }^{507}$

Hier wird nicht die Schreibkunst (Grammatik, Stil, Rhythmus etc.) betont, sondern der Zusammenhang von Kunst und Lebensführung. Die handwerkliche Autorschaftskonzeption in Menschliches steht noch im Zeichen der Loslösung von einem überspannten, leidenschaftlichen Kunstideal, wie Wagner es mit seinen Opern verkörpert. In den Vermischten Meinungen und im Wanderer

505 Vgl. auch den Aphorismus «Lob der Sentenz», in dem Nietzsche die Sentenz als appetitsteigerndes Salz beschreibt und sich damit laut Greiner auf Bacon beziehe (VM 168, KSA 2, S. 446; Greiner 1972, S. 18).

506 Mit dem «Genuss» wird auf die diätetische Ebene verwiesen, die bereits Kant dem Durchlesen unterstellte: «Das bloße Lesen ist genießen, ohne zu verdauen; es ist schwelgen.» (Kant, AA, Bd. XVI, S. 869).

507 VM 173, KSA 2, S. 453. 
wird das Handwerk zunehmend mit der Lebensführung zur Schreibsituation verbunden: «Ach, es ist viel Langeweile zu überwinden, viel Schweiss nöthig, bis man seine Farben, seinen Pinsel, seine Leinwand gefunden hat! - Und dann ist man noch lange nicht Meister seiner Lebenskunst, - aber wenigstens Herr in der eigenen Werkstatt.» ${ }^{508}$ Die dingliche, technische und materiale Situation kreativer Arbeitsprozesse wird mit dem Verweis auf Farben, Pinsel und Leinwand ebenso hervorgehoben wie die Einbettung derselben in die Lebensführung. Die Beherrschung der Schreibkunst führt zur nächsten Herausforderung, der Lebenskunst.

Im Brief zur Manuskriptsendung an Peter Gast findet sich eine interessante Formulierung Nietzsches über die einmonatige Trinkkur, welche er in St. Moritz macht: «Mein Sommer-Programm ist ausgeführt: 3 Wochen Mittelhöhe (in Wiesen), 3 Monate Engadin, und der letzte Monat davon die eigentliche St. Moritzer Trink-kur, deren beste Wirkung man erst im Winter spüren soll. Dieses Durchführen eines Programms thut mir wohl». ${ }^{509}$ Nietzsche muss für sein Wohlbefinden Programme setzen und durchführen. Die Kur bzw. die Diät ist ein Programm, das den Alltag auf vielfache Weise strukturiert. Ein solches Programm, das lässt sich nach den zahlreichen Belegen für die Diätetik des Schreibens nun folgern, ist auch die Schreibsituation von St. Moritz. Nietzsche berichtet Overbeck im Juli, dass seine «Tageseintheilung, Lebens- und Nahrungsweise» mitunter aus einem «System von 50 oft sehr delikaten Rücksichten» bestehe. ${ }^{510}$ Man denke hierbei an die selbstverordnete und durchgeführte Diät: «Mit dem Mage n bin ich jetzt, wo ich mich selber im Zimmer beköstige (Milch Eier Zunge Pflaumen (getrocknete) Brod und Zwieback) völlig in Ordnung.» ${ }^{511}$ Und im Oktober an Gast: «ich habe eben die Minuten und Viertelstunden der «Energie des Gehirns`, von der Sie sprechen, zusammenzustehlen, einem leidenden Gehirne a b zustehlen.» ${ }^{512}$ Nietzsche bezeichnet mit Blick auf den fertigen Wanderer seinen ganzen Sommer als «Programm»: Der Wanderer ist das Resultat eines diätetischen Programms, das gleich einer Kur durchgeführt wurde.

Nietzsche verbindet die Wechselverhältnisse von Ort, Klima, Diätetik und Philosophie ein Jahr nach dem Wanderer abermals zu einer Diätetik (und hat damit einmal mehr Erfahrungen des Schreibens und der Schreibsituation in Philosophie übersetzt). Ende 188o beschreibt er nämlich seine Philosophie als

\footnotetext{
508 WS 266, KSA 2, S. 667 .

509 N. an Gast, 11.9.1879, Nr. 880, KGB II 5, S. 442.

$510 \quad$ N. an Overbeck, 11.7.1879, Nr. 864, KGB II 5, S. 425.

511 N. an Franziska N., 21.7.1879, Nr. 867, KGB II 5, S. 428.

512 N. an Gast, 5.10.1879, Nr. 889, KGB II 5, S. 45of.
} 
Diätetik und verarbeitet dies kurz darauf in der Morgenröte zu einer kohärenten Formulierung über die Diätetik des philosophischen Schreibens:

A uf Umwe ge n. - Wohin will diese ganze Philosophie mit allen ihren Umwegen? Thut sie mehr, als einen stäten und starken Trieb gleichsam in Vernunft zu übersetzen, einen Trieb nach milder Sonne, heller und bewegter Luft, südlichen Pflanzen, Meeres-Athem, flüchtiger Fleisch-, Eier- und Früchtenahrung, heissem Wasser zum Getränke, tagelangen stillen Wanderungen, wenigem Sprechen, seltenem und vorsichtigem Lesen, einsamem Wohnen, reinlichen, schlichten und fast soldatischen Gewohnheiten, kurz nach allen Dingen, die gerade mir am besten schmecken, gerade mir am zuträglichsten sind? Eine Philosophie, welche im Grunde der Instinct für eine persönliche Diät ist? Ein Instinct, welcher nach meiner Luft, meiner Höhe, meiner Witterung, meiner Art Gesundheit durch den Umweg meines Kopfes sucht? ${ }^{513}$

Hier wird philosophisch ausgesprochen, was in der Schreibsituation in St. Moritz praktisch gelebt wurde: Philosophische Gedanken sind immer auch Denkprodukte ihrer diätetischen Umgebung. Diese Wechselwirkung ist jedoch individuell, was durch die Possessivpronomen («meiner Luft» etc.) angezeigt wird. Diese Formulierung zwingt die Lesenden zur Anwendung auf sich selbst und verwehrt ihnen zugleich, die Philosophie als eine vom Individuum unabhängige Tätigkeit zu denken. In einer augenzwinkernden Briefstelle überspitzt Nietzsche das Verhältnis der Diät und seiner Bücher ins Extreme: «Mir fiel dieser Tage ein, daß ich in drei Jahren «die Morgenröthe〉, <die fröhliche Wissenschaft〉 und den 〈Zarathustra〉 gemacht habe: in Anbetracht, daß diese Litteratur unter den Begriff 〈Liebigscher Fleischextract〉 gehört, darf ich mich über meine 〈Gesundheit〉 nicht verdrießen - eher v e r w u n d e r $n$ !» 514

Eine Philosophie wird somit $\mathrm{zu}$ einem erweiterten physiologischen Prozess, in dem der Autor nur ein notwendiger Umweg, ein Filter ist, um Hygiene, Diätetik, Klima, Körper und Psyche mit Hilfe der Vernunft in Philosophie zu übersetzen. Philosophie ist so gesehen ein Übersetzungsprozess der Lebensumstände. ${ }^{515}$ In diesem Sinne schreibt Nietzsche noch während seines

513 M 553, KSA 3, S. 323. Vgl. auch die Vorstufe NL 1880, 7[15], KSA 9, S. 319f.: «Diese ganze Philosophie - ist sie mehr als ein Trieb zu beweisen, daß reife Früchte, ungesäuertes Brod, Wasser, Einsamkeit, Ordnung in allen Dingen mir am besten schmecken und am zuträglichsten sind? Also ein Instinkt nach einer richtigen Diät in Allem? Und eine milde Sonne!».

514 N. an Overbeck, 28.03.1884, Nr. 497, KGB III 1, S. 488. Für Zusammenhänge zwischen Ernährung und Philosophie bei Nietzsche und Feuerbach vgl. Sommer 2012.

515 Die oft vorgenommen Parallelisierung von Diätetik und Triebphilosophie bei Nietzsche ist für die ersten Aphorismenbücher nicht haltbar. Vgl. etwa den Kommentar zum obigen Aphorismus M 553 in Schmidt 2015, S. 439. 
St. Moritzer Aufenthalts an Peter Gast: «für mich ist Venedig Ihre B rüte stätte [...]. Inzwischen habe ich me in e Art Natur gefunden, [...].»516 Peter Gast arbeitet in Venedig an seinen Kompositionen, weshalb Nietzsche vom Ausbrüten spricht. Die Situationsabhängigkeit des Denkens ist zwar mitunter der gesundheitlichen Situation Nietzsches geschuldet, führt jedoch - und darauf kommt es hier an - zu einer auf das Philosophieren ausgerichteten Lebensführung. Es wird noch zu zeigen sein, dass die Philosophie des Werdens zum Experimentieren mit der Lebensführung, der Diät und der Schreibsituation einlädt (Kap. 4.3).

\section{Schreibsituation und Geschichtswissenschaft}

Es besteht eine Parallele zwischen Nietzsches Arbeitsweise und der von ihm damals aufmerksam verfolgten Literaturgeschichte nach der Methode Hyppolite Taines: Die historisch-materialistische Methode Taines erklärt ganze Literaturepochen durch die überindividuellen Umstände von Rasse, Milieu und Moment. In der von Nietzsche um 1879 intensiv gelesenen Einleitung der Geschichte der englischen Literatur fragt Taine: «Welches ist der moralische Zustand, der eine gegebene Literatur, Philosophie, Gesellschaft, Kunst, Kunstgruppe hervorbringt? Und welches sind die zur Hervorbringung dieses moralischen Zustandes geeignetsten Verhältnisse der «Rasse, des Zeitpunktes und der Sphäre $»^{2517}$ Die berühmte Trias von Taines Literaturanalyse - Rasse, Milieu, Moment - beinhaltet durch das Milieu neben den sozialen und politischen Bedingungen auch physische und klimatische. ${ }^{518}$ Taine dachte dies radikal materialistisch: Denn würde man all die Kräfte und Aspekte von Rasse, Milieu und Moment berechnen können, so könnte man mit einer Formel die Zukunft der Zivilisation bestimmen. In diesem Sinne ist bei ihm Literatur ein Konglomerat seiner Trias, von dem aus sich gut auf die Gesellschaft und ihre Beschaffenheit schliessen lässt. So schreibt Taine in Bezug auf das Klima: «Ein geändertes Klima, eine andere Lage führen andere Bedürfnisse herbei, folglich

516 N. an Gast, 12.7.1879, Nr. 865, KGB II 5, S. 426. Nietzsche bezieht sich im Brief auf Goethes Lido-Begeisterung.

517 Taine 1878, Bd. 1, S. 30. Für Nietzsches Lesespuren vgl. das erhaltene Exemplar HAAB C 568a.

518 Vgl. für Taines Methode v.a. Taine 1878, Bd. 1, S. 15-29; Wellek 1977, S. 26-54. Leopold Katscher stellt im Vorwort fest, dass Taine «in jeder geschichtlichen, künstlerischen, literarischen u.s.w. Erscheinung ein Ergebniß der Rasse, der Zeitumstände und der Sphäre (Umgebung, Klima u. dgl.) erblickt, auf Grundlage welcher Faktoren er die Haupteigenschaft (〈faculté maîtresse`) der betreffenden Erscheinung eruiert, um dann aus dieser faculté das ganze Wesen der Erscheinung zu erläutern, zu induciren.» (in: Taine 1878, Bd. 1, S. IX). 
ein System anderer Handlungen, folglich ein System anderer Gewohnheiten, folglich endlich ein System anderer Fähigkeiten und Triebe.» ${ }^{519}$

Taine räumt ein, dass man für jeden einzelnen Maler oder Musiker aufgrund ihrer Individualität eine eigene Analyse machen müsste. Dies habe damals erst Stendhal gemacht - ein ebenfalls von Nietzsche 1879 gelesener Autor. Taine rühmt insbesondere Stendhals Gespür, die Psychologie der Autoren während der Werkentstehung zu analysieren: «Niemand hat uns besser gelehrt, die Augen zu öffnen, zu schauen, zuerst die Zeitgenossen und die Gegenwart, dann die alten authentischen Belege zu betrachten, zwischen den Zeilen zu lesen, und in alten Drucken, in altem Gekritzel zu erkennen, unter welchen Gefühlen, bei welcher Gedankenbewegung und in welchem Geisteszustande die Belege geschrieben wurden.» ${ }^{520}$ Stendhal legt bei seinen Analysen grossen Wert auf Nationalität, Klima, Temperament etc. Dieses Verfahren bezeichnet aus Sicht der Geschichtsschreibung die neue Haltung zur Autorschaft als Konglomerat von gesellschaftlichen, natürlichen und individuellen Umständen. Während die Historiker wie Taine die Produktionsumstände zum besseren Verständnis kultureller Phänomene beiziehen, nutzt Nietzsche seine Reflexionen über die Schreibsituation als praktische Anleitung zur schriftstellerischen Produktion. Es ist Nietzsches St. Moritzer Leistung, das diätetische Analysemodell in ein praktisches Produktionskonzept umgewandelt zu haben. Anstatt vergangene Kulturphänomene durch Kontextualisierung aufzulösen, konzipiert Nietzsche zukünftige Schreibsituationen, in denen keine vorhersehbaren, sondern neue Gedanken entstehen sollten. Damit durchbricht Nietzsche den Determinismus, der Taines Modell anhaftet.

\subsubsection{Fazit}

Nietzsches Wende von der Kulturpolitik zur Lehre der «nächsten Dinge» ist grundlegend, sah er doch eineinhalb Jahre zuvor in Menschliches den Freigeist als zukünftigen Regenten einer höheren Kultur. Es ist im Wanderer zwar weiterhin von einem veredelten Menschen die Rede, es lässt sich aber keine durchgehende Systematik von Freigeistern und höherer Kultur mehr feststellen. Nietzsche hat die Kulturpolitik nicht fallen gelassen, ihr aber die Diätetik vorangesetzt. Die Kulturpolitik ist im Wanderer zwar nicht abwesend, jedoch in die ferne Zukunft verschoben (Kap. 3.4.1).

519 Ebd., S. 17.

520 Ebd., S. 31. 
Die Diätetik der «nächsten Dinge» ist das zentrale Anliegen des publizierten Wanderers. ${ }^{21}$ Der Einbezug von «nächsten Dingen» wurde ein Charakterzug von Nietzsches Denken: so etwa im Diktum vom «Leitfaden des Leibes» oder in der geforderten Philosophie der Ernährung. ${ }^{522}$ Die Lehre der «nächsten Dinge» ist der diätetische Vorläufer für die leibphilosophische Verbindung von Leib und Seele, Körper und Geist. Die Hinwendung zu einer physiologischen Sicht auf kulturelle Phänomene, allen voran auf die Moral, ist hier schon weitgehend angelegt. ${ }^{523}$ Ein Streifzug durch die zahlreichen Passagen zu Klima, Örtlichkeit, Fortbewegung, Ernährung, Verdauung, Atmung oder Körperhaltung in Nietzsches Werken macht dies deutlich. So lässt sich an den Formulierungen der frühen 188oer Jahre die inhaltliche und sprachliche Nähe der Lehre der «nächsten Dinge» noch klar erkennen. Insbesondere die Morgenröte zeugt an vielen Stellen von einem diätetischen Denken. ${ }^{524}$ Dies schlug sich auch im Nachlass nieder. So etwa 1881, als Nietzsche die hintere Umschlagseite seiner intensiv gelesenen Emerson-Ausgabe mit einer Liste von «nächsten Dingen» beschreibt (Abb. 25).

Vom Kleinsten Nächsten auszugehen:

1) die ganze Abhängigkeit sich feststellen, in die / man hineingeboren und erzogen ist

2) den gewohnten Rhythmus unsres Denkens, Fühlens, / unsere intellektuellen Bedürfnisse und Nahrungsweisen

3) Versuche der Veränderung, zunächst mit den Ge- / wohnheiten zu brechen (zb. Diät /

Sich geistig an seine Widersacher einmal anlehnen, in ihrer Luft zu leben versuchen

reisen, in jedem Sinn

521 Zurecht schreibt Del Caro 2004, S. 220: «There is every reason to believe that Nietzsche regarded his discovery and advocacy of the closest things as one of his principal philosophical teachings.»

522 NL 1884, 26[374], KSA 11, S. 249; FW 7, KSA 3, S. 379; vgl. zudem Del Caro 2004, Kap. «The Quotidian Nietzsche», S. 212-221.

523 Ich argumentiere hier gegen Maria Cristina Fornari, welche diesen Umbruch auf die Lektüre Spencers anfangs 1880 zurückführt (vgl. Fornari 2005, S. 312f.). Die Kritik Nietzsches an Spencer - etwa jene, dass es keine gleichen Menschen gäbe und deshalb auch keine allgemeine, sondern nur individuell bestimmbare Lebensbedingungen - erschliesst sich schon weitgehend aus der hier beschriebenen Lehre der «nächsten Dinge». Vgl. auch die Vorstufe von WS 188, KSA 2, S. 534f. aus dem Notizbuch N IV 2, S. 3: «Historie ist Arzeneimittellehre» $[\mathrm{sic}]$.

524 Vgl. etwa M 553, KSA 3, S. 323f. oder M 462, KSA 3, S. 278: «Die chronischen Krankheiten der Seele entstehen wie die des Leibes, sehr selten nur durch einmalige grobe Vergehungen gegen die Vernunft von Leib und Seele, sondern gewöhnlich durch zahllose unbemerkte kleine Nachlässigkeiten.» 


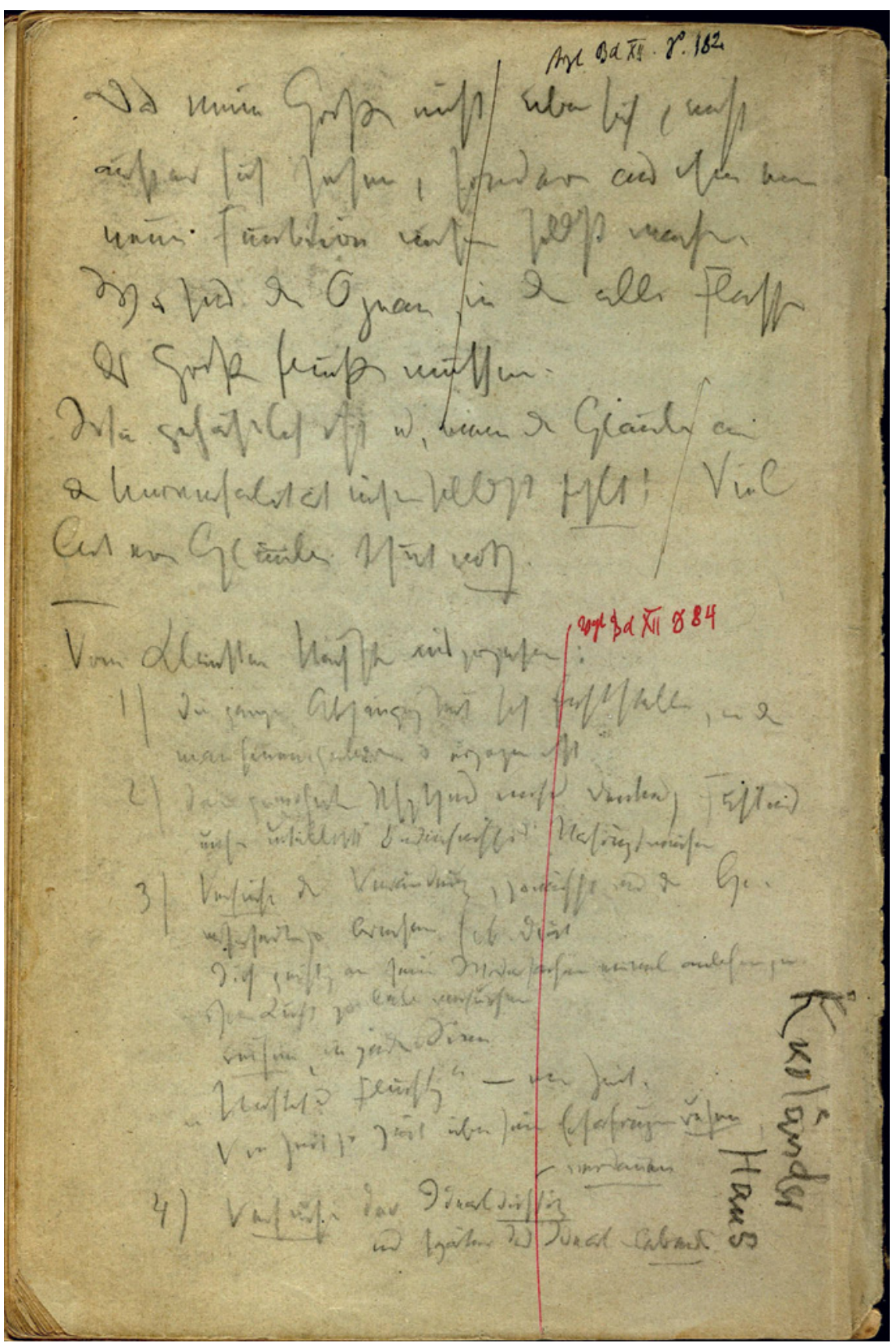

Abb. 25 Nietzsches Emerson-Ausgabe und seine Notizen auf dem hinteren Buchumschlag 
«Unstet und flüchtig» - eine Zeit.

Von Zeit zu Zeit über seinen Erfahrungen ruhen, / verdauen.

4) Versuche der Idealdichtung / und später des Ideal-Lebens. ${ }^{525}$

Luca Lupo sieht die «nächsten Dingen» gar als Vorläufer für die grosse Vernunft des Leibes in Also sprach Zarathustra. ${ }^{526}$ Und in Ecce Homo schliesslich finden sich die Aufzählungen von «nächsten Dingen» gehäuft und in höchster Ähnlichkeit zum Wanderer: «diese kleinen Dinge - Ernährung, Ort, Clima, Erholung, die ganze Casuistik der Selbstsucht - sind über alle Begriffe hinaus wichtiger als Alles, was man bisher wichtig nahm [...] Alle Fragen der Politik, der Gesellschafts-Ordnung, der Erziehung sind dadurch bis in Grund und Boden gefälscht $[\ldots]$ - dass man die 〈kleinen〉 Dinge, will sagen die Grundangelegenheiten des Lebens selber verachten lehrte...»527

Die hohe Wertschätzung des Leibes, die individuelle Diätetik und die Freude am Leben finden sich auch deutlich in der Fröhlichen Wissenschaft wieder: «Eine Gesundheit an sich giebt es nicht [...] Somit giebt es unzählige Gesundheiten des Leibes [...].» ${ }^{528}$ Zudem formuliert Nietzsche eine Lösung für das in diesem Kapitel beschriebene kulturpolitische Dilemma zwischen Wissenschaft und Kunst: «dass zum wissenschaftlichen Denken sich auch noch die künstlerischen Kräfte und die practische Weisheit des Lebens hinzufinden, dass ein höheres organisches System sich bildet [...].»529 Doch nicht nur die geschriebene Lehre der «nächsten Dinge», sondern auch die diätetische St. Moritzer Schreibsituation ist das Vorbild für die «g rosse Gesundheit» und die «Kunst der Transfiguration»:

Ein Philosoph, der den Gang durch viele Gesundheiten gemacht hat und immer wieder macht, ist auch durch ebensoviele Philosophien hindurchgegangen: er kann eben nicht anders als seinen Zustand jedes Mal in die geistigste Form undFerne umzusetzen,--diese Kunst derTransfiguration i s t eben Philosophie. ${ }^{530}$

Die diätetisch verstandene Selbstkenntnis sowie der Wille, mit diesem Wissen die eigene Existenz nach bestimmten Kriterien zu formen, findet sich erstmals in der Lehre der «nächsten Dinge» und in der St. Moritzer Schreibsituation. Die «Verbindung von Diätetik, ästhetischem Urteil und dichterischer Selbstbezüglichkeit» wird im Wanderer grundgelegt und findet in weiteren Werken immer

\footnotetext{
525 NL 1881,13[20], KSA 9, S. 621f. (eigene Darstellung). Vgl. dazu die Liste zur «Kur des Einzelnen» in NL 1881, 11[258], KSA 9, S. 539 und Kap. 4.3.

526 Lupo 2004, S. 112.

527 EH, KSA 6, S. 295f. Vgl. auch EH, KSA 6, S. 374.

528 FW 120, KSA 2, S. 477.

$529 \quad \mathrm{FW}_{113}, \mathrm{KSA}_{3}$, S. 474.

$530 \quad \mathrm{FW}$, Vorrede $3, \mathrm{KSA}_{3}$, S. 349.
} 
wieder ihren Niederschlag. ${ }^{531}$ So werden die Leser in «Scherz, List und Rache» explizit als «Esser» einer Mahlzeit angesprochen. ${ }^{532}$ In der «Kunst der Transfiguration» verschränkt Nietzsche die Wissenschaft, Kunst und Diätetik in ein kulturpolitisches Modell höherer Lebensweisen. ${ }^{533}$ Der grosse Unterschied vom Wanderer zur Fröhlichen Wissenschaft besteht darin, dass Nietzsche in St. Moritz mehr am praktischen Schreibverfahren als an der kohärenten Verflechtung seiner Philosophie interessiert ist.

Im vorletzten Teil dieses Kapitels sollte gezeigt werden, dass Nietzsche populäre Literatur las und für seinen Alltag, die St. Moritzer Schreibsituation sowie für seine Philosophie benutzt hat. Nietzsches Lehre der «nächsten Dinge» entspringt der philosophischen Würdigung des Alltags, seiner populären Lektüre und seiner diätetischen Lebensführung. Dass Nietzsche die für den Wanderer so zentrale Lehre der «nächsten Dinge» nie definiert und bloss lose Reihen von wenigen Beispielen anführt, liegt meines Erachtens auch darin begründet, dass diätetische und hygienische Vorschriften im späten 19. Jahrhundert weitgehend bekannt waren. Zudem ist das Ideal der «nächsten Dinge» auch eines der Kurorte. Der Wanderer entsteht eingebettet in die Praktiken der Zimmergymnastik und des Spazierens. Die vielen Gemeinsamkeiten populärer Einflüsse und Nietzsches Lehre der «nächsten Dinge» sollten beachtet werden, wenn man Nietzsche zu einem Gegner der «Gartenlaube-Kultur ohne Wertbedürfnisse» stilisiert. ${ }^{534}$ Es ist nicht der Nietzsche von 1879 , sondern die Rezeption, welche sich schwer damit tut. So anerkennt beispielsweise Karl Pestalozzi die Orientierung des mittleren Nietzsche am xenophontischen Sokrates, jedoch ohne den Kontext von Nietzsches Diätetik: «Die Themen [bei Xenophon] sind alltagsnaher als bei Plato, es geht um Freundschaft, Selbstbeherrschung, charakterliche Voraussetzungen für einen guten Bürger oder Staatsmann, sogar um Alltägliches wie z. B. darum, ob man zum Fleisch Brot essen solle. Kurz, der Xenophontische ist ein banalisierter Sokrates.»535 Diese «nächsten Dinge» sind für den mittleren Nietzsche keine Banalität, sondern hatten vielfache Wirkungen auf Nietzsches späteres Werk. Nietzsches Lehre der «nächsten Dinge» ist in vieler Hinsicht eine philosophische Umformulierung des zeitgenössischen Diätetikdiskurses.

Vor dem Hintergrund der Populärwissenschaften bekommt der von Kittler einseitig ausgelegte «Telegrammstil» (Kap. 3.2.4) eine andere Bedeutung: Im 19. Jahrhundert war die Vorstellung von Nerven als elektrisch geladene Drähte

\footnotetext{
531 Benne 2015b, S. 33 .

532 FWS 1, KSA 3, S. 353. Für eine entsprechende Analyse von «Scherz, List und Rache» vgl. Benne 2015b.

533 FW 382, KSA 3, S. 635-637.

534 Reschke 2015a, S. 49.

535 Pestalozzi 2004, S. 85.
} 
geläufig, weshalb eine Bezugnahme auf die Telegrafie wiederholt vorgenommen wurde. ${ }^{536}$ Nietzsche könnte beispielsweise bei Bock gelesen haben, dass Empfindungen wie Telegramme zum Hirn «telegraphirt» werden. ${ }^{537}$ Die Metapher des Telegrammstils liesse sich deshalb wie folgt auf die St. Moritzer Schreibsituation übertragen: Der Philosoph verkuppelt seinen Organismus durch Spaziergänge gleichsam maschinell mit dem Notizbuch und der St. Moritzer Landschaft. Die vom Organismus empfundenen Reize werden durch das Drahtnetz der Nerven ans Hirn telegrafiert und ans Notizbuch versendet. Schreibhand, Notizbuch und Bleistift fungieren als Telegrafenapparat. Der Telegrammstil ist so gesehen auf das Schreibverfahren und die Schreibsituation, nicht auf das aphoristische Resultat bezogen.

Einige Publikationen über Nietzsches Verhältnis zu den Naturwissenschaften sind mittlerweile erschienen. Neben der Frage, wie «ernsthaft» - d.h. wie wissenschaftlich - Nietzsche sich mit den Naturwissenschaften beschäftigte, sollte auch nach populärwissenschaftlichen Einflüssen geforscht werden. ${ }^{538}$ Trotzdem muss mit Blick auf die Schreibpraxis der Gleichsetzung von Nietzsche und den populären Ratgebern eine Differenz entgegengehalten werden: Während die populären Diätetiker die Gesundheit, Beweglichkeit oder das verlängerte Leben um ihrer selbst willen anstreben, setzt Nietzsche das diätetische Wissen für seine Philosophie ein. Im diätetischen Sommerprogramm von 1879 entstehen Notizbücher, Arbeitshefte und schliesslich ein Buch. Die Dynamik der Philosophie als diätetisches Experiment führt zur Philosophie des Werdens (Kap. 4.2).

Denken, Lesen und Schreiben sind bei Nietzsche mit diätetischen Einflüssen wie Essen, Bewegung, Geschmack oder Klima verknüpft. Die Diätetik bildet ein Modell, an und mit dem die Schreib- und Lesereflexionen wechselseitig entstehen. Die Diätetik beeinflusste nicht nur die Lehre der «nächsten Dinge», sondern auch andere Philosopheme. So wird etwa die Zimmergymnastik auch als philosophisches Modell für die Moral verwendet. Im Aphorismus «Nöthigste Gymnastik» fordert Nietzsche dazu auf, sich jeden Tag etwas zu verzagen. ${ }^{539}$ Dies sei eine unentbehrliche, tägliche Gymnastik, sofern man freudvoll und unabhängig bleiben wolle. Das Prinzip der täglichen Zimmergymnastik wird

536 Vgl. Daum 2002, S. 346; Sarasin 2001, S. 350 .

537 Bock 1870, S. 637; vgl. ebd., S. 100.

538 Solies 2013, S. 109. Diese Haltung steht in der Tradition von Karl Schlechta: Man sprach Nietzsche die wissenschaftlichen Fachkenntnisse ab, um ihn philosophisch umso ernster zu nehmen (Schlechta 1966, S. 1443f.). Leider ging dadurch auch die Reflexion über populärwissenschaftliche Einflüsse unter.

WS 305 , KSA 2, S. 689. 
hier also auf die Moral übertragen. An anderer Stelle wird die Gymnastik sogar zum Modell für die Frage, weshalb die Philosophie Lust bereitet: «Erstens und vor Allem, weil man sich dabei seiner Kraft bewusst wird, also aus dem selben Grunde, aus dem gymnastische Uebungen auch ohne Zuschauer lustvoll sind.» ${ }^{540}$ Kurz: Zimmergymnastik - Gymnastik «ohne Zuschauer» - als Modell für die Lust an der Philosophie! In diesem Sinne ist das Aphorismenbuch die konsequente Form, um dem Leser so viel interpretative Eigenständigkeit wie möglich zu geben bzw. ihn anzuregen und zum Mitmachen zu zwingen. Vom Diätetikdiskurs her betrachtet, sind Aphorismen «Denk-Kochrezepte» und 〈Denkgymnastik〉.

\subsection{Schreiben und Demokratie}

Nachdem nun die zentrale Stellung von Autorschaft, Lesen und Diätetik im Wanderer sowie in der St. Moritzer Schreibsituation dargelegt worden ist, soll nun deren enge Verknüpfung mit Nietzsches politischen Ansichten am Beispiel der Demokratie aufgezeigt werden. Nietzsches Annäherung an die Demokratie ist die meistrezipierte Thematik aus dem Wanderer. So bemerkt etwa Bruce Detwiler: «especially in The Wanderer and His Shadow [...] Nietzsche sounds far more favorably disposed toward democracy than in his earlier or later periods.» ${ }^{541}$ Die Demokratisierung bezeichnet im Wanderer nicht nur einen staatspolitischen Wandel, sondern eine umfassende Wende. Urs Marti konstatiert jedoch zurecht: «So entschieden Nietzsche in Der Wanderer und sein Schatten für die Demokratie plädiert, so unbestimmt bleibt, was er darunter versteht.» ${ }^{542}$ Auch wenn dies nicht restlos zu klären ist, soll im Folgenden die Demokratiethematik im Wanderer möglichst genau dargelegt werden (3.4.1), um danach deren Modellierung anhand des Allmählichen und des Plötzlichen aufzuzeigen: So korreliert die Demokratisierung mit der Produktionsästhetik des allmählich arbeitenden Handwerker-Autors und mit der diätetischen Vorstellung einer allmählich fortschreitenden Diät (3.4.2). Dabei wird gezeigt, dass das Aphorismenbuch einerseits der philosophischen Forderung eines

540 MA 252, KSA 2, S. 209 f.

541 Detwiler 1990, S. 171; vgl. auch Kap. 8, S. 169-188. Und Ottmann (1999, S. 123), beschreibt Nietzsches Politik dieser Zeit «als Politik eines geeinten friedlichen Europa, als Politik, die mit der Epoche der Demokratie rechnet, als Politik, die sich an bürgerliche Gesellschaft und Sozialismus annähert und doch von beiden grundsätzlich geschieden ist». Marti (1993, S. 159) spricht von einer «Demokratie-freundlichen Periode» bei Nietzsche.

542 Marti 1993, S. 198. 
europäischen Gedankenguts und einer Selbstaufklärung, andererseits den demokratischen Schreibweisen und Publikationsformen entspricht (3.4.3).

\subsubsection{Annäherung an die Demokratie}

Schon in Menschliches konstatiert Nietzsche die Unaufhaltsamkeit der Demokratie. Er gesteht den «Vielen» zu, dass sie «ihres Glückes und Unglückes eigene Schmiede» sein dürfen. Jedoch betont er im Sinne Voltaires die Beschränktheit und Unterlegenheit dieser Mehrheit: «quand la populace se mèle de raisonner, tout est perdu.» ${ }^{543}$ Nietzsche befürchtet, dass die «Mission» der Demokratie in der Entfesselung der Privatperson und im Niedergang der Nationalstaaten besteht. ${ }^{544}$ Man habe sich auf die Demokratie einzustellen wie auf ein Erdbeben. ${ }^{545}$ Die Demokratie verhindere zudem die eigentliche Aufgabe der Kultur, das Hervorbringen des Genius. ${ }^{546}$ Obwohl Nietzsche in Menschliches die Hoffnung äussert, dass der demokratische Staatenzerfall in ferner Zukunft auch sein Gutes mit sich bringen könne, bleibt er insgesamt einer elitären Kulturpolitik des Genius verhaftet. Die Entgegensetzung von elitärer Kulturpolitik und Demokratie ist zentral: Solange alle gesellschaftlichen Bemühungen auf die Erzeugung höherer Menschentypen hinauslaufen, gibt es für das Wohl der Vielen keinen Platz in der Politik.

Im Wanderer präsentiert Nietzsche die Demokratie in verändertem Ton. Er akzeptiert den demokratischen Wandel und dessen Konsequenzen: so etwa Sicherheit, Friedenszeiten, Gesundheit, Menschenrechte der geistigen und leiblichen Freiheit sowie Ermöglichung langfristiger Planung durch Verhinderung von Zerstörung. Über die Ziele der Demokratie heisst es: «Die Demokratie will möglichst Vielen Un abhängigkeit schaffen und verbürgen, Unabhängigkeit der Meinungen, der Lebensart und des Erwerbs.» ${ }^{547}$ Nietzsche thematisiert nicht die Demokratie als konkrete Regierungsform, sondern den Prozess

543 MA 438, KSA 2, S. 284.

544 MA 472, KSA 2, S. 305 .

545 MA 438, KSA 2, S. 284.

546 Vgl. exemplarisch den Aphorismus «Genius und idealer Staat im Widerspruch», in dem das Wohlleben von möglichst Vielen und die Gleichberechtigung als Hindernis für das Entstehen des Genius bezeichnet werden (MA 235, KSA 2, S. 196f.). Hier argumentiere ich ausnahmsweise gegen Patton, der glaubt, dass sich die Kulturpolitik des Genies mit der Wertschätzung der elementaren demokratischen Institutionen, v.a. der Selbstbestimmung, verträgt (vgl. Patton 2014, S. 108). Das Recht der Selbstbestimmung wird zu Gunsten des Genies aufgegeben. Das Genie entsteht gemäss Nietzsche gerade dort, wo die Ungleichheit des Besitzes und der Rechte gross sind: Grosse Unterschiede fördern grosse und aussergewöhnliche Menschen; kleine Unterschiede führen zu einem langweiligen Mittelmass, vgl. auch Siemens 2009, S. 35 .

WS 293, KSA 2, S. 685 . 
der Demokratisierung sowie dessen Eigenschaften und Konsequenzen. Seine Ansichten zur Demokratie im Wanderer liegen nicht systematisch, sondern über das ganze Buch zerstreut vor. Nietzsche besitzt keine Demokratietheorie. Die folgenden zehn Punkte sind deshalb begriffliche Zuspitzungen:

Erstens sei der Prozess der Demokratisierung unaufhaltsam. Wer gegen die Demokratie ankämpfe, gebrauche jene Mittel, welche die Demokratie bereitstellt und treibe sie dadurch an. So würden selbst die sozialistischen Bestrebungen die Demokratisierung befördern und durch progressive Steuern für Reiche einen Mittelstand schaffen, der den Sozialismus schnell vergessen machen werde. ${ }^{548}$ Die Unaufhaltsamkeit der Demokratie ist eine bekannte These aus Alexis de Tocquevilles Über die Demokratie in Amerika, das durch die Warnung vor einer «Tyrannei der Mehrheit» bis heute bekannt und aktuell geblieben ist. Tocquevilles Studie war in Europa das Standardwerk über die politische Entwicklung und Situation in Nordamerika. Nietzsches politische Ansichten im Wanderer zeigen, dass er schon 1879 auf die eine oder andere Weise Tocquevilles Thesen kannte. ${ }^{549}$

Zweitens löse die Demokratie zwingend den Adel und die Monarchie ab: Die Demokratisierung höhlt die ehemaligen Monarchien durch einen «stätig geübten gesetzmässigen Druck» aus. ${ }^{550}$ Das Kaisertum werde fortan noch als «prachtvoller Zierrath» der Demokratie dienen. Nietzsche argumentiert ähnlich wie Walter Bagehot, für dessen Schriften er sich 1879 stark interessiert. Bagehot unterscheidet in The English Constitution zwischen den «dignified parts», der englischen Krone, und den «efficient parts», dem Parlament und dem Kabinett. ${ }^{551}$ Nietzsche verschärft das Argument dahingehend, dass eine Scheinherrschaft der Monarchie gegen aussen ein effizientes Funktionieren

548 WS 292, KSA 2, S. 684; fast identisch wie Tocqueville 1836, Bd. 1, S. 5. Zudem bemerkt Nietzsche in den Vermischten Meinungen, dass die früheren Feinde der dynastischen Regierungsformen und der Sozialismus als Antipoden zusammengehören, jedoch die Demokratie eine grundsätzliche Umwälzung mit sich bringt (vgl. VM 316, KSA 2, S. 506f.).

549 Vgl. WS 287, KSA 2, S. 682. Einige von Nietzsche in dieser Zeit rezipierte Autoren waren massgeblich von Tocqueville beeinflusst, vgl. Marti 1993, S. 58-87. Für das Jahr 1879 sind Karl Hillebrand, Hyppolyte Taine sowie Jacob Burckhardt hervorzuheben. Hillebrand, dessen Bücher Nietzsche 1878 intensiv liest, gilt als «eigentlicher Schüler Tocquevilles im deutschen Sprachraum» (Marti 1993, S. 82). In den Vorlesungen von Burckhardt ist immer wieder von Tocqueville die Rede. So bemerkt Burckhardt: «Staatsmänner suchen die 〈Democratie` jetzt nicht mehr zu bekämpfen, sondern irgendwie mit ihr zu rechnen, die Übergänge zum für unvermeidlich Geltenden möglichst gefahrlos zu machen.» (2000, S. 272) Für Nietzsches eigene Tocqueville-Lektüre liegen erst ab 1880 Beweise vor, vgl. Fornari 2014, S. 329f.; Dies. 2009, S. 216-223.

$55^{\circ}$ WS 281, KSA 2, S. 676.

$55^{1}$ Bagehot 1867, S. 5. Dieser Rückgriff erhärtet sich, wenn man den Entwurf betrachtet, in dem noch klar vom konstitutiven Parlament als gewaltfreie Schwächung des Königtums 
der demokratischen Institutionen im Innern ermöglicht. Insofern ist die Monarchie für Nietzsche und Bagehot keine Dekoration, sondern eine wirksame Institution. Laut Nietzsche hat es die Demokratie in der Hand, aus dem Königund Kaisertum eine «Null» zu machen. Diese Null müsse analog zur Zahlenwelt jedoch an die richtige Stelle gestellt werden, um den Wert der Demokratie zu verzehnfachen. ${ }^{552}$ Das ist mit ein Grund, weshalb Nietzsche gegen eine reine Parteien-Demokratie ist. Er will einen Pluralismus verschiedener und möglichst unabhängiger Gruppen, welche an der Regierung partizipieren (vgl. zehntens).

Drittens führe die unaufhaltsame Demokratisierung zum Niedergang des Nationalstaates und damit zu einer Europäisierung. In Menschliches hiess es dazu noch, dass die Demokratie durch eine entfesselte Privatisierung den Staat letztendlich untergrabe und daher keine gangbare Alternative sei. Deshalb sollte die Staatenordnung noch «eine gute Weile» beibehalten werden. ${ }^{553}$ Im Wanderer ist die Übergangsform nicht mehr die Staatenordnung, sondern die europäisch-demokratische Gemeinschaft. Der europäische Völkerbund ist das unausweichliche Ziel: «Das praktische Ergebniss dieser um sich greifenden Demokratisirung wird zunächst ein europäischer Völkerbund sein [...].»554 Nietzsche sieht die Demokratisierung als europäischen Prozess und modelliert die zukünftige Ordnung nach dem Modell von föderalistischen Kantonen.

Viertens wird die Demokratisierung als Schutzmassnahme definiert: «Die demokratischen Einrichtungen sind Quarantäne-Anstalten gegen die alte Pest tyrannenhafter Gelüste [...].»555 Die Demokratisierung sei der einzig mögliche Kompromiss, um nicht den Rückfall ins Mittelalter zu riskieren. Das kommt in der Zuordnung der Demokratie zu den «prophylaktischen M a s s r e g eln» für eine neue Zeit zum Ausdruck. ${ }^{556}$ Langfristige Sicherheit, Wohlstand, Wohlfahrt und gleichgestellte Tauschmöglichkeiten bedingen sich gegenseitig. Mit der Schutzfunktion der Demokratie meint Nietzsche nicht die Parteien und Wahlverfahren, sondern die demokratischen Institutionen. Diese Sicherheit ist umso nötiger, weil die Demokratie von ihrem Wesen her «neue-

gesprochen wird, vgl. N IV 1, S. 23. Hier wie an anderen Stellen dieses Kapitels verdanke ich einige Hinweise Daniel Brühlmeier.

$55^{2}$ WS 281, KSA 2, S. 676.

553 MA 472, KSA 2, S. 307; vgl. auch MA 474, KSA 2, S. $308 f$.

554 WS 292, KSA 2, S. 684.

555 WS 289, KSA 2, S. 683 .

556 WS 275, KSA 2, S. 672. Es wäre zu untersuchen, wieviel Spencer schon in Nietzsches Ansichten steckt, da sich bei Spencer die Vorstellung eines Staates als «Anstalt des Schutzes vor äußerer und innerer Aggression» findet (Ottmann 1999, S. 132). 
rungssüchtig[ ] und versuchslüstern[ ]» sei. ${ }^{557}$ Die Schutzfunktion und langfristige Planung der Demokratie sind für Nietzsches Werk aussergewöhnlich. ${ }^{558}$ Wie direkt Nietzsche seine Meinungsänderung im Wanderer exponiert, zeigt sich daran, dass er dasselbe Wort wie in Menschliches verwendet: Damals kritisierte er die fehlenden «Maassregeln» der Demokratie zur Gewährleistung langfristiger Planung, und nun, im Wanderer, sieht er gerade in der Demokratie ein Glied in der Kette von «Massregeln», welche die langfristige Stabilität mitgarantieren wird. Die Dauerhaftigkeit war Nietzsche schon in Menschliches wichtig, wozu er Machiavelli zitierte: «Das grosse Ziel der Staatskunst sollte D a u er sein, welche alles Andere aufwiegt, indem sie weit werthvoller ist, als Freiheit». ${ }^{559}$ Der Unterschied zu Menschliches besteht lediglich darin, dass Nietzsche die Demokratie als Modell solcher Dauerhaftigkeit - und zwar der stabilsten Dauerhaftigkeit - entdeckt hat.

Fünftens werden Kriege und Umstürze als Gefahr verstanden. Gewaltsame Auseinandersetzungen verursachen grosse Schäden und zerstören die Leistungen langfristiger kultureller Arbeit. Nietzsche versteht die Demokratie als allgemein gesetzmässigen Vorgang und die Kriege als den einzigen Ausweg, diesen Prozess aufzuhalten. Im Frühwerk sollte ein heftiges Auf und Ab von Friedens- und Kriegszeiten zur stetigen Erneuerung und Regeneration hin in eine höhere zukünftige Kulturform führen. Der Krieg als Mittel zur Verjüngung einer Kultur bzw. gegen deren Ermattung ist eine Metaphorik, welche Nietzsche sehr vertraut ist von Jacob Burckhardts Vorlesungen und Texten. ${ }^{560} \mathrm{Im}$ Wanderer dienen die Kriege nunmehr zur Selbsterhaltung überkommener Tyrannen. Indem Nietzsche den Krieg nicht mehr als notwendige Erneuerung, sondern als kräfteraubende Katastrophe ansieht, kommt auch hier die Demokratie zu hohem Ansehen. So seien gar Standesheere letztlich abzuschaffen, weil sie die Wahrscheinlichkeit von Kriegen erhöhen. Das Militär erzeuge bei den Leuten «das Bild einer barbarischen, in Gefahr schwebenden Gesellschaft.»561 Die Standesheere dienen vordergründig zur Verteidigung, erregen jedoch zwingend das Misstrauen anderer Staaten. Je grösser die

557 WS 292, KSA 2, S. 684.

$55^{8}$ Vgl. dazu Gerhardt 1983, S. 125, Fussnote 50: «Die Betonung der Selbsterhaltung gilt für die mittlere Phase in Nietzsches philosophischer Entwicklung. Mit der Herausbildung des Konzepts des «Willens zur Macht〉 tritt die Funktion der Selbsterhaltung zurück.» V.a. der späte Nietzsche ist «contra Selbsterhaltung» - so der Titel des Aufsatzes von Günter Abel 1982.

559 MA 224, KSA 2, S. 189. Und weiter: «Nur bei sicher begründeter und verbürgter grösster Dauer ist stetige Entwickelung und veredelnde Inoculation überhaupt möglich.»

560 Vgl. die Vorlesung zum Studium der Geschichte, Burckhardt 200o, bes. S. 242-245.

561 WS 279, KSA 2, S. 674. 
eigenen Verteidigungsanlagen, desto grösser der implizite Vorwurf an die anderen Akteure. Nietzsche bezeichnet deshalb Standesheere als eine «Inhum an ität», die «schlimm und schlimmer als der Krieg» sei. ${ }^{562}$ Die Auflösung vonStandesheeren verlangtbereits Kant in seiner SchriftZumewigen Frieden. ${ }^{563}$ Während Kant jedoch eine Vertragslösung vorlegt, fordert Nietzsche die freiwillige Selbstentwaffnung der Mächtigsten.

\begin{abstract}
Der Lehre von dem Heer als einem Mittel der Nothwehr muss man ebenso gründlich abschwören, als den Eroberungsgelüsten. Und es kommt vielleicht ein grosser Tag, an welchem ein Volk, durch Kriege und Siege, durch die höchste Ausbildung der militärischen Ordnung und Intelligenz ausgezeichnet, und gewöhnt, diesen Dingen die schwersten Opfer zu bringen, freiwillig ausruft: «w ir zerbrechen das Schwert»- und sein gesammtes Heerwesen bis in seine letzten Fundamente zertrümmert. Sich wehrlos machen, während man der Wehrhafteste war, aus einer Höhe der Empfindung heraus, das ist das Mittel zum wirklich en Frieden, welcher immer auf einem Frieden der Gesinnung ruhen muss: während der sogenannte bewaffnete Friede, wie er jetzt in allen Ländern einhergeht, der Unfriede der Gesinnung ist, der sich und dem Nachbar nicht traut und halb aus Hass, halb aus Furcht die Waffen nicht ablegt. Lieber zu Grunde gehen, als hassen und fürchten, und z w e i mal lie b e r zu Grunde gehen, als sich hassen und fürchten machen,-diess muss einmal auch die oberste Maxime jeder einzelnen staatlichen Gesellschaft werden! ${ }^{564}$
\end{abstract}

Diese Passage gehört zu den erstaunlichsten des Wanderers überhaupt. Der Frieden dient nicht wie im Früh- und Spätwerk als Übergangszeit für neue Kriege, sondern wird als erhabene Gesinnung und als eigenständiger Zustand beschrieben. Der Gedanke eines friedlichen Europas ist hier skizziert. Noch in Menschliches waren die Kriegsbedenken vor allem darauf reduziert, dass in den Kriegen die «Höchstgebildeten zum Opfer» gebracht und Kulturgüter zerstört würden, wodurch sich das Erreichen höherer Kulturstufen massiv verzögert. ${ }^{565}$ Ein Nutzen wird dem Militär im Wanderer aber noch zugestanden:

\footnotetext{
562 WS 284, KSA 2, S. 678.

563 So schreibt Kant im dritten Präliminarartikel zum ewigen Frieden: «Stehende Heere (miles perpetuus) sollen mit der Zeit ganz aufhören.» (Kant, AA, Bd. VIII, S. 345)

564 WS 284, KSA 2, S. $678 f$.

565 MA 442, KSA 2, S. 288. Urs Marti hat nachdrücklich darauf hingewiesen, dass Nietzsche die Vorfälle im Zuge der Pariser Kommune nur sehr selektiv erschütterten: «Nicht der Aufstand, sondern der 〈Pariser Brand hat ihn «für einige Tage völlig vernichtet und aufgelöst in Thränen und Zweifeln`. Die Zerstörung von Kunstwerken lässt ihm die 〈ganze wissenschaftliche und philosophisch-künstlerische Existenz〉 als eine Absurdität erscheinen.» (Marti 1993, S. 145) Noch 1878 denkt Nietzsche an die Erschütterung dieses Vorfalls in tiefem Schmerz zurück. Er notiert sich unter «Gefährdung der Cultur» folgende Dinge: «Krieg. Tiefster Schmerz, Brand des Louvre. Schwächung des Culturbegriffs
} 
jenen, dass die unaufhaltsame Demokratie nicht zu schnell, sondern allmählich eingeführt werde. ${ }^{566}$ Ein ungebremster Wechsel in ein demokratisches System gefährde die Stabilität und berge Risiken. Deshalb tauge das Militär zur Verlangsamung dieses Prozesses. Es sei ein nützlicher «Hemmschuh der Cultur».567

Sechstens braucht es ohne bewaffnete Kriege folgerichtig Ersatzformen des Krieges. Denn auch im Wanderer hat sich die Logik, dass Kriege einen kulturellen Nutzen haben, nicht geändert. Krieg ist für eine Kultur unentbehrlich. Die gewalttätige Auseinandersetzung ist gemäss Menschliches jedoch nur eine spezifische Ausformung des Krieges. Friedlich gewordene Gesellschaften erfanden «Surrogate»: so etwa die Engländer die Abenteuerreisen und gefährlichen Schifffahrten. Nietzsche bezweifelt aber, dass diese Ersatzformen den Krieg samt seinem Energiegewinn kompensieren können. Zwar bestand bereits die Einsicht, dass Kriege eine Gesellschaft «ermatten»; die Lösung bestand indessen darin, umso furchtbarere Kriege zu führen. Deshalb gibt es laut Menschliches «einstweilen kein anderes Mittel» als den Krieg:

Man wird noch vielerlei solche Surrogate des Krieges ausfindig machen, aber vielleicht durch sie immer mehr einsehen, dass eine solche hoch cultivirte und daher nothwendig matte Menschheit, wie die der jetzigen Europäer, nicht nur der Kriege, sondern der grössten und furchtbarsten Kriege - also zeitweiliger Rückfälle in die Barbarei - bedarf, um nicht an den Mitteln der Cultur ihre Cultur und ihr Dasein selber einzubüssen. ${ }^{568}$

Offenbar hat dieses «einstweilen» nur ein gutes Jahr gedauert. Denn im Wanderer hat Nietzsche seine Einschätzung geändert. Da der Krieg als Heilmittel nur kurzfristige Erfolge, jedoch viel Zerstörung mit sich bringe, setzt Nietzsche auf Ersatzformen des Krieges, besonders auf die Diplomatie. Ihr wird unter dem Titel «Sieg der De mokratie» eine wichtige Rolle zuteil. So brauche es zukünftige Diplomaten, «die zugleich Culturforscher, Landwirthe, Verkehrskenner sein müssen und keine Heere, sondern Gründe und Nützlichkeiten

(das Nationale), Bildungsphilister.» (NL 1878, 30[166], KSA 8, S. 552) Vgl. für die frühe Kriegsbegeisterung exemplarisch CV 3: Nietzsche kritisiert darin die «Kriegsfurcht» und die zunehmenden Versuche den «Angriffskrieg» unwahrscheinlich zu machen. Der Krieg sei «für den Staat eine [...] Nothwendigkeit» (CV 3, KSA 1, S. 774).

566 Vgl. WS 279, KSA 2, S. 674f. Das «Militärwesen» sei «ein posthumes Werk der Vergangenheit, welches für die Räder der Gegenwart nur den Werth eines Hemmschuhes haben kann.»

567 Ebd., S. 674 .

568 MA 477, KSA 2, S. 478; vgl. auch MA 444, KSA 2, S. 289. 
hinter sich haben.» ${ }^{569}$ Diplomatie ist so gesehen eine höhere Form des Krieges: Der Krieg wird an interdisziplinäre Diplomaten delegiert, welche mit Argumenten und Nützlichkeiten verhandeln. Es ist entscheidend, dass Nietzsche schon in Menschliches die Machtgleichgewichte nicht mehr als objektive Gegebenheit, sondern als Resultat einer Aushandlung versteht. Dabei betont er, dass die Gleichmächtigen «sich [...] verständigen und über die beiderseitigen Ansprüche [...] verhandeln».570 Nietzsche schreibt, dass das Recht nicht die physischen Kräfteverhältnisse wiedergibt, sondern bloss die Einschätzung, wie «werthvoll, wesentlich, unverlierbar, unbesiegbar» der Andere «erschein $t » .{ }^{71}$ Gerade weil Nietzsche das Recht nicht legitimiert, interessieren ihn die praktischen Aushandlungspraktiken. Meine These ist deshalb, dass Nietzsche im Wanderer trotz Friedenszugeständnissen ein kriegerisches Denken beibehält, jedoch den Krieg zunehmend als kulturelle Praktik verstand, die auf verschiedene Weise realisiert werden kann. Nietzsche ist nicht gegen den Krieg, sondern gegen den «bewaffnete[n] Frieden». ${ }^{572}$ Erst die Möglichkeit, die Funktionen des Krieges zu delegieren, machten es für Nietzsche denkbar, vom Krieg wegzukommen. Es fragt sich deshalb angesichts der kommenden Europäisierung, ob Nietzsche an eine Gesellschaft denkt, die auf den gewaltsamen Krieg verzichten kann? Damit würde er sich in Kants politische Philosophie einreihen, die ein europäisches Weltbürgertum forderte und gemäss der eine vollendete Kultur des Kriegs nicht mehr bedarf. ${ }^{573}$ Obwohl sich Nietzsche nirgends deutlich dazu äussert, gibt es eine delikate Aussage, die den Krieg als Dekadenzphänomen erscheinen lässt: «Das ewige Leben-wollen und Nicht-sterben-können ist aber selber schon ein Zeichen von Greisenhaftigkeit der Empfindung: je voller und tüchtiger man lebt, um so schneller ist man bereit, das Leben für eine einzige gute Empfindung dahin zu geben. Ein

569 WS 292, KSA 2, S. 684. Ein Jahr zuvor in den Vermischten Meinungen hiess es noch, dass Diplomaten «von Berufswegen, also in aller Unschuld» Gelegenheit für grosse Kriege schaffen würden (VM 320, KSA 2, S. 510). Zudem ist es historisch beachtenswert, dass der Vorschlag für geschulte Diplomaten im 19. Jahrhundert schon daher demokratisch ausgerichtet ist, weil dieses Amt anhand von Kompetenzen und nicht aufgrund der Klassenzugehörigkeit vergeben wird. Schon Mill fordert in seiner Tocqueville-Rezension «geschulte[ ] Politiker» $(1875$, S. 66).

$570 \quad$ MA 92, KSA 2, S. 89.

571 MA 93, KSA 2, S. gof. Vgl. auch Gerhardt: «Es ist die einsichtige Macht, nicht pure Gewalt, die hier das Recht begründet. Recht ist das Produkt wechselseitiger, auf künftige Handlungen projizierter Machtschätzungen.» (Gerhardt 1983, S. 127).

572 WS 284, KSA 2, S. 679 .

573 Kant, AA, Bd. VIII, S. 121. Kant bemerkt aber auch, dass bis zur vollendeten Kultur ein ewiger Friede nicht denkbar sei. 
Volk, das so lebt und empfindet, hat die Kriege nicht nöthig.» ${ }^{574}$ Die hier mit «Völker» bezeichneten Nationen wehren sich im Prozess der Europäisierung mit Kriegen gegen ihre Auflösung. Nun bezeichnet Nietzsche solche Nationen als «greisenhaft», weil ihr Widerstand daher rührt, dass sie nicht «tüchtig» und «voll» gelebt hätten. Die Nation hat ausgedient und soll sich nicht länger «greisenhaft» an der Macht festhalten. So gelesen bezeichnet Nietzsche den Krieg unter Nationalstaaten als Dekadenzphänomen.

Im Zuge der Ablehnung gewaltsamer Kriege anerkennt Nietzsche siebtens den Frieden als eigenwertigen Zustand der Macht. So wird eingehend dargelegt, wie zwei verfeindete Stämme durch einen dritten Stamm zum Frieden gezwungen wurden. Letzterer befand sich mit seinen Besitztümern in einer abgeschlossenen und daher für die anderen zwei Stämme nicht angreifbaren Lage. Dieser dritte Stamm drohte nun den beiden anderen, sich im Kriegsfall mit dem Angegriffenen zu verbünden. In der friedlichen Folgezeit profitierten alle Stämme von zunehmendem Wohlstand, wofür sich der dritte Stamm ein grosses Ansehen erwarb. Was den zwei verfeindeten Stämmen jedoch als Tugend der Uneigennützigkeit erschien, war auch zum Nutzen des dritten Stammes. ${ }^{575}$ Nietzsche entdeckt am Beispiel der drei Stämme den Frieden als aktiv ausgehandeltes Machtgleichgewicht. Das diplomatische Verhandeln des dritten Stammes fungiert dabei als Surrogat für den bewaffneten Krieg. Während Gerechtigkeit in Menschliches nur unter gleichmächtigen Vertragspartnern vorkommen konnte, wird anhand des Stammesbeispiels eine komplexere Variante skizziert, welche unter Einbezug der individuellen Situation der Stämme diverse Gleichgewichtszustände und Machtpotenziale ermöglicht. Es handelt sich nicht um ein statisches, sondern um ein dynamisches Gleichgewicht. Volker Gerhardt hebt diese wechselseitige Dynamik der Stämme und des Gesamtzustandes wie folgt hervor: «Die Gleichgewichte werden nicht nur die jeweils autorisierten Seiten, sondern auch das durch sie gebildete Ganze erhalten. Einzelnes und Ganzes, Element und System können unter Gleichgewichtsbedingungen gleichermaßen überdauern». ${ }^{576}$ Die drei Stämme erhalten also nicht bloss sich selbst, sondern auch das Machtgleichgewicht unter ihnen. Thermodynamisch gesehen ist die Energie verschiedener Kräfte immer existent, wobei sie im geschlossenen System als Gleichgewicht die höchste Wirkung entfalten. Anders gesagt: Auch wenn der dritte Stamm

574 WS 187 , KSA 2, S. 634 .

575 Vgl. WS 190, KSA 2, S. 636-638.

576 Gerhardt 1983, S. 129. Diese doppelte Sicht auf die einzelnen Akteure und das Ganze sei typisch für die Nietzsche bekannte Wärmelehre, klassische Mechanik und politische Ökonomie (vgl. ebd.). 
durch seine abgelegene geografische Position die Möglichkeit hätte, sich aus dem Konflikt rauszuhalten, so würde er dadurch ein höheres Energiepotenzial verhindern. Das Energiegleichgewicht ist etwas Besonderes, das durch Vorsichtsmassnahmen erhalten werden soll - zu diesen Massnahmen gehört die Demokratie, ihre Diplomaten und ihre Institutionen. ${ }^{577}$ Es ist zentral für Nietzsches neue Ansichten zum Frieden, dass er diesen als Machtgebilde erkennt und nicht länger als passiven Ausdruck der Ohnmacht behandelt wie noch im Frühwerk. Ebenso verabschiedet er die abstrakte Vorstellung, ein Krieg sei das gesunde Messen und Reinigen zweier isolierter Kontrahenten. Trotz der deutlichen Meinungsänderung wird dieselbe Machtlogik angewandt, mit der im Frühwerk der Krieg noch gelobt wurde. Es ist laut Ottmann eine «Philosophie eines Friedens aus 〈Stärke». ${ }^{578}$ Das heisst aber auch, dass der Naturzustand in Friedenszeiten weiterhin existiert, jedoch durch aktiv erzeugte Machtausübung unterdrückt wird. Entsprechend gilt das Recht bloss solange, wie der ausgehandelte Gleichgewichtszustand anhält. Nun kann sogar die Frage gestellt werden, inwiefern eine Gesellschaft als aktiven Machtakt demokratische Institutionen wählt. Obwohl sich eine Demokratie- und Friedensbegeisterung nur schwerlich erkennen lässt, gibt es zuweilen doch bemerkenswerte Formulierungen. So bemerkt Nietzsche zu seinen Überlegungen der drei Stämme: «ja es schien, als ob der Menschenschlag in beiden Gegenden sich seitdem verschönert hätte: denn die Augen hatten sich erhellt, die Stirnen sich entrunzelt, Allen war das Vertrauen zur Zukunft zu eigen geworden, - und Nichts ist den Seelen und Leibern der Menschen förderlicher, als diess Vertrauen.» ${ }^{579} \mathrm{Ab}$ seits der ansonsten bekannten Ästhetiken des individuellen Daseins, skizziert Nietzsche hier Ansätze zu einer Ästhetik der friedlichen Gesellschaft. 580

Achtens zeitigt das neue Demokratieverständnis im Wanderer auch Konsequenzen bei der Bewertung der Chancen- und Lohnungleichheit. Nietzsche nahm sich in den St. Moritzer Notizbüchern Folgendes vor: «Den großen Werth der neuen Institutionen a ng eb e n - Schutzwehr und Bollw[erk] gegen das Räuber- und Ausbeuterthum in Geist und Geld.» ${ }^{581}$ So hält Nietzsche fest, dass es eigentlich richtig wäre, dass man die Löhne an die geleistete Arbeit knüpfen müsste. ${ }^{582}$ Nietzsche fordert «alle Arbeitswege zum kle in en Vermögen»

577 Noch 1875 setzte Nietzsche entweder energiearme oder energiereiche Zustände voraus: «Der ideale Staat, den die Socialisten träumen, zerstört das Fundament der großen Intelligenzen, die starke Energie.» (NL 1875, 5[188], KSA 8, S. 93).

578 Ottmann 1999, S. 127; vgl. auch Patton 2014, S. 98-103.

579 WS 190, KSA 2, S. 637.

580 Für Nietzsches «ästhetisch fundierte Ethiken» vgl. Zittel 2008.

581 NL 1879, 44[16], KSA 8, S. 613.

582 Vgl. WS 25 , KSA 2, S. $559 f$. 
offenzuhalten, jedoch mühelose Bereicherung zu verhindern. ${ }^{583}$ Henning Ottmann schreibt angesichts der im Wanderer genannten Progressivsteuern, Verstaatlichung und der Stabilisierung des Mittelstandes: «So manches klingt nach einer Mischung aus bürgerlicher Reformpolitik und fast schon sozialistischer Radikalität [...].» ${ }^{584}$ Der Grund ist aber nicht die Würde der Arbeit als essentielles Gut:

Die Ausbeutung des Arbeiters war, wie man jetzt begreift, eine Dummheit, ein Raub-Bau auf Kosten der Zukunft, eine Gefährdung der Gesellschaft. Jetzt hat man fast schon den Krieg: und jedenfalls werden die Kosten, um den Frieden zu erhalten, um Verträge zu schliessen und Vertrauen zu erlangen, nunmehr sehr gross sein, weil die Thorheit der Ausbeutenden sehr gross und langdauernd war. ${ }^{585}$

Die Würde des Arbeiters ist eine für die Gesellschaft nützliche Institution zur langfristigen Sicherung der Zukunft. Da Verantwortung ein nutzenabhängiges Gefühl sei, führt die Ausrichtung auf langfristige gesellschaftliche Ordnung zu einer Verantwortung gegenüber Arbeitern, Ausgebeuteten sowie auch Nutztieren. ${ }^{586}$ Mit dem Ziel der «Dauerhaftigkeit aller Zustände» vor Augen sollen eine Unzufriedenheit der Arbeiterschaft und damit allfällige Umsturzversuche derselben verhindert werden. Die «Ausbeutung des Arbeiters» und der Krieg schaden der Gesellschaft und der sicheren Zukunft, weil beide nicht auf eine jahrhundertelange Dauerhaftigkeit ausgelegt sind. Deshalb kann man anders als Ottmann behaupten, dass es im Sommer 1879 ein evidentes Interesse an «der Sicherung bürgerlicher Freiheit und Gleichheit» gibt - wenn auch kulturpolitisch und nicht demokratisch motiviert. ${ }^{587}$

Neuntens ist die Demokratie letztlich ein kulturpolitisches Mittel für höhere Zwecke. Die Demokratisierung als laufender Prozess hat nicht die Demokratie als Regierungsform zum Ziel: Ihre Leistung besteht im präventiven Schutz vor Tyrannei und Zerstörung. Die jetzigen Demokratieförderer würden gar nicht bemerken, dass es hinter ihrer Arbeit höhere Ziele gebe. Was ist aber der höhere Zweck und die höhere Kultur? Diese Frage lässt Nietzsche offen und äussert sich dazu in einer diffusen und religiösen Rhetorik: Die Demokratisierung mit all ihren Folgen diene der «geistreiche[n] Gesammtvorbereitung des höchsten Künstlers der Gartenkunst», dessen Aufgabe erst dann beginnt, wenn die Demokratisierung abgeschlossen sei. Die geheimnisvolle Metaphorik lässt offen,

583 WS 285 , KSA 2, S. 681 .

584 Ottmann 1999, S. 129.

585 WS 286, KSA 2, S. 682.

586 Vgl. WS 57, KSA 2, S. 577 f.

587 Ottmann 1999, S. 136. Vor und nach dem Sommer 1879 finden sich gegenteilige Belege. 
wer der Gärtner ist und worin seine «eigentliche Aufgabe» in ferner Zukunft bestehen wird. Diese Rhetorik mutet befremdend an, ist im zeitgenössischen Diskurs aber geläufig. So betont Alexis de Tocqueville «die Ungewissheit der Zukunft» und John Stuart Mill schreibt: «Die Demokratie ist eine zu neue und zu großartige Erscheinung, als daß irgend ein jetzt lebender Mensch ihre Folgen erfassen könnte.» ${ }^{58}$ Zudem variiert Nietzsche mit seiner Garten-Metaphorik das Bonmot von Fontenelle: «de mémoire de rose, on n'a jamais vu mourir un jardinier». ${ }^{589}$ So wie aus Sicht der einzelnen Rosen ihr Gärtner unsterblich scheint, kann von einer Generation demokratischer Erfahrung noch nicht auf die Zukunft geschlossen werden. Schon in Menschliches deutet sich in Bezug auf die Demokratie diese Rhetorik der Unbestimmtheit an, wenn es heisst: «während noch Niemand die Samenkörner aufzeigen kann, welche auf das zerrissene Erdreich nachher gestreut werden sollen.» ${ }^{590}$ Vielmehr sind ganze «Völker» und «Jahrhunderte» nunmehr ein Mittel des Ausprobierens, was dem «grossen Gesammt-Fruchtbaume der Menschheit» wohltun könne. ${ }^{591}$ Indem nicht mehr nur von der Erhöhung einer Nation, sondern ganz Europa, ja der ganzen Menschheit die Rede ist, wird auch die Demokratie ein akzeptables Experiment. Zu diesem Experiment gehört das Zeitmodell langfristiger und allmählich fortschreitender politischer Evolution. Zeitspannen werden auffällig betont: «Freilich: bei den weiten Zeitstrecken, welche hier zwischen Mittel und Zweck liegen, bei der grossen, übergrossen, Kraft und Geist von Jahrhunderten anspannenden Mühsal [...].»592 Die Demokratie wird als Übergangsphase bestimmt, jedoch im Sinne Tocquevilles als Jahrhunderte und Jahrtausende lange Phase mit unbestimmtem Ziel: «Gehen wir einige Jahrtau-

588 Mill 1875, S. 50; Tocqueville 1836, Bd. 2, S. 317 .

589 Dieses Bonmot fand insbesondere über Diderots Le Rêve de d'Alembert Verbreitung, das sich Nietzsche 1878 besorgen wollte (vgl. KGW IV 4, S. 295). Im Original heisst es: «Sur cela elles diroient, nous avons toujours vu le même jardinier, de mémoire de rose on n'a vu que lui, il a toujours été fait comme il est, assurément il ne meurt point comme nous, il ne change seulement pas.» (Fontenelle 1686, S. 351) In Nietzsches Bibliothek findet sich die deutsche Übersetzung in Fontenelle 1730, S. 183. Ich danke Daniel Brühlmeier für diesen Hinweis.

590 MA 472, KSA 2, S. $306 f$.

591 WS 189, KSA 2, S. 635. Und weiter heisst es: «und was auch immer bei diesem Ausprobiren die Einzelnen, die Völker und die Zeiten für Schaden leiden, durch diesen Schaden sind jedesmal Einzelne klu g geworden, und von ihnen aus strömt die Klugheit langsam auf die Maassregeln ganzer Völker, ganzer Zeiten über.»

592 WS 275, KSA 2, S. 672. 
sende mit einander vorwärts, meine Freunde!» ${ }^{593}$ Ottmann hat die Mischung aus Demokratieakzeptanz und Kulturpolitik wie folgt zusammengefasst:

Nietzsche hat die Demokratie nur widerwillig anerkannt als ein Mittel zu höheren Zielen. [...] Der ehemalige Kulturaristokrat hat seine 〈splendid isolation〉 von Gesellschaft und Politik der Zeit aufgegeben. Er macht Vorschläge und er therapiert auch im Detail, er ist realistischer und gemäßigter. Und doch bleibt das alles an der Oberfläche. Im Grunde ist Nietzsche der alte geblieben, auf der Suche nach einem Weg, der weder der sozialistische noch der bürgerliche sein soll. 594

Diese widerwillige Haltung zeigt sich auch am ironischen Ton, in dem Nietzsche zuweilen über die Demokratie schreibt. Betrachtet man beispielsweise die Dynamik des zentralen Demokratie-Aphorismus 275, ist ein ironischer Bruch zu bemerken. Nachdem die Unaufhaltsamkeit der Demokratie beschrieben wurde, schwappt der Ton mitten im Aphorismus in Ausrufe über:

Jetzt erst ist das Zeitalter der Cyklopenbauten! Endliche Sicherheit der Fundamente, damit alle Zukunft auf ihnen ohne Gefahr bauen kann! Unmöglichkeit fürderhin, dass die Fruchtfelder der Cultur wieder über Nacht von wilden und sinnlosen Bergwässern zerstört werden! Steindämme und Schutzmauern gegen Barbaren, gegen Seuchen, gegen leibliche und geistige Verknechtung! ${ }^{595}$

Angefangen mit «Jetzt erst ist das Zeitalter der Cyklopenbauten!» folgen gleich drei (!) weitere Ausrufesätze. Dies ist nicht nur formal ungewöhnlich. Die euphorischen Ausrufe stehen nämlich im Gegensatz zu all den beschriebenen Warnungen und Gefahren. Nietzsche rezitiert nicht seine Euphorie, sondern jene des zeitgenössischen Demokratiediskurses. Freiheit, Unabhängigkeit, Sicherheit, Zukunft, Gesundheit, kulturelle Entfaltung und Frieden sind die Versprechen der demokratischen Bewegung. Die Rhetorik der Ankündigung und die idealistische Demokratiebegeisterung können kaum dem Nietzsche von 1879 zugerechnet werden. Gleichwohl: Die Demokratie ist für das reibungslose Funktionieren und Vorwärtskommen der Gesellschaft am effizientesten eingestellt. Die tyrannischen Regierungsformen dagegen riskieren mit ihrer Ausbeutung und ihren Kriegen ständig die Zukunft. Es ist zentral für Nietzsches neue Herangehensweise an die Demokratie, dass er die zukünftigen hohen Ziele in

593 WS 183, KSA 2, S. 631. Vgl. die vielen unbestimmten Zeitwörter im Schlusswort von Tocqueville 1836, Bd. 2, insb. S. 316 .

594 Ottmann 1999, S. 129f.; vgl. auch Siemens 2009, S. 24: «even if there is an engagement with democracy as a political phenomenon, the political is still what it was for the early Nietzsche, a mere means for the advancement of cultural and human perfection.»

595 WS 275 , KSA 2, S. 672. 
die weite Zukunft verschiebt und diese undefiniert lässt. Dieses Zeitmodell hat mitunter den Effekt, die in weite Ferne gerückte Kulturpolitik der Eliten zu Gunsten einer ernsthaften Auseinandersetzung mit demokratischen Phänomenen zurückzustellen. So wie sich die Frage nach der Götterexistenz damit erübrige, dass man sie «aus der Ferne» nicht beantworten kann, so erübrigt sich die genaue Gestalt der postdemokratischen Zukunft.596

$\mathrm{Zu}$ dieser Auseinandersetzung gehört zehntens eine konstruktive Kritik an der zeitgenössischen Demokratie, welche Nietzsche noch stark mangelhaft erscheint:

Ich rede von der Demokratie als von etwas Kommendem. Das, was schon jetzt so heisst, unterscheidet sich von den älteren Regierungsformen allein dadurch, dass es mit neuen Pferden fährt: die Strassen sind noch die alten, und die Räder sind auch noch die alten. - Ist die Gefahr bei dies en Fuhrwerken des Völkerwohles wirklich geringer geworden ${ }^{597}$

Mit der abschliessenden Frage relativiert Nietzsche angesichts der Gefahren und Mängel der Demokratie seine vielen hoffnungsvollen und zukunftsbezogenen Reflexionen. Doch woran krankt die zeitgenössische Demokratie und wie kann man sie verbessern? Es liegen fünf Hinweise vor:

So gibt es a) eine konsequente Ablehnung von Parteien. Parteien würden ihre Prinzipien in Dummheiten verwandeln, setzten Loyalität über die eigene Vernunft und seien letztlich lernunfähig und stillos. ${ }^{598}$ Die Skepsis gegen Parteien geht soweit, dass Nietzsche im Wanderer die Parteien als die grössten Feinde der von der Demokratie angestrebten Unabhängigkeit bezeichnet und verhindern möchte, von Parteien gelesen zu werden. ${ }^{599}$ Weiter sieht Nietzsche b) jegliche Partikularinteressen als Gefährdung für den demokratischen Wahlprozess. Jede Bevölkerungsgruppe, die aus dem Durchschnitt herausfällt, sei eine Gefahr für die Demokratie. Deshalb soll der Mittelstand massgeblich gefördert und stabilisiert werden. Nietzsche fordert neben dem Ausschluss von Parteien auch jenen der «Besitzlosen» und «Reichen».600 Zudem gilt c), dass

596 WS $7, \mathrm{KSA}_{2}, \mathrm{~S} .543$.

597 WS 293, KSA 2, S. 685.

598 Vgl. ebd.; MA 438, KSA 2, S. 285; VM 301, KSA 2, S. 502; VM 305, KSA 2, S. 504; VM 308, KSA 2, S. 504. Es wird gar eine Auflösung der Parteien zu Gunsten einer Wissens-Elite gefordert, vgl. VM 318, KSA 2, S. 508.

599 Vgl. WS 293, KSA 2, S. 685; WS 71, KSA 2, S. 584.

6 oo Vgl. WS 293, KSA 2, S. 685. Ottmann schreibt, dass für Nietzsches langfristige Sicherheitspolitik alles «Eckige [...] abgerieben, alles Fürchterliche entschärft, alles über den kleinsten gemeinsamen Nenner der wirtschaftlichen Interessen Hinausragende eingeebnet werden» müsse (Ottmann 1999, S. 132). 
man Wahlen eigentlich nur dann als legitim bezeichnen könne, wenn vorher einstimmig von allen Bürgern das Wahlverfahren an sich angenommen wurde. ${ }^{601}$ Mit Blick auf das Pressezeitalter müsse die Politik d) langsam und bedacht agieren:

Und nun ist klar, dass im grossen Welttreiben, in Sachen der Politik, bei allem Plötzlichen und Drängenden, wie es fast jeder Tag heraufführt, eben dieses schlechte Schliessen entscheidet: denn Niemand ist völlig in dem zu Hause, was über Nacht neu gewachsen ist; alles Politisiren, auch bei den grössten Staatsmännern, ist Improvisiren auf gut Glück. ${ }^{602}$

Die demokratische Quarantäne sollte dahingehend wirken, dass sie die Wirkmacht der Politiker solchermassen in die mächtigen Institutionen einbindet, dass diese der Gesellschaft weder grossen Nutzen noch Schaden antun können. Schliesslich sind bei Nietzsche die Politiker als gewählte Parteimitglieder der Gegensatz zu sachverständigen Experten: «Mehr Ehrfurcht vor dem Wissenden! Und nieder mit allen Parteien! » ${ }^{603}$ Damit variiert Nietzsche ein Argument von Tocqueville, der die Wichtigkeit von demokratischen Institutionen als Schutz gegen die Tyrannei der Mehrheit akzentuiert. ${ }^{604}$ Der Gewinn und die Prophylaxe demokratischer Institutionen liegen darin, dass sie als Agenten einer stabilen und dauerhaften Zukunft den einzelnen Politiker sowie der Mehrheitstyrannei den Einfluss entziehen. Sie mildern die Gefahr, dass inkompetente Personen das Schicksal von Jahrhunderten mitbestimmen können. Auch deshalb sollen Standesheere und Militarisierung prophylaktisch abgeschafft werden, damit die Parteienpolitik nur wenig Schaden anrichten kann. Während die Mühlen der Politik in den Institutionen liegen, ist das Parteiengeschäft nunmehr ein vordergründiges Theater. Deshalb ist es geboten, die Monarchie als symbolische Instanz beizubehalten, um wie im Falle Englands eine Mittelbarkeit gegenüber dem Volk zu gewährleisten. Die mässigende Wirkung der demokratischen Institutionen funktioniert nach der Logik der Kettenphilosophie: So sind die Progressivsteuern, die Verhinderung schneller Bereicherung, die teilweise Verstaatlichung des Bankenwesens als Ketten zu verstehen, welche den Künstler bzw. den demokratischen Bürger gleichsam zwingen, friedlich und massvoll zu politisieren. Es geht also um demokratisch verbürgte Institutionen, die gleich Staudämmen die gefährlichen Wildwasser

601 Vgl. WS 276, KSA 2, S. 672f. Damit ist Nietzsche nahe an Vertragstheorien, wie etwa an jener von Rawls, in welcher man sich zuerst in einem Urzustand über die politische Ordnung einer Gesellschaft einigt.

602 WS 277 , KSA 2, S. 673 f.

603 Vgl. VM 318, KSA 2, S. 508; WS 280, KSA 2, S. 675 f.

604 Vgl. Tocqueville 1836, Bd. 2, S. 106-120. 
zähmen und in geordnete Bahnen lenken. Es ist bezeichnend, dass Nietzsche in Menschliches noch einen Gletscher als Grund für ein harmonisches Tal ansah, während es im Wanderer die von den Menschen gebauten Staudämme und Schutzbauten sind. ${ }^{605}$ An die Stelle von Naturgewalten treten menschliche Grossprojekte.

Den demokratischen Institutionen, welche als Agenten der Sicherheit und Dauerhaftigkeit das schlimmste verhindern, steht e) das Vorhaben zur Seite, ein ganzes Volk durch Bildung und Selbstaufklärung mündig zu machen. So liest man bereits in Menschliches:

Wie aber, wenn jene ganz verschiedene Auffassung des Begriffes der Regierung, wie sie in dem okratischen Staaten gelehrt wird, durchzudringen anfängt? Wenn man in ihr Nichts als das Werkzeug des Volkswillen sieht, kein Oben im Vergleich zu einem Unten, sondern lediglich eine Function des alleinigen Souverains, des Volkes? Hier kann auch nur die selbe Stellung, welche das Volk zur Religion einnimmt, von der Regierung eingenommen werden; jede Verbreitung von Aufklärung wird bis in ihre Vertreter hineinklingen müssen, eine Benutzung und Ausbeutung der religiösen Triebkräfte und Tröstungen zu staatlichen Zwecken wird nicht so leicht möglich sein (es sei denn, dass mächtige Parteiführer zeitweilig einen Einfluss üben, welcher dem des aufgeklärten Despotismus ähnlich sieht). ${ }^{606}$

Die Aufklärung ist also gleichsam ein Korrektiv der Demokratie. Sie macht die Bürger mündig und entschärft so die Gefahr einer Massentyrannei. Damit die Aufklärung ihre komplementäre Funktion in der Demokratie ausüben kann, bedarf es gebildeter Bürger. Die Demokratisierung ist für Nietzsche deshalb entschieden mit einer offenen Bildung verbunden: «Demokratische aufrichtige Staaten haben die höchste Erziehung um jeden Preis Allen zu gewähren.»607 Solange nämlich eine Bevölkerung unmündig sei, könnten Religion und Regierung das Volksempfinden zuverlässig steuern und für

605 Vgl. den Aphorismus «Die Cyklopen der Cultur»: «Wer jene zerfurchten Kessel sieht, in denen Gletscher gelagert haben, hält es kaum für möglich, dass eine Zeit kommt, wo an der selben Stelle ein Wiesen- und Waldthal mit Bächen darin sich hinzieht.» (MA 246, KSA 2, S. 205) Es kann dem spazierenden Nietzsche nicht entgangen sein, mit welch immensem Aufwand, die Naturgefahren im Oberengadin durch Menschenhand vermindert wurden. Im Zuge der Erschliessung Churs durch die Eisenbahn wurden in den späten 1850er Jahren u.a. «Lawinen, Wildbäche und rutschende Halden ungefährlich gemacht» (Ludwig 1878, S. 468). Zudem bezeichnet die Metapher der Zyklopenbauten im Frühwerk den Zweck der klassischen Philologie, nämlich «mit ungeheurer Wucht, aber cyklopischer Langsamkeit» die Kluft zwischen der realen und der idealen Antike zu «überbrücken» (KGW II 1, S. 253).

606 MA 472, KSA 2, S. 303 .

607 NL 1876, 17 [67], KSA 8, S. 308; vgl. auch NL 1877, 22[12], KSA 8, S. 381. 
ihre Interessen instrumentalisieren. ${ }^{608}$ War die Gefahr der Massentyrannei in Menschliches noch ein Argument gegen die Demokratie, so ist sie im Wanderer der Ausgangspunkt einer geforderten Selbstaufklärung und Bildungspolitik. Es geht nicht mehr darum, das unmündige Volk vor der Demokratie zu schützen, sondern aufgrund der unaufhaltsamen Demokratie im Volk eine Selbstaufklärung jedes Einzelnen zu erreichen.

\subsubsection{Allmähliches vs. Plötzliches}

Nietzsches Begriff der Demokratisierung ist weit über die politische Sphäre hinaus verflochten mit historischen Kunstidealen, Diätlehren, Autorschaftsmodellen, religiösen Haltungen und politischen Schreibweisen. Mazzino Montinari versuchte diese Verflechtung wie folgt zu ordnen:

Es bildet sich so eine Polarität aus: einerseits das klassische Ideal, durch französischen Klassizismus, Aufklärung, weltbürgerliches Europa, Voltaire, Napoleon, Goethe dargestellt; andererseits das christliche Ideal, in seinen verschiedenen Verkörperungen: Rousseau, Revolution, Reaktion, Romantik, Nationalismus, Sozialismus. ${ }^{609}$

Es gibt jedoch zwei Zeitmodelle, welche Nietzsches Überlegungen im Wanderer themenübergreifend strukturieren: Das Allmähliche und das Plötzliche. Viele von Nietzsche in den $1870 e r$ Jahren gelesene Autoren vertraten das Konzept einer allmählich evolvierenden Kultur. ${ }^{610}$ Tocqueville beschrieb die Demokratie als unaufhaltsame und «allmählig fortschreitende Entwickelung der Gleichheit».611 Die Zeitmodelle des Allmählichen und des Plötzlichen begegnen einem im Wanderer auffällig oft in medizinischen, diätetischen und produktionsästhetischen Metaphern: So bezeichnet Nietzsche im Wanderer beispielsweise die Demokratie als Prophylaxe, die Europäisierung als «Völker-Schwindsucht» und den Krieg als «Heilmittel». ${ }^{612}$ Das Allmähliche steht seit Hippokrates für ein diätetisches Zeitmodell. ${ }^{613}$ Dem Allmählichen entsprechen die Kur, die Prophylaxe und die Schreibarbeit, dem Plötzlichen die Narkotika, Quacksalber und die Genieästhetik. Es soll gezeigt werden, dass

\footnotetext{
608 Vgl. MA 472, KSA 2, S. 302-307.

609 Montinari 1982, S. 61.

610 Für die «organische Auffassung der Geschichte» bei Hillebrand vgl. Voci 2015, S. 236f.; für politische Systeme als langwährende Übungs- und Aufbauphasen für spätere Zwecke bei Bagehot vgl. Marti 1993, S. 215. Während Bagehot aber die Kultur als Züchtungsunternehmen denkt, ist es bei Nietzsche vielmehr eine lang andauernde Kur im Sinne der Diätetik.

611 Tocqueville 1836, Bd. 1, S. 6.

612 WS 187, KSA 2, S. 634; WS 289, KSA 2, S. 683.

613 Vgl. Foucault 1986, Bd. 2, S. 143.
} 
Nietzsche im Wanderer keine Demokratietheorie besass, sondern seine auffällig demokratiefreundlichen Ansichten durch das Zeitmodell der Produktionsästhetik und der Diätetik geformt wurden.

\section{Aufklärung vs. Revolution (Diätetik vs. Quacksalber)}

Im Zeitmodell des Allmählichen kann etwas Dauerhaftes nur allmählich eingeführt und etwas Instabiles wie der Krieg nur plötzlich aufgelöst werden. ${ }^{614}$ So schlägt sich das neue Zeitverständnis einer jahrhundertelangen Demokratie in der Bewertung von Aufklärung und Revolution nieder. Die Aufklärung geschieht allmählich am Einzelnen und auf je individuelle Weise, so dass «nur sehr langsam auch die Sitten und Einrichtungen der Völker umgebildet» werden. ${ }^{615}$ Für den wechselseitigen Prozess von Aufklärung und Demokratisierung gibt es nur eine Gefahr: die Revolution, d.h. der plötzliche Umsturz. Die revolutionäre Gewalt richtet sich gemäss Nietzsche gegen die demokratischen Institutionen, welche als aufwendig errungene Ketten die Demokratie im Kern ausmachen. Die «Umsturzgeister» wollen die politische Entwicklung gewaltsam beschleunigen. ${ }^{616}$ Sie sind gegen die Zeitlichkeit der Demokratie, welche die allmähliche Entwicklung ist. Deshalb sind die «Umsturzgeister» die «grundsätzlichsten Gegner» der Demokratie - nicht wegen ihrer politischen Ansichten. Selbst Demokraten, welche die Demokratie plötzlich einführen wollen, sind in Nietzsches Sinn antidemokratisch. Dies, während alle anderen Gegner der Demokratie, welche die Mittel und Institutionen der Demokratie akzeptieren, diese vorantreiben.

Der «Wahn in der Lehre vom Umsturz» liege im Aberglauben Rousseaus, «welcher an eine wundergleiche, ursprüngliche, aber gleichsam verschütte te Güte der menschlichen Natur glaubt und den Institutionen der Cultur, in Gesellschaft, Staat, Erziehung, alle Schuld jener Verschüttung beimisst.» ${ }^{617}$ Durch die Zerstörung von Institutionen wird die Demokratie mit all ihren aufwendigen Errungenschaften bedroht.

Leider weiss man aus historischen Erfahrungen, dass jeder solche Umsturz die wildesten Energien als die längst begrabenen Furchtbarkeiten und Maasslosigkeiten fernster Zeitalter von Neuem zur Auferstehung bringt: dass also ein Umsturz wohl eine Kraftquelle in einer mattgewordenen Menschheit sein kann,

614 Offenbar denkt Nietzsche dialektisch, weil der plötzliche Krieg nur abrupt gestoppt werden und die dauerhafte demokratische Regierungsform nur allmählich entstehen kann. Deshalb ist Kant gegen den gewaltsamen Umsturz, weil es nicht möglich ist, ein neues Recht durch einen Rechtsbruch einzuführen, vgl. Kant, AA, Bd. VIII, S. 372.

615 WS 221, KSA 2, S. 654.

616 WS 275, KSA 2, S. 671.

617 MA 463, KSA 2, S. 299. 
nimmermehr aber ein Ordner, Baumeister, Künstler, Vollender der menschlichen Natur. ${ }^{618}$

Seit Menschliches versucht Nietzsche deshalb, die Aufklärung von der Revolution loszulösen. Die Revolution habe sich die «Aufklärung auf das fanatische Haupt» gesetzt. ${ }^{619}$ In diesem Sinne schreibt Nietzsche 1881 in der Morgenröte, dass die Revolution «mit grobem Missverständniss» als Folge der Aufklärung verstanden wurde, und weiter: «Diese Aufklärung haben wir jetzt weiterzuführen, - unbekümmert darum, dass es eine 〈grosse Revolution〉 und wiederum eine 〈grosse Reaktion〉 gegen dieselbe gegeben hat, ja dass es Beides noch giebt: es sind doch nur Wellenspiele, im Vergleiche mit der wahrhaft grossen Fluth, in welcher wir treiben und treiben wollen!» 620 Umstürze sind «Wellenspiele», welche keinen Anteil an der unaufhaltsamen und allmählichen Entwicklung der Aufklärung haben. Die Revolutionäre sind so gesehen Parasiten, welche die allmählich errungenen Veränderungen der Aufklärung für ihre plötzlichen Umsturzversuche reklamieren. Nietzsche reiht sich damit in die verbreitete Ansicht ein, dass die Französische Revolution eher ein Ausdruck der längst demokratisch gewordenen Institutionen als der entscheidende Umbruch war. ${ }^{621}$ Deshalb plädiert Nietzsche in Menschliches dafür, den Lauf der Geschichte zwar hinzunehmen, die Staatenordnung aber noch eine Weile beizubehalten und die «zerstörerische[n] Versuche übereifriger und voreiliger Halbwisser» zu verhindern. ${ }^{622}$ Die Nationalstaaten leiden in Folge der Europäisierung an der «Völker-Schwindsucht» und setzen in ihrer Not auf eine kriegerische «Brutalitäts-Cur», die aber wie jede rasche Behandlung nur kurzfristige Linderung verschaffen kann. ${ }^{623}$ Eine wirksame Kur ist langsam und wirkt nur allmählich, d.h. dosiert:

\section{Ebd.}

619 WS 221, KSA 2, S. 654. Und Montinari 1982, S. 58 kommentiert: «Es war nach Nietzsche ein Fehler, die alte Aufklärung als Ursache der Revolution aufzufassen [...].»

620 M 197, KSA 3, S. 172; vgl. auch die Biografen, welche einzelne Lebensereignisse für den Strom halten, in dem diese liegen (VM 394, KSA 2, S. 530).

621 Nietzsche will wie Kant die gewaltsame Revolution (bzw. ihre öffentliche Wirkung) nicht gutheissen und als «G e s ch i ch t s z e i c h en $»$ deuten, d.h. als Zeichen einer allgemeinen Umwälzung in der Geschichte, der Unaufhaltsamkeit der Demokratie (vgl. Kant, AA, Bd. VII, S. 84). Die Verzichtbarkeit gewaltsamer Umstürze hat Jacob Burckhardt in seiner Vorlesung am Beispiel Englands aufgezeigt. Überhaupt seien England und Amerika zwei «ganz unmilitärische[ ] Nationen» (Burckhardt 2000, S. 259). Nietzsche selbst sprach von der «englisch-amerikanischen Nüchternheit» (VM 171, KSA 2, S. 451).

622 MA 472, KSA 2, S. 307.

623 WS 187, KSA 2, S. 634. Nietzsche meint mit «Völkern» die Nationen, welche im Zuge der Demokratisierung unterzugehen drohen und so gesehen an der Schwindsucht leiden. 
Die kleinen Dosen. - Soll eine Veränderung möglichst in die Tiefe gehen, so gebe man das Mittel in den kleinsten Dosen, aber unablässig auf weite Zeitstrecken hin! Was ist Grosses auf Einmal zu schaffen! [...] Man fängt ja an, auch dies einzusehen, dass der letzte Versuch einer grossen Veränderung der Werthschätzungen, und zwar in Bezug auf die politischen Dinge, - die «grosse Revolution»- nicht m ehr war, als eine pathetische und blutige Qu a cksalberei, welche durch plötzliche Krisen dem gläubigen Europa die Hoffnung auf plötzliche Genesung beizubringen wusste - und damit alle politischen Kranken bis auf diesen Augenblick ungeduldig und gefährlich gemacht hat. - 624

Das diätetische Vokabular wird auf politische Vorgänge übertragen: Die Französische Revolution ist nunmehr Quacksalberei, also das medizinische Schimpfwort für ein zwielichtiges Wundermittel, das plötzliche Heilung bringen soll, jedoch unwirksam, ja schadhaft ist. Anstatt auf ausdauernde demokratische Kur und Prophylaxe, hoffte man auf revolutionäre, «plötzliche Genesung». Demokratie und Revolution repräsentieren damit die klassische Opposition von diätetischer Prophylaxe und therapeutischen Heilmitteln. Und wie die Diätetik kein Selbstzweck ist, so ist es auch die Demokratie nicht. Sie dient der Gesundung und dem Aufbau einer Kultur, damit sie zu höheren Zuständen fähig wird. Die Gleichförmigkeit und Langeweile der Demokratie sind nunmehr unangenehme Nebenwirkungen, wie sie jede Kur oder Prophylaxe mit sich bringt. Gregory Moore verwies mit Blick auf Nietzsches Lektüre der frühen 188oer Jahre auf einen weiteren diätetischen Zusammenhang: «As Nietzsche learned from Liebig and Meinert, input must match output in the human economy. The great tasks of the future would require large quantities of Kraft.» ${ }^{625}$ Dieses Modell entspricht der Demokratie als aufbauender Diät für weit in der Zukunft liegende Ziele.

Weil der Aufklärung die «Gefährlichkeit» anhaftet, dass sie zu einer revolutionären Gesinnung radikalisiert werden kann, bedarf es der Selbstaufklärung. Es gelte nun, «an sich selber, das Werk der Aufklärung fortzusetzen und die Revolution nachträglich in der Geburt zu ersticken, ungeschehen zu machen». ${ }^{626}$ Deshalb sind die Individuen, ihr Charakter, ihre Diät und ihre Bildung, für den erfolgreichen Prozess der Aufklärung entscheidend. Dazu gehört auch die Diätetik der «nächsten Dinge»: Sie verhilft den Einzelnen zu einer Selbstregulierung, die nicht mehr durch die staatliche Autorität bestimmt werden kann. Die Diätetik und die Demokratie stehen im Wanderer nicht zu-

624 M 534, KSA 3, S. 306. Auch später überlegt sich Nietzsche, ob man Kriege und Revolutionen nicht durch gezielte Ernährung und Züchtung verhindern könne, vgl. NL 1883, 7[132], KSA 10, S. 286.

625 Moore 2004, S. 88.

626 WS 221, KSA 2, S. 654 . 
fällig nebeneinander. Es wird gleich noch zu zeigen sein, dass auch Lesen und Schreiben massgebliche Techniken der Selbstaufklärung sind.

\section{Voltaire vs. Rousseau (Produktionsästhetik)}

Für Nietzsche bilden die Namen Voltaire und Rousseau eine historische, politische, religiöse und künstlerische Kartografie. Er personifiziert die allmähliche Aufklärung durch Voltaire und die plötzliche Revolution durch Rousseau:

Nicht Vo lt a i re's maassvolle, dem Ordnen, Reinigen und Umbauen zugeneigte Natur, sondern Rouss ea u's leidenschaftliche Thorheiten und Halblügen haben den optimistischen Geist der Revolution wachgerufen, gegen den ich rufe: «Ecrasez l'infame!»Durch ihn ist der Geist der Aufklärung und der fortschreitenden Entwickelung auf lange verscheucht worden: sehen wir zu - ein Jeder bei sich selber - ob es möglich ist, ihn wieder zurückzurufen! ${ }^{627}$

Nietzsche zeichnet einen revolutionären Rousseau gegenüber einem massvollen Voltaire. Es ist bezeichnend, dass die Zeitlichkeit der Aufklärung sperrgedruckt hervorgehoben wurde. Die entgegengesetzten Zeitmodelle des Allmählichen und des Plötzlichen sind anhand von Nietzsches Produktionsästhetik modelliert, in welcher die Arbeitsweise des Handwerkers jener des Genies gegenübergestellt wurde (Kap. 3.1.1). Die Stileigenschaften des Genies vermischen sich mit jenen der revolutionären Gesinnung (leidenschaftlich, plötzlich und rauschhaft) und jene des Aufklärers mit denen des Handwerker-Autors (massvoll, allmählich und still). Das massvolle Schreiben innerhalb der Zwänge und Ketten ist für Nietzsche unrevolutionär. Dem in langer Arbeit erzeugten Künstlichen entspricht deshalb ein gemässigter Mensch, während das Naturalisieren (das vermeintlich nicht künstliche Schreiben) der masslosen Revolution entspricht. Nietzsche versteht Demokratie und Revolution literarisch, womit er an das politische Denken von Burckhardt und Taine anschliesst. ${ }^{628}$ Schreibpolitisch gesehen bedarf es deshalb eines nüchternen, massvollen und klassischen Stils, wie Nietzsche ihn anhand von Voltaire, Goethe, den Griechen und den Franzosen beschreibt. Diese strenge

627 MA 463, KSA 2, S. 299. Voltaire habe in sich «die höchste Freiheit des Geistes und eine schlechterdings unrevolutionäre Gesinnung» vereinigt» (MA 221, KSA 2, S. 182). Weiter heisst es über Rousseau: «Die Gefährlichkeit der Aufklärung. - Alles das Halbverrückte, Schauspielerische, Thierisch-Grausame, Wollüstige, namentlich Sentimentale und Sich-selbst-Berauschende, was zusammen die eigentlich revolutionäre Substan z ausmacht und in Rousseau, vor der Revolution, Fleisch und Geist geworden war [...].» (WS 221, KSA 2, S. 654) Es ist vermutlich ein Zufall und doch bemerkenswert, dass unter der Aphorismennummer 221 in Menschliches die «Revolution in der Poesie» und im Wanderer die «Gefährlichkeit der Aufklärung» thematisiert werden.

628 Burckhardt und Taine glauben, dass die französische Revolution durch Literatur und Philosophie, allen voran jener Rousseaus, vorbereitet wurde (vgl. Marti 1993, S. 63f., 71f.). 
Schreibkunst ist selbst dann positiv konnotiert, wenn sie politische Ansichten vertritt, die Nietzsche nicht entsprechen. So wird etwa der revolutionäre Nicolas Chamfort - guerre aux chateaux, paix aux chaumières (Krieg den Palästen, Friede den Hütten) - im Wanderer prominent als einer von sechs altertumsnahen Autoren genannt, welche die Renaissance fortführen würden. ${ }^{629}$ Urs Marti folgert: «Revolution ist hier zu verstehen als Protest gegen den Zwang der klassischen Strenge, als Auflösung von Form und Bindung im Bereich des künstlerischen Schaffens, als Abbruch der Tradition und als Durchbruch eines hemmungslosen Experimentierens und Kopierens.» ${ }^{630}$ Es gibt also eine dem Schreiben inhärente Politik: Die allmähliche Entwicklung der Schreibarbeit ist in der Literatur und in den Schreibweisen materialisiert. Die «Revolution in der Poe si e» ist die Vorstufe für politische Revolutionen. Deshalb besteht die Gefährlichkeit der Aufklärung darin, dass sie sich mit dem zügellosen Stil und ihrem politischen Äquivalent, der Revolution verbündet.

Innerhalb der aufgezeigten diätetisch-produktionsästhetischen Kartografie lassen sich Nietzsches politische Ansichten im Wanderer wie folgt zuordnen (Tab. 2). Der grosse Unterschied zwischen Wanderer und Menschliches liegt in der Diagnose, welche Nietzsche dem zeitgenössischen Zustand von Europa stellt und welche Therapiemöglichkeiten er empfiehlt. Nietzsche diagnostizierte 1878 der Kultur eine grosse «Ermattung» und verschrieb ihr zur Erquickung einen grausamen Krieg. ${ }^{631}$ Nun im Wanderer diagnostiziert er eine chronische Anfälligkeit der Kultur und verschreibt deshalb prophylaktisch die Demokratie, um Krankheiten und Rückfälle zu verhindern. Selbst die lockere Prosa des Wanderers birgt eine politische Aussage, da sie der Genieästhetik und damit dem Plötzlichen entgegengesetzt ist.

629 Vgl. WS 214, KSA 2, S. 646. Ida Overbeck schreibt über Nietzsche: «Er liebte das Zeitalter Ludwigs XIV. und haßte die Revolution. Er nahm es Chamfort übel, sich in den Umgang mit Revolutionsmännern gebracht zu haben, und wollte nicht, daß sein eigener Name mit dem Chamforts zusammen je genannt werde.» (aus: «Erinnerungen von Frau Ida Overbeck», zit. n. Bernoulli 1908, S. 237) Zumindest kulturpolitisch sind Nietzsche und Chamfort einer Meinung, halten sie der Gesellschaft doch beide den grossen Ausnahmemenschen vor.

630 Marti 1993, S. 13; vgl. auch Ottmann 1999, S. 157: «Für Voltaire zu votieren, hatte für Nietzsche zunächst einmal den handfesten politischen Sinn, die friedliche und allmähliche, maßvolle und Toleranz predigende Aufklärung abzugrenzen von Gewalt und Revolution, von Maßlosigkeit und Fanatismus, wie sie Rousseau gesät und die Französische Revolution geerntet haben sollte».

631 So heisst es in Menschliches 477: «dass eine solche hoch cultivirte und daher nothwendig matte Menschheit, wie die der jetzigen Europäer, nicht nur der Kriege, sondern der grössten und furchtbarsten Kriege - also zeitweiliger Rückfälle in die Barbarei - bedarf, um nicht an den Mitteln der Cultur ihre Cultur und ihr Dasein selber einzubüssen.» (MA 477, KSA 2, S. 312) Damit schloss er sich im Übrigen seinem Freund Jacob Burckhardt an, der ebenfalls einen grossen Krieg voraussagte und für gut befand, vgl. Burckhardt 200o, S. 244. 
тав. 2 Die Zeitmodelle des Allmählichen und des Plötzlichen (eigene Darstellung)

\begin{tabular}{|c|c|c|c|}
\hline Zeitmodell & $\begin{array}{l}\text { Politisches } \\
\text { Phänomen }\end{array}$ & $\begin{array}{l}\text { Diätetik und } \\
\text { Medizin }\end{array}$ & Produktionsästhetik \\
\hline allmählich & $\begin{array}{l}\text { Demokratisierung } \\
\text { und (Selbst) } \\
\text { Aufklärung }\end{array}$ & $\begin{aligned} & \text { - } \text { Kur } \\
& \text { - Prophylaxe } \\
& \text { - Quarantäne } \\
& \text { - Gegen } \\
& \text { Einschleppung von } \\
& \text { Krankheiten } \\
& \text { - Gegen Pest } \\
& \text { (Tyrannei) } \\
& \text { - } \text { Völker-Schwindsucht }\end{aligned}$ & $\begin{array}{l}\text { Handwerker-Autor: } \\
\text { - Voltaire, Goethe, } \\
\text { Hillebrand } \\
\text { - Sentenzenkunst } \\
\text { - Übung, } \\
\text { Handwerker- } \\
\text { Ernst etc. } \\
\text { Produktionsprozess: } \\
\text { - massvoll, } \\
\text { allmählich, still } \\
\text { - Zwänge, Ketten, } \\
\text { Konventionen } \\
\text { - Übersetzbar und } \\
\text { verständlich } \\
\text { - Gut-Schreiben }\end{array}$ \\
\hline plötzlich & $\begin{array}{l}\text { Krieg und } \\
\text { Revolution }\end{array}$ & $\begin{array}{l}\text { - Brutalitäts-Cur } \\
\text { - Heilmittel } \\
\text { - gegen Ermattung } \\
\text { - Verjüngung } \\
\text { - Quacksalberei }\end{array}$ & $\begin{array}{l}\text { Genie-Autor: } \\
\text { - Rousseau } \\
\text { - Inspiration } \\
\text { Produktionsprozess: } \\
\text { - leidenschaftlich, } \\
\text { plötzlich, } \\
\text { rauschhaft etc. } \\
\text { - Naturalisieren, } \\
\text { Regellosigkeit } \\
\text { - Schlecht-Schreiben }\end{array}$ \\
\hline
\end{tabular}

\subsubsection{Das Aphorismenbuch als Werkpolitik der Demokratie}

Im «Zeitalter der Vergleichung» charakterisieren die Menschen sich nicht mehr durch die soziale und räumliche Herkunft, sondern durch die «Polyphonie der Bestrebungen». ${ }^{632}$ Es handle sich um ein Zeitalter, in dem «die verschiedenen

632 MA 23, KSA 2, S. 44. 
Weltbetrachtungen, Sitten, Culturen verglichen und neben einander durchlebt werden können».633 Das wird befördert durch die Demokratie, welche freie Meinungen und verschiedene Lebensformen garantiert. Nietzsche will seine Bücher für den Zukunftsmarkt gewappnet wissen; und diese Zukunft - das war die Überzeugung der meisten von ihm zeitnah gelesenen Autoren - gehört der Demokratie. Doch wie soll das gehen, ohne ein oberflächlicher Publizist zu werden? Welche werk- und lektürepolitische Ausrichtung kann der philosophische Autor gegenüber der unaufhaltsamen Demokratie einnehmen? Dieser Frage wird in der Folge unter Berücksichtigung von Tocquevilles Kapitel zur «Physionomie littéraire des siècles démocratiques» nachgegangen. ${ }^{634}$

\section{Gute und übersetzbare Prosa schreiben}

Die zeitgemässe Schreibweise wird im Wanderer an der Prognose diskutiert, dass der Staat durch die Demokratisierung auf Dauer verschwinden werde. Dies erfordere ein Umdenken in der Schreibweise:

Gut schreiben lernen.- Die Zeit des gut-Redens ist vorbei, weil die Zeit der Stadt-Culturen vorbei ist. Die letzte Gränze, welche Aristoteles der grossen Stadt erlaubte - es müsse der Herold noch im Stande sein, sich der ganzen versammelten Gemeinde vernehmbar zu machen -, diese Gränze kümmert uns so wenig, als uns überhaupt noch Stadtgemeinden kümmern, uns, die wir selbst über die Völker hinweg verstanden werden wollen. Desshalb muss jetzt ein Jeder, der gut europäisch gesinnt ist, gut und immer besser schreiben lernen: $[\ldots] .^{635}$

Nietzsche konstatiert hier, dass es zu jedem politischen Organisationssystem geeignete Kommunikationsformen gebe. In den Stadtstaaten der Antike war die Fähigkeit des guten Redens, die Rhetorik, angemessen. In der Zwischenzeit entstanden die Nationalstaaten, welche durch die Demokratisierung in der noch grösseren Organisationsform Europa aufgehen werden. Da nunmehr schriftlich kommuniziert wird, sind Schreiben und Lesen die primären politischen Kommunikationsformen. So heisst es im selben Aphorismus weiter:

Wer das Gegentheil predigt, sich n i c ht um das gut-Schreiben und gut-Lesen zu kümmern - beide Tugenden wachsen mit einander und nehmen mit einander ab -, der zeigt in der That den Völkern einen Weg, wie sie immer noch mehr n a ti o n al werden können: er vermehrt die Krankheit dieses Jahrhunderts und ist ein Feind der guten Europäer, ein Feind der freien Geister. ${ }^{636}$

633 Ebd.

634 Tocqueville 1864, S. 89-98.

635 WS 87 , KSA 2, S. 592.

636 Ebd., S. 593 . 
Die dem Schreiben inhärente Politik ist so wirkungsvoll, dass das «gut-Schreiben» eine postnationale Orientierung erzeugt. Die Entwicklung des Schreibens, welche Nietzsche bei Goethe und den französischen Moralisten im Sinne einer Qualitätssteigerung wertet, läuft deshalb auf eine Europäisierung hinaus. Doch wer sind die Feinde des «gut-Schreibens» und «gut-Lesens»? Es ist die Nationalliteratur und die Presse.

Nietzsche fordert im Wanderer «Europäische Bücher» und nennt folgende sechs französische Autoren: Michel de Montaigne, François de La Rochefoucauld, Jean de La Bruyère, Bernard le Bovier de Fontenelle, Luc de Clapiers (Marquis de Vauvenargues) und Nicolas Chamfort. ${ }^{637}$ Nietzsche behauptet von deren Schriften, dass sie sich über die verschiedenen nationalen Geschmäcker erheben und sie von den Griechen in griechischer Übersetzung verstanden würden. Es ist zunächst irritierend, dass Nietzsche ausschliesslich französische Autoren nennt, welche in diesem Sinne europäisch schreiben. Dies hängt aber nicht mit der französischen Sprache, sondern mit dem kunstfertigen Stil der französischen Moralistik zusammen (Kap. 3.2.1). Im Falle des freien und regellosen Schreibens folgt für Nietzsche deshalb ein allgemeines Aufbäumen gegen Regeln: «Ja, man hat die 〈unvernünftigen〉 Fesseln der französisch-griechischen Kunst abgeworfen, aber unvermerkt sich daran gewöhnt, alle Fesseln, alle Beschränkung unvernünftig zu finden». ${ }^{638}$ Deshalb sind all jene, welche eine Kunst trotz Regelwerk virtuos beherrschen, gute Europäer: «Wie Beethoven über die Deutschen weg Musik machte, wie Schopenhauer über die Deutschen weg philosophirte, so dichtete Goethe seinen Tasso, seine Iphigenie über die Deutschen weg.» ${ }^{639}$ Die Kunstfertigkeit kennt keine nationalen Grenzen. Nietzsche sieht Beethoven, Schopenhauer und Goethe als Teil des europäischen Kulturguts. Wer gut schreibt, betreibt also Kulturpolitik. So heisst es am Schluss des Aphorismus «Gut schreiben lernen»: «endlich, jenen jetzt noch so fernen Zustand der Dinge vorbereiten, wo den guten Europäern ihre grosse Aufgabe in die Hände fällt: die Leitung und Ueberwachung der gesammten Erdcultur.» ${ }^{640}$ Diese europäische Mission ist auf der literarischen Ebene jedoch nur umsetzbar, wenn verständlich und übersetzbar geschrieben wird:

\footnotetext{
637 WS 214, KSA 2, S. 646.

638 MA 221, KSA 2, S. 183 .

639 VM 170, KSA 2, S. 449; vgl. auch WS 125, KSA 2, S. 607: «Von Goethe, wie angedeutet, sehe ich ab, er gehört in eine höhere Gattung von Litteraturen, als «National-Litteraturen sind: desshalb steht er auch zu seiner N a ti o n weder im Verhältniss des Lebens, noch des Neuseins, noch des Veraltens. [...] Goethe, nicht nur ein guter und grosser Mensch, sondern eine Cultur [...].»

640 WS 87, KSA 2, S. 592.
} 
Besser schreiben aber heisst zugleich auch besser denken; immer Mittheilenswertheres erfinden und es wirklich mittheilen können; übersetzbar werden für die Sprachen der Nachbarn; zugänglich sich dem Verständnisse jener Ausländer machen, welche unsere Sprache lernen; dahin wirken, dass alles Gute Gemeingut werde und den Freien Alles frei stehe; $\left[\ldots . .{ }^{641}\right.$

Nietzsche versteht unter Übersetzbarkeit die Einhaltung historisch gewachsener Konventionen des Stils und der Verständlichkeit. Dies gilt auch für die Typographie, weil Nietzsche sich für die Antiqua und gegen die deutsche Fraktur entschied. Es geht deshalb nicht um eine einheitliche Sprache, sondern um einen guten Schreibstil. Die Warnung, zu sehr in der «Muttersprache» zu schreiben, bezieht sich auf einen unkonventionellen und neuartigen Sprachgebrauch. ${ }^{642}$ Nietzsche verlangt also nicht eine einheitliche Wissenschaftsoder Gelehrtensprache, sondern einen klassischen Schreibstil, der übersetzt werden kann und verstanden wird. Gute Prosa ist für Nietzsche übersetzbare Prosa. Für einen solchen Schreibstil gibt es nicht nur die genannten Beispiele berühmter Klassiker. So lobt Nietzsche in einem Brief an Karl Hillebrand dessen Buchreihe Zeiten, Völker und Menschen: «O Bücher, aus denen eine e u ropä is che Luft weht, und nicht der liebe nationale Stickstoff!» ${ }^{643}$ Dass Nietzsche dies bei der Lektüre des populär schreibenden Hillebrand empfindet, ist kein Zufall. Die Populärliteratur verband nämlich Wissenschaft, Verständlichkeit und Anwendbarkeit auf eine Weise, die es für ein breites $\mathrm{Pu}$ blikum brauchbar machte.

Da sich gutes Schreiben und Lesen gegenseitig befördern, werden nicht nur Wissen und Kunst zum Gemeingut, sondern auch deren Produktionsweisen. So bemerkte Tocqueville, dass gerade die Schreib- und Redekunst die Demokratisierung befördere: «Die Literatur wurde ein allgemeines Arsenal, aus welchem die Schwachen und die Armen täglich sich bewaffneten.» ${ }^{644}$ Gut-Schreiben ist an keine Herkunft oder Genialität mehr gebunden. Ohne Genieglauben steht es jedem talentierten Menschen offen, gut schreiben und reden zu lernen. In Nietzsches Ablehnung der Genieästhetik liegt deshalb bereits ein demokratischer Kern verborgen, der sich im Wanderer entfaltet. Die europäische Prosa ist nicht mehr Aristokraten und Genies vorbehalten, sondern allen, welche gut schreiben können. Dieses offene Bildungskonzept entspricht der demokratischen Gleichheit. Nietzsches Forderung nach einer Aufklärung, welche in alle

\footnotetext{
641 Ebd.

642 WS 132, KSA 2, S. 131. Nietzsche ist gegen «neuern oder alterthümeln» (WS 127, KSA 2, S. 6og).

643 N. an Hillebrand, Mitte April 1878, Nr. 711, KGB II 5, S. 318.

644 Tocqueville 1836 , Bd. 1, S. 4.
} 
Vertreter hineinwirke, kann nur über eine allen verfügbare Bildung in Buchform gewährleistet werden.

Demokratische Prosa und aristokratische Poesie

Nietzsche nennt in seinen Beispielen für europäische Schreibweisen mehrheitlich Autoren, die Prosa schreiben. Das liegt zunächst an den Kriterien der Verständlichkeit und Übersetzbarkeit, welche in der Dichtung nicht gegeben sind. Man findet in Nietzsches Vorlesung zur Geschichte der griechischen Literatur aber noch einen weiteren Zusammenhang von Prosa und politischer Wirkung: Die philosophisch verständliche Prosa habe eine befreiende Wirkung, die vor allem auf den Mittelstand einwirkt, weil dieser in Denken und Handeln mehr Befreiungspotenzial habe als die Aristokratie.

So ergreifen die eigentl. Förderer der Poesie, die Dichter der mittleren Schichten, das Princip der Aristokratie, den Schutz u. die Verklärung des Herkömmlichen: während wiederum die eigentl. Förderer der Prosa u. des geistigen Ringens, die vornehmen Philosophen Redner u. Historiker das Princip der mittleren Schichten erfassen und steigern, den Fortschritt und die Unabhängigkeit im Denken u. Handeln, sei es im Interesse des einzelnen oder des Volkes. ${ }^{645}$

Nietzsche nennt die Schriftsteller die «demokratischen Förderer» und die Dichter die «aristokratischen Förderer». Als prosaisch schreibender Philosoph kann Nietzsche gemäss seiner eigenen Einteilung als «demokratischer Förderer» des Mittelstands (und als vornehmer Philosoph) bezeichnet werden. Damit ist 1875/76 der Konflikt vorgezeichnet, in welchen der kulturpolitische Nietzsche der «höheren Cultur» durch sein beständiges Insistieren auf besserem Schreiben und Lesen zulaufen wird: Gute Prosa fördert die Demokratie und den Mittelstand, was wiederum die Kulturpolitik der Geniehervorbringung relativiert und vermindert. Wie gleich noch gezeigt wird, weist das prosaische Schreiben als politischer Akt auf die Selbstaufklärung, das aktive Lesen sowie die Adressierung verschiedener Publika.

Tocqueville unterscheidet politische Ausdrucksformen eines zu Ende gehenden aristokratischen und eines beginnenden demokratischen Zeitalters. Mit dem Sentenzenstil, dem perfektionierenden Schreiben sowie dem philologischen Lesen beschreibt Nietzsche das, was Tocqueville den untergehenden aristokratischen Autoren attestierte: «Le style y paraîtra presque aussi

645 KGW II 5, S. 342. Während die Dichter meistens aus dem Mittelstand stammen und die Aristokratie verklären, seien die prosaischen Schriftsteller vornehmer Herkunft und würden in ihrem Freiheitsdrang die Standesschranke durchbrechen. Vgl. dazu auch Marti 1993, S. 19of. 
important que l'idée, la forme que le fond, le ton en sera poli, modéré, soutenu. $[\ldots]$ les écrivains s'attacheront plus à perfectionner quà produire.» ${ }^{646}$ Der von Nietzsche gelobte körnige, kunstvoll geschmiedete und abgeschliffene Sentenzenstil entspricht dem aristokratischen Ideal. Wie dargelegt, hat Nietzsche im Wanderer nicht nach dieser alten Werkpolitik geschrieben (Kap. 3.2.2). Vielmehr ähnelt der Wanderer Tocquevilles Merkmalen eines demokratischen Stils:

Le style s'y montrera souvent bizarre, incorrect, surchargé et mou, et presque toujours hardi et véhément. Les auteurs y viseront à la rapidité de l'exécution plus qu'à la perfection des détails. Les petits écrits y seront plus fréquents que les gros livres; l'esprit que l'érudition, l'imagination que la profondeur; il y régnera une force inculte et presque sauvage dans la pensée, et souvent une variété très-grande et une fécondité singulière dans ses produits. On tâchera d'étonner plutôt que de plaire, et l'on s'efforcera d'entraîner les passions plus que de charmer le goût. ${ }^{647}$

Es treffen gewiss nicht alle Charakteristika zu. Auffällig nahe an den Eigenschaften vom Wanderer sind aber die rasche Schreibproduktion, der lockere Stil, das geringe Mass an perfektionistischem Feilen, die lose Ordnung der Aphorismen, die kurze Aphorismenform, die erhoffte Wirkung auf die Einbildungskraft des Lesers und die grosse Themenvarietät.

Nietzsche betont neben der Politik des Schreibstils im Wanderer auch jene der Ideenvielfalt. So bemerkt er im Aphorismus «Tyra nn en des Ge is te s», dass Theophrast und Molière aus zeitgenössischer Sicht Tyrannen seien, weil ihre moralischen Ansichten von «fixen Ideen» geleitet werden. Dies sei nicht länger zeitgemäss: «Jetzt herrscht die Demokratie der Begriffe in jedem Kopfe, - viele zusammen sind der Herr: ein einzelner Begriff, der Herr sein w oll te, heisst jetzt, wie gesagt, 〈fixe Idee〉. Diess ist un sere Art, die Tyrannen zu morden, - wir winken nach dem Irrenhause hin.» ${ }^{648}$ Das heterogene Aphorismenbuch unterscheidet sich durch seine Meinungsvielfalt von der durch eine fixe Idee geleiteten Moralistik. Auf derselben Seite wie der umgeschriebene Aphorismus 230 findet sich im Arbeitsheft auch die Umschrift vom Aphorismus 63 über «Die moralischen Charaktermasken», der im Entwurfsstadium noch die «fixe Idee» enthielt und deshalb den Unterschied von demokratischer und tyrannischer Schreibweise erhellt:

\footnotetext{
646 Tocqueville 1864 , S. 93 .

647 Ebd., S. 96f.

648 WS 230, KSA 2, S. 657. Der Aphorismus ist auch ein Verweis auf den gleichnamigen Aphorismus in Menschliches, indem die griechischen Philosophen als Tyrannen beschrieben werden (vgl. MA 261, KSA 2, S. 214-218).
} 
In der Zeit, wo der Unterschied der Stände

für absolut gilt, werden die Moralisten

auch die Charaktermasken [wie] absolut hin

stellen (Molière Labruyère) Wie war's

in Athen? Die Menschen prägten ihren $\tau \iota \varsigma$

mehr aus. (Jetzt erscheint eine Charaktermaske

als krankhaft («fixe Idee»)) [sic] ${ }^{649}$

Die «fixe Idee» erscheint als Synonym für die bei den Griechen entlehnte «Charaktermaske», die nunmehr krankhaft erscheine: So steht an der von Colli und

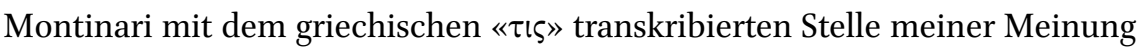
nach «tic», d.h. die umgangssprachliche Bezeichnung für eine befremdliche Eigenheit, die anderen Menschen pathologisch erscheint. ${ }^{650}$ Fixe Ideen und kohärente Charaktermasken bieten eine zu kleine Varietät von Meinungen an, welche laut Nietzsche die Demokratie jedoch auszeichnet. Eine solche «fixe Idee» ist die «amour propre», die in unzähligen Sentenzen ausdifferenziert, aber nur selten mit anderen Ansichten konkurrenziert wurde. Die griechische Literatur und auch die in Menschliches gelobte französische Moralistik sind tyrannisch. Demokratische Leser bedürfen einer heterarchischen Vielfalt von Ideen. Es ist die Herausforderung des demokratischen Buchmarkts zugleich locker und verständlich sowie ernsthaft und hochstehend zu schreiben; dem Leser zugleich genussvolle Erholung zu bieten und ihn zu aktivem Lesen zu verführen. So schreibt Tocqueville treffend, dass sich im allmählichen Übergang von einem ins andere Zeitalter aristokratische und demokratische Stilelemente verbinden können. ${ }^{651}$ Man kann Nietzsches erste Aphorismenbücher als Versuch deuten, dies umzusetzen.

\section{Selbstaufklärung durch (Aphorismen-)Bücherlesen}

Es ist Nietzsches Überzeugung, dass die Aufklärung noch lange nicht vollzogen ist. Aufklärung heisst für ihn wie für Kant, selbst mündig zu werden und nicht mehr auf andere Autoritäten angewiesen zu sein. Aufklärung wird also nicht nur als politischer Umbruch verstanden, sondern muss auch an jedem Einzelnen stattfinden. Das aufklärerische Credo der Unabhängigkeit und

649 N IV 2, S. 12; leicht abgeändert transkribiert gemäss KGW IV 4, S. 318. Vgl. dazu WS 63, KSA 2, S. 581 .

650 Nietzsche kannte dieses Wort, vgl. N. an Gast, 14.10.1888, Nr. 1130, KGB II 5, S. 450. Das französische Wort «tic» macht auch hinsichtlich der französischen Beispiele Sinn.

651 Tocqueville 1864, S. 97: «Dans le passage qui conduit un peuple lettré de l'un à l'autre, il survient presque toujours un moment où le génie littéraire des nations démocratiques se rencontrant avec celui des aristocraties, tous deux semblent vouloir régner d'accord sur l'esprit humain.» 
Eigenständigkeit problematisiert menschliche Autoritäten und in dieser Konsequenz das Buch als Vermittlungsform. Philipp Sarasin hat in Bezug auf Kants Warnung vor Priestern, Seelsorgern und Büchern die zentrale Frage gestellt, mit welchen Mitteln man dann noch seinen Verstand gemäss dem Sapere Aude gebrauchen dürfe: «Indem man ein Buch liest? Kant schneidet diesen Ausweg ab: Auch das Buch ist eine fremde Instanz, die das Denken am Gängelband führt. Wie aber soll man, zumal im Kontext der Aufklärung, denken und wissen, ohne zu lesen?» ${ }^{652}$ Auch Nietzsche konnte dieses Dilemma nicht lösen, schliesslich war er nach Aufgabe seiner Professur mehr Schriftsteller denn je zuvor. Mit dem Wechsel auf Aphorismenbücher reagierte er aber auf diese Problematik. Nietzsche war nach der Geburt der Tragödie und den Unzeitgemässen Betrachtungen auf der Suche nach einem eigenständigen Buchformat, das seine veränderten philosophischen Ansichten und die Politik des aktiven Lesens miteinschloss.

Diese weitere Akzentverschiebung hin zum unabhängigen Leser, der sich durch Bücher selbst aufklärt, lässt sich gut an den Schreibarbeiten am Aphorismus «Die Lehrer im Zeitalter der Bücher» beobachten, bei dem es im Notizbuch noch darum ging, die Qualität der Lehrer durch Selbsterziehung zu erhöhen: «Der Lehrer ist durch Verbreitung von / Selbst-Erziehung, auf die höchsten An / sprüche zu steigern, in seinen mittleren / Formen zu vernichten.» ${ }^{63}$ Später im Arbeitsheft heisst es, der Lehrer sei gar nicht mehr nötig:

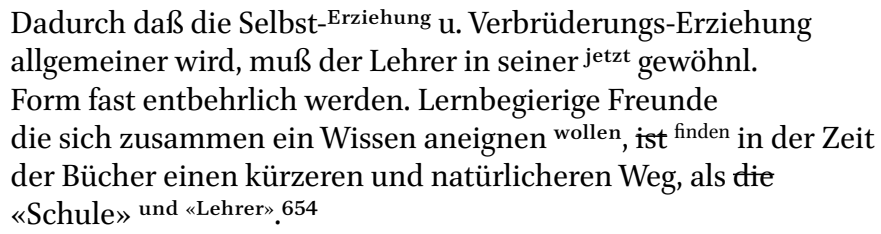

Es geht also im Wanderer nicht mehr darum, den Lehrer, sondern die Selbstständigkeit der Lernenden bzw. der Leser zu steigern. Das freie und aktive Lesen emanzipiert den Leser von den existierenden Meinungen und Hierarchien. Das hat auch Auswirkungen auf den Bildungsbegriff bei Nietzsche. ${ }^{655}$

\footnotetext{
652 Sarasin 2001, S. 25 .

653 N IV 2, S. 29f. (eigene Darstellung einer Transkription der früheren HyperNietzsche-Edition); WS 180, KSA 2, S. 629.

654 M I 2, S. 52 (eigene Darstellung einer Transkription der früheren HyperNietzsche-Edition).

655 Im Frühwerk und insbesondere in den Bildungsvorträgen ist die Erzeugung des Genius das Ziel der Bildung. Es geht um einen grossen Bildungsaufwand für wenige Genies. Diese Haltung wird bereits in Menschliches durch die Geniekritik verändert, jedoch durch die raren und wenigen Freigeister auch weitergeführt. Wichtig ist der Wechsel von einzelnen
} 
Denn die Forderung nach Selbstaufklärung ist nicht exklusiv auf eine Elite beschränkt. Die Selbsterziehung durch Bücher demokratisiert die ehemals exklusive Bildung. Es geht hier nicht um die Befähigung einer akademischen Leserschaft, sondern eines demokratischen Lesepublikums. Um Bildung und Bücher wirksam zu machen, bedarf es daher aktives Lesen und entsprechend verfasste Bücher. Mit der Tugend des «gut-Lesen[s]» wächst auch jene des «gut-Schreiben[s]». So heisst es schon 1874: «Sprechen- und Schreibenkönnen heisst freiwerden: [...]. Barbar ist einer, der sich nicht ausdrücken kann, der sklavenhaft plappert.» 656

Nietzsches Votum für die Selbstaufklärung hängt mit seinen Aphorismenbüchern zusammen, die den Lesern nicht mehr die Lektüreweise vorgeben, sondern sie zwingen sollen, selbst mitzudenken. Wenn man in der Demokratie nicht mehr erwarten könne, dass alle dieselben Meinungen und Haltungen haben, dann ist ein Buch mit dem Titel «Vermischte Meinungen und Sprüche» das Format, um dieses heterogene Publikum zu erreichen. Dieses will Bücher, an denen sich jeder selbst seine Meinung bilden und die man verschieden interpretieren kann; Bücher, die man unterwegs, an unterschiedlichen Orten, mit verschiedenen Moralvorstellungen und kulturellen Erwartungen lesen kann. Solche Bücher dürfen keinen festdefinierten Sinn haben, sondern müssen immer wieder neu auslegbar sein. Das Schreiben von vielen Aphorismen ist für Nietzsche per se demokratisch, weil im Unterschied zu wenigen fixen Ideen in Aphorismenbüchern viele Ideen präsentiert werden. Sie entfalten somit ein aufklärerisches Potenzial. Aphorismenbücher sind die werkpolitische Lösung für eine pluralistisch-demokratische Gesellschaft.

Diese These soll an Nietzsches unverwendeter Vorrede von 1876 und an Tocquevilles Einsichten über die Beschaffenheit demokratischer Literatur erhärtet werden. Nietzsche verwarf zwar den folgenden Entwurf, jedoch lässt sich daran seine intensive Suche nach neuen Bucharten erkennen und nicht zufällig orientiert er sich am Gestus des Reisebuchs und der Gesundheitsratgeber:

Reisebuch

unterwegs zu lesen

[...] Es müssen Bücher sein, welche man nicht durchliest, aber häufig aufschlägt: an irgend einem Satze bleibt man heute, an einem anderen morgen hängen und denkt einmal wieder aus Herzensgrunde nach: für und wider, hinein und drüber hinaus, wie einen der Geist treibt, so dass es einem dabei jedesmal heiter und

Genies zu Bildungsgruppen sowie das Wegfallen der «höchsten Ansprüche» in der Umschrift, weil dies auf die Kulturpolitik und den Genius als höchste Form verwies.

$656 \mathrm{NL}$ 1874, 37 [8], KSA 7, S. 834. 
wohl im Kopfe wird. Allmählich entsteht aus dem solchermaassen angeregten ächten, weil nicht erzwungenen - Nachdenken eine gewisse allgemeine Umstimmung der Ansichten: und mit ihr jenes allgemeine Gefühl der geistigen Erholung, als ob der Bogen wieder mit neuer Sehne bespannt und stärker als je angezogen sei. Man hat mit Nutzen gereist. ${ }^{657}$

Es geht bei den besagten Büchern nicht mehr um die Vermittlung von fixen Wissensinhalten, sondern um ein heiteres und angeregtes Nachdenken. Nietzsche selbst kritisiert im Wanderer, dass in der «Z eit de r Arbeit» die Kunst nunmehr als «Sache der Musse, der Erholung» gelte. ${ }^{658}$ Sein Vorredenentwurf richtet sich mit Fokus auf Erholung und Stärkung also an Leser des demokratischen Zeitalters. Geistige Reisebücher wirken nicht primär durch die Präsentation von begründeten Argumentationen, sondern durch eine erholsame Lesepraxis. Die hier genannten Merkmale sind gerade nicht jene der philosophischen Bücher des 19. Jahrhunderts. ${ }^{659}$ Mal reinblättern, irgendwo hängenbleiben, kursorisch lesen, den Geist fit halten - all dies sind die Merkmale der Ratgeberliteratur, jedoch umgemünzt auf die geistigen Bedürfnisse der Philosophie. Nietzsche will, dass seine Bücher gebraucht werden. Diese Wende zeichnete sich schon nach Menschliches ab, als sich Nietzsche hocherfreut zeigte, wenn ihn jemand «praktis ch» verstand. ${ }^{660}$ So berichtet Nietzsche über seine Bekanntschaft mit dem Kochbuchautor Josef Wiel : «Der Dr. Wiel [...] ist ein berühmter denkender Kochkünstler und Verfasser eines viel gebrauchten, in alle Sprachen übersetzten diätetischen Kochbuchs.» ${ }^{661}$ Nietzsche findet es «revolutionär», dass Dr. Wiel «an Stelle der Receptir-Bücher ein wissenschaftlich begründetes Kochbuch für die Hausküche stellt - ein ebenso einfacher als schwierig zu findender Gedanke, scheint mir». ${ }^{662}$ Nietzsche bewunderte die Idee eines übersetzbaren Gebrauchsbuches, das anders als die «Receptir-Bücher» wissenschaftliche Begründungen und individuelle Anwendbarkeit vereinigt. Die Selbstbildung durch Bücher ist ein Hauptmerkmal der Ratgeberliteratur, welche meist in praktischen Formen wie Anleitungen, Kataloge, Kochbücher oder Handbücher publiziert wurde. ${ }^{663}$ Es sind also Wissensformen, welche die Leser anwenden und weiterverwenden konnten.

\footnotetext{
657 NL 1876/1877, 23[196], KSA 8, S. 473 f.

658 WS 170, KSA 2, S. 623.

659 Die einflussreichen Buchdefinitionen von Kant und Fichte bewerten das Buch noch weitgehend abseits des Buchobjekts als Geisteserzeugnis und kommunikativen Akt zwischen Autor und Publikum, vgl. Kammer 2017 und Kap. 4.2.4.

66 o N. an Fuchs, Ende Juni 1878, Nr. 729, KGB II 5, S. 334.

661 N. an Rohde, 1.8.1875, Nr. 474, KGB II 5, S. 92.

662 N. an Overbeck, 11.8.1875, Nr. 481, KGB II 5, S. 105.

663 Vgl. Daum 2002, S. 331-336.
} 
Die sorgfältig illustrierte Zimmer-Gymnastik ist der Inbegriff eines Buchs, das keiner weiteren Beratung bedarf. Nietzsche erlebte an der Ratgeberliteratur einen neuen Buch-Gestus, jenen vom Selbsthilfe-Buch oder Do-it-yourselfBuch, mit dem man sich selbst helfen und heilen kann. In diesem Sinne ist die Lehre der «nächsten Dinge» als ungezwungener Werkzeugkasten zu verstehen, die der Philosoph seinen Lesern zur selbstständigen Kur empfiehlt.

Gemäss Tocqueville liest und schreibt man in der Demokratie «pour goûter à la dérobée les plaisirs de l'esprit. Ils ne font donc point de ces plaisirs le charme principal de leur existence; mais ils les considèrent comme un délassement passager et nécessaire au milieu des sérieux travaux de la vie». ${ }^{664}$ Weil diese neuen demokratischen Leser nur wenig Zeit haben, können sie nicht in die Tiefen der Künste gelangen. Jedoch, und das interessiert hier, können sie sich erholen. Tocqueville erwähnt im Zusammenhang mit der demokratischen Literatur gleich mehrmals die «plaisirs» und «jouissances de l'esprit». ${ }^{665}$ Der Nutzen des erholenden Lesens liegt in der Freiheit und Ungezwungenheit, durch welche die eigene Meinungsänderung unvermerkt geschieht. Anders als bei der «fixen Idee» der französischen Moralisten wird die Umstimmung nicht «erzwungen», sondern frei im eigenen Nachdenken erreicht. Folglich ist es eine demokratische Leserschaft, die Nietzsche in seiner verworfenen Vorrede adressiert. Es geht ihm nicht um Aufklärung der Unwissenden, sondern um die Selbstaufklärung als Lektürepraktik.

Die allmähliche und unvermerkte «Behebung〉 schädlicher Meinungen kann laut der Morgenröte durch philosophischen Rat erreicht werden:

\begin{abstract}
Aber namenlos und leicht verspottet leben, zu niedrig, um Neid oder Feindschaft zu erwecken, mit einem Kopf ohne Fieber, einer Handvoll Wissen und einem Beutel voll Erfahrungen ausgerüstet, gleichsam ein Armenarzt des Geistes sein und Dem und Jenem, dessen Kopf durch Meinungen verstört ist, helfen, ohne daß er recht merkt, wer ihm geholfen hat! Nicht vor ihm Recht haben und einen Sieg feiern wollen, sondern so zu ihm sprechen, dass er das Rechte nach einem kleinen unvermerkten Fingerzeig oder Widerspruch sich selber sagt und stolz darüber fortgeht! [...] Das wäre ein Leben! Das wäre ein Grund, lange zu leben!666
\end{abstract}

Das Aphorismenbuch gibt seinen Lesern unaufdringliche Denkanstösse, die durch ihre Verschiedenheit nicht einer Autorperson zugeschrieben werden müssen. Dies wiederum macht die Meinungsänderung einfacher, da sie scheinbar von den Lesern selbst angestossen wurde. Die allmähliche Umstimmung

664 Tocqueville 1864, S. 96.

665 Ebd., S. 94, 96.

666 M 449, KSA 3, S. 272. 
in den Ansichten verläuft dann analog zur allmählich erlangten Fitness durch die regelmässige Zimmer-Gymnastik.

\title{
Aphorismenbücher im Kontext der populären Literatur und des Buchmarkts
}

Die ersten drei Aphorismenbücher Menschliches, die Vermischten Meinungen und der Wanderer entstehen inmitten eines wachsenden Buchmarkts und einer sich stark verbreitenden populären Literatur. Die beschriebenen Merkmale der guten Prosa decken sich grösstenteils mit denen populärer Literatur im 19. Jahrhundert. Im Gefolge der Aufklärung wurden viele Wissensbereiche wie Medizin, Biologie, Botanik, Klimatologie oder Astronomie im Format der Reise- und Ratgeberliteratur popularisiert. Dies wurde im letzten Kapitel exemplarisch an Nietzsches Lektüre populärer Diätetik gezeigt (Kap. 3.3.4). Die Popularisierung veränderte besonders die Philosophie, welche in der Öffentlichkeit zunehmend in ihrer populären Form wahrgenommen wurde:

\begin{abstract}
Während sich die Universitätsphilosophie auf dem Wege zu einer immer reineren Wissenschaftlichkeit befand, verstärkten sich nach dem Jahre 1848 die Lesebedürfnisse im weitesten Sinne politischer und lebensanschaulicher Lektüre, die von Fachphilosophen selbstverständlich nicht befriedigt werden konnten. Durch den ständigen Zugewinn neuer Leserschichten für populäre naturwissenschaftliche, historische und auch philosophische Texte, durch eine [...] Erweiterung des Buch-, Journal- und Zeitschriftenmarktes [...] verlor die Universitätsphilosophie dasjenige Gewicht für die Formulierung der öffentlichen Meinung, das sie noch bis zur Revolution weitgehend unangefochten hatte beanspruchen können. 667
\end{abstract}

Gerade die Aphoristik ist im 19. Jahrhundert eine längst bekannte Form des philosophischen Schreibens und eine stetig beliebter werdende Lektüre. Der populärwissenschaftliche Stil etablierte sich nach 1848 und hat folgende Eigenschaften: voraussetzungslose Sprache, Ineinanderfliessen von persönlicher und wissenschaftlicher Erfahrung, knappe Texte, keine fachwissenschaftlichen Diskussionen, keine langen Zitate, wenig Belege, keine Belehrung, Verzicht auf wissenschaftliche Vollständigkeit etc. ${ }^{668}$ Dieses neue Buchangebot zeichnete sich durch eine Ausrichtung auf den wachsenden Buchmarkt aus und richtet sich demnach an Verständlichkeit, Praktikabilität und Unterhaltung aus: «Der mit narrativen und anekdotischen Elementen aufgeladene essayistische Stil

667 Köhnke 1986, S. 116f. Vgl. für die populärwissenschaftliche Bedeutung der Gartenlaube Stockinger 2018.

668 Daum 2002, S. 251-254; vgl. auch das Kap. 4, S. 280-299. 
setzte sich seit 1870 in breiter Front auf dem Buchmarkt durch.» ${ }^{669}$ Insbesondere in Nietzsches Lektüre der späteren 1870er Jahre finden sich essayistische Gedankensammlungen von Lichtenberg, Stendhal, Karl Hillebrand, Hyppolyte Taine, Ralph Waldo Emerson, Jonathan Swift und vielen mehr. Die von Nietzsche im Wanderer genannten Beispiele europäischer Autoren sind nicht nur bekannt, sondern zuweilen massgeblich an der Popularisierung beteiligt gewesen. ${ }^{670}$ La Rochefoucauld prägte den verständlichen Stil einfacher Worte und Fontenelles Entretiens sur la pluralité des mondes ist ein aufklärerisches Gründungsdokument der populärwissenschaftlichen Literatur. ${ }^{671}$ Die in Nietzsches Aphorismenbüchern verhandelten Themen wie Moral, Zivilisation, Religion, Strafe, Fortschritt oder Bildung waren in der essayistischen Literatur etabliert. Einiges, was man heute als besonders nietzscheanisch empfinden mag, war dem gebildeten Lesepublikum als Topoi bekannt. So mutet beispielsweise die Interpretation des Blicks in Raffaels «Sixtinischer Madonna» zunächst originell an. Es war aber eine zeitgenössisch bewegende Frage, zu der sich viele Autoren - so auch Schopenhauer und Taine - geäussert haben. ${ }^{672}$ Man stritt sich, ob die Maria im Bild eine Heilige, eine ideale Mutter, antike Schönheit oder ländliche Jungfrau darstelle. Am meisten ist Nietzsches Aphorismus aber eine Reaktion auf die Bayreuther Blätter, in denen Wagner nach seiner Kritik an Menschliches das Jesuskind der «Sixtinischen Madonna» als göttlichen Ausdruck der Erlöserfigur stilisierte. ${ }^{673}$ Im letztbenutzten Notizbuch, das ihm hauptsächlich für die Abschlussarbeiten am Wanderer in Naumburg diente, finden sich über sieben Seiten verstreut Notizen, um den direkt ins Druckmanuskript eingefügten Raffael-Aphorismus zu erarbeiten. ${ }^{674}$ Viele Aphorismen Nietzsches fügen sich für das zeitgenössische Publikum in den populären Diskurs ein.

\footnotetext{
669 Ebd., S. 330.

670 WS 214, KSA 2, S. 646.

671 Vgl. Hess 1957, S. 10; Daum 2002, S. 265f.: «Bernard Fontenelles Entretiens sur la pluralité des mondes [...] werden vielfach als Begründung der populär-naturwissenschaftlichen Literatur angesehen.»

672 WS 73 , KSA 2, S. 585 f. Es finden sich Bemerkungen zur «Sixtinischen Madonna» von Hebbel, Schopenhauer, Taine, Stendhal (vgl. dazu umfassend das Kapitel zu Raffaels «Sixtinischer Madonna» in Löhneysen 1992, S. 206-211). Auch die Augen des Jesuskindes boten Stoff für zahlreiche Interpretationen.

673 Wagner 1878, S. 220.

674 Vgl. KGW IV 4, S. 319; WS 73, KSA 2, S. 585 f. Damit handelt es sich um eine der komplexesten Textgenesen, die in den Wanderer-Manuskripten vorkommt. Eine zusätzliche Pointe dieser Reaktion besteht darin, dass Wagner in seinem Artikel die Gelehrten dafür kritisiert, über Gegenstände zu schreiben, ohne sie aus eigener Anschauung zu kennen. Nietzsche hatte Raffaels Gemälde 1879 höchstens aus Repräsentationen gekannt.
} 
Im Rahmen der aufkommenden Populärliteratur wurden Dialoge, Unterhaltungen, Selbstgespräche, Streifzüge, Wanderungen und Spaziergänge zu viel verwendeten Narrativen. ${ }^{675}$ Dies ging einher mit einer wachsenden Kritik am so genannten Gelehrtenstil, der als unverständlich und ungeniessbar galt. ${ }^{676}$ Theodor Eimer rügt in seinem Beitrag für die Populärzeitschrift Humboldt den Gelehrtenstil in provokativem Ton: «Gar einmal etwas 〈populär〉 zu schreiben - wer weiss nicht, wie viele unserer Gelehrten auf diese Kunst vornehm herabblicken!» ${ }^{677}$ So forderte Alexander von Humboldt - als einer der wichtigsten Popularisierer der Wissenschaft - eine Verbindung von literarischen und wissenschaftlichen Zwecken. ${ }^{678}$ Humboldt war massgeblich daran beteiligt, dass der populäre Erfolg nicht länger negativ bewertet wurde. So schrieb er an einen weiteren Bestseller-Autor, Emil Adolf Rossmässler, dass «truly popular writings» nur jenen Autoren gelingen, «who are in possession of the honorable testimony of profoundest knowledge.» ${ }^{679}$ Nietzsche wiederum forderte in den Vermischten Meinungen ein Sprachideal für niedere Stände, um die Naturgeschichte breit vermittelbar zu machen:

Immerhin ist den Engländern zuzugestehen, dass sie in ihren naturwissenschaftlichen Lehrbüchern für die niederen Volksschichten bewunderungswürdige Schritte nach jenem Ideale hin gemacht haben: dafür werden diese auch von ihren ausgezeichnetsten Gelehrten - ganzen, vollen und füllenden Naturen gemacht, nicht, wie bei uns, von den Mittelmässigkeiten der Forschung. 680

Gute populäre Bücher zeugen vom grossen Können der Autoren. Das populäre Schreiben ist eine Herausforderung für die Besten ihres Fachs. Der aus der Universität ausgeschiedene Philologe Nietzsche will sich auf dem Buchmarkt

675 Eine Liste mit Buchbeispielen aus dieser Zeit findet sich in Daum 2002, S. 33of, v.a. in den Fussnoten 20-25.

676 Vgl. ausführlich ebd., S. 243-264.

677 Eimer 1887, S. 3. Und ebd. heisst es: «Hand in Hand mit übertriebener Specialarbeit geht die Ausbildung des Unvermögens, allgemein verständlich zu schreiben. Nur zu häufig scheint der deutsche Gelehrte zu meinen, er müsse seinen Stoff in eine möglichst schwerfällige, mit Fremdwörtern übervoll gespickte Sprache bringen, fast als wolle er absichtlich nur ganz besonders engen Kreisen leichten Einblick in die Schätze s e in er Wissenschaft und seines Wissens gestatten.»

678 Vgl. Daum 2002, S. 251.

679 Humboldt 1852. In meiner eigenen Abschrift vom Original: «Truly popular writings, such as for the noble object of distributing useful knowledge and to refute the dogmatic axioms of an arrogant half-knowledge, that have accumulated for centuries, are successfully written only by these, who are in possession of the honorable testimony of profoundest knowledge, as you are.» Humboldt antwortete mit diesem Lob auf die Zusendung von Rossmässlers Populäre Vorlesungen aus dem Gebiet der Natur.

$68 \mathrm{O}$ VM 184, KSA 2, S. 460 . 
beweisen und eben jenen Beweis abliefern, den der populäre Erfolg verspricht, nämlich gut schreiben zu können und kompetent zu sein. Diese Mischung aus Erfolg und Anerkennung begleitete Nietzsche seit dem Antritt der Basler Professur, als er sich dem breiten Leserpublikum durch die essayistischpolemische Geburt der Tragödie (1872) präsentierte. Seine viel beachtete Streitschrift gegen David Friedrich Strauss' Bestseller Das Leben Jesu (1835) erschien in der Schriftenreihe Unzeitgemässe Betrachtungen, die sich nicht an die Wissenschaft, sondern an die Bayreuther Gemeinde und die deutsche Öffentlichkeit wandte. Die Bände zu Wagner und Schopenhauer thematisieren zwei populäre Persönlichkeiten, wobei Letztgenannter an den deutschen Universitäten wenig anerkannt war, dafür umso mehr von den intellektuellen Zeitschriften- und Zeitungsautoren rezipiert wurde. ${ }^{681}$ Verständlich, dass die philologischen Kollegen ihre Zweifel an der wissenschaftlichen Integrität Nietzsches hegten. Ulrich von Wilamowitz-Moellendorff brachte dies auf den Punkt, als er Nietzsche aufforderte, vom «Katheder» der Wissenschaft runterzusteigen. ${ }^{682}$ Es deutete sich schon da ein komplexes Verhältnis zur Popularität an, das sich immer wieder aktualisieren würde: sei es an kleinen Werbeanzeigen seiner Verleger oder an utopischen Verkaufserwartungen.

Auch wenn Nietzsches Aphorismenbücher zunächst keinen grossen Absatz fanden, lösten sie bei seinen Zeitgenossen das Gefühl eines populären Buchformats aus. So bestärkt Karl Hillebrand im Sommer 1879 - also nach Erscheinen von Menschliches und den Vermischten Meinungen - Nietzsches Verleger Schmeitzner: «[...] in zehn, fünfzehn Jahren werden Nietzsche's Schriften eine gewaltige Nachfrage finden, daher seien sie sicher und verlieren Sie den Muth nicht.» ${ }^{683}$ Kurz nach dieser Prognose erreichte Schmeitzner das Manuskript vom Wanderer.

Richard Wagner kommt just in seiner Artikelserie «Publikum und Popularität» in den Bayreuther Blättern auf Menschliches zu sprechen - ohne diesen Buchtitel oder den Autor namentlich zu nennen. So einseitig und fachlich fragwürdig Wagner urteilt, so sehr lassen sich von seiner Kritik historische Leseeindrücke ableiten. Wagner kritisiert zunächst, dass Philologen und Philosophen zunehmend mit Physik und Chemie argumentierten (freilich ohne viel davon

681 Der philosophische Materialismus oder den rund um Schopenhauer entstandenen philosophischen Pessimismus beschäftigten in erster Linie die damalige Öffentlichkeit und wirkten «nahezu ausschließlich auf außeruniversitäte Wirkungskreise» (Köhnke 1986, S. 112). Für Nietzsches Orientierung an der populären zeitgenössischen Philosophie, vgl. Thüring 2008, S. 133 .

682 Wilamowitz-Moellendorff 1872, S. 32.

683 Zit. n. KSA 15, S. 107. 
zu verstehen). ${ }^{684}$ Diese Anbiederung fusse auf einem Aufmerksamkeitsbedürfnis, das die fehlenden fachlichen Herausforderungen, namentlich der Philologie, kompensieren will. Die Anspielung auf die «Chemie der Begriffe und Empfindungen» von Nietzsches Menschliches wird jedoch noch deutlicher:

Jeder deutsche Professor muss einmal ein Buch geschrieben haben, welches ihn zum berühmten Manne macht: nun ist ein naturgemäss Neues aufzufinden nicht Jedem beschieden; somit hilft man sich, um das nöthige Aufsehen zu machen, gern damit, die Ansichten eines Vorgängers als grundfalsch darzustellen, was dann um so mehr Wirkung hervorbringt, je bedeutender und grösstentheils unverstandener der jetzt Verhöhnte war. ${ }^{685}$

Wagner kritisiert philosophische und philologische Professoren, die aufgrund fehlender Erkenntnisse in ihren Fächern, über populäre Aufmerksamkeitsstrategien berühmt werden wollen. Da Wagner diesen publikumsorientierten Publikationen den Status neuer oder wichtiger Erkenntnisse abspricht, hebt er umso mehr hervor, dass es nur um Aufsehen und Popularität geht. ${ }^{686}$ Mit den «Ansichten eines Vorgängers» ist hier ebenso Schopenhauer wie Wagner selbst gemeint, die in Menschliches vielfach explizit und implizit kritisiert werden. Der Vorwurf an Nietzsche lautet also, dass dieser durch eine oberflächliche Kritik an populären Geistesgrössen - gleichsam als Trittbrettfahrer Aufmerksamkeit erregen will. Wagner kritisiert mit der Artikelüberschrift also nicht den ihn ärgernden Inhalt, sondern die populärliterarische Form von Nietzsches erstem Aphorismenbuch. Nietzsche muss diese Kritik, wie oben anhand des Raffael-Aphorismus gezeigt, aufmerksam gelesen haben.

Nietzsche als populärer Autor? Der grosse Aphoristiker als Populäressayist? Nietzsche als Leser von populärer Literatur? Die populäre Ausrichtung von Nietzsches Aphorismenbüchern steht in scheinbarem Widerspruch mit seinen Aussagen gegen Presse, populäre Literatur und Vielschreiberei. ${ }^{687}$ So sprach Nietzsche angesichts von 12'0oo deutschen Buchveröffentlichungen im Jahr 1872 von der «wüstesten Buch- und Zeitungsmacherei» und bezeichnet in den Vermischten Meinungen gerade die beliebtesten Bücher als mittel-

\footnotetext{
684 Wagner 1878, S. 215 f.

685 Ebd., S. 216.

686 Vgl. ebd., S. 217.

687 Er plante 1873 sogar eine Unzeitgemässe Betrachtung über «Viel-Lesen und Viel-Schreiben. Der Gelehrte» (NL 1873, 29[163], KSA 7, S. 699). Für weitere einschlägige Stellen sowie eine Einschätzung von Nietzsches Kritik an der Publizistik seiner Zeit, vgl. Fietz 1992, S. 329-350 sowie Reschke 2015a. Angesichts von Nietzsches Lektüre populärer Literatur könne man diese Kritik ironisch verstehen (Moore 2004, S. 72).
} 
mässig und schlecht. ${ }^{688}$ Das wachsende Lesepublikum verführe die Autoren, gefallsüchtig die Bedürfnisse der Leser zu befriedigen. Das täuscht über die populären Strategien hinweg, die Nietzsche und seine Zeitgenossen in den Aphorismenbüchern sahen. Selbst der moderne Sentenzenstil ist weniger eine griechische Rückbesinnung, sondern wie Paul Rées Definition von Sentenzen zeigt, eine Reaktion auf die zeitgenössische Bücherflut: «Ausserdem macht der große Umfang der Litteratur eine kurze Ausdrucksweise wünschenswerth.»689 So gesehen ist auch die Aufwertung des langsamen, philologischen Lesens eine Konsequenz des Buchmarkts. Die Wahl für einen Aphorismenstil ist im späten 19. Jahrhundert also immer auch ein Statement gegenüber dem wachsenden Buchmarkt - und gerade nicht gegen den Buchmarkt. Es ist deshalb Vorsicht geboten, wenn man Nietzsches Beschimpfungen von Zeitungen und Zeitschriften vorschnell Glauben schenkt. ${ }^{690}$ Zudem unterstützt man dadurch ein falsches Bild der Publizistik im 19. Jahrhundert, welche alles andere als plump verfasst war. Das Niveau vieler Zeitschriften ist hoch und nicht selten haben namhafte Autoren ihre Bücher aufgrund von vorangegangenen Zeitungsveröffentlichungen erstellt. Es ist deshalb empfehlenswert, Nietzsches Kritik an Zeitung und Zeitschriften nicht kategorisch aufzufassen und dadurch die Verstrickung dieses Philosophen mit der populären Literatur zu übersehen. Es ist bezeichnend, dass die Kritik an der populären Literatur meistens von Seiten populärer Autoren wie Nietzsche, Wagner, Herder, Hillebrand, Humboldt und Co. aufkam. ${ }^{691}$ Dass über diesen Diskurs hinweg trotzdem viel geschrieben und gedruckt wurde, versteht sich von selbst.

\subsubsection{Fazit}

An den Gedanken zu Frieden und Demokratie zeigt sich eine stark veränderte Haltung Nietzsches. Für einen Sommer lang nähert er sich trotz ironischem Ton auffällig nahe an demokratische Ideale, Rechte und Institutionen an. Nietzsche war 1879, wie er selbst schreibt, der Demokratie gegenüber «geduldiger und milder gestimmt».692 Es ist deshalb richtig, wenn Henning Ottmann behauptet: «Der immer wieder als Verherrlicher des Krieges rezipierte

688 N. an von Meysenbug, Ende Februar 1873, Nr. 297, KGB II 3, S. 128; VM 158, KSA 2, S. 443.

689 Reé 1875, S. 3.

690 Vgl. Fietz 1992, S. 329-350. Fietz ahmt Nietzsches abfälligen Ton nach, ohne je historische Quellen zu konsultieren.

691 Wobei gerade Humboldt mit seinem Bestseller Kosmos zwar viel gekauft, aber selten verstanden wurde. Der grosse Anstossgeber der populärwissenschaftlichen Schreibe verstand es selber nämlich nicht, allgemeinverständlich zu schreiben (vgl. Daum 2002, S. 273-279).

692 NL 1879, 47[10], KSA 2, S. 620. 
Nietzsche muß als Philosoph des Friedens erst noch entdeckt werden.» ${ }^{693}$ In Menschliches votierte Nietzsche primär für den Krieg, weil Friedenszeiten eine Kultur ermatten und absterben lassen. Nun fordert er die Demokratie und ihr jahrhundertelanges Bestehen. Es änderte sich die Diagnose, welche Nietzsche als Arzt der europäischen Kultur stellt. Dies wurde am Deutlichsten beim Aphorismus über die drei friedlich koexistierenden Stämme. Der Hinweis, dass die Menschen durch die Friedenszeiten schöner geworden seien, verleiht Nietzsche gar eine humanistische Haltung. Das Ziel einer kulturellen Erhöhung steht zwar immer noch am Ende der demokratischen Übergangszeit. Es ist nun aber in eine unbekannte Zukunft späterer Generationen verschoben. Aufgrund der zahlreichen Parallelen mit Alexis de Tocqueville muss Nietzsches Kenntnis darüber vorausgesetzt werden. Damit wäre der von Maria C. Fornari für 1880 und die Morgenröte stark gemachte Umbruch im Denken Nietzsches auf 1879 und den Wanderer vorzuverlegen. ${ }^{694}$

Nietzsches Aussagen zu Demokratie, Krieg, Aufklärung und Revolution wurden nicht systematisch entwickelt. Sie verdanken ihre Kohärenz aus den Nietzsche vertrauten Sphären des Schreibens, des Lesens, der Produktionsästhetik und der Diätetik. Zudem ist die Demokratieannäherung synergetisch mit dem lockeren Stil als demokratische Prosa sowie mit dem populären Format des Aphorismenbuchs verbunden. Die Engführung von Politik und Literatur lässt auf eine literarische Vorstellung von Kultur, Bildung und Politik schliessen. Die Forderung der Selbstaufklärung durch Schreiben und Lesen bestätigt diesen Befund. Deshalb kann mit Karl Hillebrand auch für den Wanderer kritisiert werden, dass Nietzsche die Literatur kulturpolitisch überhöhe. ${ }^{695}$

Nietzsches Produktions- und Publikationspraktiken sowie Teile seiner Leseanleitungen entsprechen einer demokratischen Werkpolitik. Nietzsche sucht nach neuen Buchformaten, und das in einer Zeit, in welcher die gesellschaftlichen Veränderungen ebenfalls neue Buchformen verlangen. Wachsender Buchmarkt, demokratische Meinungsfreiheit, extensive Lektüre, stilles Lesen, generelle Alphabetisierung, grosser potentieller Adressatenkreis und neue Lesesituationen stimmen auffällig mit den Eigenschaften von Aphorismenbüchern überein, weshalb diese von einigen Zeitgenossen als populäre Schriften

693 Ottmann 1999, S. 127.

694 Fornari 2005, S. 310.

695 Karl Hillebrand kritisiert dies an den Unzeitgemässen Betrachtungen: «So z. B. ist es durchaus verfehlt das Wesen einer Cultur allein in den Styl zu setzen. Der Styl ist nur die Form einer Cultur, und wo diese Form fehlt, ist eben die Cultur auch formlos, d. h. unschön. Deshalb ist er aber noch nicht die Cultur selber: diese wirkt zunächst auf das Wesen selber.» (Hillebrand 1875, S. 302). 
angesehen wurden. Das Format des Aphorismenbuchs ist ein marktaffines Buchformat für demokratische Leser. Die unverwendete Vorrede zu Menschliches ist wie gezeigt eine Umsetzung der von Tocqueville bestimmten Merkmale demokratischer Literatur. Im aufstrebenden Buchmarkt garantieren vieldeutige Aphorismen, dass möglichst viele Leser etwas mit dem Gelesenen anfangen können. Das «Buch für Alle und Keinen» kann auch als werkpolitische Antizipation des demokratischen Buchmarkts interpretiert werden (ein Untertitel, der für Kants Kritiken absurd wäre). Aphorismen bieten demokratisches Denken für demokratische Köpfe. Der lockere Stil vom Wanderer ist so gesehen ein demokratisches Statement. ${ }^{696}$ Ebenso kann Nietzsches Offenheit für die demokratischen Literatursorten auch aus der Perspektive seiner Lektüre analysiert werden. Seine Beschäftigung mit publizistisch erfolgreichen Büchern sowie der ständige Kontakt mit der Ratgeberliteratur machte Nietzsche nicht nur auf Strategien der breiten Verständlichkeit aufmerksam, sondern auch auf die unabhängige Bildung und Aufgeklärtheit eines mittelständischen, bürgerlichen Publikums. Der zeitgenössische Kontext von Buchmarkt und Populärliteratur muss bedacht werden, wenn ein junger ehemaliger Professor ab 1878 innert kurzer Zeit drei philosophische Gedankensammlungen publiziert.

Kurze Zeit nach dem Wanderer war Nietzsches Annäherung an die Demokratie beendet. Aufgrund seiner wiederaufgenommenen Kulturpolitik höherer Menschen konnte seine Demokratieauseinandersetzung keine weiteren Früchte tragen: «Die Demokratie repräsentirt den Unglauben an große Menschen und an Elite-Gesellschaft.» ${ }^{697}$ Im Spätwerk hat Nietzsche

696 Die Geschwätzigkeit des 19. Jahrhunderts führt zur Auflösung der Hierarchien und Standesunterschiede unter den Gesprächspartnern. Es gibt einen Zusammenhang zwischen dem unterhaltenden Ton und der stärkeren Durchmischung der französischen Stände, was Linke anhand von zeitgenössischen Lexika nachgewiesen hat (vgl. Linke 1996, S. 148).

697 NL 1884, 26[282], KSA 11, S. 224. Entscheidend ist auch die stärker werdende Gewichtung des Willens, welche im Nachlass schon 1880 auftritt: «Die große Leidenschaft der M[acht] (Napoleon Cäsar) man muß dabei eitler erscheinen als man ist, es wollen, um das Gefühl der Macht bei den Werkzeugen (Nationen) zu befriedigen.» (NL 188o, 4[197], KSA 9, S. 149) Vgl. auch Jenseits von Gut und Böse, in dem alle demokratischen Aspirationen des mittleren Werks wieder getilgt werden: «Das Wesentliche an einer guten und gesunden Aristokratie ist aber, dass sie sich nicht als Funktion (sei es des Königthums, sei es des Gemeinwesens), sondern als dessen Sinn und höchste Rechtfertigung fühlt, - dass sie deshalb mit gutem Gewissen das Opfer einer Unzahl Menschen hinnimmt, welche u m i hretwillen zu unvollständigen Menschen, zu Sklaven, zu Werkzeugen herabgedrückt und vermindert werden müssen. Ihr Grundglaube muss eben sein, dass die Gesellschaft n i cht um der Gesellschaft willen dasein dürfe, sondern nur als Unterbau und Gerüst, an dem sich eine ausgesuchte Art Wesen zu ihrer höheren Aufgabe und überhaupt zu einem höheren S e in emporzuheben vermag [...].» (JGB 258, KSA 5, S. 206f.). 
die Demokratie und den Frieden dann als Dekadenzphänomen behandelt verbunden mit einem starkem Votum für den Krieg. ${ }^{698}$ Es wäre aber verfehlt, diese Wandlungen als rein geistige Meinungsänderungen zu verstehen. Der Bruch mit der Demokratie entsteht nämlich auch im Stil, in der Schreibweise und in den Leseanleitungen. So bemerkt Nietzsche kurz nach der Publikation vom Wanderer: «Das Princip der Gedanken- und Preßfreiheit ruht auf dem Unglauben an die Unsterblichkeit.» ${ }^{699}$ Damit bestätigt sich einmal mehr, dass man politische Ansichten bei Nietzsche nicht von seinem Schreiben trennen kann. ${ }^{700}$ Nietzsche ist kein apolitischer Denker und noch weniger ein apolitischer Schriftsteller.

698 Vgl. NL 1888, 14[192], KSA 13, S. 379: «Eine Gesellschaft, die endgültig und ihrem I n s t in k t nach den Krieg und die Eroberung abweist, ist im Niedergang: sie ist reif für Demokratie und Krämerregiment...». Vgl. auch JGB 210, KSA 5, S. 142-144; JGB 238, KSA 5, S. 175; JGB 239, KSA 5, S. 175-178.

699 NL 1880, 3[160], KSA 9, S. 98.

700 Vgl. Patton 2014, S. 95. 